Western University

Scholarship@Western

Digitized Theses

Digitized Special Collections

1993

\title{
Multiple Maltreatment, Attribution Of Blame, And Adjustment Among Adolescents
}

Robin A. McGee

Follow this and additional works at: https://ir.lib.uwo.ca/digitizedtheses

\section{Recommended Citation}

McGee, Robin A., "Multiple Maltreatment, Attribution Of Blame, And Adjustment Among Adolescents" (1993). Digitized Theses. 2387.

https://ir.lib.uwo.ca/digitizedtheses/2387

This Dissertation is brought to you for free and open access by the Digitized Special Collections at Scholarship@Western. It has been accepted for inclusion in Digitized Theses by an authorized administrator of Scholarship@Western. For more information, please contact tadam@uwo.ca, wlswadmin@uwo.ca. 
MULTIPLE MALTREATMENT, ATTRIBUTION OF BLAME, AND ADJUSTMENT AMONG ADOLESCENTS

by

Robin A. McGee

Department of Fgychology

Submitted in partial fulfilment

of the requirements for the degree of

Doctor of Philosophy

Faculty of Graduate Studies

The University of Western Ontario

London, Ontario

July, 1993

- Robin A. McGee, 1993 
National Library

of Canadr

Acquisitions and

Bibliographic Services Branch

395 Wellington Streti

Ottawa. Ontario

K1A ON4
Bıblıothèque natıonale

du Canada

Direction des acquisitions ef

des services biblographigues

395. rue Wellingtion

Otlawa (Ontanio)

KIAON4
The author has granted an irrevocabie non-exclusive licence allowing the National Library of Canada to reproduce, loan, distribute or sell copies of his/her thesis by any means and in any form or format, making this thesis available to interested persons.
L'auteur a accordé une licence irrévocable et non exclusive permettant à la Bibliothèque nationale du Canada de reproduire, prêter, distribuer ou vendre des copies de sa thèse de quelque manière et sous quelque forme que ce soit pour mettre des exemplaires de cette thèse à la disposition des personnes intéressées.

L'auteur conserve la propriété du droit d'auteur qui protège sa thèse. Ni la thèse ni des extraits substantiels de celle-ci ne doivent être imprimés ou autrement reproduits sans son autorisation.
The author retains ownership of the copyright in his/her thesis. Neither the thesis nor substantial extracts from it may be printed or otherwise reproduced without his/her permission. 


\section{ABSTRACT}

The present study had two purposes. First, it examined the combined and unique contribution of five maltreatment types to varıance in adolescent adjustment $(i . e .$, physıcal abuse, sexual abuse, emotional abuse, neglect, and exposure to family violence). In sccordance with contemporary social learning theory (Bocial cognitive theory), it was hypothesized that aggressive forms of maltreatment would predict externalizing problems, particularly for boys, whereas nonaggreselve maltreatment would predict internalizing problems. Second, the study examined the predictive utility of blame attributions for maltreatment. Integrating the writings of several theorists regarding blame attribution. it was predicted that self-blame would mediate or moderate internalizing problems, whereas other-blame would mediate or moderate externalizing problems. Mediator and moderator models were tested separately.

Adolegcents $(\underline{N}=160$, aged 11-17) were randomly selected from the open caseload of a child protection agency. Subjects made global severity ratings regarding their experiences of the five types of maltreatment. Similar ratings were made for each subject by the adolescent's social worker and by trained raters of case files. Subjects also completed the Attribution for Maltreatment Interview (AFMI) to assegs self- and perpetrator-blame for each type of maltreatment they experienced. Subjects also completed a battery of measures assessing self- and caretaker-reported externalizing and internalizing eymptomatology.

Discrepancies in maltreatment occurrence and Beverity judgements were found between adolescents and professionals. Adolescent maltreatment ratings aignificantly predicted self-reported adjustment, even when controlling for sex, age, SES, receptive vocabulary, and stressful life events. Emotional abuse was the most predictively potent 
maltreatment type, and enhanced the predictive utility of other maltreatment types.

The tFMI yielded five subscales: self-blaming cognition, selfblaming affect, gelf-excusing, perpetrator-blame, and perpetratorexcusing. Controlling for maltreatment severity, these subscales explained significant variance in self-reported adjustment. Selfblaming affect was the most potent, particularly anong females. Attributions were found to both mediate and moderate maltreatment geverity.

The findings were consistent with recent developments in social learning theory. They illustrated that victims " subjective appraisals of maltreatment are important to adjustment. The sophistication of blame attribution processes among victims was urderscored. Implications for theory, measurement, and clinical practice are discuseed. 


\section{ACRNOWLEDCEATNTS}

I extend my sincerest gratztude to the many people who have contributed to the assessment project and the dissertation.

To my husband Andrew, for his steadfast support, loving patience, and wonderful cooking.

To my parents Bob and Janette McGee, for their unfailing falth in me throughout all my university years.

To Dr. Pat Bourdeau and Dr. Sugan Wilson, my "Bleterg in arms", for their warm constancy and indomitable valour.

To Jean Carnochan, my comrade and colleague on the project, for her skill, hard work, and good humour.

To Frances Bauer, Uwo Ombudsperson, who kept the light burning at the end of the tunnel.

To my comnittee members Dr. Greg Moran and Dr. Rod Martin, for their sage advice.

To Dr. Nick Kuiper, for his incigive commentary on the document as well as his direction during a difficult time.

To the workers of the London-Middlesex Children's Aid Society, for their dedication, enthusiasm, and generosity.

Special thanks to my eleventh hour advisor Dr. James Olson - his compassion, integrity, and extraordinary competence were both enormossly inspiring and greatly healing.

Finally, to all the youth who participated in the study, for sharing with me their many storieg of pain and courage. This volume 28 dedicated to them. 


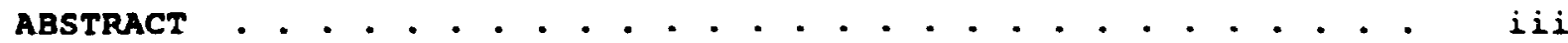

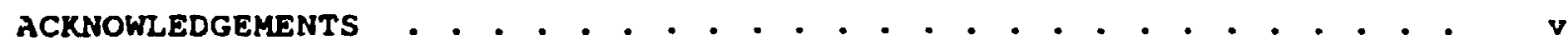

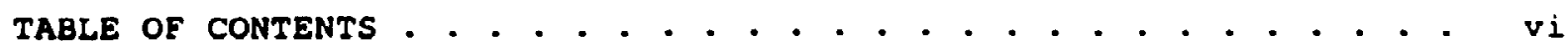

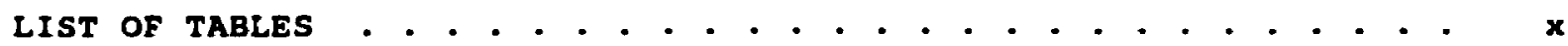

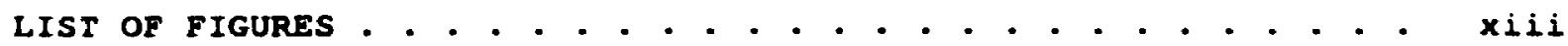

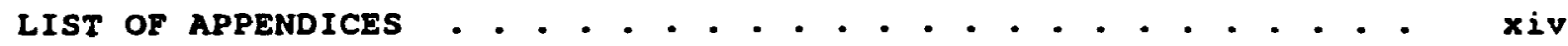

CHAPTER I - INTRODUCTION - . - . . . - . . . . . . . . . . . . . . . 1

Purpose and Overview . . . . . . . . . . . . . . . . . . . . 11

The Relationship between Maltreatment and Internalizing and

Externalizing Disorders . . . . . . . . . . . . . . . . 3

Social Learning and social cognitive Theory . . . . . . 3

The Sequelae of Maltreatment Typee: Externalizing and Internalizing Symptomatology . . . . . . . . . . 6

Physical Abuse . . . . . . . . . . . . . . . . 6

Exposure to Family Violence - . . . . . . . . . . 8

Paychological Maltreatment . . . . . . . . . . . 10

Neglect . . . . . . . . . . . . . . . . . . 12

Sexual Abuse . . . . . . . . . . . . . . . . 13

Summary . . . . . . . . . . . . . . . . . . 13

Conceptual and Methodological Issues in Maltreatment Research . . . . . . . . . . . . . . . . . . . 14

Conceptual and Operational Definitions of

Maltreatment . . . . . . . . . .

Conceptual and Operational Definition of Maltreatment Subtypea . . . . . . . . . 16

Measurement of Adjuetment . . . . . . . . . . . . 18

Appropriate Controls . . . . . . . . . . . . . 19

Age... . . . . . . . . . . . . . . . 19

sex....................... 20

Socioeconomic status . . . . . . . . . . . 21

Stressful life events............. . 22

Receptive vocabulary . . . . . . . . . . . 22

Summary and Hypotheses Regarding Maltreatment and

Adjustment ....................... . 23

The Role of Blame Attribution in Adjustment . . . . . . . . . 24

Overview . . . . . . . . . . . . . . . . . . . . . 24

Components of Blame Attribution . . . . . . . . . . . . 26

Previous Research on Blame Attribution and Adjustment . 29

Self-blame Attribution and Adjustment . . . . . . 29

Behavioral versus characterological blame. 29

Learned helplessiess theory . . . . . . . 30

Critique and Implications of Self-blame

Research . . . . . . . . . . . . . . . 31

Other-blame Attributions and Adjustment . . . . . 34

Attributions in intimate relationships . . 35

Attributional bias in aggressive children - 36
critique and Implications of other-blame

Children's Research

Critique and Implications of Research on ${ }^{*} \cdot{ }^{*} \cdot{ }^{\prime}$

Children's Reactions to Maltreatment . . . 40 
Possible Influences on Blame Attribution . . . 40

Age ....................... . 40 40

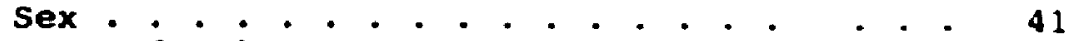

Type of maltreatment . . . . . . . . . . . 41

Models of the Relationship between Maltreatment
Severity, Blame Attribution, and Adjustment . . . 42

Attributions: Moderatora or Mediatora? . . . . . 43

Summary and Hypotheses Regarding Attribution and

Adjustment ....................... 45

CHAPTER II - METHOD . . . . . . . . . . . . . . . . . . . . . . . . 48

Overview of the Measures and Desıgn . . . . . . . . . . . . . 48

Subjects - . . . . . . . . . . . . . . . . . . . . . . . . 449

Sample size and Selectloir. . . . . . . . . . . . . 49

Sample characteristics . . . . . . . . . . . . . . . . 50

Materials... . . . . . . . . . . . . . . . . . . . . 552

Criterion Variables. . . . . . . . . . . . . . . . . 52

Externalizing and Internalizing Symptomatology $\quad$ - 52

The Child Behavior Checklist . . . . . . 53

The Youth Self-Report... . . . . . . . . 54

The Anger Response Inventozy . . . . . . . 34

Predictor Variables . . . . . . . . . . . . . . . . 56

Global Maltreatment Ratings . . . . . . . . . . . 56

File Judge Ratings . . . . . . . . . . 57

Social Worker Ratinge. . . . . . . . . . . 58

Adolescent Ratings . . . . . . . . . . . . 59

Covariates . . . . . . . . . . . . . . . . . . . . . 60

Age and sex................... . 60

Sociceconomic etatus . . . . . . . . . . . 60

Streseful iffe events............ 61

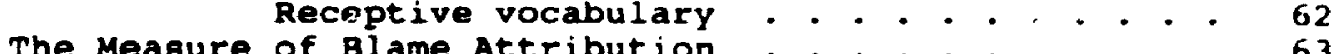

procedure . . . . . . . . . . . . . . . . . . . . . . . . 65

CHAPTER III - RESULTS - . . . . . - . . - . . . . . . . - . . . . . 70

Preliminary Analyвeg • . . . . . . . . . . . . . . . . . . . . 70

Comparison of Participants to Nonparticipants . . . . . 70

Description of the Sample: Criterion Measures . . . . . 70

Means anc Standard Deviations of Crilerion

Measures . . . . . . . . . . . . . 70

Intercorrelations Between Criterion Measures . - 73

The Occurrence and Severity of Maltreatment: Agretment

Between Reporting Sources................. . . 75

The Occurrence of Maltraatment . . . . . . . . . . . . 75 Severity of Maltreatment . . . . . . . . . . . . 78

Intercorrelations Among Maltreatment Types . . . 82

The Relationship Between Maltreatment and Adjustment . . . .84

Hypotheses One and Two: The Association Between Covariates, Maltreatment, and Adjugtment . . . . 84

Hypothesis One: Maltreatment and Adjustment in the Sample Overall . . . . . . . . . . . . . . . 85

Hypothesis Two: Maltreatment and Adjustment within the

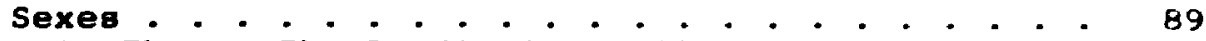

Hypothesis Three: The Predictive Utility of Maltreatment to Adjustment . . . . . . . . . . . 90 Examination of Assumptions . . . . . . . . . . . 91 Prediction using Maltreatment Rat.ngs from Official Sourcea . . . . . . . . . . . . . 95 Prediction using Maltreatmen- Ratings from Adolescents... . . . . . . . . . . . . . 96 Separate regresilons for each sex. . . . . 96 
or she would feel in this situation, and how he or she would respond to the peer.

Several authors have speculated on the origins of aggressive attributional bias towards peers. Dodge and Richard (1985) epeculate that "early trauma, such as that which occurs in physical abuse" may be a contributor (p. 53). Parke and slaby (1983) suggest that attributions for parental maltreatment may influence attribution for the "victimizing" behavior of peers. They conjecture that perception of hostile parental intent generalizes to peers. There is some evidence that physical abuse is associated with an aggressive response biae towards peers. Using hypothetical peer provocation scenarios, Downey and Walker (1989) found that children with both a psychiatrically disturbed parent and a maltreating parent showed more hostile attribution and aggressive response bias than control children. Similarly, Dodge, Bates, and Pettit (1990) evaluated the re:iponses of 46 physically abused children and 263 controls to several peer provocation video vignettes. Physically abused children were more likely than controls to make attributions of hostile intent to stimulus charactera. Unfortunately, no systematic research exists on maltreated children's attributions regarding parental intent for the original maltreatment. As a consequence, there are no data to suppcrt a generalization hypothesis.

Criticue and Implications of Other-blame Researci:

Disparate literatures suggest that other-blame may be associated with maladjustment, particularly aggressive behavior. Maltreatment has been associated with both aggression and hostile attributional bias. By extension, it could be hypothesized that maltreated children who blame the perpetrator for the maltreatment may demonstrate relatively higher levels of externalizing problems. As in the self-blame literature, other-blame studies are limited by a reliance on hypothetical "projective" measures. Likewise, measures of outcome have been limited 


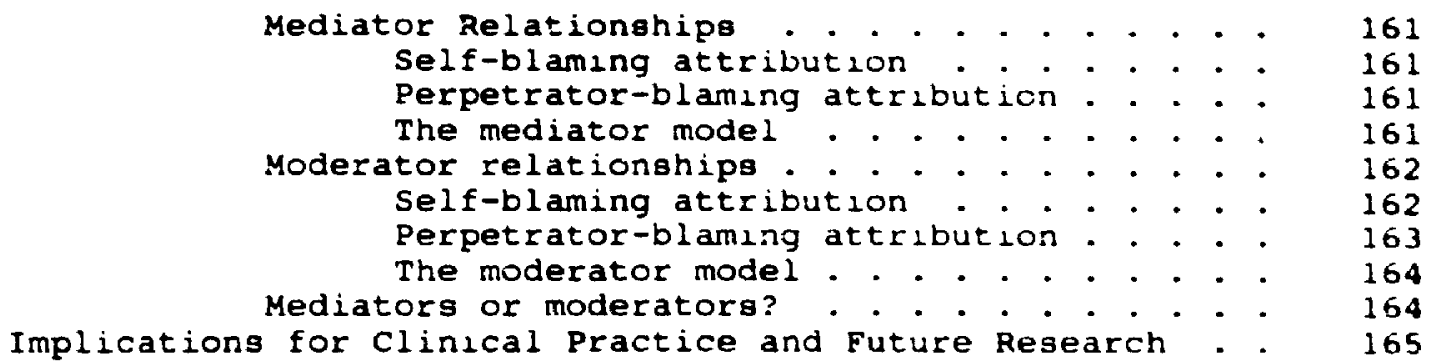




\section{LIST OF TABLES}

Table Description

Table 1. Means, Standard Deviations and Skewness of Covariate and Adjustment Measures. . . . . . . . . . 71

Table 2. Intercorrelations of Criterion Adjustment Measures . . 74

Table 3. Means, Standard Deviations, and Skewness of Maltreatment Ratings ................... . . 76

Table 5. Percentage Agreement among Report Sources on the occurience/nonoccurrence of Maltreatment . . . . . . .

Table 6. Percentage Disagreement between Adolescents and official Sources Regarding the Occurrence/nonoccurrence of Maltreatment . . . . . . .

Table 7 . Correlations Among Reporting Sources' Maltreatment Severity Ratings (All Sources Agree that Maltreatment Occurred) . . . . . . . . . . . . . . . . . . . .

Table 8. Intercorrelations of Maltreatment Ratings within each Reporting Source . . . . . . . . . . . . . . . . .

Table 9. Correlations between Social Worker Maltreatment Ratings and Adjustment Measures . . . . . . . . . . . . 86

Table 10. Correlations between File Judge Maltreatment Ratings and Adjustment Mearures . . . . . . . . . . . . . . . .

Table 11. Correlations between Adolescent Maltreatment Ratings and Adjustment Measures .... . . . . . . . . . . . . 88

Table 12. Intercorrelations among Covariate Measures . . . . . . 92

Table 13. Correlations between Covariates and Maltreatment Ratings, by Reporting Source . . . . . . . . . . . . .

Table 14. Correlations between Covariates and Adjustment Meagures . . . . . . . . . . . . . . . . . . . .

Table 15. Hierarchical Regressions of Adjustment Measures on Adolescent Maltreatment Ratings, Controlling for Covariates . . . . . . . . . . . . . . . . . . .

Table 16. The Unique Contribution $\left(s r^{2}\right)$ of Adolescent Maltreatment Ratings to Adjustment Measures . . . . .

Table 17. Means, Standard Deviation and Skewness of Severity Ratings and Attribution For Maltreatment Subscales

Table 18. Intercorrelations of Severity Ratings and Attributions for Hostile Maltreatment . . . . . . . . . . . . . .

Table 19. Intercorrelations of Severity Ratings and Attributions for Family Violence... . . . . . . . . . . . .

Table 20. Intercorrelations of Severity aatings and Attributions for Neglect. . . . . . . . . . . . . . . . . . . 
Table 21. Intercorrelations of Severity Ratings and Attributions

for Sexual Abuse . . . . . . . . . . . . . . . . . 110

Table 22. Hierarchical Regressions of Hostile Maltreatment

Attributions on Adjustment, Controlling for Severity

114

Table 23. Hierarchical Regressions of Adjustment on Attributions for Family Violence, Controlling for Severity. . . .

Table 24. Hierarchical Regressions of Adjustment on Attributions for Negiect, Controlling for Severity . . . . . . . 116

Table 25. Hierarchical Regressions of Adjustment on Sexual Abuse, Controlling for Severity . . . . . . . . . . 117

Table 26. Correlations between Adjustment Measures and Attributions for Hostile Maltreatment... . . . . .

Table 27. Correlations between Adjustment Measures and Attributions for Family Violence . . . . . . . . . .

Table 28. Correlations between Adjustment Measures and Attributions for Neglect . . . . . . . . . . . . .

Table 29. Correlations between Adjustment Measures and Attributions for Sexual Abuse . . . . . . . . . . . .

Table 30. The Unique Addition of Each Attribution for Hostile Maltreatment $\left(s r^{2}\right.$ ) to Predicted Variance in Adjugtment, Controlling for Severity and All other Attributions . . . . . . . . . . . . . . . . . . .

Table 31. The Unique Addition of Each Attribution for Family Violence $\left(8 r^{2}\right.$ ) to Predicted Variance in Adjustment, controlling for severity and All other Attributions.

Table 32. The Unique Contribution of Each Attribution for Neglect $\left(B r^{2}\right)$ to Predicted Variance in Adjustment, Controlling for Severity and All Other Attributions.

Table 33. The Unique Contribution r,f Each Attribution for Sexual Abuse $\left(8 r^{2}\right)$ to Predicted Variance in Adjustment, Controlling for severity and All other Attributions.

Table 34. Final Factor Solution of the Self-directed Items of the AFMI for Hostile Maltreatment............ 200

Table 35. Final Factor solution of the self-directed Items of the AFMI for Family Violence. . . . . . . . . . . 201

Table 36. Final Factor solution of the self-directed items of the AFMI for Neglect. . . . . . . . . . . . . . . 202

Table 37. Final Factor solution of the self-directed items of the AFMI for Sexual Abuse. . . . . . . . . . . . 203

Table 38. Final Factor Solution of the Perpetrator-directed Items of AFMI for Hostile Maltreatment. . . . . . . . 204

Table 39. Einal Factor Solution of the perpetrator-directed Items of the AFMI for Family Violence. 
Table 40. Final Factor Solution of the Perpetrator-directed

Items of the AFMI for Neglect. . . . . . . . . . . 206

Table 41. Final Factor Solution of the Perpetrator-directed

Items on the AFMI for Sexual Abuse. . . . . . . . . 207

Table 42. Internal Reliability Coefficients for the AFMI

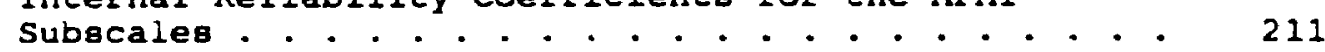

Table 43. Test-Retest Reliability Coefficients for the AFMI

Subscales. ....................... . 212

Table 44. Means, Standard Deviations and skewness of Covariate and Adjustment Meagures . . . . . . . . . . . . . 215

Table 45. Intercorrelations of Adjustment Measures . . . . . . 217

Table 46. Interrater Reliability Coefficients for File Judges

Maltreatment Ratinga. . . . ........ . . . . 231

Table 47. Test-retert Reliability Coefficients for Adolegcent

Maltreatment Ratings. . . . . . . . . . . . . . 235

Table 48. Breakdown of Attribution for Maltreatment Interviews by Perpetrator and Maltreatment Subtype . . . . . . . 255

Table 49. The "Major Cause" for Hostile Maltreatment and the Adolescent $\theta$ Perceived Role in it . . . . . . . . . . 256

Table 51. The "Major Cause" for Neglect and the Adolescent' $s$ Perceived Role in it ..................... . 258

Table 52. The "Major Cause" for sexual Abuse and the Adolegcent's Perceived Role in it..... . . . . . 259 


\section{LIST OF FIGURES}

Figure 1. Self-blaming affect as a moderator of the relationship between severity of hostile maltreatment and

adjustment. . . . . . . . . . . . . . . . . . .

Figure 2. Blaming the perpetrator of family violence as a moderator of the relationship between famliy violence severity and adjustment. 
Appendix

APPENDIX A The Development oi the Attribution for Maltreatment Interview.......................... . 173

APPENDIX B Rationale for the selection of Criterion Measurea . . 213

APPENDIX C The Anger Response Inventory . . . . . . . . . . . - 220

APPENDIX D A Record of Maltreatment Experiences, pages 1 to 31 Interrater Reliability Coefficients för File Judges. 227

APPENDIX E Ratings of Past Life Events Scale Test-retest Reliability Coefficients . . . . . . . 232

APPENDIX $\mathrm{g}$ The Iife Events Checklist . . . . . . . . . . . . . 236

APPENDIX G Letter of Permision to contact . . . . . . . . . . . 241

APPENDIX H Letter of Research Explanation and Informed Consent (Parents and Adolescents) . . . . . . . . . . . . . 243

APPENDIX I Comparison of Participante to Nonparticipants . . • . 248

APPENDIX $J$ The Prediction of Caretaker-reported (CBCL) and selfreported (YSR) Behavior Problem Total Scores . . . .

APPENDIX $\mathrm{K}$ Content Analyses of Subjects' Responses to the Attribution For Maltreatment Interview . . . . . . 
The author of this thesis has granted The University of Western Ontario a non-exclusive license to reproduce and distribute copies of this thesis to users of Western Libraries. Copyright remains with the author.

Electronic theses and dissertations available in The University of Western Ontario's institutional repository (Scholarship@Western) are solely for the purpose of private study and research. They may not be copied or reproduced, except as permitted by copyright laws, without written authority of the copyright owner. Any commercial use or publication is strictly prohibited.

The original copyright license attesting to these terms and signed by the author of this thesis may be found in the original print version of the thesis, held by Western Libraries.

The thesis approval page signed by the examining committee may also be found in the original print version of the thesis held in Western Libraries.

Please contact Western Libraries for further information:

E-mail: libadmin@uwo.ca

Telephone: (519) 661-2111 Ext. 84796

Web site: http://www.lib.uwo.ca/ 


\section{CBAPTER I - INTRODUCTION}

Purpose and Overview

Is has been documented that child victims of abuse and neglect experifence deleterious physical and psychological consequences. General: : aking, the literature on the sequelae of child maltreatment has cocuse on medical problems (Fontana, 1984; Green, Voeller, Gaires Kubie, 1981; Kempe, Silverman, Steele, Droegemueller, \& Silver, 19621, cognitive or intellectual impairment (Gregg \& Elmer, 1969; HoffmanP. jkin \& Twentyman, 1984), mother-child attachment (Crittenden \& A. Jorth, 1989; Egeland \& Sroufe, 1981; Lamb, Gaensbauer, Malkin, G Schultz, 1985), or clinical and behavioral symptomatology (Ammerman, Cassisi, Hersen (Van Hasselt, 1986; Lamphear, 1985). Particularly, maltreated children dieplay a greater number of negative exterializing behaviors (e.g., aggressiveness, delinquency, conduct problems) and negative internalizing behaviors (e.g., withdrawal, anxiety, depression) than do controls (for reviews see Ammerman et al., 1986; Lamphear, 1985 ).

Much of the previous research has been atheoretical: few regearchers have attempted to find the mechanisms that underlie behavioral problems among maltreated children. In contrast, in the adult literature a considerable amount of social poychological research has examined the mediating role of attrlbutions of cauge and blame in adjustment to victimization le.g., Bulman \& Wortman, 1977; Follingstad, Neckerman, \&ormbrock, 1988; Janoff-Bulman, 1979; Holzworth-Munroe, 1988; Miller \& Porter, 1983; Silver, Boon, \& Stones, 1983). Attributions are causal judgements or reasong for a behavior or event. Previous research in the adult domain has guggested that attributing victimization to the self can, under certain conditions, predict depression. Attribution of cause and blame to a role-other has been 
aseociated with angry affect and coercive interchange in inimate relat zonships (Eincham, Bradbury, Grych, 1990; Mackinnon, 1989 ). iss indicated, there is a marked pausity of research on children's attributions for parental maltreatment. Also, there has been no research that has examined the compreherisive victimization history of maltreated youth. The present research attempted to establish a connestion between types of maltreatment, attributional processes, and specific patterns of behavioral disturbance. It was hypothesized that the specific types of maltreatment experienced by a child, in conjunction with the attribution of blam made to account for it, can agaigt in the differential prediction of externalizing and internalizing eymptomatology. In accordance with recert developments in social learning theory, it was hypothesized that aggressive forms of maltreatment would predict externalizing problems, particularly for boys, whereas nonaggressive maltreatment would predict internalizing difficulties. Integrating the writings of several theorists regarding the attribution of blame in jaterpersonal relationships (Fincham, 1985; Shaver, 1985; Snyder \& Higgins, 1988; Tennen \& Affleck, 1990), it was predicted that self-directed blame attributions would mediate or moderate internalizing probleins, whereas other-directed attributions would mediate or moderate externalizing problems. Mediation occurs when a third variable represents the generative mechanism through which a predictor ig able to influence a criterion (e.g., the impact of a life event and adjustment ig channelled or mediated through the subjective appraisal of that event). Moderation occurs when a third variable interacts with a predictor to aid in the prediction of a criterion (e.g., the impact of a life event is differentially influenced or moderated by race cr sex). Mediator and moderator models of the role of attribution with regpect to maltreatment severity and adjustment were tested separately. Also, the influence of gender and maltreatment type were explored. 
The iltroduction is organized into two main gections. Firet, the researsh on the sequelae of maltreatment is reviewed and critiqued. Second, theory and remearch linking self-and other-directed attributions to adjustment among victims is examined. Throughout, the implications for the present research are highlighted.

Tne Relationship between Maitreatment and Internalizing and Externalizing Disorders

Sociat Learning and Social cognitive Theory

According to Bandura*a bocial learning theory (Bandura, 1977; 1989) and the epeculations of a host of researchers in the development of children's behaviors (e.g., Baumrind \& Black, 1967; Patterson, 1982; Wahler (Dumas, 1986), children's behavior is eignificantly influenced by the models to which they have been exposed. If a child has baen a witness to or a recipient of aggressive parental behavior, he or ahe will incorporate such behavior into his or her behavioral repertoire and may imitate aggressive behavior with others. Similarly, if a child has been exposed to inadequate, depressed, or withdrawn parental behavior, the child may imitate helpless, avoidant parent behavior.

In 1989. Bandura published an amplified version of social learning theory, called "social cognitive theory". Although this model still emphasized the direct effects of observational learning, it was expanded to encompass various social cognitive processes. According to social cognitive theory, a modelled event is transduced into a tenaviorally matched event through a variety of cognitive, emotional, and mntivational processes. This theory emphasizes the importance of internal processes and capacities (e.g., symbolization, vicarious learning, forethought, self-regulation, and self-reflection). Social cognitive theory elaborates that processes relevant to the subjective perception of events and subsequent attribution of blame are important to the manifestation of behavior. 
Achenbach and Edelbruck (1978; 1988; Achenbach, 1990) developed a taxonomic syetem for classifying childhood behavior problems. According to them, children's behavior problems can be delineated roughly into two "broad band" categories: externalizing and internalizing disorders. Externalizing disorders refer to aggressive or delinquent behavior, whereas internalizing disorders refer to depressed, anxious, or avoidant behavior. Research from several quarters has supported this distinction; this ccnceptual framework is characteristic of an enormous literature in child psychopathology research (for reviews, see Achenbach, McConaughy, \& Howell, 1987; Ollendick \& Hersen, 1989; Mash * Terdel, 1988).

Internalizing and externalizing symptomatology also covary, such that elevations on one behavior problem dimension are often associated with elevations on the other (Achenbach Edelbrock, 1983). The notion that adjustment problems and clinical symptoms correlate with each other ig a common finding in poychopathology research (Davison \& Neale, 1982; Wicks-Nelson Isael, 1991). Internalizing and externalizing behavior problems are associated with each other because they both represent a core construct of maladjustment. Moreover, several processes may underlie both: failure to regulate affect, failure to inhibit impulseg, maladaptation to environmental stresses, and learning of inappropriate behavioral strategies. Both behavior problem types may represent a failure to acquire or learn more adaptive approaches to internal affect and the external environment. Despite the fact that they are associated, the differential prediction of internalizing problems and externalizing remains considerably important from a clinical perspective. Externalizing problems are costly to both the individual and society in terms of damage to persons and property. Internalizing gymptoms are more insidious and less likely to be noticed by observers until the individual is at high risk. Research that aids in the 
prediction and detection of dangerous behavior and subjective pain is valuable for assessment, treatment, and social policy.

Social cognitive theory has implications for the differential prediction of internalizing and externalizing disorders. It emphasizes that humans have an innate and sophisticated capacity to learn via observation and vicarious affective experiences. The observational learning hypothesis is a central tenet of much of the theory and research on the effects of violence on adjuetment (for review, see widom, 1989). On the basis of this component of social cognitive theory, one would predict that children who have experienced phyeical abuse or exposure to family violence should demonstrate externalizing or aggregsive behavior. That is, they will learn to be aggressive through obeerving aggression in their families (Feshbach, 1980; straus, Gellee, * steinmetz, 1980). They will also vicariously acquire the angry affect apparent in their families. Given the literature that characterizeo neglecting parents as frequently passive, avoidant, and inadequate (Crittenden \& Bonvillian, 1984; Egeland sroufe, 1981a), social cognitive theory suggests that children of neglecting parents may learn this behavioral style and hen e demonstrate internalizing or withdrawn behavior. Also, neglected children may vicariously acquire the depreased affect often displayed by negligent parents. Children experiencing maltreatment, whether aggressive or nonaggressive, may fail to learn appropriate self-soothing affect regulation strategies. Thıs may be particularly true for neglect, in which children may be legs actively socialized in general (Egeland s soufe, 1981a).

Previous research in child maltreatment has largely substantiated the prediction that aggreasive maltreatment types are asgociated with externalizing symptomatology and nonaggressive types are associated with internalizing symptomatology. However, conceptual and methodological problems in child maltreatment research have limited its contribution to the underatanding of the processes underlying the relationehip between 
maltreatment types and a epecific type of behavioral disturbance. The following sections detail the sequelae of physical abuse, exposure to wife aseault, peychological maltreatment, neglect, and sexual abuse. A critique of the conceptual, definitional, and methodological shortcominge of child maltreatment research will follow.

The Sequelae of Maltfeatment Types: Externalizing and Internalizing Symptomatology

\section{Phyeical Abuge}

Phyeically abueed children demonstrate both externalizing and internalizing behavior problems, although externalizing problems are most evident. "A robust finding in the literature," wrote Ammerman et a1. (1986) in their review, "is the prevalence of externalizing behavior problems in <physically> maltreated ch.ildren" (p. 300). George and Main (1979) observed the behavior of preschoolers, and found that abused children directed significantly more aggreseion towards peers than controle. These findings have been replicated among achool-aged children (Bousha c Twentyman, 1984; Hoffman-Plotkin \& Tentyman, 1984 ). Both prospective (e.g., Mccord, 1983) and retrospective (e.g., Lewis c Shanok, 1977) investigations of delinquency in adolescents have implicated physical abuse as a predictive factor. Longitudinal research with high risk mothers (Egeland \& Sroufe, 1981a; Egeland, Sroufe, \& Erickson, 1983) has underscored the direction of the relationship between abuse anci subsequent child aggression: maltreatment in infancy preceded behavior problems in toddlerhood and preschool years. Physically abused children have scored higher on externalizing problems on several behavior checkligt measures, such as the Behavior Problem Checklist (Reidy, 1977), the Child Behavior Form (Hoffman-Plotkin \& Twentyman, 1984), the Eyberg Behavior Inventory (Aragona \& Eyberg, 1981), ard the Child Behavior Checklist (Salzinger, Kaplan, Pelcovitz, Samit, \& Krieger, 1984; Wolfe \& Mosk, 1983). Widom (1989) reviewed 
studies of physical child abuse and exposure of wife assault, as well as prospective and retrospective research involving juvenile delinguents and violent offenders. She concluded that although the literature has many Iimitations, it indicates shat an abused child is at risk for becoming more ielinquent, violent, or criminal in later life. Although it ig argued that criminality and violent behavior can be heritable, twin and adoption studies demonstrate that environment contributes eupetantially to the likelihood of these problems (Dilalla c Gottesman, 1991). Taken together, the previous literature suggeats that a modelling component may account for oome of the externalizing probleme among pryoically abused youngsters.

Salizinger, Rosario, Feldman, Hammer, Alvarado, Caraballo, and Ortega (1989) attempted to predict externalizing and internalizing symptomatology differentially among physically abused children. They predicted that behavior problems would vary with the geverity and the pervasiveness of abuse in the family. Pervasiveness was considered present when abuse was directed towards other family members ae well as the target child. They predicted that children were most likely to develop externalizing problems in the pervasive context, and moet likely to develop internalizing problems when they were the sole victim in the household. Of 18 single and composite measures documenting the occurrence of physical abuse and family violence, all were found to predict parent and teacher ratings of externalizing and internaizing behavior problems significantly. Furthermore, the geverity and pervasiveness of physical abuse were found to predict externalizing disturbance better than interralizing disturbance. Differential prediction of externalizing and internalizing problems was not achieved consistently. However, the authors caution that this finding may have resulted from the fact that almost all the physically abugive households in their sample were also pervasively violent. 
Although externalizing symptoms are the most common sequelae of physical abuse, several studies have shown that physically abused children also display elevations on internalizing symptoms such as anxiety and depression. Using psychiatric interviews with mothers of school-aged children, Green (1978) found that abused children displayed more self-destructive behaviors le.g., suicide attempts, self-mutilation) than neglected or control children. Martin and Beezley (1977) found that many of the abused children they observed were withdrawn. Kazdin, Moser, Colbus, and Bell (1985) examined the incidence of depression in physically abused and nonabused peychiatric inpatients (aged 6 to 13 ) using severai self-report measures of depression, hopelessness, and self-esteem. Relative to nonabused children, the abused sample reported greater depression, lower eelf-esteem, and more hopelessness. Children with both past and current abuse histories had more severe problems than those with either past or current abuse. Because these studies did not assegs the co-occurrence of externalizing oymptomatology, differential prediction could not be examined.

\section{Exposure to Family Violence}

Child witnesses of wife assault demonstrate both externalizing and internalizing behavior problems. However, the preponderance of research hat focused on externalizing difficulties. Widom (1989) described three kinds of research that has suggested a link between witnessing conjugal violence and subsequent aggression and delinquency: large scale correlational surveys, retrospective research with violent or delinguent offenders, and studies of the children of battered women. Survey research using national samples with over 1,000 adults has detected correlations between gelf-reported exposure to parental violence and self-assessments of interpersonal violence (Kalmuss, 1984; Owens \& Straus, 1975). Retrospective studies have indicated high levels of witnesed wife assault in the backgrounds of violent or delinguent 
offenders (Bach-y-Rita veno, 1974, Kratocoski, 1985; Lewis, Shanok, Pincus, G Gaser, 1979). Research with children of battered women has suggested that children who have been exposed to wife assault show eignificantly more behavior problems relative to children from nonviolent homes. Specifically, boys from violent homes displayed higher internalizing and externalizing behavior problems, as well as lower social competence (Hughes \& Barad, 1983; Jaffe, Wolfe, Wilson, 6 Zak, 1986a; Porter \& O'Leary, 1980; Rogenbaum \& O'Leary, 1981). In contrast, girls displayed internalizing behavior problems but generally showed fewer overall adjustment difficulties than boye (Jaffe, Wolfe, Wilson, $\mathrm{zak}, 1986 \mathrm{~b})$. In their review of 21 studies of the effects of witnessing conjugal violence, lantuzzo and Lindquist (1989) identified seven that indicated that male witnesses were more likely to demonstrate externalizing problems and that female witnesses were more likely to demonstrate internalizing problems. These aex differenced in outcome have been interpreted as steming from children's attempta to model the behaviors of the same-sex parent (Jaffe et al., 1986b).

In a direct test of the modelling hypothesis, Cummings and his colleagues (Cummings, 1987; Cummings, Iannotti, 6 Zahn-Waxler, 1985; Cummings, Zahn-Waxler, Radke-Yarrow, 1981) conducted a series of studies in which children were exposed to verbal aggression between adult confederates. Children in both control and experimental conditions were monitored before, during, and after these interactions. Both toddlers and preschoolers found background anger distressing, and subsequently displayed increased aggressiveness in play with a familiar peer. Boys displayed more aggressive behavior following the gimulation, whereas girls showed more distress during the simulation. Exposed to the manipulation again at one-month follow-up, witnesses evidenced even higher levels of aggression and distress relative to controls.

In summary, previous research has suggested an associatici between witnessing wife assault and externalizing behaviors, particularly among 
males. When these stidies have concurrently assessed internalizing problems, high level of depression and anxiety were also found in witnesses relative to controls.

\section{Paychological Maltreatment}

Although there is considerable speculation on the nature and impact of psychological maltreatment (e.g., Garbarino, Guttman, \& Seeley, 1986; Brassard, Germain, \& Hart, 1987) there is very little empirical reaearch on the topic. In part, this lacuna reaults from the difficulties inherent in defining the concept (MoGee \& Wolfe, 1991a). specifically, several studies have defined the concept tautologically by defining "emotional abuse" in terms of emotional damage to the child (e.g., Claussen \& Crittenden, 1991; Martin \& Walters, 1982). Nevertheless, there are several lines of research that can clarify the impact of emotionally abusive parenting practices: studies on the relationship between parenting styles and behavior, survey research on verbal aggression in families, and retrospective studies with adults. Generally, previous research has suggested that emotional abuse is associated with externalizing behavior problems. There is an normous literature demonstrating that insensitive, inconsiste.zt, and verbally aggressive parent behavior is strongly asseciated with aggression and conduct problems in children (for reviews see Parke Slaby, 1983; Wahler \& Dumas, 1986). Vissing, Straus, Gelles, and Harrop (1991) demonstrated an association between emotional abuse (defined as verbal aggression) and aggressive child behavior. As part of a national telephone survey, respondents from households in which there was a child under age $17(\underline{N}=3346)$ were asked to describe the frequency of interpersonal conflict within the family. Parents were asked to describe the frequency of physical and verbal aggression towards the child over the past year using the conflict Tactics scale (Straus, 1979). Physical aggression was quantified into three geverity levels. The meanure of child outcome was not standardized: parents were asked if 
the child had experienced each of the items on a list of peychosocial behavior problems. The authors computed their own indices of delinquenry, aggression, and interpersonal problems. Results using logistic regression analyses revealed a main effect for physical and verbal aggression even when controlling for child age, gender, and socioeconomic status. As verbal aggression by parents increased, the probability of problem behavior also increased. The authors concluded that verbal aggression is more strongly relatea to children's aggression and interpersonal problems than is physical aggression, but that children exposed to both were at greatest $x$ isk for maladjustment. Studies examining the retrospective accounts of adults have suggested that emotional abuse is also associated with internalizing problems. Briere and Runtz (1988) asked undergraduate women to rate the frequency with which they were yelled at, insulted, criticized, or otherwige "put down" by parents. Only paternal paychological abuse predicted scores of anxiety, depression, interpersonal sensitivity, dissociation, and suicidal ideation on a standardized symptom checklist. Thig remained true even after physical abuge had heen partialled out of the regression equation. Similarly, snell (1989) used a self-report measure of maltreatment to predict dysfunctional attitudes and maladaptive behavior in university undergraduates. Low scores on constructive parenting (representing both poychological and physical neglect) were significantly associated with having extreme self-worth contingencies and higher self-reported frequency of self-defeating behaviors. MeCranie and Bass (1984) likewise found that college women who scored highly on measures of self-criticism and depression described their parents as emphasizing strict control and expressing inconsiatent affection.

Taken together, the literature linking parental paychological maltreatment to gymptomatology has suggested that emotional abuse is associated with both externalizing and internalizing symptomatology. 
studies that have used the reports of parents or third parties regarding maltreatment have tended to emphasize externalizing problems. Studies that have employed self-report of abuse experiences have focused on internalizing problems. No studies have examined both internalizing and externalizing problems concurrently; therefore, differential prediction has not been queried.

Neqlect

The effecta of physical neglect on child behavior problems have received relatively little research attention. The few studieg that exist have suggested that neglected children are most likely to manifeat internalizing eymptomatology. For example, Hoffman-Plotkin and Twentyman (1984) found that leglected children were more withdrawn in the classroom than either abused or nonmaltreated children. Bousha and Twentyman (1984) likewise found that neglected children displayed a depreseed rate of positive social behavior, less verbal and nonverbal interaction, and made fewer social initiations compared to other children. However, neglected children also displayed high rates of phyeical aggression relative to controls. Similarly, longitudinal research (Erickson \& Egeland, 1987) has indicated that neglected children were "anxious, withdrawn, lacking initiative, strong need for approval and encouragement, and lacking sense of humour" relative to controls (p. 160). These authors noted that neglected children appeared to have the worgt developmental outcomes of any of the abuse types they followed. Studies comparing neglect victims to physically abused children have indicated that neglected youngsters display fewer prosocial and aggressive behaviors, and inore social withdrawal (Bousha 8 Twentyman, 1984; E. Herrenkohl, Herrenkohl, Toedter, $c$ Yanushefski, 1984; Hoffman-plotkin \& Twentyman, 1984; Reidy, 1977; Roherbeck E Twentyman, 1986). Several theorists have speculated that the internalizing behavior of neglected children may be due to the imitation 
of withdrawn and depressed parental behavior (Bousha G Twentyman, 1984; Egeland, sroufe, ( Pinata, 1989).

\section{Sexual Abuge}

There is an enormous literature associating a history of sexual abuse with adjustment problems in children (for reviews, Bee Alter-keid, Gibbs, Lachenmeyer, Sigal, \& Massoth, 1986; Beitchman, Zucker, Hood, Dacosta, Akman, 1991; B.cowne \& Finkelhor, 1986) and adulte (for reviews, see Hanson, 1990; Peterg, 1988). Caveral gtudies have demonstrated that adolescent survivors display internalizing behavioro and feelings indicative of fear, anxiety, guilt, depreseion, and peychosomatic complaints (Burgese, Hartman, Mccausland, Powers, 1984; Gomes-Schwartz, Horowitz, Cardarelli, 1990; Lindenberg Diatad, 1985; Sansonnet-Hayden, Haley, Marriage, Fine, 1987). Indeed, internalizing problems appear to be the haj.lmark of gexual victimization in childhood. However, some studies have documented delinglent behaviors (Runtz Briere, 1986) and elevated externalizing scores among sexual abuee victims (Friedrich, Urquiza, Beilke, 1986). Thus, although internalizing disorders are prototypical among sexual abuse victime, externalizing behaviors also have been found to occur.

social learning or social cognitive theory has not been used to account for the pervasiveness of: internalizing problema among sexual abuse victims. Rather, theorists have focused on mechanisms relevant so self-blame, stigmatization, traunatic sexualization, and violation of basic trust (e.g.. Finkelhor \& Browne, 1984).

\section{Summary}

Maltreated children and youth demonetrate higher levels of both externalizing and internalizing problems relative to nonmaltreated controls. Social cognitive theory predicts that aggressive maltreatment types would contribute relatively more to externalizing difficulties, whereas neglect would contribute more to internalizing difficultiee. Physical abuse, emotional abuse, and exposure to family violence have 
been associated with externalizing symptoms relatively more often than with internalizing symptoms. Neglect and sexual abuse have been associated with internalizing behaviorg relatively more often than with externalizing behaviors. However, it remains unclear whether there is a specific association between each maltreatment type and a pattern of behavioral dieturbance.

Maltreatment research has suffered from several conceptual and methodological shortcominge that may have obscured the actual pattern linking maltreatment types with specific symptom profilea. The obeervational learning hypothesis cannot be unequivocally aupported in view of these methodological limitations. These limitations include inadequate conceptual and operational definitions of maltreatment, limited measurement of symptomatology, and insufficient controls for confounding influences. In particular, previous studies have failed to addrese the complexity and likelihood of multiple maltreatment. The following section discusses these issues, as well as the implications for the present atudy.

\section{Conceptual and Methodological Issues in Maltreatment Research}

\section{Conceptual and Operational Definitions of Maltreatment}

Several authors have stressed the critical importance of adequate conceptual definitions of maltreatment in child abuse and neglect research (Aber \& Zigler, 1981; Besharov, 1981; Cicchetti \& Barnett, 1991; McGee \& Wolfe, 1991a; Plotkin, Azar, Twentyman, \& Perri, 1981). Aber and zigler (1981) outlined three perspectives that have influenced the research definition of maltreatment: the medical approach, the legal approach, and the sociological approach. In the medical approach, maltreatment is defined by physical injury to the child le.g., Kavanagh, 1982). In the legal approach, maltreatment is that which resulte in meacurable serious harm to the child (although not necessarily physical 
harm). In the sociological approach, maltreating acts are defined by the state.

The sociological perspective is the conceptual approach to definition employed most commonly in previous research. Using this perspective, maltreatment is operationally defined by a family's involvement with a child protection agency. The specific type of maltreatment is usually defined by the protection agency's official reason for service (e.g., Egeland \& Sroufe, 1981; Wolfe \& Mosk, 1983). Recent atudies have extended this approach to include maltreatment ratings made by child protection workers (e.g., Strainer Thieman, 1991; V. Wolfe, Gentile, Wolfe, 1989). Using the sociological approach has the advantage of assuring social relevance; however, such definitions will vary across nations and states. In an effort to improve reliability, some researchers have used trained judgas to quantify maltreatment on the basis of protection agency recoris (e.g.. Barnett, Manly Cicchetti, 1991). Thus, researchers apply their own criteria to the operational definition of maltreatment.

Recently, a new approach to measuring maltreatment has emerged. In this "gubjective" tradition, maltreatment is defined by the victim. Maltreatment is operationally defined by respondents' self-report of occurrence and severity, rather than "objective" criteria dictated by legal or statutory requirements. In literature examining the maltreatment history of adults (e.g, Briere \& Runtz, 1988, 1990; Rausch \& Knutson, 1991) and adolesc...tts (Powers, Eckenrode, \& Jaklitsch, 1990; Stiffman, 1989), self-report methods are employed. Typically, this approach involves global severity ratings (e.g., Ney, Moore, McPhee, \& Trought, 1986) or frequency ratings of specific items (e.g., Berger, Knutson, Mehm, \& Perkins, 1988).

Despite the variety of approacheg to the measurement of maltreatment, no gtudies have examined the basic concordance or equivalence of the different reporting sources. Equivocal findinge in 
the previous literature may be attributable to differing operational definitions. The present study compared two operational definitions from the sociological tradition with one from the "subjective" selfreport tradition. In consideration of the sociological tradition, subjects were adolescents serviced by a child protection agency. Global ratings of the severity of adolescents' maltreatment experiences were obtained from the adolescents' protection workers and from researchers who rated the protection agency files. In consideration of the "gubjective" tradition, global ratings were also obtained from the adolescent him or herself. The present study compared these methods to each other in terms of concurrence and predictive validity regarding adolescent adjustment.

Conceptual and Operational Definition of Maltreatment subtypeg

Another conceptual issue in the definition of maltreatment concerns the delineation of subtypes of abuse. "One of the most crucial gape in our knowledge base," wrote Cicchetti and Barnett (1991), "is that we do not yet have an adequate taxonomic system for conceptualizing and reliably differentiating between the varying manifestations of maltreatment within the spectrum of maltreatment phenomena" (p. 346). Each subtype of maltreatment comes with its own definitional difficulties. Although physical and sexual abuse have undergone definitional refinement, the conceptual and operational defirition of neglect has been elusive (zurvain, 1991). The definition of paychological or emotional maltreatment is particularly problematic. McGee and Wolfe (1991a) have articulated some principles regarding the research definition of psychological maltreatment. To avoid tautology, emotional or psychological maltreatment must be defined by parental acts, not by consequences to the child. Moreover, it is imperative that physically and sexually abusive acts should be excluded from the conceptual and operational definition of emotional. maltreatment in order to avoid redundancy with other abuse forms. 
Previous research has been vitiated by over-reliance on simplistic approaches to -ne measurement of maltreatment. Most commonly, an occurrence/nonoccurrence judgement is made on th? basis of social Bervice agency information, particularly the overall reason for mervice (e.g., Wolfe Mosk, 1983). Although use of broad labels (e.g., "physically abused") to categorize children simplifies resenrch by permitting control comparisons, it obscures differences in the severity of abuse and ignores the co-occurrence of many types of maltreatment in the lives of many children (McGee Wolfe, 1991a). Moreover, use of the official reason for service label provided by the protection agency confounds maltreatment with extraneous issues relevant to caseworker decision-making. For example, "neglect" is a label that is frequently reserved for resistant dysfunctional families (Alter, 1985).

Previous studies have ignored the fact that most maltreated children experience more than one form of maltreatment. Verbal aggression, phyoical abuse, and exposure to wife assault have been found to co-occur frequently (R. Herrenkohl, Herrenkohl, Egolf, 1983; E. Herrenkohl et al., 1984; Straus et al., 1980). Recent studies have reported considerable overlap among the types of maltreatment experienced by clinical subjects (Aber \& Allen, 1987; Egeland sroufe, 1981a; Salzinger, Rosario, Feldman, Hammer, Alvarado, Carabello, * Ortega, 1989). They have demonstrated that "pure" forms of maltreatment are extremely rare. Indeed, studies that have attempted to $f$ ind "pure" cases of verbal abuse have resulted in so few subjects as to make analyses impossible (e.g., Egeland, Sroufe, Erickson, 1983; Clausgen Crittenden, 1991). Becauge previous research has not dealt adequately with the co-occurrence of various types of maltreatment, it is unknown whether the behavior problems displayed b: maltreated children are the result of the specified abuse, unspecified maltreatment, or the interactive or additive effects of a combination of types. Controlling for the presence of other maltreatment types has been recommended by 
researchers in family violence (Fantuzzo Lindquist, 1989), physical abuse (Mash Wolfe, 1991), and sexual abuse (Beitchman et al., 1991). However, these researchers counsel controlling for only one other maltreatment type. To date, no study has attempted to control for them all.

operationally defining maltreatment using abused/nonabused categories also ignores the variance in outcome attributable to maltreatment severity. Very fow studiea have attempted to quantify maltreatment severity and establigh its impact on adjustment ( $C$. Friedrich et al., 1986; v. Wolfe et al., 1989). These probleme have led several authore (e.g., Barnett et al., 1991; McGee \& Wolfe, 1991a, 1991b) to argue for the continuous measurement of maltreatment. To addrese these issues, the present study measured each type of maltreatment distinctly and continuously (i.e., using severity ratings). Regression techniques were used to determine the unique and combined relationship of each maltreatment type with adolescent adjustment. By controlling for all other maltreatment types, the predictive utility of each maltreatment type was examined. Meagurement of Adiugtment

The legal approach to maltreatment definition ouggests that psychological harm to the child should be quantified using atandardized, norm-referenced measures of adjustment. Unfortunately, much maltreatment research has enployed arbitrary indices of behavior and emotional problems (e.g., Visging et al., 1991). The source that reported on the victim's adjustment also varied across studies. Operational definitions of "adjustment problems" have included opinions of social workers (Conte schuerman, 1987), impressions of observers (e.g., Claussen \& Crittenden, 1991), parent-report measures (e.g., Jaffe et al., 1986a; 1986b), and self-report measures (e.g., Briere o Runtz, 1988). As meta-analytic research has revealed considerable discrepancies between self- and third-party reports of adjuetment 
(Achenbach et al., 1987), squivocal findings in the previous literature may be due to this plethora of measurement approaches. The present study avoided mono-source bias by measuring symptomatology from two sources: the adolescent's caretaker and the adolescent him or hereelf. standardized measurement of adjustment allows for a clearer understanding of the impact of emotional maltreatment (McGee Wolfe, 1991a). Standardized norm-referenced measures of symptomatology were used in the present study to ensure reliability, validity, and clinical relevance.

Previous studies have often focused on only one form of behavioral disturbance, either internalizing or externalizing symptomatology. This is problematic, as poychopathology research has demonetrated that elevatione on one type of broad-band behavior problem are often accompanied by elevations on the other (Achenbach Edelbrock, 1983). Externalizing and internalizing disorders are distinct but related. To test the principles of social cognitive theory that emphasize differential prediction, they both must be measured. The precent etudy examined internalizing and externalizing eymptomatology in association with each type of maltreatment.

\section{Appropriate Controle}

Much of maltreatment research has been compromised by designs that fail to take into account other influences on symptomatology. These include victims" age, sex, socioeconomic status, stressful life events, and receptive vocabulary. By virtue of their association with both maltreatment and adjustment, the present otudy treated these variablee as covariates in a regression design.

Age. In child development research, age is often treated as a proxy for the child's developmental atage or level. The age of the subject may directly influence his or her experience or perception of maltreatment. As other researchers have pointed out $10.9 .$, Lusk c Waterman, 1986), the duration of abuse is associated with the age of the 
victim, such that older adolescente will have "more" maltreatment than younger children. Developmental theories that emphasize adolescents' need to individuate from their parents (e.g., Duncan, 1978; Erickson, 1968) suggest that older adolescents may make higher parental maltreatment ratings than younger children. That is, older adolescents may see the ratings as an opportunity to complain about their parents or to exprees emotional distance from them. In the present study, age is controlled in two ways. Subject selection was limited to the adolescent age range $(11-17)$. Also, age was used as a covariate in apecific regreseion analyses.

Sex. An enormous literature on sex differences in psychopathology underscores the greater incidence of externalizing probleme among males, in both childhood (Eme, 1979; Maccoby Jacklin, 1974) and adulthood (Dohrenwend c Cohrenwend, 1975). The male preponderance in aggressive behavior has been termed "the most unequivocal sex difference in the literature" (Eme, 1979, p. 583). Similarly, among adolescents and adults, females are more prone to the internalizing disorders of depreasion and anxiety (Dohrenwend \& Dohrenwend, 1974; Nolen-Hoeksema, 1987). Investigation of the impact of maltreatment on externalizing and internalizing symptomatology must address the relative vulnerabilities of the sexes to these disorders.

Many theorists have identified observational learning mechanisms as critical to the acquisition of male aggressiveness. However, some studies have suggested that aggressive behavior is easier to facilitate in boys. There is consigtent evidence that observed aggression has a greater impact on males relative to females. Studies on the impact of aggressive models (e.g., Bussey Bandura, 1984) as well as the long term effects of television violence (e.g., Eron, Huesman, Lefkowitz, \& Walder, 1972) suggest that boys are more likely than females to behave aggreseively in response to aggressive models or stimuli. In maltreatment research, male witnesses to spouse assault demonstrate more 
externalizing behaviors than female witnesses (Jaffe, Wolfe, \& Wilson, 1990). Retrospective studies linking physical maltreatment in childhood and adolescence to aggression and delinquency in adulthood also emphasize this connection for males (Malamuth, Socklodkie, Koss 6 Tanaka, 1991: Widom, 1989). Taken together, previous research has suggested that boys may be more likely to demonstrate externalizing problems as a result of experiencing or witnessing aggressive maltreatment relative to girla.

Another reason for identifying gender as an important variable in the examination of the Iink between maltreatment and adjugtment is that the incidence of certain maltreatment types varies between the sexes. For example, females are victims of sexual abuse far more often than males (Badgley, 1984). Some authore (e.g., Carmen, Ruseo, c Miller, 1981; Walker \& Browne, 1985) suggest that this factor alone may account for the female preponderance in internalizing disorderg. Similarly, recent reviewe of socialization practices suggest that boys are more likely to be physically punished than girle (Lytton Romney, 1991). To control for the influence of gender, the present study employed it as a covariate in several analyses. To evaluate the impact of gender on post-maltreatment adjustment, the current study examined prediction equations separately for each sex.

Socioeconomic status (SES). The literature on risk factors associated with maladjustment identifies ses as one of the key influences on outcome (Rutter, 1983). The incldence of behavioral and psychological problems in childhood and adolescence 18 greater among disadvantaged families; also, the incidence of rertain maltreatment types (e.g.. physical abuse) is greater in lower ses populations (Trickett et al., 1991). Although SES ig properly regarded as an aggregate of variables that exert combined influence or adjustment (Magh \& Wolfe, 1991), its aignificance has made it a xey considecation in clinical outcome research. Statiotical or derign controle for ses have 
become de rigeur fur maltreatment research (Aber \& Allen, 1987; Mash c Wolfe, 1991; Trickett et al., 1991; Widom, 1989). The present study controlled for ses by using it as a covariate in certain regressions. Also, the population of interest (i.e., adolescents serviced by a child protection agency) typically has a restricted range of socioeconomic statua.

Stregsful life events. Considerable research has demonstrated that the adjustment of children and adoleacents is adversely affected by etressful iffe events. As the number of stressors experienced by the child increases, adjustment difficulties also increase (Johnson \& McCutcheon, 1980; Dohrenwend \& Shrout, 1985; Rowlison \& Felner, 1988). Therefore, to determine the unique predictive value of maltreatment, the influence of other stressors must be considered and controlled. This is particularly important because many maltreatment experiences may be associated with certain stressors (e.g., removal from the home, moving to a shelter, courtroom testifying). Care must be taken to distinguish maltreatment-related atressors from the maltreatment itgelf. The present study controlled for the influence of stressful life events by documenting the number of stressful life events occurring in the past year and treating it as a covariate in regression analyses.

Receptive vocabulary. Several studies have demonstrated that receptive vocebulary plays an important role in the manifestation of social-cognitive deficits among abused populations (Barahal, Waterman, * Martin, 1981; Frodi E Smetana, 1984; Smetana, Kelly, \& Tentyman, 1984). When its influence is controlled, social-cognitive deficits in maltreated children are less apparent (Barahal et al., 1981). It has been found to be negatively correlated with behavioral adjustment (Dehorn \& Klinge, 1978). Measures of receptive vocabulary are highly correlated with IQ (Dunn \& Dunn, 1981). Statistical or design controls for its influence have been recommended by researchers in the maltreatment area (e.g., Barahal et al., 1981). The present atudy 
treated receptive vocabulary as a covariate in certain regression analyees.

\section{Summary and Hypotheses Regarding Maltreatment and Adjustment}

Social cognitive theory predicts that direct imitation of hostile or avoilant parental behaviors may account for eimilar behavior in aggressive or withdrawn children. There is also extensive evidence that certain types of child maltreatment result in externalizing and internalizing behavior problems, although the relative contribution of each type of maltreatment to each type of behavior problem is unclear. Therefore, the present study hypothesized a direct association between the deg:ee of hostile maltreatment (physical abuse, exposure to family violence, and emotional abuse) the adolescent has experienced and the degree of externalizing symptomatology he or she displays. Social cognitive theory would predict that as exposure to aggroseive types of maltreatment increases, externalizing symptoms should also increase. This should be particularly true for boys. Similarly, it is hypothesized that there will be a direct associacion between the degree of neglecting maltreatment an adolescent has experienced and the degree of internalizing symptomatology he or she displays. Social cognitive theory cannot adequately explain the empirically-demonstrated covariation between sexual abuse and internalizing behaviors; nevertheless, a comprehensive examination of the impact of maltreatment on symptomatology requires that sexual abuse be included in the study to establish its unique relationship with adjustment.

The lack of comprehensive measurement of maltreatment and adjustment in previous studies may have obscured any systematic variance between the type of maltreatment experienced and behavioral disturbance. To explore these hypotheses thoroughly in the present study, the maltreatment history of each subject was measured using three distinct reporting sources: the child protection worker, trained judges of agency 
recorde, and the adolescent him or herself. Five subtipes of maltreatment were meastired using a continuous metric. Both internalizing and externalizing symptomatology were assessed using caretaker-report and self-report standardized measures. It was predicted that maltreatment ratings would gignj.ficantly contribute to variance in symptomatology, over and above the contribution made by sex, age, socioeconomic status, stressful life events, and reseptive vocabulary. To clarify the relationship between maltreatment and adjustment for each gender, the increment in adjustment variarce attributable to maltreatment ratings was examined for each sex. Social cognitive theory (Bandura, 1989) emphasizes that cognitive processes are very relevant to behavioral expression, above and beyond the original observational learning experience. specifically, individual's capacity for self-regulation of affect, motivation, and behavior will govern behavioral expression. The theory identifies the attribution of blame as an important part of the self-regulation process. Self- or other-blame can act as the mechanism by which a negative life experience influences subsequent behavior. The following section describes the previous literature linking self- and other-blame to internalizing and externalizing behaviors, and explores possible models of this mechanism.

The Role of Blame Attribution in Adjugtment

\section{Overview}

Considerable research has been conducted on the attributions of adulc "victims" and the ways in which such cognitive appraisals influence adjustment. In the social psychological literature, the label "victim" has had a variety of applications. Studieg have involved victims of natural and technological disasters (e.g., Baum, Flemming, Singer, 1983; Titchener, Kapp, \&inget, 1976), those who have experienced serious accident, or illnesses le.g., Bulman wortman, 
1977; Schulz \& Decker, 1985; Taylor, Lichtman, \& Wood, 1994), and the family members of the chronically ill (e.g., Pagel, Becker, coppel, 1985; Tennen, Affleck, \& Gershman, 1986). Other research has focused primarily on crime victims, particularly on victims of rape (Abbey, 1987; Meyer \& Taylor, 1986; Scheppele \& Bart, 1983) and spouse assault (Follingstad et al., 1988; Holtzworth-Munroe, 1988). Only a few studiea have examined the attributions of child maltreatment victims.

Many of these studies have examined victims' attributions of cause, blame, and responsibility for the aversive event. Generally, the results suggest that self-blame is associated with internalizing problems, whereas other-blame is associated with externalizing problems. On the basis of studies involving interpersonal victimization (e.g., Follingstad et al., 1988; Holtzworth-Munroe, 1988; Miller C Porter, 1983) and family conflict (Fincham \& Jaspers, 1980; Fincham, Beach, C Nelson, 1987; Fincham \& Bradbury, 1987; Bradbury \& Fincham, 1990), gelf-blame for victimization has been associated with depreseed affect and behavior. Although the research on the role of other-blame for victimization has been sparse (Tennen affleck, 1990), Btudies in marital conflict (Bradbury \& Fincham, 1990) and aggreseive blas (Dodge \& Richard, 1985) have suggested that other-blame is associated w_th hostile affect and behavior. However, no studies have examined selfand other-blame for victimization concurrently, or examined their combined and unique relationship with gymptomatology.

The present study examined whether the attributions associated with self-and other-blame for maltreatment improve the prediction of externalizing and internalizing symptomatology. specifically, it assessed the incremental contribution of both self-and other-blame attributions to variance in adjustment, controliing for maltreatment severity. Also, it evaluated whether attribution moderated or mediated the relationship between maltreatment severity and aymptomatology. 
The following sections review the previous literature. First, the theoretical components of blame attribution are clarified. Second, the literature on self- and other-blame are reviewed. Third, studies on children's perceptions of maltreatment are summarized. Throughout, the theoretical and methodological implications for the present study are highlighted.

\section{Components of Blame Attribution}

Blame is a conceptually complex construct. In order to determine the role of blame attributions in predicting adjustment, the nature of blame mugt be clarified. Blame can be understood to comprise geveral components. These include cognitions relevant to the assignment of blame, cognitions relevant to the avoidance of blame (i.e., excuses or justification), and blaming affect. Theory and research from several quarters have underscored these elements.

Theory (Shaver, 1985; Shaver Drown, 1986) and research (Bradbury * Fincham, 1990; Fincham Jaspers, 1980; Fincham Bradbury, 1987; Tennen Affleck, 1990) describe blame as the end product of a complex chain of attributional judgements. Drawing on the theoretical elaborations of Heider (1958), Shaver (1985) has outlined the sequence of cognitions that result in an attribution of blame. First, the perceiver evaluates the causal contribution of the other (or self) to the event using the dimension of causal locus le.g., evaluation of whether the aspects internal to the individual contributed to the event). Next, the perceiver will attribute responsibility on the basis of several factors. In Shaver's model, attributions of responsibility to a transgressor will increase with increases in the following factors: the extent to which the offender could foresee the consequences or his or her action, intent to bring about the event, degree of volition, and appreciation of the moral wrongfulness of the action. Attribution of blame is an evaluative response that occurs after the perceiver assesses 
and does not accept the validity of the offending person's justification or excuse for an effect that the perceiver believeg was intentionally brought about (Shaver, 1985; Shaver \& Drown, 1986). Blame, therefore, is an amalgam or product of these cognitions. Fincham and his colleagues (Fincham \& Jaspers, 1980; Fincham \& Bradbury, 1987) also promote this "entailment model" of attribution, in which blame judgements presuppose judgements of responsibility, which in turn presuppose judgements about the locus of a cause.

Some theoriste (Fincham et al., 1990; Shaver \& Drown, 1986) distinguish between blaming cognitions and blaming affect. Blaming affect arises from blaming cognition, and is thought to be directly associated with mood and behavioral intentions. Several studies (e.g., Fincham et al., 1990; Wollert, Heinrich, Wood, \& Werner, 1983) have suggested that the affective responses of anger and sadness arise from the attribution of blame, as opposed to the attribution of cause. Wollert and colleagues (Wollert et al., 1983; Wollert \& Rowley, 1987) had subjects rate causal attribution, self-blame, and mood following manipulated failure on a laboratory task. Self-blame remained correlated with depressed mood, even when controlling for causal locue attributions, although the reverse was not true. Similar results were obtained in a longitudinal study of attributions for exam performance (Wollert \& Rowley, 1987). Research relevant to other-blame has produced similar findings. In a variety of studies assessing the relationships between causal attribution, blame attribution, anger, and behavioral intentions in digtressed marriages, Fincham and his colleagues (Fincham \& O'Leary, 1983; Fincham \& Bradbury, 1987; Fincham et al., 1990) have found that blame attributions predicted angry affect, whereas causal attributions did not. Path analyses indicated that blaming af fect was predictive of hostile behavioral intention. Thus, affective reaction to blame attributions is an important component of the blame process, and a likely part of the connection between blame, mood, and behavior. 
Shaver (1985) has emphasized that an attribution of blame will result when excuses for an offence are not accepted. This is true of both self- and other-blame. Snyder and his colleagues (Snyder $t$ Higging, 1988, Snyder, Higgins, stucky, 1983) have proposed a theory of excuse-making. According to Excuse Theory, self-blame can be avoided by manipulating the elements of a responsibility attribution (e.g., by modifying attributions of causal locus, intent, control, foreseeability. and awareness of wrongfulness). Although Excuse Theory emphasizes selfdirected excuees, it can encompass excuses directed toward eignificant other8. Presumably, vitiating a blame attribution through excuses will also avoid the negative affective sequelae of blame attribution, and result in less self- or other-directed affect. Thus, excuses are an important component to a comprehensive understanding of the blame process.

Many of the previous atudies in blame processes have artificially aimplified blame processes by focusing exclusively on self- or otherblame. In actuality, victims make both self-and other-blame attributions. Both kinds of blame processes may influence adjustment; therefore, they must be considered concurrently in statistical analyees. The present study measured each of the following dimensions: selfblaming cognition, self-blaming affect, self-directed excuses, otherblaming, and other-directed excuses.

The following section examines the relationship between victimization, blame attribution, and adjustment found in the previous literature. These studies have typically not integrated all aspects of the blame process outlined above. Rather, they focus on gmaller elements of it (e.g., causality judgments). Nevertheless, these studies suggest that self-blame, broadly defined, is associated with internalizing problems, whereas other-blame is associated with externalizing problems. 


\section{Previous Regearch on Blame Atcribution and Adjugtment} Self-blame Attribution and Adjustment

Previous thought on the relationship between attribution and adjustment was influenced by two explanatory models that emerged during the late 708 and early 808: theories of "behavioral" versus "characterological" blame (Janoff-Bulman, 1977) and learned helplesenees theory (Abramson, Seligman, Teasdale, 1978; Peterson seligman, 1983). Although both models suffered from serious conceptual and methodological shortcominga (Brewin, 1985; Shaver Drown, 1986; Brewin E Antaki, 1987), they have generated considerable research and continue to influence thinking regarding the relationship between victimization and adjustment.

Behavioral vergus characterological blame. Interest in the dynamics of self-blame began with Bulman and Wortman's (1977) interesting finding that apportioning cause for an accident to the eelf among accident victims was positively associated with independent estimates of the subjects' adjustment. These counterintuitive findinge were explained by suggesting that self-blame may have a functional value by enabling victims to believe that they are in control 0 : their livea (Wortman, 1976), by preserving belief in a just world (Lerner Miller, 1978), and by imposing meaning on significant life events (Frankl, 1963; Silver Wortman, 1980). Building on Lerner and Miller's (1978) juet world findings, Janoff-Bulman (1979) distinguished between "characterological blame" and "behavioral blame". For characterological blame, negative events were attributed to enduring features of one's character. For behavioral blame, negative events were attributed to one's behaviox. Because behavior is modifiable, attribution to this factor was thought to be associated with a belief in the avoidability of future negative outcomes and hence to result in positive adjuatment. 
Attribution to the stable, relatively immutable dimension of character was thought to be associated with helplessness and depression.

Studies using manipulated failure and vignette methodologies have demonetrated that raters do distinguish between behavioral and characterological blame (Anderson Jennings, 1980; Howard, 1987; Janoff-Bulman, 1982; Janoff-Bulman, Timko, Carli, 1985). However, behavioral blame has been inconsistently associated with outcome in empirical studies involving accident and illness victims (Shaver \& Drown, 1986; Tennen \& Affleck, 1990). Also, studies involving the selfreports of victime of interpersonal violence have not supported the dietinction (e.g.. Abbey, 1987; Holtzworth-Munroe, 1988; Muyer Taylor, 1986; Miller \&orter, 1983). Although there is evidence that "gelfblame" in general is associated with depression after interpersonal victimization (e.g., Andrewa \& Brewin, 1990; Meyer \& Taylor, 1986), there is no empirical evidence that behavioral blame is associated with better outcomes among victims of violence.

Learned helplesgnegg theory. In 1978, Abramson, Seligman, and Teasdale presented a reformulation of the learned helplessness model of depression. According to the reformulatsd model, causal attributions mediated the relationship between negative life events and depression. Casual attribution occurred along three dimensions: internal-external, stable-unstable, and global-specific. Helplessness and depression were assumed to result if the individual attributed failure to internal-stable-global causes and success to external-unstable-specifis causes. In this model, "self-blame" is defined as an internal, stable, and global causal explanation. The authors noted that "controllability is logically orthogonal to the internal x global x stable dimensions" (p. 62) and hence did not develop it as a construct in their model. Peterson and Seligman (1983) extended this model to victimization experiences. Essentially, the theory posited that victims interpret victimization as a "failure" experience and seek attributional 
explanations accordingly. Recently, the learned helplessness model has been revised as the "hopelessness mclel", which demphasizes causal attributions as central to the development of dapresiion (Abramson, Metalsky, Alloy, 1989). Nevertheless, the previous formulation has guided thought and research on the connection between child maltreatment and subsequent maladjustment.

Very few studies have examined the role of causal attributions among maltreatment victims. Generally, these studiea have employed research designs that compared victims to nonvictims on measures of attributional atyle, responses to hypothetical vignettes, and depression. On the whole, these studies have demonstrated that maltreated populations have greater internalizing aymptoms than controle (Gentile, 1988; Gold, 1988; Proulx, Dyck, Quinonez, Chohan, \& Koverola, 1992). Although some studies have suggested that victims and nonvictime differ in attributions for hypothetical events (Gold, 1988; Green 4 Cicchetti, 1988), reaults have been contradictory (Gentile, 1988). In some studies, within the victim group, "self-blaming" attributional style predicted internalizing symptoms (Gold, 1988; Proulx et al.. 1992). Only two atudies evaluated victims' attributione for the actual maltreatment experience. Gentile found no association between selfreported depression and a measure of attribution for sexual abuse among female children, whereas Proulx et al. (1992) found such an association among female adults.

critique and Implications of self-blame Research

Taken together, theory and research from the behavioral/ characterological model and the learned helplessness model have suggested that "self-blame", broadly defined, is associated with internalizing symptomatology among victims. As yet, however, the specific relationship between self-blame for actual maltreatment and post-victimization adjustment is unclear. Conceptual and methodologlcal limitations of the self-blame literature may account for the equivocal 
findinga among actual victims. The present research attempted to redrese some of these limitations.

Shaver and Drown (1986) have argued that conceptual confusion has resulted from inappropriate operationalization of sause, responsibility, and blame. Previous research has confused causal attribution with reefronsibility attribution, when the former is properly regarded as a subprocesa in a larger sequence leading to the attribution of responsibility and self-blame. In their view, "behavioral self-blame" i. really velf-attribution of causality, whereas "characterological self-blame" is really self-attribution of responsibility. The behavioral/characterological model and the learned helplessness model both fail to go beyond causal attribution. Omission of considerations such as the causal agent' control, foreseeability, intent, and selfjustification will create an incomplete picture of blame attribution. Both modele are remise in that they have not integrated the notion of controllability over the cause of the victimization. Prospective longitudinal research involving adolescents has revealed that perceptions of controllability are important in determining whether internal attributions for negative events lead to depressed affect (Brown E Siegel, 1988). Similarly, Anderson and Aroult (1935) have found that subjects' ratings of the controllability of the cause for hypothetical events was the most significant predictor of scores on measures of depression, loneliness, and shyness, over and above the variance predicted by ratings of causal locus, stability, and globality. Neither model acknowledges the complexity of victimization in an interpersonal context (Abbey, 1987; Fincham et al., 1986; Miller, Smith, - Uleman, 1981; Tennen Affleck, 1990; Shaver Drown, 1986). That is, they fail to acknowledge the reciprocity and interpersonal dynamic underlying conflict in close relationships. In real life, victims make attributions for the perpetrator's behavior as well as their own behavior. The circumetances motivating the perpetrator'a behavior may 
iapinge on the victin's assessment of why the events occurred to him or her. Moreover, mutual influence will also operate to influence selfdirected attribution (Fincham, 1985), particularly in the family context. If blame judgements influence negative affect, and selfblaming affect potentiates depression, a compreheneive atudy of the relationship between blame ascription and maladjustment must incorporate attributions for the perpetrator's actions.

Previous attributional literatures have imposed a "hydraulic" underetanding of the nature of eelf- and other-blame attributione. That is, many studies have been predicated on the fundamental aseumption that self-blame and other-blame are inversely related. The hydraulic model is so entrenched in social poychological thinking that conventional attributional reasures (e.g., the Attributional scale Questionnaire, Peterson, Semmel, Von Bayer, Abramson, Metalsky, Seligman, 1982; the Children's Attributional style Questionsaire, Kaslow, Tannenbaum, c Seligman, 1978) quantify causal locus (internal-external) as "totally due to me" versus "totally due to other people or circumetancea". The Causal Dimension Scale (Ruseell, 1982) unfortunately melde personal and other-based control into a single dimension "controllable by you or other people" versus "uncontroliable by you or other people". These bipolar item formats impose inverse relationehips between welf- and other-directed attributions (Cutrona, Russell, Jones, 1984; Norman * Antaki, 1988). Various authors have called for theoretical and measurement concessions that will allow self-and other-blame to be conceptualized and quantified as separate entities (e.g., Howard, 1987; Tennen a Afleck, 1990). The present study examined self- and otherdirected attributions as separate constructs, using a measure uniquely designed for that purpose (see Appendix A).

Pinally, much of the research for these two model has rested on the undemonstrated aseumption that attribution for the original maltreatment will turn into an attributional "atyle", which then will 
influence eubeequent attribution for life events and hence subsequent adjuetmont. Researchera have been guilty of tautological reasoning by inferring the victime' attribution for maltreatment from their responees to "projective" measures such as the Aso or hypothetical vignettee. Remarkably fow etudies have permitted victims to make attributions for their actual maltreatment experiences. Moreover, there is no evidence that maltreatment victims conceptualize victimization as a failure experience, making the application of achievement models questionable. Aleo, no etudy hes examined whether victime make behavioral or characterological attributions pontaneously, although eeveral reserchers have questioned this aseumption (e.g., Abbey, 1987; Miller c Porter, 1983).

To addrees these concerne, the present atudy proceeded with a more complex model of blame attribution. It allowed maltreated adolescente to make pontaneous causal attributions fol both their own and the perpetrator' role in ectual maltreatment. Responees were content analyzed to determine their relevance to the behavioral/ characterological dietinction. Subjects' responses were ecored along dimeneione relevant to reeponsibility judgements: causal locus, controllability, foreseeability, and intent. To ensure compreheneive meaeurment, gelf-blaming affect was measured separately from selfblaming cognition. Excuses were measured for both the gelf and tr: perpetrator.

Qther-blame Attributions and Adjustment

Other-blame has been linked to anger and aggresaion in both child and adult populations. Recent research has demonstrated an association between attributions of biame towards others and subsequent adjustment difficulties (Tennen Affleck, 1990). Unfortunately, Tennen and Affleck' reviow focused on "victims" of accidents and illness, making generalization to child maltreatment victime problematic. Only one of the otudies (Meyer \& Taylor, 1986) roviowed by Tennen and Affleck (1990) 
concerned violent victimization; in that reeearch, other-blame was not associated with adaptation after rape. Tennen and Affleck (1990) speculated that other-blame is associated with negative affectivity through restriction of coping atrategies and challenges to just world beliefs. Interpersonal alienation was considered to gerve as anothur path from other-blame to maladjustment (Mittelstaedt G Wollert, 1991; Tennen a Afleck, 1990). The relationahip between other-blame and externalizing problems is auggeeted by two literatures: research on attributions in marital conflict, and the study of hostile attributional bias in aggreseive children.

Attributions in intimate relationghipg. Knowledge regarding the impact of other-blame in close interpersonal relationships comes mainly from the literature on marriage. Generally, the findinge auggest that blaming the epouse for negative events is associated with retaliatory behavior and coercive exchange. Fincham and O'Leary (1983) asked dietressed and nondistreseed couples to make attributions for hypothetical positive and negative spousal behaviors. Subjecte $c^{\prime a c}$ etated their behavioral intentions if faced with that particular scenario. Persons who regarded their spolise's negative behavior as intentional, selfighly motivated, and blameworthy were more likely to report a negative affective reaction and intend to respond in a punishing, retaliatory fashion. This was true even when controlling for marital satisfaction. Path analyses indicated that blaming affect mediated the relationship between attributions and behavioral intentions. Like shaver (1985), Fincham and his colleagues distinguish between attributions about = cause (i.e., global, stable, internal) and attributions of personal responsibility. Their research with spousee has demonstrated that responsibility attribution, not causality attribution, predicted the affective reaction and intended response to opousal bahavior (Fir sham et al., 1987, Fincham \& Bradbury, 2987 ). Other research has indicated that distresed epouses are more 1 ikely to 
make dispositional as opposed to situational attributions for negative gpouse behaviors (Jacobson, McDonald, Follette, Berley, 1985). Doherty (1982) found that wives' tendencies to infer a negative intention or trait on the part of a story character was positively associated with observed criticism of their spouses and self-reported angry responses to coercive spouse behavior.

With respect to parent-child relatıc.shipg, Mackinnon (1989) examined children's attributions of parental intent for parent-child conflict. In her study of 57 mother-son dyads, she examined the relationship between attributions, perceptions of intentionality, problem-solving skills, and interpersonal interaction. Boys' attributions of cause and intent for actual and hypothetical aversive parent behavior were related to observed aggressive behavior towards the parent during laboratory observations.

Attributional bias in aggressive children. Another literature suggests that other-blame is associated with aggression. Several authors (Dodge \& Richard, 1985; Parke \& Slaby, 1983; Rubin \& Rrasnor, 1986) have suggested that aggressive behavior in children develops from inappropriate attribution of others' hostile intent. A growing literature has documented an association between aggressive behavior in children and a tendency to attribute nostile intent to the ambiguous behavior of peers. Attribution of hostile intent has been found to be directly related to the child's decision to retaliate aggressively (Dodge, 1980; Dodge \& Frame, 1982; Dodge, 1986; Dodge, Murphy \& Buschbium, 1984; Stelnberg, \& Dodge, 1983; Nasby, Payden, \& depaulo, 1980). Usually, the existence of a hostile attributional bias is assessed through the use of hypothetical vignettes in which the child is asked to imaglne that he or she has experienced an ambiguous and potentially provocative peer behavior $(e . g .$, being hit in the back with a ball). The child is asked why the peer behaved in this manner, how he 
or she would feel in this situation, and how he or she would respond to the peer.

Several authors have speculated on the origins of aggressive attributional bias towards peers. Dodge and Richard (1985) speculate that "early trauma, such as that which occurs in physical abuse" may be a contributor (p. 53). Parke and slaby (1983) suggest that attributions for parental maltreatment may influence attribution for the "victimizing" behavior of peerg. They conjecture that perception of hostile parental intent generalizes to peers. There is some evidence that physical abuse is associated with an aggressive response bias towards peers. Using hypothetical peer provocation scenarios, Downey and Walker (1989) found that children with both a paychiatrically disturbed parent and a maltreating parent showed more hostile attribution and aggressive response bias than control children. Similarly, Dodge, Bates, and Pettit (1990) evaluated the responees of 46 physically abused children and 263 controls to several peer provocation video vignettes. Physically abused children were more likely than controle to make attributions of hostile intent to etimulus characters. Unfortunately, no syotematic research exists on maltreated children's attributions regarding parental intent for the original maltreatment. As a consequence, there are no data to suppcrt a generalization hypothesis.

Critigue and Implications of other-blame Researc:

Disparate literatures suggest that other-blame may be associated with maladjustment, particularly aggressive behavior. Maltreatment has been associated with both aggression and hostile attributional bias. By extension, it could be hypothesized that maltreated children who blame the perpetrator for the maltreatment may demonstrate relatively higher levels of externalizing problems. As in the gelf-blame literature, other-blame studies are limited by a reliance on hypothetical "projective" measures. Likewise, measures of outcome have been 1 imited 
to reports of behavioral intention. To ensure external validity, the present study examined actual maltreatment experiences as opposed to hypothetical vignettes, and employed standardized outcome measures.

\section{Children's Reactions to Victimization}

Very few atudies have examined the perceptions of child victims regarding their maltreatment experiences. Nevertheless, they generally support four conclusions. First, maltreated children make simultaneous gelf- and perpetrator-directed attributions regaxding the maltreatment. second, self-blame for physical maltreatment is inversely proportional to the perceived severity of the experience. Third, physically abused children incorporate notions of "deservingness" inte their definitions of phyaical abuse. Finally, children and youth frequently attribute parental punishment to benign parental intent.

Herzberger, Potts, and Dillon (1981) interviewed 14 physically abused and 10 nonabused boys in residential care regarding their explanations for parental behavior. Subjects were asked "when your parent hit you, was it because you did something bad?" and also "was it because $8 /$ he was mean?" (p.87). Both abused and control children felt their bad behavior was relevant. However, abuged children were also more likely to attribute being hit to parental meanness, and less likely to think their experiences were deserved. Rausch and Knutson (1991) administered a questionnaire to 1526 university undergraduateo regarding their physical punishment experiences. Among those subjects the authors defined as physically abused, perceived deservingness and labelling oneself as abused were negatively correlated. That is, if deservingness is considered a form of self-blame, self-.blame decreased as physical abuse severity increased. These results corroborate those found with victims of wife assault: self-blame decreases and perpetrator-blame increases with increasing abuse severity (Frieze, 1979; Holtzworth-Munroe, 1988; Miller \& Porcer, 1983). 
Amsterdam, Brill, Bell, and Edwards (1979) surveyed 103

adolescents and young adults regarding their punishment experiences. On a checklist of coping mechanisms, respondents most commonly attributed punishment to benign parental intent (e.g., to make them a good child). The majority of subjects believed that they deserved most or all of their punishment; this was more true of femaleg. In contrast with other studies, perceived deservingness was positively correlated with severity. Approximately one quarter reported coping with punishment by blaming themselves. Internalizing responses such as withdrawal and guicidal ideation were reported by 38\%, with more females than maleo reporting such tendencies. Externalizing responses such as retaliation, angry outbursts, displaced aggression, and running away were reported by 658. Despite its limitations, the study suggested that youth do make "excuses" when explaining aversive parental behavior, and resort to internalizing or externalizing ways of coping.

Ney, Moore, McPhee, and Trought (1986) interviewed 57 school-aged peychiatric inpatients regarding various forms of maltreatment. Using a visual analogue scale, mothers and psychiatric unit staff rated the frequency and severity of the child's experience of five types of maltreatment. A measure of the child's perception of "fault" was obtained, although it is unclear whether the interviewer, child, or parent completed it. Self-blame for physical abuse decreased as severity increased. Self-blame for sexual and verbal abuse supposedly showed a curvilinear relationship, with children accepting more "fault" at mild and severe levels of maltreatment. The authors reported that "the relationship for neglect was unclear, but children generally thought it was their fault" (p. 511). Although this study represented an insightful attempt to quantify multiple forms of maltreatment and asgegs children's self-blame for each, serious conceptual and methodological flaws limited its contribution. 
Critique and Implicationg of Research on Children's Reactions to Maltreatment

Research examining maltreated youth's perceptions of maltreatment has been largely descriptive. None of these studies evaluated the connection between attributions and adjustment. Research methods, particularly the quantification of maltreatment and "blame" in such atudies, have been questionable. Nevertheless, these studies suggest that as phyeical abuse severity increaseg, self-blame decreases and other-blame increases. For other maltreatment types, the relationships between self-blame and severity and between self-blare and other-blame are unknown.

Pogsible Influences on Blame Attribution

There are other factors that may influence the nature of blame attributions maltreated youth may make for their victimization. Respondents' age, sex, and specific maltreatment experiences may influence the nature and extent of self- and other-blame. The present study addresses these considerations.

Age. Consistent findings have indicated that children begin to make attributions for their own behavior in a manner similar to adults at the age of eight or older (Didgon Gotlib, 1985; Rholes, Blackwell, Jordan, Wallers, 1980). Research on children's other-directed attributions has indicated a developmental shift from entity attributions to person att=ibutions at approximately age nine (Kassin \& Pryor, 1985; Rholes Ruble, 1984; Ruble, Feldman, Higgins, \& Karlovac, 1979). After age nine, children are able to view others' traits as predictive of their future behavior and to see these traits as "causal". Several studies indicate that children can make use of mitigating circumstances in deciding how much to blame a protagonist for some act (Darley, Klosson, Zanna, 1978; Karniol, 1978; Schleifer, Shultz, \& Lefebvre-pinard, 1983), with the most sophisticated reasoning evident after the age of 11 . Hook (1989) examined the literature relevant to 
developmental progress through Heider's (1958) levels of attribution of responsibility. Arguing that the foreseeability rule requires forms of reasoning ascribed to Piaget's (1965) stage of formal operational thought, Hook asserted that children do not adopt the foreseeability rule until the age of 11 or later. Several recent studieg that have corrected the methodological shortcomings of earlier work support this assertion (Hook, 1989; Sanvitale, Saltstein, \& Blank, 1987; Schleifer et al., 1983). The present atudy involved youth from ages 11-17, to ensure the necessary cognitive maturity to make sophisticated attributions of blame.

Sex. Social paychology studies using vignette methodologies have demongtrated that males and females sometimes attribute blame to victims and perpetrators differently. A consistent finding is that males attribute greater blame to victims and less blame to perpetrators than do females. This is a particularly robust finding with respect to rape (Cahoun, Selby, Cann, Keller, 1978; Howard, 1984; Kanekar, Pinto, Mazumdar, 1985; Krulewitz, 1982; Krulewitz Nash, 1979; Thornton, Robbins, \& Johnson, 1981). It has also been detected with child neglect (Ringwalt \& Caye, 1989), sexual harassment (Jensen Gutek, 1982), and wife assault (Koski \& Mangold, 1988; Skiffington, 1983). By extension, one might expect gender differences in attribution regarding persoral maltreatment. Unfortunately, there is little empirical literature contrasting the attributions or perceptions of males and females with respect to their own victimization experiences, although several authore have speculated that males may minimize such events (e.g., Finkelhor, 1984; Gully, Pepping, \& Dengerink, 1982). The present study explored possible sex differences in attributions for various maltreatment types, as well as the relationship between gender, attribution, and outcome. Iype of maltreatment. Different maltreatment experiences may yield different attributions of self- and other-blame. Both theory (Kelley, 1967; McArthur, 1972) and research (Alloy Ahrene, 1987; 
Crocker, Alloy, Kayne, 1988; Haack, Dykman, Metalsky, \& Abramson; cited in Abramson et al., 1989) have suggested that situational information surrounding a negative life event will influence the kinds of causal explanations made for it. For example, physical abuse and emotional abuse often occur in the context of discipline (R. Herrenkohl et al., 1983), which may increase the likelihood that a youth could attribute the cause to him or herself (i.e., to his or her misbehavior). In contexts of overt parental aggression (e.g., physical abuse, wife assault), in which the behavior can be sudden and unpredictable, the child has the opportunity to attribute the violence to uncontrollable and unintentional factors (e.g., "bad moods"). In contrast, the secret and deliberate nature of sexual abuse may lead the sexually victimized child to perceive the offender's behavior as planned or intentional. The perpetrator may also vary across maltreatment experiences. In the present study, each type of maltreatment is considered separately along with the self- and other-directed attributions generated for each.

Modele of the Relationship between Maltreatment Severity, Blame

\section{Attribution, and Adiustme.te}

Previous research on both self- and other-blame attribution has suffered from an important deficit. It has typically ignored the influence of event severity, either on attribution or adjustment (Tennen \& Affleck, 1990). That is, the perceived severity of the maltreatment experience has not been incorporated into models of the relationship between events, blame attribution, and adjustment. Given that maltreatment severity is thought to influence both symptomatology (Cicchetti \&arnett, 1991) and attribution (Holtzworth-Munroe, 1988), examination of its role is crucial to a thorough understanding of the mechanisms underlying post-victimization adjustment. There are two conceptual models that describe the relationship between maltreatment 
severity, blame attribution, and symptomatology: the moderator model and the mediator model. The present study examined both models.

Attributions: Moderators or Mediators?

Baron and Kenny (1986) distinguish between the moderator model of third variables and the mediator model of third variables. A moderator is a third variable that affects the direction and/or strength of the relationship between an independent variable and a dependent variable. It partitions an independent variable into subgroupg that eatabliah ita domains of maximum effectiveness in regard to a certain dependent variable. In this model, the predictor (maltreatment ceverity) and the moderator (blame attribution) may each have main effects on adjuatment; nevertheless, the model suggests that they interact to predict symptomatology. Conceptually, moderator variablea specify when certain effects will occur. Statistically, the presence of a moderator is determined through a test for the significance of the crossproduct of the moderator and the independent variable in a regression equation (Cohen \& Cohen, 1983).

A mediator, on the other hand, is a third variable that representa the causal mechanism through which the independent variable is thought to influence the dependent variable. It explains how external physical eventa take on paychological aignificance. The effects of atimuli on behavior are mediated by various transformation processes internal to the organism (e.g.. "O" in classic S-O-R theory). There is a causal chain between the independent variable, the mediator, and the dependent variable. Conceptually, a mediator illustrates why certain effects occur between an independent and dependent variable. Statiotically, thc. potency of a mediator is indicated when removing the effects of the mediator gignificantly reduces the relationship between the independent variable and dependent variable.

Is blame attribution for maltreatment a mediator or a moderator of maltreatment severity? There is evidence for both models. In the 
moderator model, severity and attribution retain direct effects on adjugtment - the influence of severity is not completely "channelled" through attribution. Tennen and Affleck (1990), in their treatise on othar-blame, theorize that event severity will have both direct and indirect effects on adaptation. Baron and Kenny (1986) outline that moderator variables are often examined when there is a weak or inconsistent relationship between predictors and criteria in the literature. As the relationship between maltreatment severity and internalizing and externalizing problems has been inconsistent, attributions of eelf-: id other-blame could be axamined for their moderating influence on post-maltreatment adjustment.

Other theory and research have suggested that attributions may act as mediators of the relationship between event severity and subsequent outcome. Theories relating aspects of self-blame to adjustment (e.g., learned helplessness theory, posit a causal mechanism linking external evente to depression through an internal "transformation" of the perception of the events. According to attributional theories, event severity can "cause" attributions by stimulating attributional search (Tennen Affleck, 1990; Weiner, 1985). Similarly, excuse theorists (Forsythe, 1989, cited in fennen Affleck, 1990) suggest that the more severe the precipitating situation, the greater the victim's need to externalize blame. Some empirical evidence among victims of violence suggest that perceived event severity is functionally associated with gelf- and other-blame (e.g., Holtzworth-Munroe, 1988; Ney et al., 1986). Although Baron and Kenny (1986) recommend that mediation is best tested in the case of a strong relationship between the predictor and the criterion variable, theoretical considerations suggest that examination of the mediator model is warranted.

The present study examined the moderator and mediator model oeparately. In accordance with the previous literature, it was predicted that self-blane attributions would mediate or moderate 
internalizing problems, whereas perpetrator-blame attributione would mediate or moderate externalizing problems.

How should maltreatment severity be quantified to explore these models? Some evidence suggests that relative to "objective" sources, the victim's subjective evaluation of event severity better predicts attribution and adjugtment. Research with medical patients has indicated that victims' perceptions of severity were associated with other-blame and adaptation, whereas estimates from phyeicians were not (e.g.. Affleck, Allen, Tennen, McGrade, Ratzan, 1985). Moreover, previous research on interpersonal violence has demonetrated a relationship between subjective severity estimatee and self-blame (e.g.. Holtzworth-Munroe, 1988). Given that the mediator model posita an "internal" process, aubjective severity estimates represent the firat step in the putative causal sequence between the event and subsequent adjustment. Therefore, the present study employed subjective ontimater of maltreatment severity in exploring the mediator/moderator models of attribution.

\section{Sumr Iy and Hypotheges Regarding Attribution and Adjugtment Attribution theory predicts that attributions for maltreatment} will be associated with adjustment among victims. Recent theory and research have emphasized that attribution of blame may be more important to adjustment than the attribution of cause. Blame can be understood to comprise blaming cognitions, excuses, and blaming affect. Previous research on victims has focused primarily on the role of self-blame; however, in actuality, blame will be directed at both the gelf and the perpetrator. In the present otudy, victims' self- and perpetratordirected attributions were quantified using a structured clinical interview. This interview yielded five composites: eelf-blaming cognition, self-directed excuses, self-blaming affect, perpetratorblame, and perpetrator-directed excuses. It was hypothesized that these 
attribution composites, taken together, would contribute gignificantly to variance in aymptomatology, over and above the contribution made by percelved naltreatment severity. Maltreatment type and sex were considered possible influences on blame attribution; therefore, the predictive utility of attributions was examined for each maltreatment type and each gender. The unique relationship of each attribution composite to adjustment was also examined.

studies examining the behavioral/characterological blame dietinction, as well as those examining learned helplessness theory among victime, auggest that attribution of cause to the belf for victimization is associated with internalizing problems. Although both of these approaches emphasize the importance of the content of victims. caueal attributione, few studies have examined victims' spontaneous causal attributions for real-life victimization. The present study content analyzed victims' spontaneous attributions of cause for both the self and the perpetrator.

Also, research on the attribution of blame has often neglected to incorporate the perceived severity of the experience into models of the impact of event and attribution upon adjustment. Two modele are posaible. Self-blame attributions may mediate maltreatment geverity by internally "transforming" or channelling the perceived severity of the negative event into subjective distress and symptomatology. Self-blame attributions may moderate maltreatment severity by affecting the atrength and/or the direction of the relationship between severity and adjustment. Both models may account for some of the findings in the previous literature. Because self-directed attributions have been associated with internalizing problems, it was hypothesized that selfblame attributions would mediate and/or moderate the relationship berween maltreatment severity and internalizing problems. Mediator and moderator models were tested separately. 
The literature on other-blame in interpersonal victimization has been sparee. However, findings in the area of marital conflict and hostile attributional bias in aggressive children have suggested that other-blame is aseociated with externalizing behavior. Therefore, it was hypothesized that perpetrator-blame would mediate and/or moderate the relationohip between maltreatment severity and externalizing behaviors. Again, mediator and moderator models were tested separately. It was also predicted that the present study would replicate eeveral findings in the maltreatment attribution literature. specifically, it was predicted that blame towarde the perpetrator would increase as abuse severity increased. Also, attribution of blame to the self was expected to decrease as severity of maltreatment increaced. Because little ie known about other-blane (Tennen \& Affleck, 1990), ita agsociation with adjustment and self-directed attributions was explored. 
Canpras II - MLIHOD

Overview of the Measures and Design

The present atudy used a correlational, multiple regression design. Multimethod assessment of current adolescent adjustment (i.e., externalizing and internalizing symptomatology) was conducted. The criterion variables included caretaker-report and self-report of both internalizing and externalizing behavior problems. Self-reported difficulties in managing anger arousal were also measured. As part of a larger study, aubjecta completed aeveral other measures in addition to those described in this disentation'. Appendix B outlines how the criterion measures used in this diseertation were selected. To reduce the number of criterion variables, those redundant (i.e., highly correlated) with those representing a similar construct were dropped. Analybes were planned in two major sections. In the firgt ection, hierarchical regreseions were employed to determine if the addition of information regarding maltreatment eeverity improved prediction of adjustment heyond that afforded by age, sex, sociueconomic etatus, receptive vocabulary, and recent atressful life events. The adolescent's history of maltreatment was operationally defined by global severity ratings of five types of maltreatment: physical abuse, gexuai abuse, emotional abuse, neglect, and exposure to wife assault. These global ratings were obtained from three separate sources: the adolescent, the adolescent's social worker, and trained judges of the adolescent'B case history file. To clarify gerder differences in the ralationship between maltreatment and adjustment, similar regregsion equations were con. ated for each sex.

'Other measures included: The parent Perception Inventory (Hazzard, Chrieteneen, Margolin, 1983). The Child Depression Inventory (Kovacs, 1981). The self-perception Profile for Adolescents (Harter, 1988), The Perceived Control Inventory (Connell, 1985) and an interview regarding Poet-Traumatic strese Disorder. 
The second set of analyses focused on those adolescents who identified themselves as victims of specific types of maltreatment. Four types of maltreatment were examined: hostile maltreatment (comprised of physical and/or emotional maltreatment), exposure to family violence, neglect, and sexual abuse. The research question concerned the proportion of variance in adjugcment accounted for by attributions, over and above the proportion accounted for by perceived maltreatmert severity. For each of type of maltreatment, severity was operationally defined as the highest severity rating made by the adolescent acrose all possible perpetrators. Attributions regarding a maltreatment type were operationally defined as the subscale ncores obtained from an interview about that most eevere experiense. These aubscales measured five attribution-related composites: self-blaming cognition, self-blaming affect, self-directed excuses, perpetratorblame, and perpetrator-directed excuses. Hierarchical regreesions examined the increment in adjustment variance accounted for by the attribution subscales taken as a set, over and above the variance accounted for by adolescents' ratings of maltreatment eeverity. To clarify the role of gendex in the relationship of attribution and adjustment, regressions were computed for each sex. In addition. specific regressions were computed to examine the mediator and moderator models of the relationship between maltreatment severity, blame attribution, and symptomatology.

The overall bample size $(\underline{N}=160)$ was selected to main:ain an adequate case to variable ratio and adequate power (398) to detect an effect size of .3 at an aipha level of .05 .

\section{Subjects}

Sample size and selection

Two hundred and fifty-nine adolescents were invited to participato in the study. All adolescents were randomly selected from the open 
cageload of the London/Middlesex Children's Aid Society, a child protection agency that gervices a primarily urban county in southwestern ontario. A control group couid not be employed in the study jesign, as nonagency youth do not have records describing their maltreatment histories. Apart from age, there were no other selection criteria for potential participants; that is, they were not selected on the basis of maltreatment history or any other characteristic. The only exclusionary criteria were organic dysfunction (e.g., diagnosed brain damage, autiom), a current diagnosis of mental retardation, or a psychotic disorder (e.g., chilcihood schizophrenia). On the basis of information providad in agency files and through the report of the adolescent's oocial worker, four adolescents were rejected froin consideration for these reasons. One hundred and sixty-two adolescents elected to participate in the study. Of these, two teens returned unusable data. Thus, 160 adolescents ( 70 males, 90 females) were retained in the study (628 participation). Subjects were between the ages of 11 and 17 years, with a nean age of 13.8 years.

\section{Sample Characteristics}

The adolescents and/or their families were receiving service for a wide variety of family problems. For each family, the child protection agency codes an "fficial reason for service" on two occasions: at intake and several years post-intake. Based on this code, most subjects were serviced at intake for parental inadequacy (26.68), folj owed by alleged physical abuse (18.18). Other major reasons for service included parent-child conflict (14.48) and child behavior problems (14.48). A smaller percentage were originally serviced for sexual abuse (7.5). Often, the "current" reason for service for the gample was diflerent whan the intake reason for service. The proportion of families serviced for parent-child conilict (22.58) and child behavior problems (258) increased. The proportion serviced for parental inadequacy decreased (15.68). 
Approximately half the sample (568) were living with their natural motherg at the time of recruitrent. Only 12.38 were living with their natural fathers. Few (5.68) of the youth lived with both natural parente. Almost a quarter of participants (23.18) were wards of the crown. The remainder were in the temporary care of the agency, living with foster parents or in group homes. Most of the reapondents (69.48) had entered agency care at least once. The average age at which subjects first entered care was 8.8 years for an average duration of 12.5 months. The mean number of agency placemen, s experienced by subjects was 2.4 , whereas the number of changes in primary caregiver occasioned by the family of origin was 7.2. Of the adolescents in temporary care, virtually all (988) had at least monthly contact with their natural mother.

Similar to other samples used in child protection research (e.g., Trickett et al., 1991; Salzinger, Feldman, Hammer \& Rosario, 1991; Salzinger et il., 1989) the sample was a socioeconomically disadvantaged one. The majority of adolescents (688) came from families of origin that were dependent on public assistance. Of the working families (N = 51), 628 were supported by jobs at the three lowest levels of Holiingshead's gocioeconomic scale (i.e., menial gervice, unskilled or semiskilled occlpations). This sample uas also simllar to other research samples in the degree of dysfunction in the family background (cf. Salzinger et al., 1991). Information determired from case fileo and protection workers indicated a large percentage of the total number of subjects had a mother with a history of one or more of the following problems: alcohol abuse (40.18), drug abuse (248), paychiatric problems (52.28), or a criminal history (19.18). When information was available on natural fathers $(\underline{N}=124)$, these indices were even greater: over half (548) abused alcshol, a querter (288) abused drugs, a third (348) had psychiatric problems, and half (47\%) had criminal histories. The 
incidence of these difficulties was very similar for stepfathers, when guch information was available $(\underline{N}=86)$.

\section{Materialo \\ Criterion Variables}

\section{Externalizing and Internalizing symptomatology}

Several measures were used to quantify internalizing and externalizing symptomatology. To avoid mono-sourse bias, behavioral disturbance was quantified using both caretaker-report and self-report measures. The items on the behavioral measures describe specific behaviors displayed by the target child, as opposed to feeling states. Given that the subjective nature of affective states is beet addressed by self-report meawires, a self-report measure of anger arou .l management was employed.

For each of the criterion measures described below, raw ecores were converted into standardizen $\mathrm{I}$-8cores with a mean of 50 and a standard deviation of 10. An individual's T-gcore represents the extent to which an he or she deviates from the mean of the standardization sample used to develop the instrument. Individuals who score two standard deviations away from the mean of the normative population (i.e., a T-score greater than 70) are considered to be in the "clinical range" on that dimension.

The present study employed T-scores as criteria for several reasons. First, because the present study did not employ a "normal" control group, it was imperative to examine variance in subjects' aymptomatology in terms of deviation from the nonclinical normal population. Second, in regression analyses, predictor variables can be understood to predict the degree of deviance from established norms. Third, T-scores are recommended for analyses that include children of both sexes and/or different age ranges (Achenbach, 1991). 
The Child Behavior Checklist (CBCL; Achenbach \& Edelbrock, 1983; Achenbach, 1991a). The CBCL is a well-btandardized measure of the social competence and behavior problems of children aged 4 to 18 . It is completed by the child's primary caretaker. The CBCL, which was originally developed in 1983, has been used extensively in researrh and clinical settings. New norms for the instrument have been recently reported, using a normative sample of 2368 children (Achenbach, 1991 a). These 1991 norms were used in the present study.

The CBCL generates factor scales reflective of a given child's social competence and behavior problems. For the present otudy, only the behavior problem scores were of interest. The behavior problem eection of the CBCL consigta of 118 items. Each item describer a specific behavior (e.g., "cries alot", "gets in many fightg"). Item ecores range from 0 ("never or rarely occurs") to 2 ("occurs often or very often"). The CBCL yields nine subscales indicative of specific syndromes or bellavior problems. It also yields a behavior problem total score, a. "externalizing" score, and an "internalizing" score. The internalizing score is composed of the sum of three subscales: withdrawal, somatic complaints, and anxiety/depression. The externalizing scale comprises the delinquency and aggression subscales. The behavior problem to'al gcore includes the internalizing and externalizing scales, as well as subscales indicative of social problems, thought problems, attention proolems, and sex problems. Raw scores on the CBCL are converted into standardized $\mathrm{T}$-scores.

The CBCL has excellent tegt-retegt reliability, with a mean tegtretegt reliability for behavior problems of .89 over a one-week interval. The mean stability coefficient for behavior problem Bcores was .75 at one year and .71 at two years. Mean interparent agreemer.t ranged from .65 to .75 . The CBCL has also demonstrated excellent construct validity, correlating .82 with the Conners' Parent 
Questzonnaire and .81 with the Quay-Peterson Revised Behavior Problem Checkligt (Achenbach, 1991a).

The Youth Self-Report (YSR; Achenbach Edelbrock, 1987;

Achentach, 1991b). The YSR is a self-report measure of social

competence and behavioral difficulties appropriate for adolescents aged

11 to 18. It is virtually identical to the CBCL in format and content, but is zompleted by the adolescent. Like the CBCL, the YSR has been renormed using a sample of 1315 adolescents (Achenbach, 1991b). On the new revision, the subscales that comprise the Internalizing and Externalizing factors are entirely consigtent with those on the CBCL. The pregent etudy employed the T-scores obtained for the internalizing and externalizing factors of the YSR. Reliability estimates at one week reteat for the YSR total gcor 28 are very good, ranging from .79 to .81. Longer term otability is moderate, with a mean of .49 at seven month retest (Achenbach, 1991b).

In a meta-analysis of the relevant literature (Achenbach et al., 1987), the correlation between gelf- and parent-ratings of behavior problems was estimated to be .25 . This association suggested that YSR ecores and CBCL scores contribute unique information to the understanding of adolescent behavioral disturbance and warranted the inclusion of both measures in the present study.

The Anger Response Inventory (ARI; Hoshmand \& Austin, 1987). The ARI is a 68-item self-report measure of anger expression and control. The ARI inquires about the sibject's responses to angry affect (e.g., "When I am angry, I threaten to hurt the person who is making me angry") using a 4-point rating scale from "never" to "almost always". Factor analytic psychometrics on the original normative sample of adults and older adolescents $(\underline{N}=236)$ revealed that the ARI yields six subscales: Maladaptive Behavior, Maladaptive Cognition, Behavioral Skill Deficit, Cognitıve Skill Deficit, Anger Arousal Intensity, and Anger Arousal Duration. Maladaptive Behavior refers to behavioral acting-out when 
angry ("I hit other people"). Maladaptive Cognition referg to inappropriate thoughts when angry ("I tell myself 'I must show people that I am really tough""). Behavioral skill Deficit and cognitive skill Deficit are operationalized as the reverse-scores of adaptive responses to anger using behavior ("I ask people to give me time to cool off") or cognition ("I picture myself remaining calm and in control"). Anger Arousal Intensity refers to physiological responses to anger ("I get all choked up"), whereas Arousal Duration refers to the enduringness of physiological reactions ("I get choked up for hours").

Psychometric data (Hoshmand \& Austin, 1987) collected on normal and clinical samples have indicated that the ARI has high internal consigtency (alpha range $=.76$ to .89 ). Test-retest reliability is also high, ranging from .73 to .83 at a 4 week ilserval. Research on the criterion validity of the ARI has indicated that scores are eignificantly correlated with clinician ratings of temper control problems. Hoshmand and Austin (1987) found that the ARI could successfully discriminate between normal and clinical (spouse batterer) samples, and that scores in the clinical group were gignificantly reduced after therapy for anger control problems.

For the purposes of the present study, riew adolescent norms were obtained for the ARI. The ARI was administered to 230 adolescents between the ages of 14 and 18 at a local high school (Horner, 1991 ). Within this sample, subscale reliability coefficients (Cronbach's alpha) ranged from .73 to $.87(\underline{M}=.81)$. Although no grade differences were found witinin the normal population, sex differences were apparent. Females indicated more arousa? management difficulties and males reported more behavioral and cognitive control difficulties. Therefore, separate sex norms were developed for each subscale.

The present study employed only the Anger Arousal Intensity Bubscale of the ARI. Becauge this subscale meagured the frequency of physiological distress when angry, it was conceptually distinct from the 
externalizing and internalizing symptomatology measured by the CBCL and YSR. Ostensibly, poor management of anger arousal could lead to either internalizing or externalizing problems. Psychometric information obtained from Horner's (1991) adolescent normative sample suggested that the Anger Arousal Intensity subscale had no relationship with social desirability $(\underline{r}=.03)$, and had excellent internal reliability (Cronbach's alpha $=.86)$. Because some research has suggested that arousal is managed differently in males and females (Harris \& Siebel, 1976), this subscale may share unique variance with gender. Finally, because the subscale is based on self-report of physiological symptoms, it is 1988 prone to the critique of tautology when used as a criterion for cognitive predictors. The ARI is found in Appendix C.

\section{Predictor Variables}

\section{Global Maltreatment Ratings}

In recent years, some researchers have begun to quantify maltreatment continuously, using global severity ratings by judges of case history files (e.g., Barnett et al., 1991), child protection workers (e.g., Strainer Thieman, 1991; v. Wolfe et al., 1989), and the victims themselveg (e.g., Briere \& Runtz, 1988; Ney et al., 1986). However, no previous research has ever employed a multimethod approach to measurement by using more than one reporting source. Because multimethod quantification is vital to the establishment of validity in non-experimental research (Cook \& Campbel1, 1979), and because there is no information on the basic concordance or equivalence of these methods, the present study employed severity ratings by file judges, sncial workers, and adolescent victims. Global severity ratings were employed for several reasons. First, they have been used in the previous literature. Second, they were eagy to obtain. Third, on the basis of pilot information, glotal ratings were considered more clinically seneitive than asking victims to detail opecific acts of abuse. 
File Judge Ratings. The global maltreatment ratings obtained by file judges were derived from a larger instrument, a Record of Maltreatment Experiences (ROME) (McGee, Wolfe, Wilson, 1990). The ROME is an 87-item instrument aimed at documenting the complete victimization history of a given child, based on frotection agency files. The ROME was derived from tho History of Victimization Form (V. Wolfe, Gentile, Bourdeau, 1986). The ROME is organized into five subscales examining five major types of maltreatment: physical abuse, sexual abuse, exposure to family violence, emotional abuse, and neglect. Each scale involves documentation of the frequency of specific maltreating acts (e.g., "hits child with en object") across severıl age ranges.

In addition to specific acts of maltreatment, the ROKE provides global maltreatme ratings of the same five types of maltreatment. Separate ratings are obtained for each of natural mother, natural father, and "other" (adoptive and foster parents were considered to be "other"). Maltreatment experiences are rated along a four-point scale: "not at all", "mildly", "moderately", and "severely". After completing the detailed subscales of the ROME on the basis of all agency records for a target child, a trained judge completed these global ratings. File judges were instructed to rate their global perception of the parental behavior itself, not its impact on the child. This scoring rule helped to lessen the risk of tautology, particularly for the construct of emotional maltreatment (McGee Wolfe, 1991a).

A maximum score was obtained for each type f maltreatment by taking the maximum rating across perpetrators. Two file judges rated the case files. The percentage of files rated by each judge were approximately equal (608 trained assistant, 40 primary investicator). The file judges agreed in 100 of the cases regarding the 1lentity of "other" perpetrators. Interrater reliability between the two judges for all ratings was obtained on 29 cases (18: of the sample). Interrater 
reliability coefflcients (Pearson $\underline{\underline{ }}$ ) of the maximum scores were very good, ranging from .79 to .96. The first three pages of the Rom and all interrater reliability coefficients for file judges are found in Appendix D.

Social Worker Ratings. Independently, the protection worker for a aubject also completed the ROME global ratings. Although the worker made his or her ratings in the presence of a file judge, thc worker was blind to the ratings made by the judge.

On average, workers had serviced the cases they rated for 18 montins $(\underline{S D}=14.02)$. Workers also rated how well they knew the case, on a ecale of 1 ("do not know at all") to 5 ("know extremely well"). For the majority of the 160 sibjects (58.88), the workers indicated that they knew the case very well or extremely well. For an additional 33.18, workers knew the case gomewhat well. The remainder (8.18) were rated as cases of which the worker knew very little. In no instance did a worker indicate that she did not know a case at all.

Unfortunately, tegt-retest and interrater reliability estimates for the ROME global ratings were not obtained for agency social workers. Because the amount of time agency personnel could spend on the project was limited, and becasse they we. already extensively involved in other project tasks, it was not feasible to have them rate each other's cases or to rate several cases twice. However, previous psychometric research during the development of the ROME has suggegted that protection workers are sensitive to differences between cases and substantially agree on maltreatment when examining the same case (McGee \& Wolfe, 1990). In that study, 130 social workers read a hypothetical case file. Half the sample received a different version, slightly altered to reflect different psychologically abusive dynamics (a previous study had confirmed the desired manipulation). Workers were asked to complete the ROME on the basis of the case material. ROME scores differed in the predicted direction in response to the manipulation. Also, percentage 
agreement on maltreatment ratings among worker's rating the same case was acceptable, ranging from 648 (emotional maltreatment) to 1008 (Bexual abuse). Similar levels of concordance have been found in other studies of child protection decigion-making (e.g., Alter, 1985).

Adolescent Ratings. During an individual interview, each subject made ratings regarding his or her maltreatment history using the Ratings of Past Life Events Scale (McGee, 1990). To assist them, eubjects were aided by a visual analogue graphic that represented maltreatment as a horizontal line anchored at "not at all", "mildly", "moderately", or "severely". This analogue approach has used in previous research with younger victims (e.g., Ney et al., 1986). Also, it allowed adolescents to communicate such clinically sensitive information in a simple and straight forward fashion.

During the adolescent interview, each type of maltreatment included brief behavioral examples or prompts to ensure comprehension and reliable interpretation. The prompts were as follows: physical abuse was prompted as "hit or slapped"; sexual abuse was "touched in a sexual way that made you uncomfortable"; exposure to family violence was "witnessing physical fighting between parents and/or their partners"; psychological maltreatment was "being criticized, yelled at, or treated unfairly"; and neglect was "not being cared for properly (e.g., lack of food, medicine), ignored, not paid attention to".

Test-retest reliability of adolescent ratings was established on a subsample of 33 subjects (208 of the sample). The retest interval ranged from 10 days to 113 days, with a mean of 31 days. Retest reliabilities on maximum scores (the highest severity rating made across perpetrators) were very good, ranging from .70 for emotional maltreatment to .93 for sexual abuse. Appendix E containg the Ratings of Past Life Events Scale, as well as all the test-retest reliability coefficients obtained on this meagure. 


\section{Covariateg}

Previous research has demonstrated that several variables can influence adolescent adjustment. To determine the impact of maltreatment on adjustment, the influence of these other factors must be controlled. The covariates employed in the present study included age, sex, socioeconomic status, recent life stress, and receptive vocabulary. The following section describes relevant covariates and the operaticnal definition of each.

Age and sex. The influence of age was broadly controlled in the present study by selecting subjecte in a specified age range (11 - 17 ). To control for differences within that range, age was used as a covariate in several analyses. The age of the subject referred to his or her age at the time of the clinical interview.

The cender of the participant was treated as a covariate in several analyees in the present etudy when removal of its influence from adjustment was required. However, because gender differences are interesting in themselves, the sample was sometimes civided on the besis of gender for separate inferential investigation.

Sociofeconomic gtatue. To estimate the socioeconomic status of the adolescent's family of origin, the ROME requested the occupation and higheat level of education of the subject's mother. Unfortunately, most case records had no information on the mother's educational status. Therefore, the 9-point Hollingshead scales were used to code sES categorically (Hollingshead, 1975). The category of "public assistance" wr.: added to help describe this sample. Because the preponderance of subjects (63.88) came from families on public assistance, ses was subsequently dichotomized into working and non-working families. Tabachnick and Fidell (1989) suggest dichotomizing variables in which the distribution is very significantly skewed, as was the case with the prosent a ample. 
stregsful life events. Recent, non-maltreatment otressea in the Iife of the adolescent were quantified using the Life Events Checklist (LEC) (Johnson \& McCutcheon, 1980). The LEC lists 46 events considered to be atressful in the lives of children and adolescents. The measure also provides an opportunity for the respondent to 2 ist additional events. The respondent indicates those events that have occuried to him or her in the past year. Also, the child indicates whether the event was "good" or "bad". The child can also indicate the effect the event had on his or her life, using four anchors ranging from "no effect" to "great effect". The LEC yielde two values: a poeitive life change score and a negative life change score. The positive ecore is derived by aumming the impact $e^{2}+$ ings ( 0 to 3 ) of all the life events rated "good". whereas the negative life score is the sum of impact ratings for all events viewed as "bad". The LEC does not include items indicative of maltreatment, apart from the suggestive item "more argumento with parenta".

Several authors have argued that using impact ratings for etressful life events conceptualiy confounds the atressor with its impact (Johnson McCutcheon, 1980; Dohrenwend \& shrout, 1985; Rowlison \& Felner, 1988). They recommend measuring stress by the number of streseful life events, rather than using weights or impact ratings. This approach was adopted in the present investigation, such that the LEC was used to quantify stressful life events as the number of "bad" events that occurred to the teen in the previous year. Scorea can range from 0 to 46.

Pgychometric validation of the LEC indicates its value as a measure of childhood stress. Test-retest reliabilities of the LEC over a two-week interval have been reported at .69 and .72 for positive and negative life change scores, respectively. With respect to concurrent validity, negative life change scores have been significantly aseociatod with reports of physical problems (Gad f Johnson, 1980), as well ae 
meavures of depreseion, anxiety, emotional maladjustment, and external locus of control (Johnson McCutcheon, 1980). Because few btudies have found behavioral correlates for the positive life change score (Johnson, 1986), it is rarely used in stress research with this measure. The LEC is found in Appendix F.

Receptive vocabulary. Verbal ability was assessed using the The Peabody Picture Vocabulary Test - Revised (PPVT-R) (Dunn E Dunn, 1981). The PPVT-R measures children's receptive vocabulary and thus serves as an approximate measure of the adoledcent's verbal intelligence. It is euitable for an age range of 2.5 years to adulthood. Subjects are presented with four pictures. The examiner aye a word, and the gubject muet eelect from the array the cture that boet showe the meaning of that word. The PPVT-R has a eplit-half rel+ability of .67 with children aged 2.6 to 18 . Alternate-form reliability ranges from .74 to .89 . In 11 studies surnarized by sattler (1988), the correlation of the PPVT-R with the Weechler Intelligence Scale for Children - Revieed (WISC-R) ranged from .16 to .86. The median correlations were .68 for the Full scale IQ, .47 for the Performance Scale, and .72 for the Verbal scale. These correlations are gimilar to those obtained with other measures of intelligence (e.g." stanford-Binet) (Sattler, 1988).

The PPVT-R has a variety of advantages as a measure of receptive vocabulary. Ite picture-presentation format allows one to bypage the reading difficulties and disabilities frequently encountered in clinical populations. It is brief. Because it measures receptive verbal vocabulary, it can be useful in identifying subjects who may not understand the written or oral instructions for other measures. The PPVT-R has been used ag a measure of receptive vocabulary in previous research with maltreated children (e.g., Green cicchetti, 1991 ; V. Wolfe et al., 1989 ). 


\section{The Measure of Blame Attribution}

The second section of results examined whether attributions about maltreatment predicted adjustment when controlling for the percelved Beverity of the experience. Although there are a variety of measurement techniques regarding attribution for guccess and failure, the measurement of attributions of responsibility and blame for real life events are less deveioped (Tennen Affleck, 1990). Currently, there are no measures of attribution designed specifically for victims of maltreatment. Th.8 lacunae prompted the development of a new measure of self- and perpetrator-directed attributions for the purposes of the present study: the Attribution for Maltreatment Interview (AFMI; McGee. 1990). A detailed description of the theoretical rationale for the AFMI items, as well as all empirical procedures underlying its peychometric development, is provided in Appendix A.

The AFMI is comprised of four etructured clinical interviews, one for each major type of maltreatment. Subjects can be interviewed regarding Hostile Maltreatment (physical and emotional abuse), Expcsure to Family Violence, Sexual Abuse, and Neglect. Respondenta complete only the interviews that are relevant to their personal history (e.g., if they have a rating higher than "not at all" on the Rating of past Life Events scale for a specific maltreatment type).

The AFMI is introduced using a standard text (see AFMI Introduction, Appendix A). This introduction provides examples of the coricepts of cause, responsibility, and blame. Subjects are oimultaneously provided with the $8 \times 11 "$ graphic show 1 ng four lev=lo of agreement, ranging from "do not agree" to "strongly agree" (see Appendix A). After the introduction, the subject makes practice agreement ratings with respect to a brief hypothetical story involving him or her self as a young child and a negligent babysitter.

Eacil maltreatment type interview has the same format. First, subjects are asked to gene.-ate a list of porsible causes for the 
maltreatment. they identified on the Ratings of Dast Life Events Scale. From this ilst, they are asked to select the major cause for the I.:ltreatment. All responfes are recorced verbatim by the interviewer. Next, respondents are asked to make agreement ratings to a series of 26 statements read aloud by the interviewer. Agreement is expressed along a four point scale, ranging from 1 ("do not agree") to 4 ("strongly

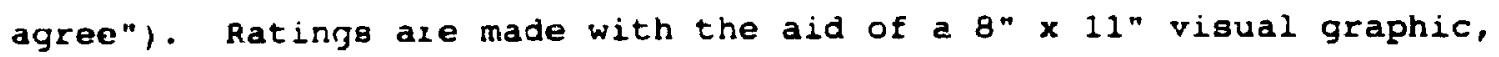
using numbered bars to illustrate strength of agreement (see Appendix A). Stcteme . a are arranged in the following order: items abodt the major $c^{\prime}$ se, items abou the perpetrator and his or her role, and items regarding the subject and $h+s$ or her role. Prior to the questions about the victim'p role, the interviewer probes to determine the subject's perception of his or her own role. This order was selected to allcw the major cuse to be rated on several dimensions, and to allow for geparate, sensitive probing of the victim's perception of hig or her role in the maltreatmen:.

For each of the four maltreatment types, the AFMI yields five eubrcaies: self-blaming cognition, self-blaning affect, self-excusing, perpetrator-biaming, and perpetrator-excusing. Self-blaming cognition relatea to cognitions about pereonal blame and responsibility fe.g., "I am responsible for the effect this has had on my life", "I ghould be blamed for my behavior". "The <major cause> was due to something about me"). Self-blaming affect refers to feelings about one's role in the maltieatment (e.g, "When I think about my role in what happened. I feel sad" or "...I feel angry"). Self-excusing comprises iteins indicating gelf-justification le.g., "I could not help myself - something made me

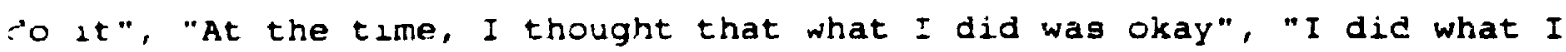
did de:iberately and on purpost"). Perpetratnr-blaming consists or Ltems reflective of the, Ender's responsibilicy le.g., "<perpetrator> ghould be blamed for his jehavior", "Tre <major cause> was sonething helohe cculd have controiled or changed", "<Perpetrator> is responsible 
for the effect this hsa had on my life"). Perpetrator-excusing reflects feeling sorry for the perpetrator and feeling he or she was forced or driven to the maltreating behavior $(\mathrm{e} . \mathrm{g} .$, "When I think about <perpetrator's> role in what happened I feel sad", "nhe perpetrator couldn't help it - something made him or her do it", "The <major cause> was due to something about (perpetrator's> situation or circumstances"). Internal reliability coefficients (Cronbach's alpha) ranged from a Low of . 4C (excusing perpetrator of neglect) to a high of .84 (blaming perpetrator of hostile maltreatment). The mean and medizn coefficienta were . 62 and .70 , respectively, indicating moderate irterna! reliability. Test-retest reliability on AFM subscales was obtained using 33 subjects (208 of the sample). Retest coefficients obtained at a mean int srval of 31 daya were good, ranging from .58 to .98 $(\underline{M}=.83$, median $=.86$ ). Appendix A comprises the AFMI, the theoretical and empirical rationale behind the development of the AFMI, and the psychometrj.c properties of each subscale.

\section{Procedure}

The Children's Aid Society provided the research team with a computer printout of all the names of families in which there was an adolescent between the ages of 11 and 17 . Each family rame was written on a piece of paper, colour coded to indicate the identity of the family's social worker. The names were then put into a large container. Each name was selected at random from this container.

Once $a \mathrm{n}$, was selected, the regearch coordinator contacted the family's caseworker. The caseworker could then elect to approach the family personaliy regarding participation. Alternatively, he or ahe could authorize sending of a "letter of permision to contact" to the family (See Appendix G). In cases where the soclal worker isghed to initiate the contact, the family was not contacted by the research team until the worker had relayed the family's verbal consent to participate. 
In the majority of cases, the workers waived this step, and the letter of permission to contact was sent to the family.

Parents were contacted by the research coordinator by telephone one week after the letter was sent. The research was explained to parents and teens as a study on the relationship between background life events in childhood and current adjustinent in adolescence. If family members were willing to participate, a research assistant visited them at home. During this vigit, the assistant obtained informed consent from both the adolescent and the parent. (see Appendix $r$ ). The adolescent completed the Youth Self Report, the Child Depression Inventory, and the Anger Response Inventory. These measures took approximately one hour to complete. The adolescent's caretaker completed the Child Behavior Checklist. If the adolescent was a ward of the crown, consent was obtained from the caseworker and the adolesce.nt; in these instances, the adolescents' primary caregiver (e.g., fostar parent, group home worker) would complete the CBCL. The adolescent battery took approximately one hour to complete. The CBCL was typically compleced in 20 minutes.

After the family had agreed to participate, one of two trained judges read the target adolescent's case history file to obtain iniormation regarding maltreatment. These case history files included caseworker notes, police reports, assessments compiled by intervening professionals (e.g., physicians, psychologists, public health nurses), foster or residential care progress reports, juvenile and family court summaries, school records, documents pertaining to legal issues (e.g., wardship status), all the agency's correspondence regarding the adolesrent, and any other relevant material. The time required to peruse the material ranged frum one to several hours. Using this wealth of information, the judges completed the ROME. After documenting the more precise ROME subscaie items, the file judges made global ratings of each form of maltreatment the adolescent experienced, using the format 
displayed on the first page of the ROME (see Appendix D). The primary invegtigator and a trained assigtant completed 408 and 608 of the ROMEs, respectively.

Following each file review, the file judge would make an appointment with the adolescent's social worker. First, workers were asked to make global ratings of the adolescent's maltreatment experiences, using the same format as judges (i.e.. page 1 of the ROME). Judges did not share or expose their ratings to the social worker; thus, file judge and worker global ratings were independent assessments.

If a family refured to participate, the agency agreed to provide demographic information and worker maltreatment ratings provided that the subject's identity would be protected. Only one member of the research team (the member who contacted families regarding participation) knew the names of families who opted not to participate. That member arranged for the relevant social worker to complete the first two pages of the ROME. During that seseion, the team member marked each nonparticipant's information with a spe ial subject number and obliterated the family name and all other identifying information. In this fashion, nonparticipants were identified only by subject number, and no other member of the research team was ever privy to their identities. No further information was obtained. The reason for refusal was recorded. In this way, differences between participants and nonparticipants could be determined and limits to the generalizability of the study established.

Approximately one week after the home visit, the adolescent attended a personal interview at the Children's Aid Society. The interviews took place in a separate office located some distance from the Children's Aid building. He or she was interviewed by the primary investigator (488) or a trainted assistant with a background in clinical social work (518). For approximately half of the interviews (458), both interviewerg were present. 
All measures were administered in interview format - that is, the relevant form was placed before the adolescent, the interviewer read the items aloud, and recorded the adolescent's response. This procedure was adopted for several reasons. Firgt, several of the measures were designed to be administered in interview fashion (e.g., PPVT-R). Second, adolescenta' interpretation of items coula be explored and/or corrected. Third, sensitive issues such as maltreatment could be treated with due care and consideration. Fourth, allowing interviewers to read the items aloud bypassed the reading difficulties often encountered with adolescents from a clinical fopulation.

The order of administration for each assessment was standard. First, subjects completed the Peabody Picture Vocabulary Test - Revised, followed by the Life Events Checklist. After a short break and refreshments, the interviewer introduced the Ratings of Past Life Events scale. The interviewer explained that the study was about life events and adjustment, and that the scale contained life event items that many individuals found personal and sensitive. Subjects were reminded that they did not have to answer any quegtion that made them uncomfortable, and that they could akip over anything they did not want to answer. Using the Ratings of Past Life Events Scale and the $8 \times 11^{\prime \prime}$ graphic displaying a line from "not at all" to "severely" (See Appendix E), subjects were asked to indicate on the line "how much" they had experienced each of the maltreatment types over their lifetime, with respect to each of their natural mother, natural father, or "other". Scoring rules were identical to those used with file raters and social workers (e.g., adoptive and foster parents were recorded under "other"). The Attribution for Maltreatment Interview was then introduced, using a standard text (see AFMI Introduction, Appendix A). Selection of the topic for the AFMI proceeded in a gystematic fashion. For each of the Family Violence, Neglect, and sexual Abuse Interview sahedules, the interviewer gelected the eubject's rost gevere global rating from the 
Ratings of Past Life Events Scale. For the Hostile Maltreatment Interview, the interviewer selected the most sevore rating from either physical or emotional maltreatment, wilichever was the most severe. This aggregation policy was adopted to reduce the interview demands on youth who have experienced both forms of maltreatment and seemed justified on the basis of situational similarities between these two maltreatment types. In the event that identical ratings were given for perpetrators, the subject was asked to identify which of the situations "upset you the most". Each subject completed as many of the maltreatment interviows as were appropriate to their history. That is, a subject was given the relevant interview if he or she made a rating on the Ratings of Past Life Events Scale that was greater than "not at all".

At the end of the session, adolescents were paid fifteen dollars in cash for their participation, and transportation to their next destination was arranged. Finaliy, if the parent and child had previously consented, a clinical report (2-3 pages) summarizing the test and interview results was sent to the family's social worker. 
CHAPTER III - RESULTS

Preliminary Analyses

Comparison of Participants to Nonparticipants

Ninety-seven adolescents and/or their parents refused to participate in the study, and 162 agreed. Appendix I details comparisons made between participants and nonparticipants on demographic and family history variables, as well as social worker ratings of maltreatment. Although no differences were found between groups on adolescents' age, sex, or frequency of contact with natural parents, other results indicated that families who refused to participate were actually higher functioning than those who did participate.

\section{Description of the Sample: Criterion Measures}

Means and standard Deviations of Cxiterion Measures

Five criterion measures were employed in the present stuciy: caretaker-rt: :rted (CBCL) internalizing, caretaker-reported (CBCL) externalizing, self-reported (YSR) internalizing, self-repurted (YSR) externalizing, and self-reported anger arousal intensity (the Anger Arousal Intensity scale of the ARI). To describe the sample, means and atandard deviations were computed for each criterion measure. Because the normality of variables is important to the assumptions underlying most statistical analyses (Tabachnick \& Eidell, 1989), skewness is also reported. The significance of the departure from normality is obtained by dividing the skewness by the standard error of skew. A resultant z value in excess of $+/-2.58$ indicates significant skew. Table 1 indicates the distributions of covariatf, (age, stressful life eventg, and receptive vocabulary, and criterion measures. Although several measures have a significant positive skew (indicating that most scores fall at the lower end of the distribution), the sample size was large enough to retain the means as a reasonable estimate of central tendency (Tabachnick \& Fidel1, 1989). 
Table 1.

Means, standard Deviations and Skewness of Covariate and Adjustment Measures

\begin{tabular}{|c|c|c|c|c|}
\hline Measure & Mean & SD & Median & Skewnegs \\
\hline \multicolumn{5}{|l|}{ Covariates } \\
\hline Age & 13.8 & 1.7 & 14.0 & -.164 \\
\hline stressful life events" & 5.8 & 3.2 & 6.0 & .544 \\
\hline Receptive vocabularyb & 89.9 & 12.3 & 89.0 & $.871 *$ \\
\hline \multicolumn{5}{|l|}{ Adjuetment measures } \\
\hline CBCL Internalizinge & 61.2 & 12.4 & 61.5 & -.346 \\
\hline CBCL Externalizing & 63.1 & 10.7 & 64.0 & -.250 \\
\hline YSR Internalizing ${ }^{d}$ & 56.5 & 10.0 & 56.0 & -.200 \\
\hline YSR Externalizing & 58.2 & 9.7 & 58.5 & .147 \\
\hline Anger Arousal Intensity & 47.5 & 9.4 & 46.2 & $.876 *$ \\
\hline
\end{tabular}

* indicates significant departure from normality, $\mathrm{p}<.01$

- Life Eventa Checklist - number of bad life events in past year

- Peabody Picture Vocabulary Test - Revised, Btandard Bcore

child Behavior Checklist

- Youth Self Report

- subscale on the Anger Response Inventory 
For measures derived from normative samples, the sample means were compared with the publiahed norms. Adolescente in Achenbach's (1991a, b) normative samples for the CBCL and the YSR obtained a mean T-sco:e of approximately 50. Using the standard deviations from the normative populations, t-test comparisons indicated that the CAS adolescents scored significantly higher on caretaker-reported (CBCL) internalizing $(\underline{M}=61.2, \underline{t}(2366)=1.1, E<.001)$, externalizing $(\underline{M}=03.1, \underline{t}(2366)=$ 15.0, $\mathrm{p}<.001)$ and behavior problem total scores $(\underline{\mu}=63.0, \underline{t}(2366)=$ 15.2, $\mathrm{P}<.001$ ) than the adolescents in Achenbach's (1991a) normative sample. Recalling that $\mathrm{T}$-gcore distributions have a standard deviation of 10, it can be seen that CAS youth scored approximately one standard deviation above population norms for caretaker-reported behavior problems.

Similarly, the sample differed significantly from the norms on self-reported (YSR) internalizing $(\underline{M}=56.5, \underline{t}(1313)=7.6, \underline{p}<.001)$, externalizing $(\underline{M}=58.2, \underline{t}(1313)=10.0, \underline{p}<.001)$, and behavior problem total scores $(M=57.6, \underline{t}(1313=8.9$, $\underline{D}<.001)$. The CAS adolescents. reports of their behavior problems were approximately one-half a standard doviation above the norm. Comparing the reports of the youth to those of their caretaktrg, the findings suggest that caretakers in this sample regarded adolescents' adjustment difficulties as more extreme than did the teens themselves.

Because Achenbach (1991) indicates that scores falling between 60 and 70 approach the clinically deviant range, the data suggested that CAS youth, as a group, exhibit considerable behavioral difficulties. cloger examination of the distribution of behavior problem scores indicated that approximately one quarter of the sample obtained CBCL Iscores above the clinical cutoff of 70 (278 for externalizing, 31.38 for internalizing). When using the YSR, 13.88 and 9.48 excee ied the cutoff for externalizing and internalizing behavior problems, respectively. 
No differences were found between CAS youth and the relevant normative sample on the Anger Arousal Intensity subscale of the Anger Response Inventory.

Comparisons with the norms for reseptive vocabulary on the PPVT-R suggest that the CAS youth obtained sianificantly lower standard scores $(\underline{\mu}=89.9)$ than the normal population $(\underline{M}=100), \underline{t}(4198)=10.1, q<$ .001 . On average, the CAS youth were three-quarters of a standard deviation below the norm on this measure of receptive vocabulary.

In summary, the CAS sample showed more behavioral disturbance than the nonreferred youth in the standardization samples, further warranting investigation of the correlates of adjustment in this population. Intercorrelations Between Criterion Measures

Table 2 hows the intercorrelations of the criterion variables employed in the present study. Caretaker-reported (CBCL) internalizing and externalizing scores correlated more highly with each other than with their counterparts on the XSR. Although this pattern of results may seem surprising, it is consistent with meta-analytic research indicating that behavior problem scores obtained from different reporting sources tend to correlate at a modest level (approximately .25) even when the same behavior problem is being rated (Achenbach et al., 1987). It further underscores the importance of the reporting source to the measurement of adjustment. Anger Arousal Intensity currelated similarly with gelf-reported (YSR) internalizing and externalizing ( $\underline{E}=.54$ and .49 , respectively). These correlations suggested that although anger arousal intensity shared variance with YSR scores, it is not a specific measure of either internalizing or externalizing symptomatology. 
Table 2.

Intercorrejations of Criterion Adjustment Measures

\begin{tabular}{|c|c|c|c|c|}
\hline $\begin{array}{l}\text { Criterion } \\
\text { measure }\end{array}$ & $\begin{array}{c}\text { CBCL } \\
\text { external }\end{array}$ & $\begin{array}{c}\text { YSR } \\
\text { interna }{ }^{\circ} \\
\end{array}$ & $\begin{array}{c}\text { YSR } \\
\text { externalc } \\
\end{array}$ & Arousal ${ }^{d}$ \\
\hline $\begin{array}{l}\text { CBCL } \\
\text { Internalizing }\end{array}$ & .60 & .36 & .29 & .21 \\
\hline $\begin{array}{l}\text { CBCL } \\
\text { Externalizing }\end{array}$ & & .14 & .41 & .17 \\
\hline $\begin{array}{l}\text { YSR } \\
\text { Internalizing }\end{array}$ & & & .56 & .54 \\
\hline $\begin{array}{l}\text { YSR } \\
\text { Externalizing }\end{array}$ & & & & .49 \\
\hline $\begin{array}{l}\text { N }=160 \\
\text { Child Behavior } \\
\text { Child Behavior } \\
\text { C Youth Self Repo } \\
\text { Youth Self Repo } \\
\text { - Angur Arousal I }\end{array}$ & $\begin{array}{l}\text { Checklist I } \\
\text { Checklist } \\
\text { ort Internal } \\
\text { ort External } \\
\text { Intensity ou }\end{array}$ & $\begin{array}{l}\text { Internalizing } \\
\text { Externalizing } \\
\text { lizing ocale } \\
\text { lizing ocale } \\
\text { abscale of the }\end{array}$ & $\begin{array}{l}\text { Bcale } \\
\text { Bcale } \\
\text { Anger Response }\end{array}$ & Inver \\
\hline
\end{tabular}


The Occurrence and Severity ,f Maltreatment: Agreemen: Between

Reporting sources

The occurrence of Maltreatment

The predictor variables examined in this section include the maltreatment ratings made by social workers, file judges, and the adolescents themselves. The common scale ranged from 0 ("not at all") to 3 ("severely"). Table 3 outlines the means and standard deviations of the maltreatment ratings made by each source. As shown, for all sources the distribution of sexual abuse ratings had a gignificant positive skew, suggesting sexual abuse occurred to a minority of subjects. Official sources' ratings of emotional maltreatment have a mild negative skew, indicating their perception that high levels of emotional abuse were common in this population.

Repeated measures MANUVA, which compared the mean ratinge given by each source, injicated overall mean differences in ratings for physical abuse $(E(2,158)=19.9, \underline{P}<.001)$, emotional abuse $(\underline{E}(2,158)=6.9, \underline{P}$ $<.001)$, and neglect $(\underline{E}(2,158)=11.7, \underline{Q}<.001)$. Planned contrasts comparing adolescent to professional reports indicated that adolescents' ratings of physical abuse $(\underline{M}=1.61)$ were higher than those of officialo $(\underline{M}=1.20), \underline{D}<.001$. Adolescents ratings of emotional abuse $(\underline{M}=$ 1.61) and neglect $(y=1.29)$, however, were lower than those of official sources $(\underline{\mu}=1.95$ and $\underline{\mu}=1.61$, respectively, $\mathrm{gs}<.01)$. There were no mean differences between sources for either family violence or gexual abuse.

To aid in the description of the sample, Table 4 shows the percentage of the sample rated as having experienced each type of maltreatment (i.e., all cases in whlch a rating greater than "not at all" was given). As shown, there was considerable variation in the incidence of maltreatment, depending on the reporting source. According to "official" sources (file judges and social workers), more than onethird of the sample had been sexualiy abused, two-thirde had been 
Table 3.

Meang, Standard Deviations, and Skewness of Maltreatment Ratings

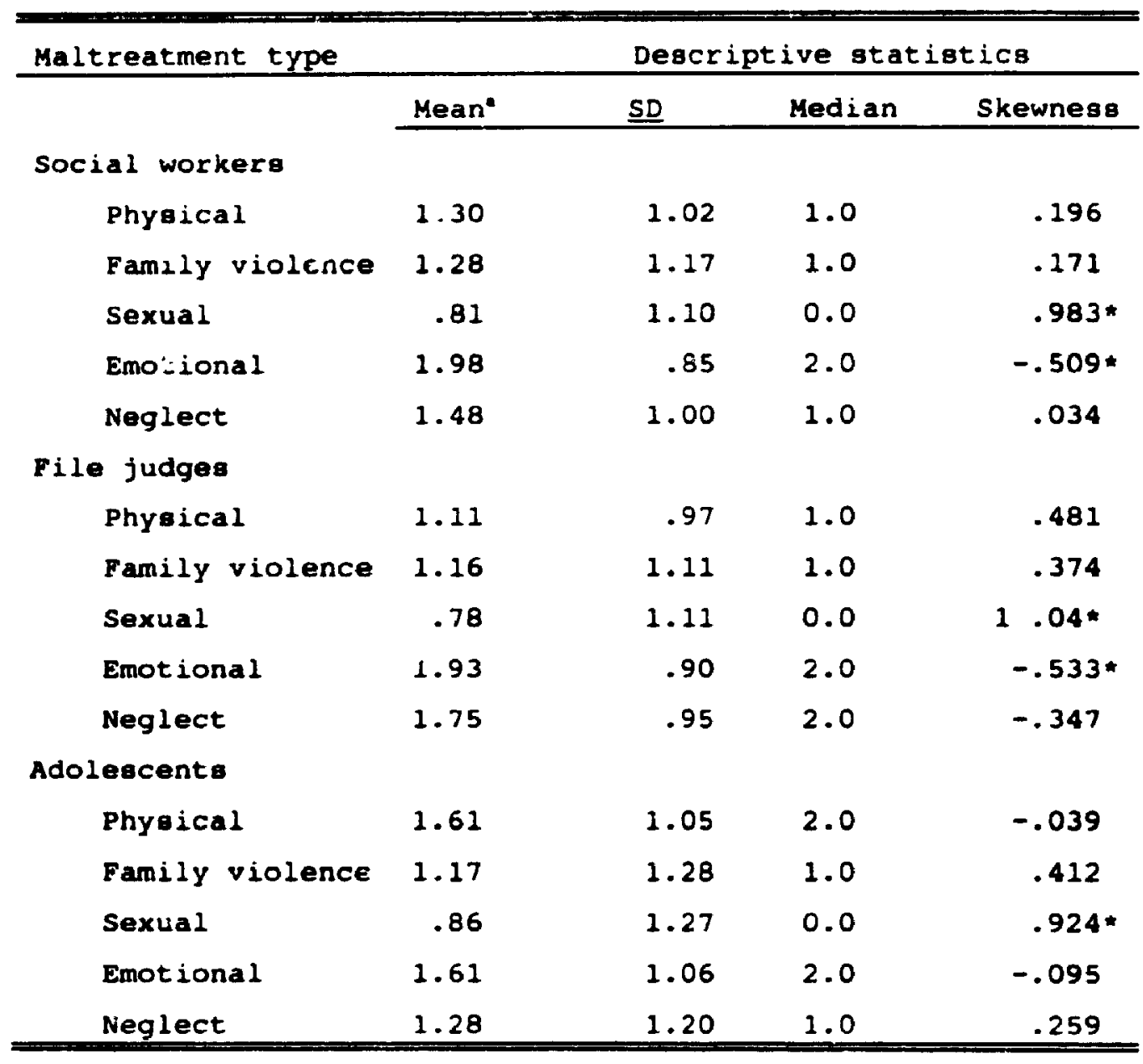

$\underline{N}=160$

"scale ranges from 0 ("not at. all") to 3 ("geverely")

- indicates significant departure from normality, $p<.01$ 
Table 4 . Percentage of the Sample Experiencing Maltreatment, According to Each
Reporting source

\begin{tabular}{|c|c|c|c|c|}
\hline \multirow[t]{2}{*}{ Maltreatmeile type } & & \multicolumn{3}{|c|}{ Percentage maltreated } \\
\hline & $\begin{array}{c}\text { By } \\
\text { mo:her }\end{array}$ & $\begin{array}{c}\text { By } \\
\text { father }\end{array}$ & $\begin{array}{c}\text { By } \\
\text { other }\end{array}$ & Overall \\
\hline \multicolumn{5}{|l|}{ Social Workers } \\
\hline Phyaical & 47.5 & $31 \cdot 2$ & 31.9 & 73.1 \\
\hline Family violence & 58.7 & 40.0 & 37.5 & 61.3 \\
\hline sexual & 0.0 & 8.1 & 2.5 & 37.5 \\
\hline Emotional & 76.9 & 51.9 & 45.0 & 94.4 \\
\hline Neglect & 64.4 & 45.6 & 25.6 & 80.6 \\
\hline \multicolumn{5}{|l|}{ File Judges } \\
\hline Physical & 45.0 & 25.6 & 30.0 & 68.8 \\
\hline Family vioience & 60.6 & 40.6 & 34.4 & 61.3 \\
\hline Sexual & 0.6 & 10.0 & 34.4 & 39.4 \\
\hline Emotional & 76.9 & 52.5 & 45.0 & 91.9 \\
\hline Neglect & 77.5 & 49.5 & 32.5 & 87.5 \\
\hline \multicolumn{5}{|l|}{ Adolescents } \\
\hline Physical & 49.4 & 37.5 & $41 \cdot 3$ & 83.8 \\
\hline Family violence & 46.9 & 32.5 & 30.0 & 53.1 \\
\hline Sexual & 0.6 & 7.5 & 28.7 & 34.4 \\
\hline Emotional & 53.7 & 41.3 & $42 \cdot 5$ & 81.9 \\
\hline Neglect & 35.6 & 36.2 & 27.5 & 62.5 \\
\hline
\end{tabular}

$\underline{N}=160$ 
physically abused or witnesses to family violence, nearly 808 had experienced neglect, and virtually all (approximately $90 \eta$ ) had been emotionally abuged. Morenver, according to oificial sources, 36 of the CAS youth had experienced four of the five types of maltreatment, and 208 had experienced them all. According to so:ial workers and agency records, only 6.38 of the sample had encountered one kind of victimization alone.

The occurrence of maitreatment reported by adolescents differed from official sources. Table 4 shows the percentage of the adolescents who indicated that a type of naltreatment had occurred to them. Table 5 shows the percentage of agreenent between adolescents and of $f$ icial sources regarding the occurrence/nonoccurrence of maltreatment. Table 6 shows the percentage and nature of the disagreement across sources. The results suggested that adolescents' agreement with officials regarding maltreatment occurrence varies with the type of maltreatment. For sexual abuse, the disagreement was fairly low, with adolescent denials (7.58) slightly outnumbering new disclosures (2.58). For physical abuse, 18.88 of the adolescents reported being physically abused, even though the agency had no information of this kind. However, for all other types of maltreatment, adolescents tended to deny known occurrenceg. Over 16.38 denied known family violence, 14.48 denied known emotional abuse, and 29.48 denied neglect - all in instances where social workers and agency records indicated that these forms of maltreatment had in fact occurred. These findings suggest considerable discrepancies in the perceptions of victims and official sources regarding the definition of abuse occurrence.

\section{Severity of Maltreatment}

Adolescents and official sources also disagreed substantially regarding the severity of the adolescents' experiencea. Table 7 shows tive correlations between adolescents and official sources regarding 
Table 5 .

Percentage Agreement among Report sources on the

occirience/nonoccurrence of Maltreatment

\begin{tabular}{|c|c|c|c|}
\hline Maltreatment type & & Reporting & source \\
\hline & & File judge & Adolescent \\
\hline \multicolumn{4}{|l|}{ Physical } \\
\hline & Social worker & 81.9 & 73.1 \\
\hline & File judge & & 72.5 \\
\hline \multicolumn{4}{|l|}{ Fanily violence } \\
\hline & Social worker & 88.7 & 72.5 \\
\hline & File judge & & 77.5 \\
\hline \multicolumn{4}{|l|}{ Serdal } \\
\hline & Social worker & 93.1 & 88.1 \\
\hline & File judge & & 90.0 \\
\hline \multicolumn{4}{|l|}{ Emotional } \\
\hline & Social worker & 92.5 & 81.3 \\
\hline & File judge & & 81.3 \\
\hline \multicolumn{4}{|l|}{ Neglect } \\
\hline & Social worker & 81.9 & 59.4 \\
\hline & File judge & & 65.0 \\
\hline
\end{tabular}

$\underline{N}=160$ 
Table 6.

Percentage Disagreement between Adolegcents and official Sources Regarding the occurrence/nonoccurrence of Maltreatment

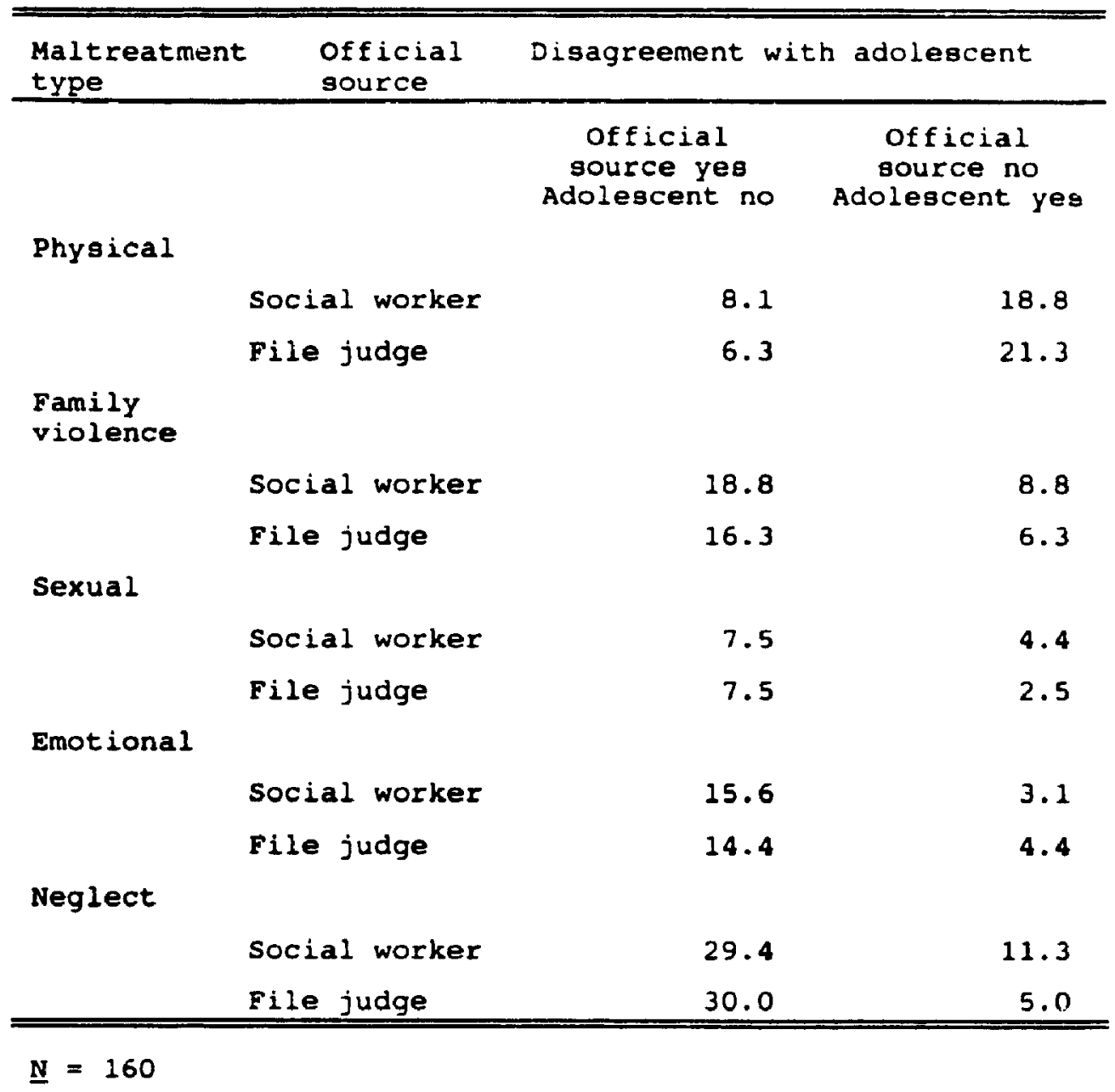


Table 7 .

Correlations Among Reporting Sources' Maltreatment Severi-y RatingB (All Sources Agree that Maltreatment Occurred)

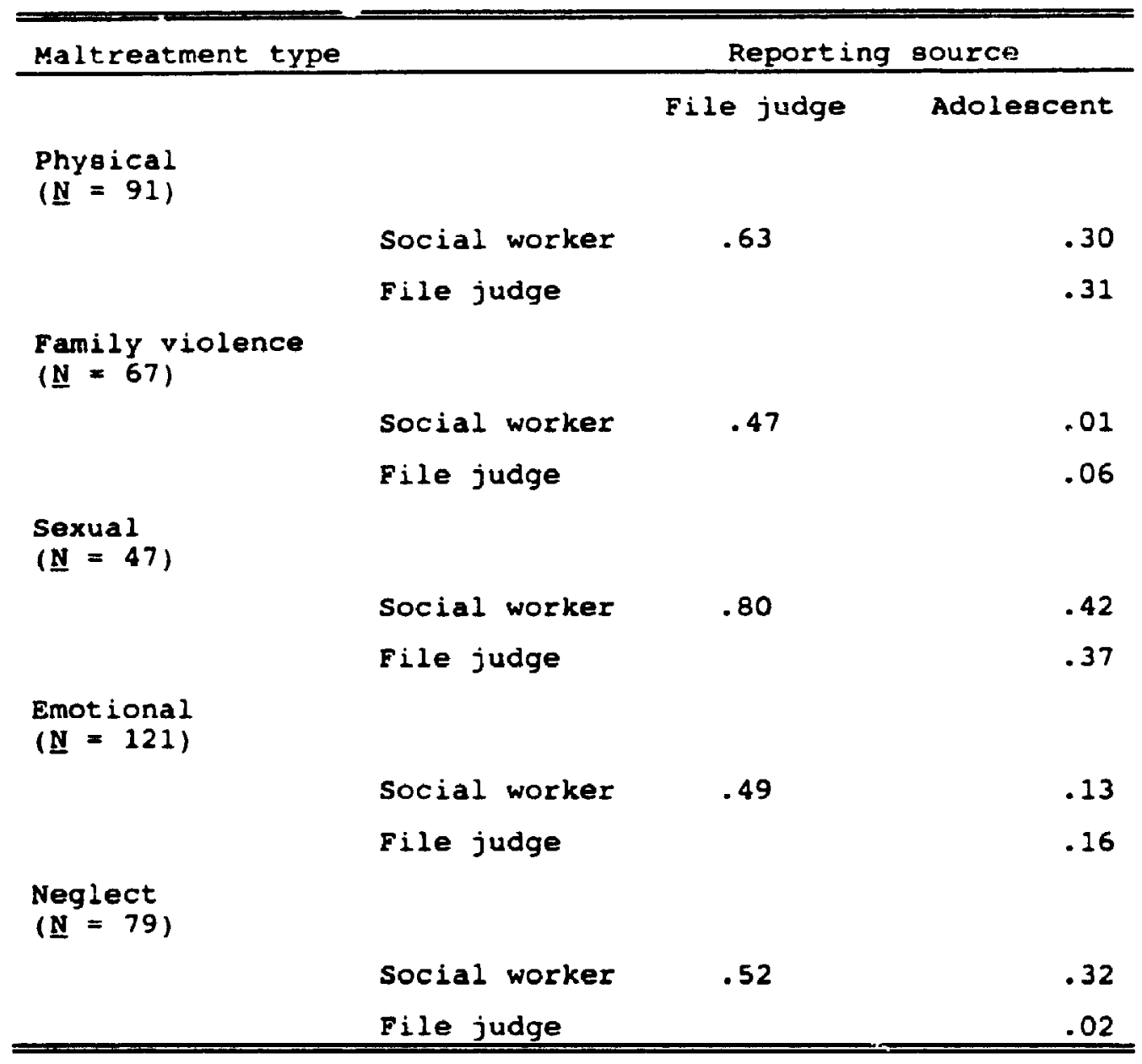


severity ratings - in instances where all sources agreed the

maltreatment had occurred. Particularly poor agreement was obtained on the severity of exposure to family violence $(\underline{E}=.0 j)$. The best agreement was still modest $(\underline{r}=.42)$ for sexual abuse. Intercorrelations Among Maltreatment Iypes

Further evidence of the difference in perception of maltreatment between officials and victims can be found in Table 8 , which shows the intercorrelations of ratings within each source. Official sources appeared to have a different perception of how maltreatment types clustered than did adolescents. Among official sources, many of the highest correlations were among aggressive maltreatment types: family viclence was highly correlated with emotional maltreatment and physical abuse. However, among adolescents, emotional abuse correlated most highly with physical abuse $(\underline{\underline{I}}=.59)$ and neglect $(\underline{I}=.60$ ) and had a weak relationship with family violence $(\underline{I}=.18)$. Relative to officials $(\underline{\underline{r}}=.30)$, the correlation between neglect and physical abude was higher among adolescents $(\underline{\underline{r}}=.41)$. It appears, therefore, that professionalo conceptualize maltreatment along dimensions of aggression and violence, whereas adolescents conceptualize it along dimensions of parenting ${ }^{2}$. Nevertheless, all sources perceived a similar association between physical and emotional abuse $(\underline{I}=.49$ to .59$)$, reflecting the cooccurrenc $=$ of crese maltreatment forms.

In si: ". the prediction that aggressive maltreatment types would covar., ace ved limited support. Professional sourcer appeared to make this aggregation, whereas adolescents did not. There were considerable discrepancieg between professionals and adolescents regarding maltreatment occurrence. Even when sources agreed the maltreatment occurred, their ratings of severity were not highly correlated.

\footnotetext{
${ }^{2}$ Factor analyses confirmed this interpretation of the dimeneions. For ease of presentation, only the correlational matrices are reported here.
} 
Table 8 .

Intercorfelations of Maltreatment Ratings within each Reporting Source

Maltreatment Type

Family
violence Sexual Emotional Neglect

Soclal workers

Physical

Family

Violence

Sexual

Emotional

File judges

$$
\text { Physical }
$$

violence

Sexual

Emotional

Adolescents

Physical

Family

violence

sexual

Emotional
$.38 \star$

$.29 *$

.17

$55 *$

.43 *

.18

.14

$.44 *$

$.30 *$

.27 *

.06

$.49 *$

$.30 \star$

$.42 *$

.27 *

$.28 \star$

.18

$.50 *$

$.27 \star$

.18

$.59 *$

$.41 *$

.06

.18

$.23 *$

.14

.11

$\underline{N}=160$

$\star \mathbf{P}<.005$ 
The Relationghip Between Maltreatment and Adjustment Hypotheses one and Two: The Association Between Covariates,

\section{Maltreatment, and Adjustment}

The first two hypotheses dealt with the differential prediction of internalizing or externalizing problems. It was predicted that aggressive maltreatment forms (i.e., emotional maltreatment, family violence, and physical abusel would be associated with externalizing symptomatology, whereas nonviolent maltreatment forms (i.e., neglect and sexual abuse) would be associated with internalizing symptomatology. This prediction concerred the sample overall. Exarining sex differences within the sample is a special case of the first prediction. Hypothesis Two suggested that aggregsive maltreatment forms will have stronger associations with externalizing problems in males.

Hypothegis One: Aggresgive maltreatment forms (i.e., paychological maltreatment, family violence, and physical abuse) will be associated with externalizing symptomatology, whereas nonviolent maltreatment forms (i.e.. neglect and sexual abuse) will be asgociated with internalizing symptomatology.

Hypothesis Two: The relationship between maltreatment and maladjustment will differ between the sexes, with aggressive types of maltreatment more associated with externalizing problems for males than females.

The "family-wise" approach to the minimization of Type I error is adopted throughout the tests of significance presented here, with the revised alpha level presented in all tables (Lees Neufeld, in press)

\footnotetext{
${ }^{3}$ Separate MANOVAs were conducted to check for sex differences in symptomatology, maltreatment, and the covariates (i.e., age, SEs, stressful life events, PPVT-R scores). No sex differences were found on the adjustment measures or the covariates. According to all reporting sources, females received higher ratings for sexual abuse. This was attributable to the greater incidence of sexual abuse among females. When sexual abuse was removed from the MANOVA, no differences in maltreatment were found.

When testing the significance of correlations, protection for Type I error is recommended (Larzelere * Mulaik, 1977; Lees $c$ Neufeld, in press). Although Larzelere and Mulaik recomment dividing the alpha 
Hypothesis one: Maltreatment and Adjustment in the sample Overall

Tables 9 through 11 present the univariate correlations of the criterion adjustment measures with the maltreatment ratings made by social workers, file judges, and adolescents, respectively. Controlling for Type I error, correlations must obtain a significance level of less than $.01(.05 / 5$ maladjustment measures, treating each criterion measure as a family). To clarify the relationship between maltreatment and maladjustment within each sex, the correlations for males and females are also presented in these tables.

Looking at the sample overall, univariate associations between "aggressive" maltreatment types and externalizing problems were few. Only adolescent report of emotional maltreatment predicted self-reported (YSR) externalizing $(\underline{E}=.20, \mathrm{p}<.01)$, although tinis relationship is smaller than for self-reported (YSR) internalizing ( $\underline{E}=.37, \mathrm{p}<.001$ ). In fact, physical abuse and emotional abuse were most often associated with internalizing problems. Ratings of physical abuse by file raters and adolescents were correlated with self-reported (YSR) internalizing scores $(\underline{I}=.19$ and .22 , respectively, $\mathrm{ps}<.01)$. Adolescent physical abuse ratings were also correlated with caretake:- - $0=3 x t e d$ (CBCL) internalizing scores $(\underline{\underline{s}}=.18, \mathrm{p}<.01)$. Emotional abuse ratings by file iudges were related to caretaker-reported (CBCL) internalizing ( $\underline{\underline{k}}=$ .22, $\mathrm{p}<.01)$. Family violence ratings had no relationship to any adjugtment measure.

The prediction that sexual abuse and neglect would be associated with internalizing problems received some support. Sexual abuse ratings

(...continued)

level by the total number of correlations tested in the entire study, Lees and Neufeld (in press) recommend dividing it by the number of variables in a conceptually-relevant family. The "family-wise" approach 1. lese likely to result in Type II errors and may be more appropriate when uaing multi-method data. 
Table 9.

Correlations between Social Worker Maltreatment Ratings and Adjugtment Measures

\begin{tabular}{|c|c|c|c|c|c|c|}
\hline \multirow[b]{2}{*}{$\begin{array}{l}\text { Subject } \\
\text { pool }\end{array}$} & \multirow[b]{2}{*}{$\begin{array}{l}\text { Maltreatment } \\
\text { Lype }\end{array}$} & \multicolumn{5}{|c|}{ Adjustment Measures } \\
\hline & & $\begin{array}{l}\text { CBCL } \\
\text { int }\end{array}$ & $\begin{array}{l}\text { CBCL } \\
\text { ext }\end{array}$ & $\begin{array}{l}\text { YSR } \\
\text { int }^{e} \\
\end{array}$ & $\begin{array}{l}\text { YSR } \\
\text { ext }\end{array}$ & Arousa $1^{\bullet}$ \\
\hline \multirow[t]{5}{*}{$\begin{array}{l}\text { All } \\
\text { subjects } \\
(\underline{N}=160)\end{array}$} & Physical & .12 & .12 & .12 & -.03 & .03 \\
\hline & Family violence & .10 & .07 & -.05 & -.10 & .02 \\
\hline & Sexual & $.21 *$ & .15 & .11 & .00 & -.01 \\
\hline & Emotional & .11 & .15 & .12 & .01 & .07 \\
\hline & Neglect & .11 & .00 & .11 & -.03 & -.04 \\
\hline \multirow[t]{5}{*}{$\begin{array}{l}\text { Males } \\
(\underline{N}=70)\end{array}$} & Physical & .14 & .14 & .20 & -.03 & -.05 \\
\hline & Family violence & .13 & .05 & .05 & .00 & .00 \\
\hline & Sexual & .19 & .19 & .16 & .01 & .08 \\
\hline & Emotional & $.29 *$ & .24 & .17 & .09 & -.03 \\
\hline & Neglect & .19 & .04 & .05 & -.04 & -.18 \\
\hline \multirow[t]{5}{*}{$\begin{array}{l}\text { Females } \\
(\mathbb{N}=90)\end{array}$} & Physical & .10 & .11 & .05 & -.03 & .10 \\
\hline & Family violence & .08 & .07 & -.12 & -.18 & .04 \\
\hline & Sexual & .22 & $.25 \star$ & .05 & -.02 & -.02 \\
\hline & Emotional & .00 & .07 & .09 & -.03 & .13 \\
\hline & Neglect & .05 & -.04 & .15 & -.03 & .03 \\
\hline
\end{tabular}

$\star \mathbf{p}<.01$

- Child Behavior Checklist Internalizing scale

- Child Behavior Checklist Externalizing scale

c Youth Self Report Internalizing scale

d Youth Self Report Externalizing scale

- Anger Arousal Intensity subscale of the Anger Regponse Inventory Note: Correlations in italics are significantly different at the .002 level from the corresponding correlation in the other gender. 
Table 10.

Correlations between File Judge Maltreatment Ratings and Adjustment Measures

\begin{tabular}{|c|c|c|c|c|c|c|}
\hline \multirow[b]{2}{*}{$\begin{array}{l}\text { Subject } \\
\text { pool }\end{array}$} & \multirow[b]{2}{*}{$\begin{array}{l}\text { Maltreatment } \\
\text { type }\end{array}$} & \multicolumn{5}{|c|}{ Adjustment Measures } \\
\hline & & $\begin{array}{l}\text { CBCL } \\
\text { int }\end{array}$ & $\begin{array}{l}\text { CBCL } \\
\text { ext }\end{array}$ & $\begin{array}{l}\text { YSR } \\
\text { int }^{c}\end{array}$ & $\begin{array}{l}\text { YSR } \\
\text { ext }^{d}\end{array}$ & Arousal \\
\hline \multirow[t]{5}{*}{$\begin{array}{l}\text { All } \\
\text { gubjects } \\
(\underline{N}=160)\end{array}$} & Physical & .14 & .15 & $.19 \star$ & .01 & .08 \\
\hline & $\begin{array}{l}\text { Family } \\
\text { violence }\end{array}$ & .04 & .00 & .05 & -.10 & .00 \\
\hline & Sexual & $.23 *$ & $.18 *$ & .11 & .00 & .00 \\
\hline & Emotional & $.22 *$ & .12 & .12 & -.02 & .02 \\
\hline & Neglect & .06 & -.01 & .05 & -.09 & .00 \\
\hline \multirow[t]{5}{*}{$\begin{array}{l}\text { Males } \\
(N=70)\end{array}$} & Phyeical & .17 & .19 & .26 & -.01 & .07 \\
\hline & $\begin{array}{l}\text { Family } \\
\text { violence }\end{array}$ & .07 & .05 & .07 & .02 & -.03 \\
\hline & Sexual & $.28 \pi$ & $.30 *$ & .20 & .06 & .10 \\
\hline & Emotional & .25 & .16 & .25 & .05 & -.01 \\
\hline & Neglect & .18 & .07 & .13 & -.05 & -.07 \\
\hline \multirow[t]{5}{*}{$\begin{array}{l}\text { Females } \\
(\underline{N}=90)\end{array}$} & Physical & .13 & .11 & .14 & .04 & .09 \\
\hline & $\begin{array}{l}\text { Family } \\
\text { violence }\end{array}$ & .03 & -.06 & .03 & -.19 & .03 \\
\hline & Sexual & .21 & .23 & .04 & -.06 & -.02 \\
\hline & Emotional & .20 & .08 & .05 & -.07 & .03 \\
\hline & Neglect & -.03 & -.01 & .00 & -.11 & .04 \\
\hline
\end{tabular}

* $\mathbf{C}<.01$

- Child Behavior Checklist Internalizing scale

- Child Behavior Chectlist Externalizing scale

- Youth Self Report Internalizing scale

- Youth Self Report Esiternalizing scale

- Anger Arousal Intensity subscale of the Anger Response Inventory 
Table 11.

Correlations between Adol ocent Maltreatment Ratings and Adjustment Measures

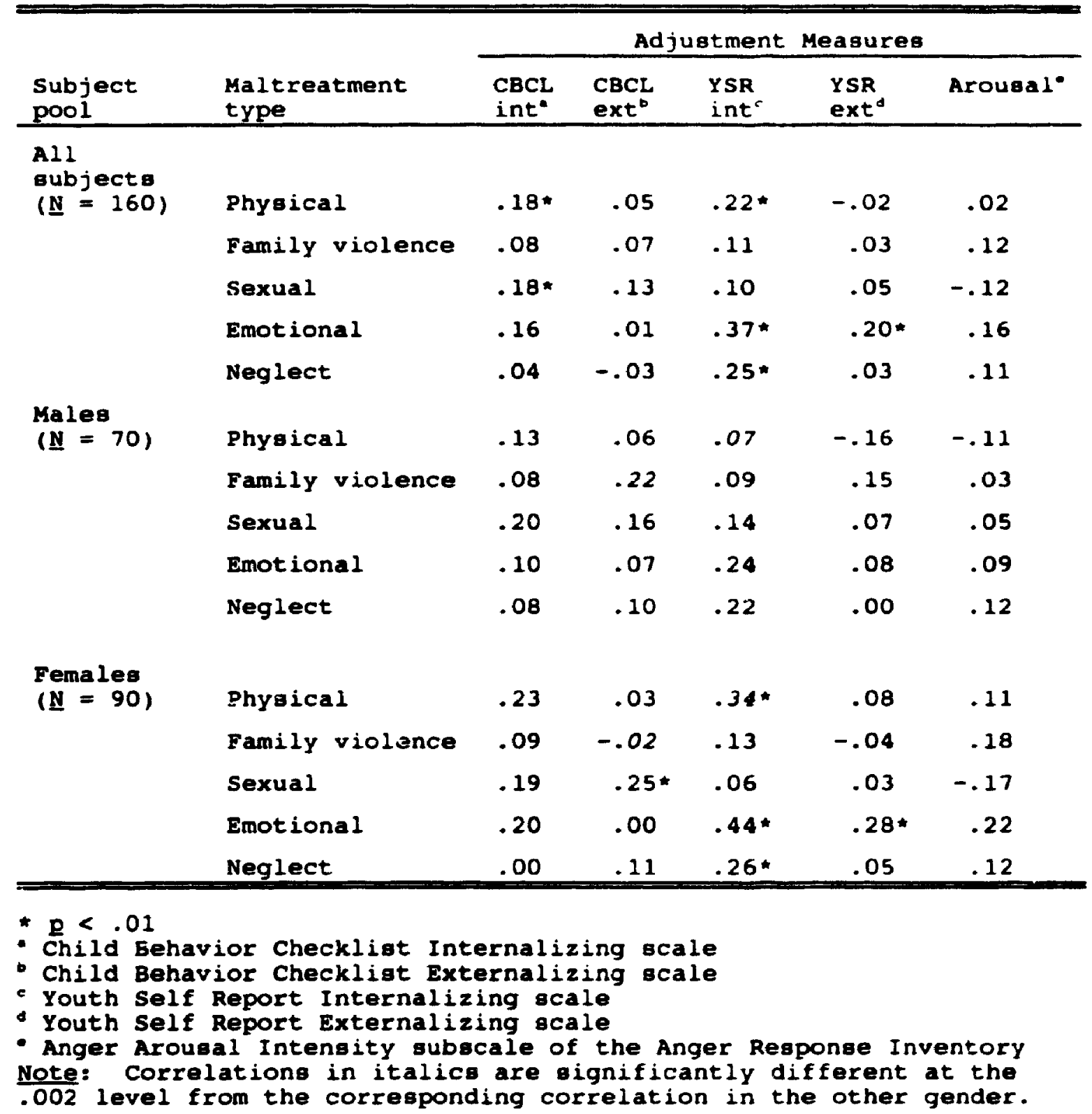


made by accial workers $(\underline{\underline{E}}=.21, \mathrm{~g}<.01)$, file judges $(\underline{\underline{I}}=.23 . \mathrm{p}<.01)$ and adolescents $(\underline{I}=.18, \mathrm{p}<.01)$ were significantly correlated with caretaker-reported (CBCL) internalizing scores. Although these correlations are modest in quantitative terms, they are still remarkable in that they contain no method bias; that is, third-party estimates of maltreatment can predict ca:etaker report of adjustment problems. According to file judges, sexual abuse ratings were also associated with caretaker-reported ( $\mathrm{CBCL}$ ) externalizing problems ( $\underline{E}=.18, \underline{\underline{0}}<.01$ ).

The prediction that neglect would be associated with internalizing problems was supported in one instance. Adolescent ratings of neglect were associated with self-reported (YSR) internalizing ( $\underline{E}=.25$, $\mathrm{Q}<$ .001 ). Notably, neglect was only associated with internalizing problems - neglect ratinge had no relationship with any externalizing measure. Social worker and file judge ratings of neglect had no association with any adjustment measure.

\section{Hypothesis Two: Maltreatment and Adjugtment within the Sexes}

Tables 9 through 11 also present the correlations between maltreatment and maladjustment for males and females separately. Tests of the differences between correlations obtained within each sex are also indicated. Correlatione that differ significantly between the sexes are indicated in italics. Because 25 comparisons are possible, a Bignificance level of .002 was adopted to control for Type I error.

On the basis of theory and previous literature, it was predicted that aggressive behavior problems would be more associated with aggreseive maltreatment types among males than among females. This prediction was supported in only one instance. The relationship between adolescent ratings of family violence and caretaker-reported (CBCL) externalizing was significantly greater among boyg $(\underline{E}=.22)$ than among girls $(E=-.02)$, $\mathrm{D}<.002$. Despite the sex difference, the size of this relationship among boye was not significant. 
All other gignificant sex comparisong concerned the differential prediction of internalizing problems. Sccial worker report of emotional maltreatment was more associated with caretaker-reported (CBCL) internalizing for boys $(\underline{\underline{x}}=.29)$ than girls $(\underline{\underline{x}}=.00), \mathrm{Q}<0.02$. When uring adolescent ratıngs, physical abuse better predicted self-reported (YSR) internalizing among girls $(\underline{\underline{r}}=.34)$ than boys $(\underline{r}=.0 \%), p<.002$.

In summary, the hypothəsis that aggressive types of maltreatment are more predictive of externalizing problems for males received some oupport. Relative to females, the caretaker-reported externaizing behavior problems of male subjects were better predicted by their own report of family violence. No other aignificant sex differences on externalizing problems were obtalned.

The other significant sex differences concerned the relationship between emotional maltreatment and internaiizing problems. The relationship was oignificantly greater among females when self-report measures of maltreatment and adjustment were used. The results suggested that adolescent-reported physical and emotional maltreatment were significantly associated with internalizing problems in the sample overall. Examination of the sex differences in correlations indicated that the overall findings are largeiy due to the gubstantial gize of these relationshipe among females.

\section{Hypothesis Three: The Predictive Utility of Maltreatment to}

\section{Adjustment}

The third hypothegis concerns the predictive utility of maltreatment ratings in the prediction of adjustment problems, when controlling for the influence of demographic and individual-difference information. 
Hypothesis Three: Maltreatment ratings will account for a 3ignificant amount of variance in adjustment, over and above that accounted for by sex, age, socioeconomic status, atressfu: life events, and receptive vocabulary.

For each reporting source, a hierarchical regression was computed first entering the covariates, ano then the maltreatment ratings made by that sourre. There were five criterion variables: CBCL Internalizing, S3:-L Externalizing, YSR Interr-lizing, YSR Externalizing, and the Anger Arousal Intensity subscale $f_{2}=$ the Anger Response Inventory . To protect for Type I error, a .01 alpha level was adopted for tests of multiple R (.05 divided by the number of adjustruent measures). Separate regressions were conducted for each sex. Examination of Agsumptions

For each regression equation, screening for the assumptions of multiple regression was conducted (Pedhazur, 1982; Tabachnick Fidell, 1989) . Intercorrelations between maltreatment ratings are reported in Table 8; intercorrelations between covariates are reported in Table 12. Intercorrelations between maltreatment ratings and covariates are reported in Table 13. In all instances, correlations are less than the .70 level specified as indicating dangerous levels of multicollinearity. Contrary to expoctation, the measures for age, sex, SES, and receptive vocabulary had : relationship to the criterion measures in this sample overall (Table 14). However, even when controlling for Type I error with an alpha level of .01, the number of stressful life events in the past year was significantly associated with all criterion measures except caretaker-reported internalizing. Nevertheless, for

\footnotetext{
'Although differential prediction was the focus of the study, it was also important to demonstrate the relationship between maltreatment and general maladjustment. Therefore, the analyses were also conducted predicting the Behavior Problem Total scores of the CBCL and the $Y S R$. $A$ description of the regults is found in Appendix $\mathrm{J}$.

This included screening for missing data, univariate and multivariate outliers, as well as assumptions of normality, linearity, homoecedasticity, and independence of residuals.
} 
Table 12 .

Intercorrelations among Covariate Measures

\begin{tabular}{|c|c|c|c|c|c|}
\hline $\begin{array}{c}\text { subject } \\
\text { pool }\end{array}$ & & $\begin{array}{c}\text { Stressful } \\
\text { Iife } \\
\text { events" }\end{array}$ & $\begin{array}{l}\text { Receptive } \\
\text { vocabulary }\end{array}$ & $\operatorname{SES}^{c}$ & Age \\
\hline \multicolumn{6}{|l|}{$\begin{array}{l}\text { All } \\
\text { subjects } \\
(\underline{N}=160)\end{array}$} \\
\hline & Sex & .06 & -.06 & -.17 & .05 \\
\hline & $\begin{array}{l}\text { stresoful } \\
\text { life events }\end{array}$ & & $-.22 \star$ & -.03 & -.02 \\
\hline & $\begin{array}{l}\text { Recept ive } \\
\text { vocabulary }\end{array}$ & & & .03 & .00 \\
\hline & SES & & & & .21 \\
\hline \multicolumn{6}{|l|}{$\begin{array}{l}\text { Males } \\
(\underline{N}=70)\end{array}$} \\
\hline & $\begin{array}{l}\text { Stressful } \\
\text { life events }\end{array}$ & & -.16 & .02 & -.05 \\
\hline & $\begin{array}{l}\text { Receptive } \\
\text { vocabulary }\end{array}$ & & & .01 & -.20 \\
\hline & SES & & & & .25 \\
\hline \multicolumn{6}{|l|}{$\begin{array}{l}\text { Females } \\
(\underline{N}=90)\end{array}$} \\
\hline & $\begin{array}{l}\text { Stregsful } \\
\text { life events }\end{array}$ & & -.25 & -.06 & -.01 \\
\hline & $\begin{array}{l}\text { Receptive } \\
\text { vocabulary }\end{array}$ & & & .02 & .14 \\
\hline & SES & & & & .20 \\
\hline
\end{tabular}

* $\mathrm{P}<.005$, two tailed

- Life Events Checklist - number of bad life erents in past year

- Peabody Picture Vocabulary Test - Revised, standard score

c Working versus welfare status (Hollingshead index)

Note: Correlations in italics are significantly different at the .008 level from the corresponding correlation in the olier gender. 
rable 13.

Correlations between Covariates and Maltreatment Ratings, by Reporting source

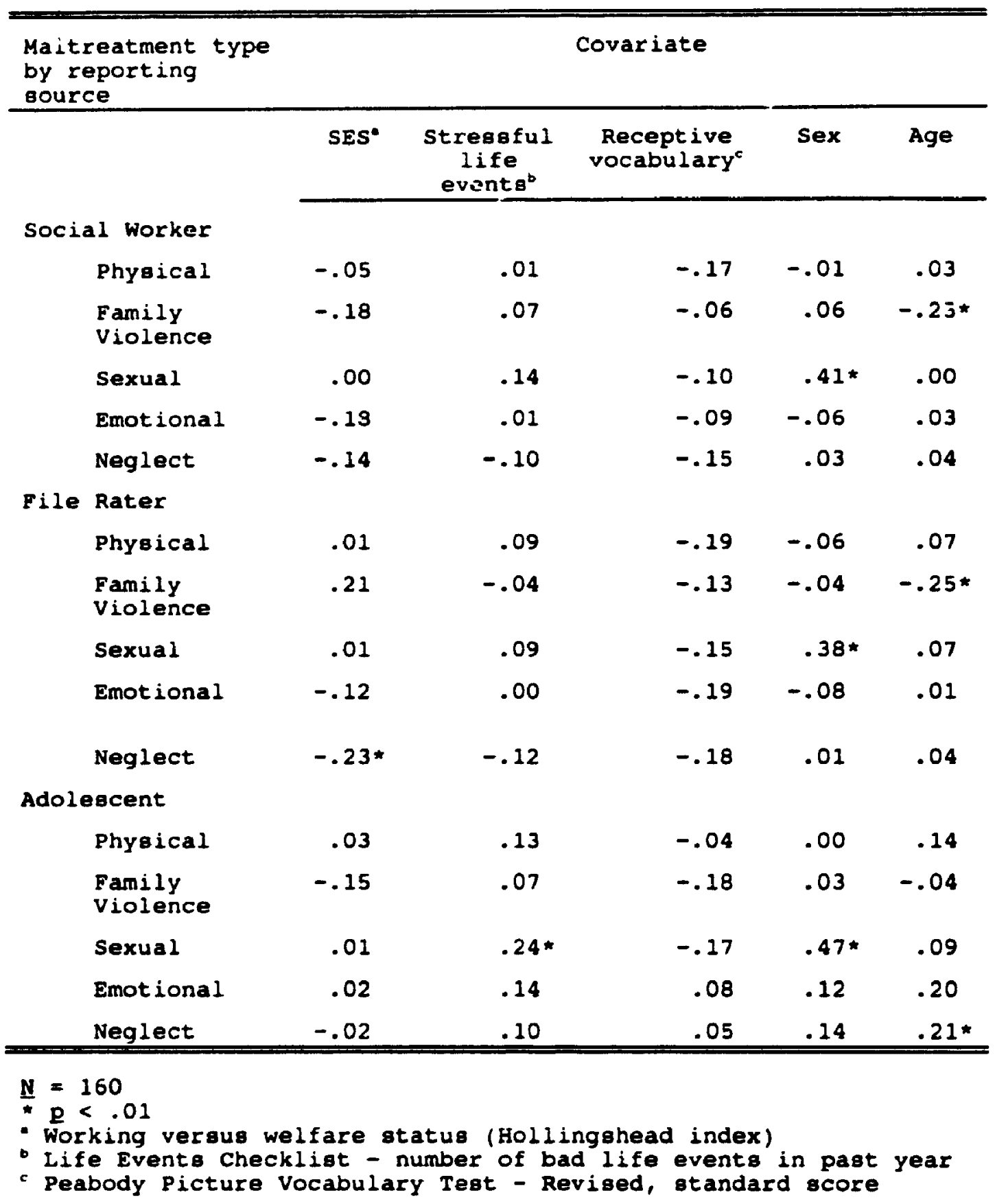


Table 14

Correlations between Covariates and Adjustment Measures

\begin{tabular}{|c|c|c|c|c|c|c|}
\hline \multirow{2}{*}{$\begin{array}{l}\text { Subject } \\
\text { pool }\end{array}$} & \multirow[t]{2}{*}{ Covariate } & \multicolumn{5}{|c|}{ Adjustment measure } \\
\hline & & $\begin{array}{l}\text { CBCL } \\
\text { int }\end{array}$ & $\begin{array}{l}\text { CBCL } \\
\text { ext }\end{array}$ & $\begin{array}{l}\text { YSR } \\
\text { int }^{e}\end{array}$ & $\begin{array}{l}\text { YSR } \\
\text { ext }\end{array}$ & Arousa $1^{\circ}$ \\
\hline \multicolumn{7}{|c|}{$\begin{array}{l}\text { All } \\
\text { subjects } \\
(\underline{N}=160)\end{array}$} \\
\hline & $\operatorname{ses}^{2}$ & -.06 & .02 & -.02 & .01 & .08 \\
\hline & $\begin{array}{l}\text { Stressful } \\
\text { life eventsg }\end{array}$ & .08 & $.23 \star$ & $.28 \star$ & $.45 *$ & $.21 *$ \\
\hline & $\begin{array}{l}\text { Receptive } \\
\text { vocabulary }\end{array}$ & -.05 & -.17 & -.07 & -.12 & -.07 \\
\hline & $\operatorname{sex}$ & .05 & -.11 & .07 & .03 & -.04 \\
\hline & Age & .03 & -.08 & .04 & .03 & .04 \\
\hline \multicolumn{7}{|l|}{$\begin{array}{l}\text { Males } \\
(\underline{N}=70)\end{array}$} \\
\hline & $\mathbf{s}=\mathbf{s}$ & $-.28 \star$ & -.03 & -.02 & .09 & $.28 *$ \\
\hline & $\begin{array}{l}\text { Stressful } \\
\text { life events }\end{array}$ & .13 & .19 & .23 & $.43 *$ & $.38 *$ \\
\hline & $\begin{array}{l}\text { Receptive } \\
\text { vocabulary }\end{array}$ & -.21 & $-.29 *$ & -.08 & -.20 & -.15 \\
\hline & Age & .17 & .09 & .08 & .10 & .23 \\
\hline \multicolumn{7}{|l|}{$\begin{array}{l}\text { Eemales } \\
(\underline{N}=90)\end{array}$} \\
\hline & SES & .14 & .03 & .00 & -.04 & -.07 \\
\hline & $\begin{array}{l}\text { Stressful } \\
\text { life events }\end{array}$ & .03 & $.28 \star$ & .30 & $.46 \%$ & .12 \\
\hline & $\begin{array}{l}\text { Receptive } \\
\text { vocabulary }\end{array}$ & .07 & -.09 & $=.05$ & -.07 & -.02 \\
\hline & Age & -.09 & -.22 & .01 & -.01 & -.09 \\
\hline
\end{tabular}

* $\mathrm{p}<.01$, two tailed

- Child Behavior Checklist Internalizing scale

- Child Behavior Checklist Externalizing scale

- Youth Self Report Internalizing acale

- Youth Self Report Externalizing scale

- Anger Arousal Intensity subscale of the Anger Response Inventory

* Working versug welfare status (Hollingshead index)

- Life Events Checklist - number of bad life events in past year

" Peabody Picture Vocabulary Test - Revised, otandard bcore

Note: Correlations in italics are significantly different at the .0025 level from the corresponding correlation in the other gender. 
theoretical integrity, all covariates were retained for subsequent analyees'

within each sex, certain other covariates were associated with adjustment. Among boys, as receptive vocabulary decreased, caretakerreported (CBCL) externalizing problems increased $(\underline{\underline{\varepsilon}}=-.29, \underline{\mathrm{p}}<.01)$. Similarly, for males, lower SES was associated with greater caretakerreported (CBCL) internalizing problems $(\underline{\underline{E}}=-.28, \mathrm{P}<.01)$ but lower levels of anger arousal problems $(\underline{\underline{L}}=.28, \mathrm{Q}<.01)$. Apart from the relationship between stress and adjustment, no additional significant relationships were detected anong girls. Further, the relationship between age and receptive vocabulary was significantly different among males $(\underline{r}=-.20)$ than females $(\underline{\underline{r}}=.14), \mathrm{Q}<.008$. Overall, these findings suggest that the covariates may be more predictive of adjustment in boys. The relative potency of the covariates among males underscore the importance of computing separate hierarchical regressions for each sex.

Prediction using Maltreatment Ratings from official Sources

Social worker and file judge maltreatment ratings did not predict adjustment when controlling for age, sex, SES, receptive vocabulary, and stressful life events. Neither source was useful in predicting adjustment for each sex separately. The increment in prediction gained by file judge ratings approached significance for caretaker-reported externalizing problems $(6.28), \underline{Q}=.056$, for the sample overall, $\underline{\mathrm{R}}=$ $.39, \mathrm{P}<.01$. They added gignificantly $(7.98)$ to the prediction of caretaker-reported (CBCL) internalizing problems, $\mathbf{D}<.05$, although the multiple $\mathbf{R}$ for this equation did not attain significance at the .01 level. These multivariate findings are consigtent with the univariate correlations presented in Tables 9 and 10, in which few significant

Theoretical considerations must be the primary guide to the inclusion of variables in multiple regression (Lees c Neufeld, in press; Pedhaz'sr, 1982). Keeping a uniform set of covariates across analyses clarifies interpretation and avoids tautological hypothesis testing (Lees Neufeld, in press). 
correlations between maltreatment and adjustment resulted from social worker or file judge ratings.

Prediction using Maltreatment Ratings from Adolescents

When considering the sample as a whole, adolescents' ratings of maltreatment accounted for a significant increase in explained variance across ail self-report measures of adjustment. Multiple $\mathrm{B}$ was significant beyond the .01 level in the prediction of gelf-reported (YSR) internalizing $(\underline{R}=.44, \mathrm{~g}<.001)$, gelf-reported (YSR) externalizing $(\underline{R}=.53, \underline{D}<.001)$, and Anger Arousal Intensity $(R=.38$, $\underline{p}<.01)$. Over and above the covariates, maltreatment ratings predicted 11.18 of self-reported (YSR) internalizing ( $P<.01$ ), 7.7 of selfreported (YSR) externalizing ( $P<.01$ ), and 8.58 os anger arousal problems ( $\mathrm{p}<.05)$. The contribution of adolescent ratings to caretaker-reported internalizing (6.68) approached bignificance ( $\boldsymbol{D}=$ $.061)$. Table 15 presents the change in $\underline{R}^{2}$ occurring at each step in the hierarchical regresaions. The significance of the $\mathrm{R}^{2}$ change reported for maltreatment ratings represents the significance of the change after the covariates had been entered.

Separate reqressions for each sex. Separate hierarchical regressions were computed for each sex. The results are also represented in Table 15. For males, multiple $\underline{R}$ remaired aignificant at

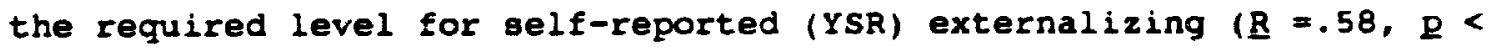
$.01)$ and anger arousal intensity $(\underline{R}=.56, \underline{P}<.01)$. For females, multiple $\underline{R}$ was oignificant for self-reported (YSR) internalizing ( $.53, \mathrm{R}<.001)$ and externalizing $(\underline{R}=.56, \mathrm{D}<.001)$. The $\mathrm{R}^{2}$ change coefficients reported in Table 15 reveal that the maltreatment ratings add to prediction only for females. When restricting the regression to females only, even Larger increments in variance attributable to maltreatment were obtained than for the sample overall: 13 of anger arousal difficulties $(R<.05)$, and $19.38 \mathrm{ig}<.001$ ) and $108(\mathrm{R}<.05)$ of self-reported (YSR) internalizing and externalizing, respectively. 
Table 15.

Hierafchical Rearessions of Adjustment Measures on Adolescent Maltreatment Ratinab, Controlling for Covariates

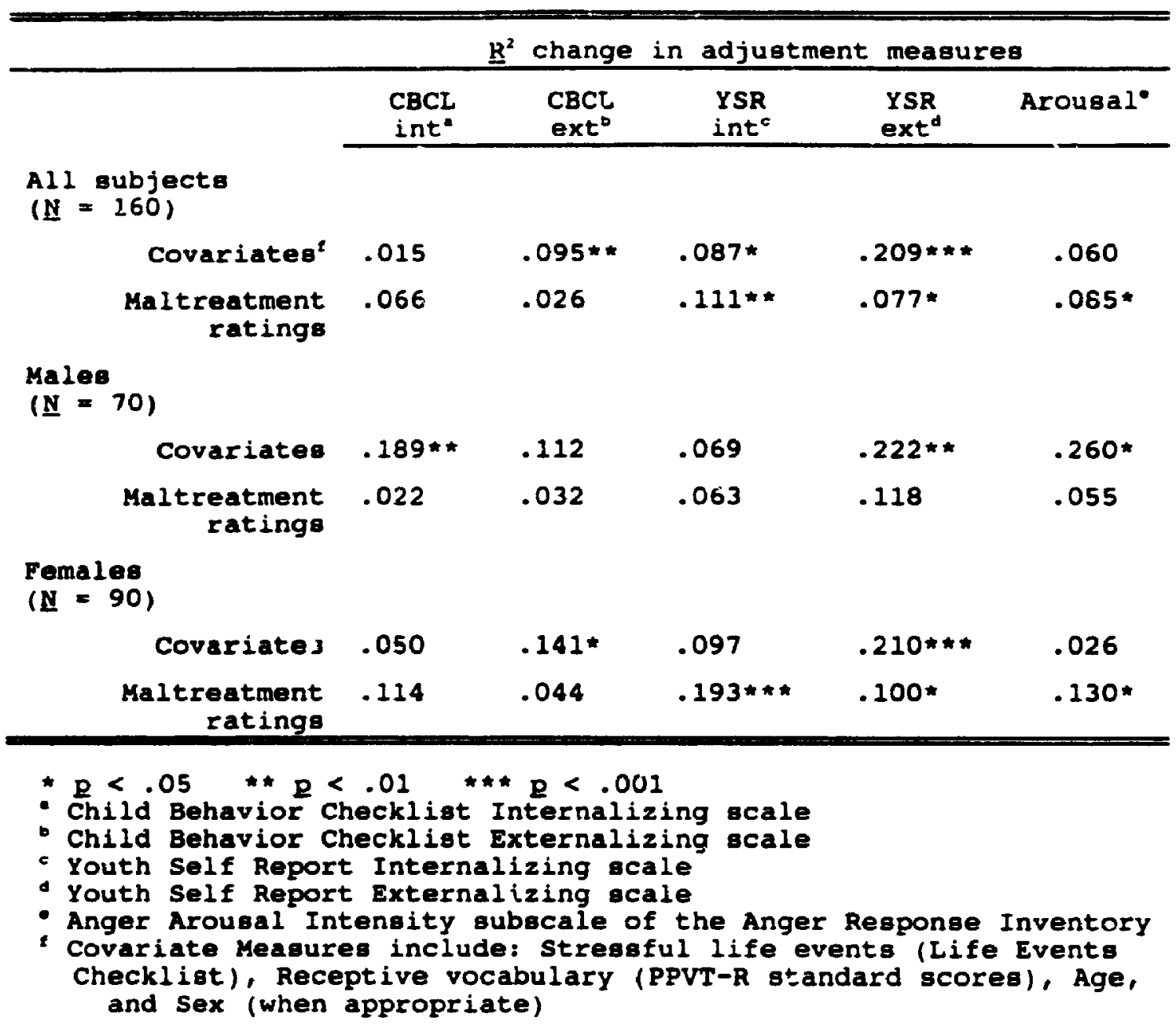


Among males, maltreatment ratings did not add above covarixtes on any adjustment measure. The relatively greater potency of age, receptive vocabulary, stress, and SES on adjustment in males is underscored by the size and significance of the variance accounted for by the covariatss: 188 for caretaker-reported (CBCL) internalizing, 228 for eelf-reported (YSR) externalizing, and 268 of anger arousal problems.

The Additive Value of Specific Maltreatment Types

Controlling for the covariates and for all other abuse types, does any one maltreatment type add uniquely to the prediction of adjustment? The squared semipartial correlation $\left(B r^{2}\right)$ represents the unique contribution of that variable to prediction, when controlling for all other variables in the equation. Because several authors (Winne, 1983; Lees and Neufeld, in press) suggest caution when interproting hierarchical regression, the findings must be understood to refer to residualized variables'.

Table 16 presents the squared semipartial correlation corresponding to each type of adolescent maltreatment rating. Blarka were inserted in Table 16 when the increment in variance was less than 18. The most consistent pattern relates to emotional maltreatment. Even when controlling for all covariates and all other forms of maltreatment, emotional abuse added uniquely to the prediction of all measures of self-reported adjustment for the sample overall. It adds uniquely to self-reported (YSR) externalizing for both males and females.

\footnotetext{
'This caution arises because residualized variables do not exist in nature. However, Winne (1983) emphasizes that multiple regression can still be used to answer simple questions of additivity to prediction. Because $\frac{x^{2}}{2}$ represents the increment in variance accounted for by that variable when it is entered last in a regres;ion equation, it can be interpreted in additive terms. If the predictor variable set remaine consistent across several equations, the conceptual identity of the last-entered variable will also be consistent across equations. Thus, although emotional abuse with other abuse types partialled out of it may no longer be "emotional abuse", the meaning of the now residualized emotional abuse will be consistent in equations using identical predictors. Throughout this dissertation, $x^{2}$ convey the addition to prediction achieved using identical set. of predictor variables.
} 
Table 16 .

The Unique Contribution $\left(8 r^{2}\right)$ of Adolescent Maltreatment Ratings to Adjustment Measures

\begin{tabular}{|c|c|c|c|c|c|c|}
\hline \multirow[b]{2}{*}{$\begin{array}{l}\text { Subject } \\
\text { pool }\end{array}$} & \multirow[b]{2}{*}{$\begin{array}{l}\text { Maltreatment } \\
\text { type }\end{array}$} & \multicolumn{5}{|c|}{ Adjustment Measures } \\
\hline & & $\begin{array}{l}\text { CBCL } \\
\text { int }\end{array}$ & $\begin{array}{l}\text { CBCL } \\
\text { ext }\end{array}$ & $\begin{array}{l}\text { YSR } \\
\text { int }^{c}\end{array}$ & $\begin{array}{l}\text { YSR } \\
\text { ext }\end{array}$ & Arousal \\
\hline \multirow[t]{5}{*}{$\begin{array}{l}\text { All } \\
\text { gubjects } \\
(\underline{N}=160)\end{array}$} & Physical & & & & $.03 *$ & .01 \\
\hline & Family violence & & & & & .01 \\
\hline & sexual & .02 & .02 & & & $.03 * *$ \\
\hline & Emotional & .01 & & $.05 * *$ & $.06 * * *$ & $.03 * *$ \\
\hline & Neglect & & & & .01 & \\
\hline \multirow[t]{5}{*}{$\begin{array}{l}\text { Males } \\
(\underline{N}=70)\end{array}$} & Phyaica! & & & .01 & $.09 * *$ & $.05 *$ \\
\hline & Family violence & & .01 & & $.03 *$ & \\
\hline & Sexual & .01 & & & & \\
\hline & Emotional & & & .02 & $.05 *$ & .01 \\
\hline & Neglect & & & & .01 & \\
\hline \multirow[t]{5}{*}{$\begin{array}{l}\text { Fema les } \\
(\underline{N}=90)\end{array}$} & Physical & & & & .01 & \\
\hline & Family violence & .01 & & & & .02 \\
\hline & Sexual & .02 & .03 & & & $.04 *$ \\
\hline & Emotional & .02 & & $.06 * \star$ & $.09 * * *$ & .02 \\
\hline & Neglect & .01 & & & & \\
\hline
\end{tabular}

$* \mathrm{p}<.05 * \mathrm{Q}<.01 \quad * * \mathrm{p}<.001$

- Child Behavior Checkliat Internalizing scale

- Child Behavior Checkliat Externalizing scale

- Youth Self Report Internalizing scale

- Youth Self Report Externalizing acale

- Anger Arousal Intensity subscale of the Anger Response Inventory Note: Blanks inserted for contributions to variance of less than 18 
Comparing Table 16 with Table 11 indicated that "aggress 1 ve"

maltreatment types may contribute to externalizing problems when they are considered in the context of the covariates and other maltreatment types. Although physical abuse was not significantly correlated with self-reported (YSR) externalizing in the overall sample ( $\underline{r}=-.02)$, it had a larger and significant Beta weight ( $\underline{B}=.24$ ) when in the company of the covariates and other maltreatment types. This situation signals the presence of a suppresscr variable (Tabachnick f Fidell, 1989 ). Systematic deletion of other variables in the equation indicates that emotional abuse acts a suppressor variable in this predictor combination (i.e., when emotional abuse is deleted, the Beta weight for physical abuse is significantly reduced to .09). Thus, physical abuse is not related to self-reported externalizing unless emotional abuse is taken into account. The notion that physical abuse contributes uniquely to the prediction of externalizing behavior problems is in accordance with the first hypothesis regarding the association between aggressive maltreatment and aggressive behavior.

Physical abuse and family violence also added uniquely to the belf-reported (YSR) externalizing problems of boys, when controliing for all other variables. Emotional abuse appeared to act as a suppreseor variable in this predictor combination, allowing physical abuee to predict unique variance when present. The univariate correlation of physical abuse to self-reported (YSR) externalizing in boys was not Bignificant $(\underline{\underline{E}}=-.16)$. However, the Beta weight $(\underline{B}=.44, \underline{Q}<.05)$ in this regression is large and significant, and was reduced considerably when emotional maltreatment was systematically deleted from the equation $(\underline{B}=.27, \underline{E}<.05)$. Physical abuse also acted as a suppressor for emotional abuse among boys: although emotional abuse had a weak univariate correlation with self-reported (YSR) externalizing probleme $(E=.08)$ and hed a small Beta weight when phyoical abuse wav abeent from the equation $(B=.12)$, it had a large and ignificant relationahip 
when physical abuse was present in the equation ( $\underline{B}=.37, p<.05$ ). Similarly, the Beta weight for family violence $(\underline{B}=.27)$ was reduced when emotional abuse was absent from the equation $(\underline{B}=.15)$, although the trend is less striking. Taken together, these results suggest that these "aggressive" maltreatment types predict unique variance in externalizing problems for boys when they are considered in combination. These results provided additional information regarding the second hypothesis that aggressive maltreatment results in greater aggressive behavior in boys.

In summary, the hypothesis that maltreatment adds to the prediction of adjustment above the influence of the covariates received partial support. The robustness of the finding depended on the reporting source: ratings made by adolescents predicted their selfreported adjustment, whereas the ratings made by official sources did not. Moreover, the adjustment of females was predicted more strongly than the adjustment of males. Controlling for covariates and all other maltreatment types, emotional abuse yielded the strongest and most consistent relationships with self-reported adjustment. Physical abuse and emotional abuse each contributed unique variance to self-reported (YSR) externalizing when both were present.

The Relationship Between Attributions for Maltreatment and Adjustment

This section of the results concerns the relationship between maltreatment and attributions for that maltreatment, as well as the importance of each to explaining variance in adjustment. Hypothesis Four examined whether information regarding self- and perpetratordirected attributions improved prediction of adjugtment beyond that afforded by perceived maltreatment severity. Severity of maltreatment was operationally defined as the maximum severity rating made by the adolescent for each type of maltreatment across possible perpetrators. 
Self- and perpetrator-directed attributions were operationally defined by scores on the AFMI. Hypothesis Five examined whether attributions mediated or moderated the relationship between maltreatment severity and adjustment. Because exploration of an adolescent's attribution for a certain type of maltreatment required that the adolescent first acknowledged he or she had experienced it, analyses were restricted to self-ccnfessed victims. Therefore, analyses involved fewer than the full 160 adolescents in the sample. Of the entire sample, 81 were interviewed regarding hostile maltreatment, 608 for neglect, 45 for family violence, and 338 for sexual abuse.

\section{Content Analygeg of Victim's Regpongeg regarding the vaior Cauge of}

\section{Maltreatment}

Victims descriptions of the major cause of the maltreatment were content-analyzed for two reasons: to examine whether victims made spontaneous attributions to "behavioral" or "characterological" blame and to better understand victims' attribution scores. A thorough description of the content analysis is found in Appendix $x$.

In seneral, the majority of the victims spontaneously attributed the major cause of the maltreating events to the perpetrator: 64 for hostile maltreatment, 100 for family violence, 88, for neglect, and 938 for sexual abuse. Therefore, most adolescent victims did not spontaneously regard the maltreatment as "their fault". However, when probed, subjects could make statements about their role in the maltreatment. The perceived contribution varied with the maltreatment type. For hostile maltreatment, the majority (578) identified "misbehavior" as their contribution to the maltreating event. In contrast, for family violence and sexual abuse, most victims identified their role in the maltreatment as their failure to provent the maltreating act (618 and 678, respectively). Neglect victims were lese 
specific, but also described doing nothing (328) or failing to prevent it $(208)$.

These results suggested that victims make both self-and perpetrator-directed attributions, but make perpetrator-directed ones more readily. Spontaneous "behavioral" or "characterological" gelfblame was not evident for family violence, aexual abuse, or neglect. Indeed, only a handful of subjects referred to their characters during the interview - these individuals described what they regarded to be positive aspects of their nature (e.g.. defying the perpetrator). When probed regarding their personal role in the maltreatment, "behavioral" explanatione were offered for phyeical and emotional maltreatment; however, these were rare for other maltreatment types. Rather, those who had experienced family violence, eexual abuse, and neglect dwelt on the avoidability of the events.

\section{Degcription of the Predictor Meagures: Severity and Attribution} Meang and Standard Deviations of Severity and Attribution Measures Ethically, attributional interviews could only be conducted with those adolescents who had identified themselves to be victims. If a youth maintained that he or she had not experienced a certain type of abuse, but social worker or file information indicated that he or she had in fact been maltreated, no efforta were made to challenge the subject's assertion. In the interests of clinical sensitivity, subjects' views regarding their maltreatment history were respected. Therefore, interviews were conducted with all adolescents who identified themselves as victims of that maltreatment type; that is, all subjects who gave a rating for any perpetrator greater than "not at all". A few adolescents identified themselves as victims but did not complete the 
relevant interview'. The results that follow refer only to those gubjects who completed both the relevant rating and the interview. Attributions were solicited for the perpetrator for whom the adolescent made the greatest severity rating ${ }^{\prime \prime}$.

Table 17 presents the means and standard deviations of the severity ratings and actribution subscales for each maltreatment type. Recalling that the severity scale was anchored at 1 ("mild") to 3 ("severe"), the mean severity ratings reported in Table 17 suggest that attributions were made with regard to moderate maltreatment experiences on average. Severity ratings were normally distributed. Sexual abuse was an exception: most victims of sexual abuse regarded the experience as severe, as indicated by the median and significant negative skew of this variable.

With respect to the attribution variables, a significant positive skew was evident on self-blame for family violence, neglect, and sexual abuse, indicating that most subjects had self-blame scores at the lower end of the distribution. For hostile maltreatment (physical and emotional abuge), self-blame was normally distributed and the mean was greater than for the other maltreatment types. The means and distributions of the self-blame subscale scores reflect the spontaneous causal attributions made by the subjects, in which misbehavior was identified as the most common cause of hostile maltreatmert. In

\footnotetext{
'A procedural change early in the study resulted in some subjects missing one appropriate AFMI Interview 113 for Hostile Maltreatment, 8 for Family Violence). For ethical reasons, subjects were allowed to refuge any part of the interview process they found uncomfortable. This opportunity was taken by two sexual abuse victims, three victims of neglect, and one witness to family violence.

${ }^{10}$ There were two exceptions to this general rule. By mistake, one female subject'g Hostile Maltreatment Interview focused on her current stepfather rather than on a worse past etepfather. One bexually abused boy "as interviewed about the "mild" abuse by his natural father, rathor than the single incident with a babysitter he regarded as "moderate". In both cases, the severity score was amended to refer to the perpetrator about whom the subjects were interviewed.
} 
Table 17 .

Meanse Standard Deviation and Skewnegs of Severity Ratings and Attribution For Maltreatment subscales

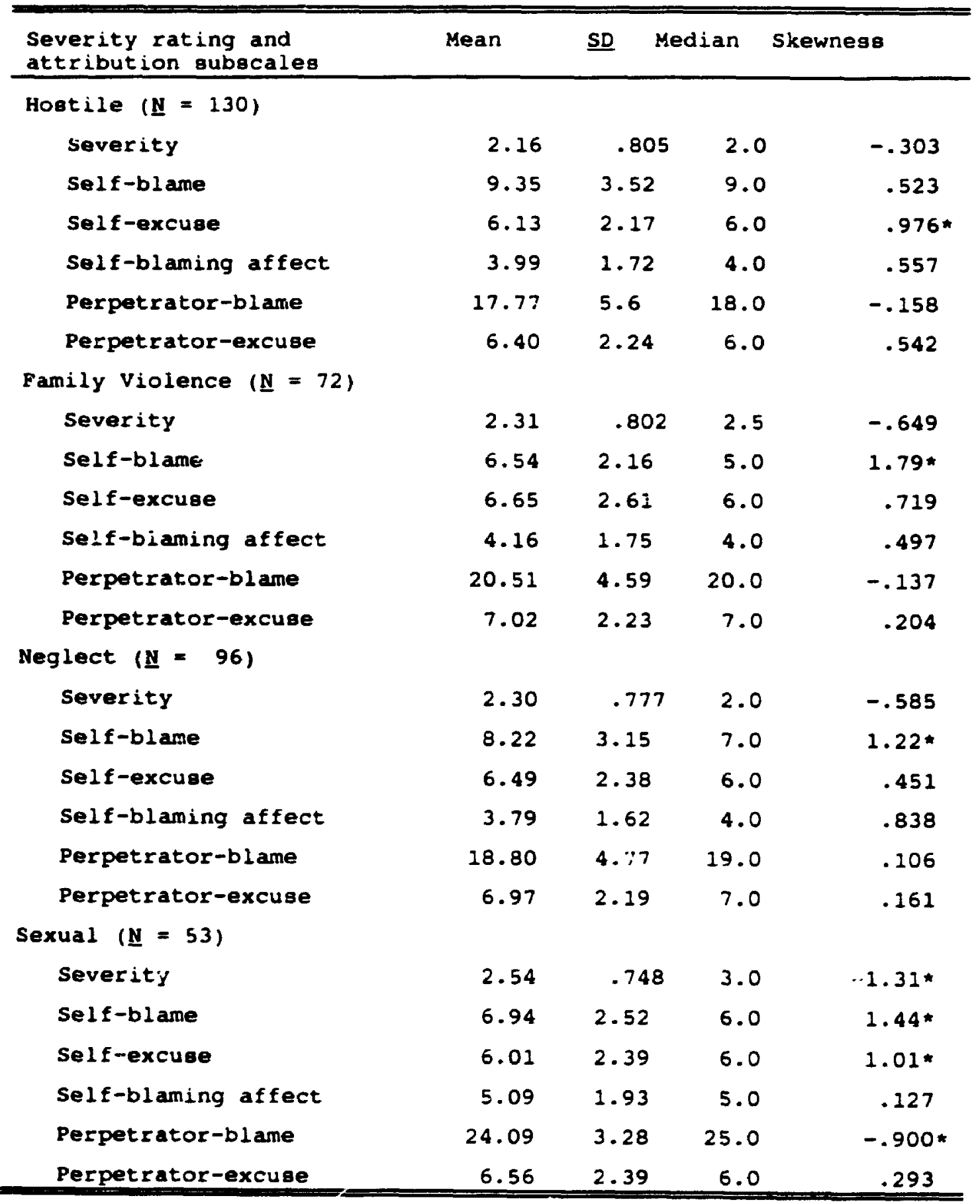

- probability of departure from normality $\mathrm{P}<.01$

Note: Potential maximum: Severity, 3; Self-blame, 16; Self-excuse, 12 ; Self-blaming affect, 8; Perpetrator-blame, 28; Perpetrator-excuse, 12. 
accordance with the causal attributions made by sexual abuse victims, most subjects had high levels of perpetrator-blame.

Sex Differences In Maltreatment Severity and Attributions

Restricting the sample to those adolescents who acknowledged themselves to be victims, tests were conducted to determine $\mathrm{Bex}$ differences in the perceived severity of maltreatment. Separate $\underline{t}-t e s t a$ were conducted on each severity rating. Although the mean differences were always in the direction of higher severity ratings for females, the only significant difference was for beverity of sexual abuse. Sexually abused females reported their sexual abuse experiences to be more severe $(\underline{M}=2.62)$ than did sexually abused males $(\underline{M}=1.71), \underline{t}(53)=-3.17, \underline{p}$ $<.01$. Hr wever, because the number of sexually abused females $(N=48)$ greatly outnumbered the number of eexually abused males $(\underline{N}=7$ ), this mean difference may be unstable.

To determine whether the sexes differed in their attributiona, separate MANOVAs were conducted using the five attribution compositese as criterion variables. Because so few males were sexually abused, no sex comparisons were made for sexual abuse attributions. No main gender effects were found for attributions of hostile maltreatment or neglect. However, significant differences were found for attributione regarding family violence, $\underline{F}(5,66)=3.79, \underline{Q}<.004$. Female witneggeg had higher levels of self-blaming affect regarding the violence $(M=4.6)$ than did male witnesses $(\underline{M}=3.5), \underline{D}<.05$. Also, female witnesses were more likely to blame the batterer $(\underline{M}=21.7)$ than were male witnesses $(\underline{M}=$ $18.8), \mathrm{Q}<.01$

Intercorrelationg Among Severity Ratings and Attributiong

Tables 18 through 21 show the correlations betw'een severity ratings and the attributional subscales for hostile maltreatment, family violence, neglect, and sexual abuse, respectively. Each table reports the correlations for males and Eemaleo combined, as well ae for males and females eeparately. To control for Type I error, an alpha lovel of 
Table 18.

Intercorrelations of Severity Ratings and Attributions for Hostile Maltreatment

\begin{tabular}{|c|c|c|c|c|c|c|}
\hline \multirow[t]{2}{*}{$\begin{array}{l}\text { subject } \\
\text { pool }\end{array}$} & \multirow{2}{*}{$\begin{array}{l}\text { Severity } \\
\text { and } \\
\text { attribution } \\
\text { (Hostile) }\end{array}$} & \multicolumn{5}{|c|}{ Attributions } \\
\hline & & $\begin{array}{l}\text { Self } \\
\text { blame }\end{array}$ & $\begin{array}{l}\text { Selt } \\
\text { excuse }\end{array}$ & $\begin{array}{c}\text { Self } \\
\text { blame } \\
\text { affect }\end{array}$ & $\begin{array}{l}\text { Perp } \\
\text { blame }\end{array}$ & $\begin{array}{l}\text { Perp } \\
\text { excuse }\end{array}$ \\
\hline \multirow[t]{5}{*}{$\begin{array}{l}\text { All } \\
\text { subjects } \\
(\mathbb{N}=130)\end{array}$} & severity & $-.27 \star$ & -.02 & .15 & $.54 *$ & .21 \\
\hline & self blame & & .22 & .15 & $-.42 *$ & -.07 \\
\hline & Self excuse & & & .14 & .07 & .18 \\
\hline & $\begin{array}{l}\text { Self-blame } \\
\text { affect }\end{array}$ & & & & .06 & $.32 \star$ \\
\hline & $\begin{array}{l}\text { Perpetrator } \\
\text { blame }\end{array}$ & & & & & $.24 \star$ \\
\hline \multirow[t]{5}{*}{$\begin{array}{l}\text { Males } \\
(\underline{N}=54)\end{array}$} & Severity & -.29 & -.11 & -.17 & $.52 \star$ & .29 \\
\hline & Self blame & & $.38 *$ & .33 & $-.36 *$ & -.22 \\
\hline & self excuse & & & .05 & .02 & .14 \\
\hline & $\begin{array}{l}\text { Seli-blame } \\
\text { affect }\end{array}$ & & & & -.11 & .25 \\
\hline & $\begin{array}{l}\text { Perpetrator } \\
\text { blame }\end{array}$ & & & & & $.37 \star$ \\
\hline \multirow[t]{5}{*}{$\begin{array}{l}\text { Females } \\
(\underline{N}=76)\end{array}$} & severity & -.25 & .03 & $.39 *$ & $.56 \star$ & .16 \\
\hline & self blame & & .14 & .03 & $-.46 \star$ & .02 \\
\hline & self excuse & & & .18 & .09 & .21 \\
\hline & $\begin{array}{l}\text { Self-blame } \\
\text { affect }\end{array}$ & & & & .18 & $.38 \star$ \\
\hline & $\begin{array}{l}\text { Perpetritor } \\
\text { blame }\end{array}$ & & & & & .16 \\
\hline
\end{tabular}

$* \mathrm{P}<.003$

Note: Correlations in italics are significantly different at the .003 level from the corresponding correlation in the other gender. 
Table 19.

Intercorrelations of Severity Ratings and Attributions for Family violence

\begin{tabular}{|c|c|c|c|c|c|c|}
\hline \multirow[t]{2}{*}{$\begin{array}{l}\text { Subject } \\
\text { pool }\end{array}$} & \multirow{2}{*}{$\begin{array}{l}\text { Severity and } \\
\text { attributions } \\
\text { (Family } \\
\text { violence) }\end{array}$} & \multicolumn{5}{|c|}{ Attributions } \\
\hline & & $\begin{array}{l}\text { Self } \\
\text { blame }\end{array}$ & $\begin{array}{l}\text { Self } \\
\text { excuge }\end{array}$ & $\begin{array}{c}\text { Self } \\
\text { blame } \\
\text { affect }\end{array}$ & $\begin{array}{l}\text { Perp } \\
\text { blame }\end{array}$ & $\begin{array}{c}\text { Pexp } \\
\text { excuea }\end{array}$ \\
\hline \multirow[t]{5}{*}{$\begin{array}{l}\text { Al1 } \\
\text { subjects } \\
(\underline{N}=72)\end{array}$} & severity & .17 & .10 & .23 & $.43 \star$ & .05 \\
\hline & Self blame & & .00 & $.32 \star$ & .22 & .01 \\
\hline & Self excuse & & & .02 & .17 & .18 \\
\hline & $\begin{array}{l}\text { Self-blame } \\
\text { affect }\end{array}$ & & & & $.45 *$ & .23 \\
\hline & $\begin{array}{l}\text { Perpetrator } \\
\text { blame }\end{array}$ & & & & & .00 \\
\hline \multirow[t]{5}{*}{$\begin{array}{l}\text { Maleg } \\
(\underline{N}=31)\end{array}$} & severity & .20 & .25 & .27 & .50 & .06 \\
\hline & Self blame & & .27 & .36 & .34 & .32 \\
\hline & self excuse & & & .00 & .30 & .27 \\
\hline & $\begin{array}{l}\text { Self-blame } \\
\text { affect }\end{array}$ & & & & .36 & .44 \\
\hline & $\begin{array}{l}\text { Perpetrator } \\
\text { blame }\end{array}$ & & & & & .08 \\
\hline \multirow[t]{5}{*}{$\begin{array}{l}\text { Females } \\
(\underline{N}=41)\end{array}$} & Severity & .16 & .02 & .14 & .30 & .01 \\
\hline & self blame & & -.22 & .33 & .16 & -.20 \\
\hline & Self excuse & & & .15 & .21 & .15 \\
\hline & $\begin{array}{l}\text { Self-blame } \\
\text { affect }\end{array}$ & & & & .42 & .07 \\
\hline & $\begin{array}{l}\text { Perpetrator } \\
\text { blame }\end{array}$ & & & & & -.14 \\
\hline
\end{tabular}

tp<.003

Note: Correlations in italics are significantly different at the .003 level from the corresponding correlation in the other gender. 
Table 20.

Intercorrelations of Severity Ratings and Attributions for Neglect

$\begin{array}{ll}\text { Subject } & \text { Severity and } \\ \text { pool } & \begin{array}{l}\text { attributions } \\ \text { (Neglect) }\end{array}\end{array}$

Attributions

\begin{tabular}{ccccc}
$\begin{array}{c}\text { Self } \\
\text { blame }\end{array}$ & $\begin{array}{c}\text { Self } \\
\text { excuse }\end{array}$ & $\begin{array}{c}\text { Self } \\
\text { blame } \\
\text { affect }\end{array}$ & $\begin{array}{c}\text { Perp } \\
\text { blame }\end{array}$ & $\begin{array}{c}\text { Perp } \\
\text { excuse }\end{array}$ \\
\hline
\end{tabular}

All subjects $(\underline{N}=96)$

severity

$-.07$

.13

$.09 .40 * \quad .17$

Self blame

.39 *

$.36 *-.07$

$.29 *$

Self excuse

.03

$.21-.01$

Self-blame

.17

$.38 *$

affect

Perpetrator

blame

\begin{tabular}{|c|c|c|c|c|c|c|}
\hline \multirow[t]{5}{*}{$\begin{array}{l}\text { Maleg } \\
(\underline{N}=38)\end{array}$} & severity & -.08 & .24 & -.07 & .25 & -.14 \\
\hline & Self blame & & $.58 *$ & .42 & .15 & .33 \\
\hline & Self excuse & & & .11 & .36 & .06 \\
\hline & $\begin{array}{l}\text { self-blame } \\
\text { affect }\end{array}$ & & & & .22 & .35 \\
\hline & $\begin{array}{l}\text { Perpetrator } \\
\text { blame }\end{array}$ & & & & & .00 \\
\hline \multirow[t]{5}{*}{$\begin{array}{l}\text { Femaleg } \\
(N=58)\end{array}$} & severity & -.09 & .06 & .20 & $.55 *$ & $.36 *$ \\
\hline & self blame & & .27 & .32 & -.21 & .27 \\
\hline & Self excuse & & & -.11 & .13 & -.05 \\
\hline & $\begin{array}{l}\text { Self-blame } \\
\text { affect }\end{array}$ & & & & .14 & $.39 *$ \\
\hline & $\begin{array}{l}\text { Perpetrator } \\
\text { blame }\end{array}$ & & & & & .21 \\
\hline
\end{tabular}

$\star \mathbf{p}<.003$

Note: Correlations in italics are significantly different at the .003 level from the corresponding correlation in the other gender. 
Table 21.

Intercorrelations of severity Ratings and Attributions for Sexuat Abuse

\begin{tabular}{|c|c|c|c|c|c|c|}
\hline \multirow[t]{2}{*}{$\begin{array}{l}\text { Subject } \\
\text { pool }\end{array}$} & \multirow[t]{2}{*}{$\begin{array}{l}\text { Seve-ity and } \\
\text { attribution } \\
\text { (Sexual abuse) }\end{array}$} & \multicolumn{5}{|c|}{ Attributions } \\
\hline & & $\begin{array}{l}\text { Self } \\
\text { blame }\end{array}$ & $\begin{array}{c}\text { Self } \\
\text { excuse }\end{array}$ & $\begin{array}{l}\text { self } \\
\text { blame } \\
\text { affect }\end{array}$ & $\begin{array}{l}\text { Perp } \\
\text { blame }\end{array}$ & $\begin{array}{l}\text { Perp } \\
\text { excuse }\end{array}$ \\
\hline
\end{tabular}

Al1 oubjects $(\underline{N}=53)$

Severity

.03

.2

.12

$.33-.15$

self blame

$.43 \star$

.37 *

.15

.20

self excuse

.33

.11

self-blame

affect

.33

Perpetrator

$-.01$

blame

Femaleg

$(\underline{N}=47)$

Severity

.02

.23

.07

.04

self blame

$.43 *$

.34

.22

.12

.18

self excuse

.30

.25

.08

self-blame

.30

$.39 *$

affect

$-.06$

Perpetrator

blame

$\star \mathrm{e}<.003$ 
.003 is adopted (.05/the number of possible combinations). These correlations were examined for three reasons: first, to replicate the inverse relationship between maltreatment severity and blame found in other studies; second, to examine whether self- and perpetrator-blame were related in a "hydraulic" fashion; and third, to examine the extent of shared variance among conceptually related attribution composites (e.g., self-blaming cognition and self-blaming affect) ${ }^{11}$

The results indicated that hostile maltreatment was unique among maltreatment types in the relationship between severity and attributions, reflecting that it most often occurred in the context of discipline. Severity and self-blame-related attributions were negatively associated for hostile maltreatment, but not for other maltreatment types. As the severity of hostile maltreatment increased, gelf-blaming cognition decreased $(\underline{\underline{y}}=-.27, \underline{\mathrm{p}}<.003)$. Severity of hostile maltreatment was positively related to self-blaming affect in females $(\underline{\underline{I}}=.39)$ but not in males $(\underline{\underline{x}}=-.17), \underline{\mathrm{p}}<.001$. For all other maltreatment types, severity was not associated with either self-blaming cognition or self-blaming affect. Moreover, Belf-blame was inversely related to perpetrator-blame only for hostile maltreatment $(\underline{x}=-.42)$.

Generally, across maltreatment types, perpetrator-blame increased as maltreatment severity increased $(\underline{E}=.54, .43, .40$ for hostile maltreatment, family violence, and neglect, respectively, all $\mathrm{Q}^{\prime} \mathrm{s}<$ $.003)$. No relationship was found for sexual abuse, perhaps due to the significant skew of both these variables for that maltreatment type. Severity was not correlated with either self-excusing or perpetratorexcusing for any maltreatment type.

Self-blaming cognition was positively associated with self-blaming affect across maltreatment types $(\underline{I}=.32, .36, .37$ for family violence, neglect, and sexual abuse, respectively, all $\mathrm{D}^{\prime} \mathrm{s}<.003$ ). For hostile

\footnotetext{
"These intercorrelations also demonstrate that the multicolinearity among these variables is within acceptable 1 imits.
} 
maltreatment, self-blaming cognition was related to self-blaming affect $(\underline{\underline{r}}=.33)$ in males but not in females $(\underline{\underline{r}}=.03, \underline{\underline{p}} .003)$.

Generally, self-blame and self-excusing were not inversely related. Typically, the oignificant correlations between gelf-blame and self-excusing were positive. Self-blaming affect had no association with self-excusing. Perpetrator-blame was never inversely associated with perpetrator-excusing. Rather, it had either no association with perpetrator-excusing or a positive correlation in the case of hostile maltreatment.

Hypothesis Four: The Incremental Value of Attributions for Maltreatment

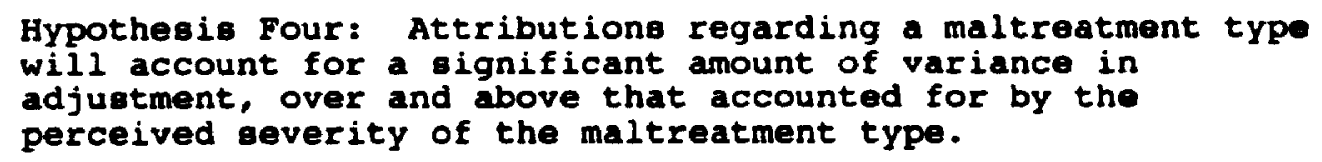

The planned hierafchical regressions examined whether information about attributions added to the prediction of adjustment beyond that afforded by perceived maltreatment severity. This regression model does not include the covariates epecified earlier, for eeveral reasone ${ }^{12}$ First, this model is simpler - it contains only cognitive variables in accordance with attributional modela. Second, becaube previous analyees generally demonstrated that gelf-reported maltreatment severity is associated with adjustment, even coltrolling for the covariates, a second demonstration would be redundant. Third, the case to variable ratio is jeopardised if five covariates are added to the $\mathrm{g} i x$ implied in the attributional model. Attributional analyses can only be applied to those subjects acknowledging the abuse and making attributions, and this

\footnotetext{
${ }^{12}$ When the covariates were entered on the first step in the hierarchical regression equations, the regults were not oubstantially different than when they were not. For hostile maltreatment and sexual abuse, the gize and significance of $\underline{R}^{2}$ change did not alter. For neglect, this procedure rendered nonsignificant the $\mathrm{B}^{2}$ change for YSR externalizing overall, CBCL inte"nalizing in boys, and YSR internalizing in girle. For family violence, it rendered nonsignificant the increment due to severity for CBCL internalizing.
} 
number decreases even further when dividing the victims by sex. (For example, only 31 males acknowledged witnessing family violence.)

Therefore, for each maltreatment type, the hierarchical regressions were conducted as follows: first, adolescents' reported severity of a specific maltreatment type was entered on the first step, and the five attribution variables for that maltreatment type were entered as a set on the second step. Self-reported (YSR) and caretaker-reported (CBCL) internalizing and externalizing scores, as well as Anger Arousal Intensity scores, were each used as the criterion's. To control for Type I error, interpretation was restricted to the equations for the overall sample having a multiple $\underline{\mathrm{R}}$ significant at the .01 level. If $\underline{\mathrm{R}}$ was significant for the equation, the increments attributable to each block of variables were examined. Separate analyses were conducted for each sex.

Hierarcnical regression results for hostile maltreatment, family viol:nce, neglect, and sexual abuse are found on Tables 22 through 25, respectively. Regressions were computed for the sample overall and separately for each sex. In the tables, the reported significance relates to the significance of the change in $\underline{R}^{2}$.

Hostile Maltreatment attributions. Results for hostile maltreatment are reported in Table 22 . Multiple $\underline{R}$ was significant beyond the .01 level for the prediction of oelf-reported (YSR) internalizing $(\underline{R}=.49, \underline{Q}<.001)$. Over and above severity ratings, attribution added 168 to the prediction of self-reported (YSR) internalizing. Although the multiple $\underline{R}$ between predictors and selfreported (YSR) externalizing scores only approached significance at the .01 level, $(\underline{R}=.32, \underline{Q}=.028)$, the increment in variance explained by attribution (9.48) was significant.

\footnotetext{
${ }^{13}$ To demonstrate the association between attribution and general maladjuetment, the same analyses were conducted to predict the Behavior Problem Total scores on the CBCL and the YSR. A description of the resulte is presented in Appendix $J$.
} 
Table 22.

Hierarchical Regressions of Hostile Maltreatment Attributions on Adjustment, Controlling for Severity

\begin{tabular}{|c|c|c|c|c|c|}
\hline \multirow[t]{2}{*}{ Subject pool } & \multicolumn{2}{|c|}{$\underline{R}^{2}$ change } & \multicolumn{2}{|c|}{ in adjustment mea } & \multirow{2}{*}{$\frac{\text { res }}{\text { Arousal" }}$} \\
\hline & $\begin{array}{l}\text { CBCL } \\
\text { int. }\end{array}$ & $\begin{array}{l}\text { CBCL } \\
\text { ext } \\
\end{array}$ & $\begin{array}{l}\text { YSR } \\
\text { int }^{c} \\
\end{array}$ & $\begin{array}{r}\text { YSR } \\
\text { ext } \\
\end{array}$ & \\
\hline \multicolumn{6}{|l|}{$\begin{array}{l}\text { All subjects } \\
(\underline{N}=130)\end{array}$} \\
\hline Severity & .019 & .004 & $.084 * *$ & .012 & .003 \\
\hline Attributions & .015 & .021 & $.160 * * *$ & $.094 *$ & .065 \\
\hline \multicolumn{6}{|l|}{$\begin{array}{l}\text { Males } \\
(\underline{N}=54)\end{array}$} \\
\hline Severity & .001 & .007 & .018 & .000 & .010 \\
\hline Attributions & .029 & .054 & .144 & .112 & .073 \\
\hline \multicolumn{6}{|l|}{$\begin{array}{l}\text { Females } \\
(\mathbb{N}=76)\end{array}$} \\
\hline Severity & .040 & .029 & $.153 * *$ & .035 & .030 \\
\hline Attributions & .038 & .031 & $.180 * * *$ & .126 & .097 \\
\hline
\end{tabular}

$\star \mathrm{g}<.05 * \mathrm{e}<.01 * \mathrm{e}<.001$

- Child Behavior Checklist Internalizing scale

- Child Behavior Checklist Externalizing scale

- Youth Self Report Internalizing scale

- Youth Self Report Externalizing scale

- Anger Arousal Intensity subscale of the Anger Response Inventory 
Table 23.

Hierarchical Regressions of Adjustment on Attributions for Family violence, controlting for Severity

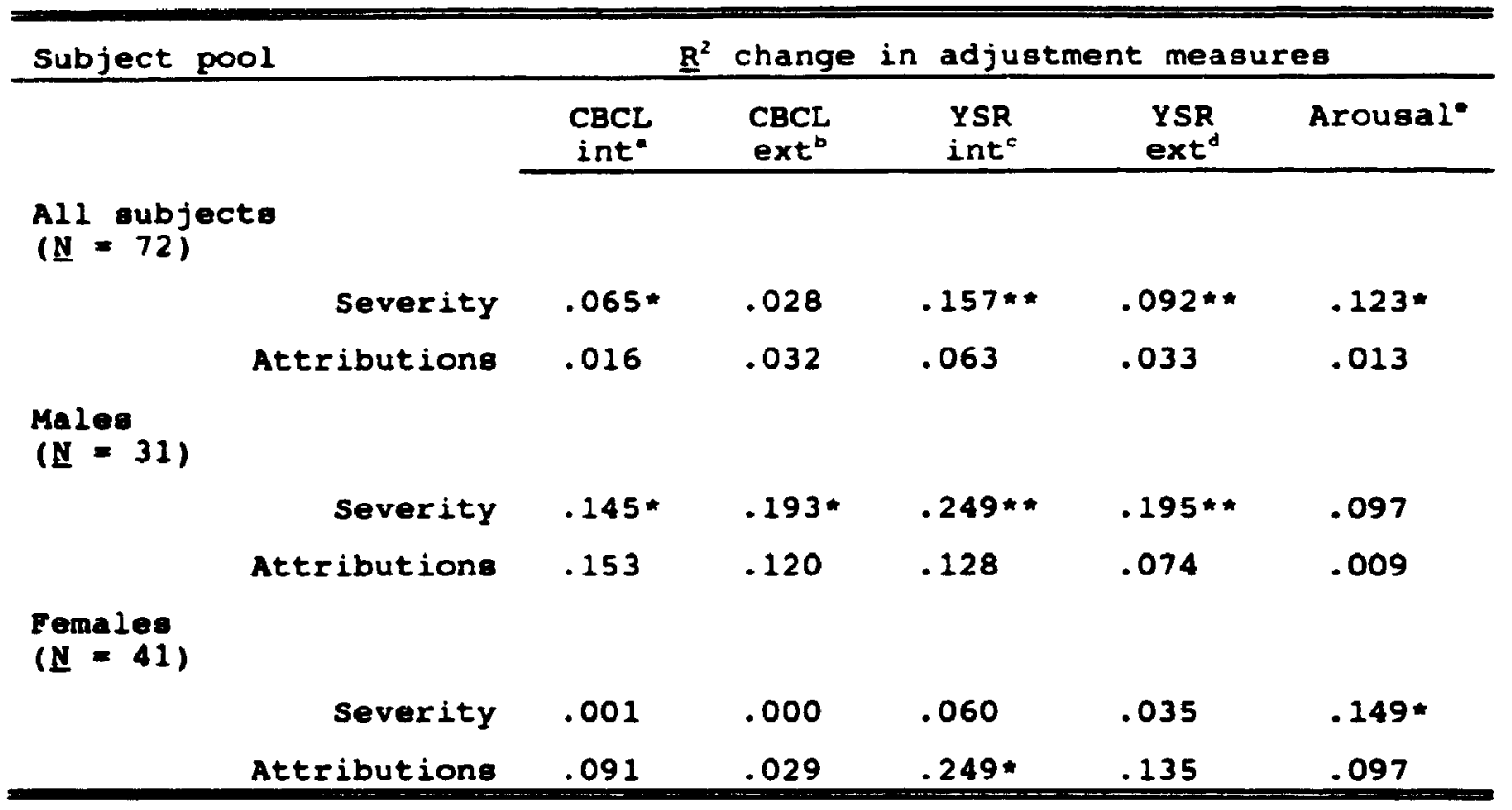

* $<.05 * \mathbf{g}<.01 * * \mathbf{p}<.001$

- Child Behavior Checklist Internalizing scale

- Child Behavior Checklist Externalizing scale

- Youth Self Report Internalizing scale

- Youth Self Report Externalizing scale

- Anger Arousal Intensity subscale of the Anger Response Inventory 
Table 24.

Hiera jical Regressions of Adjustment on Attributions for Neqlect, Contro:iling for Severity

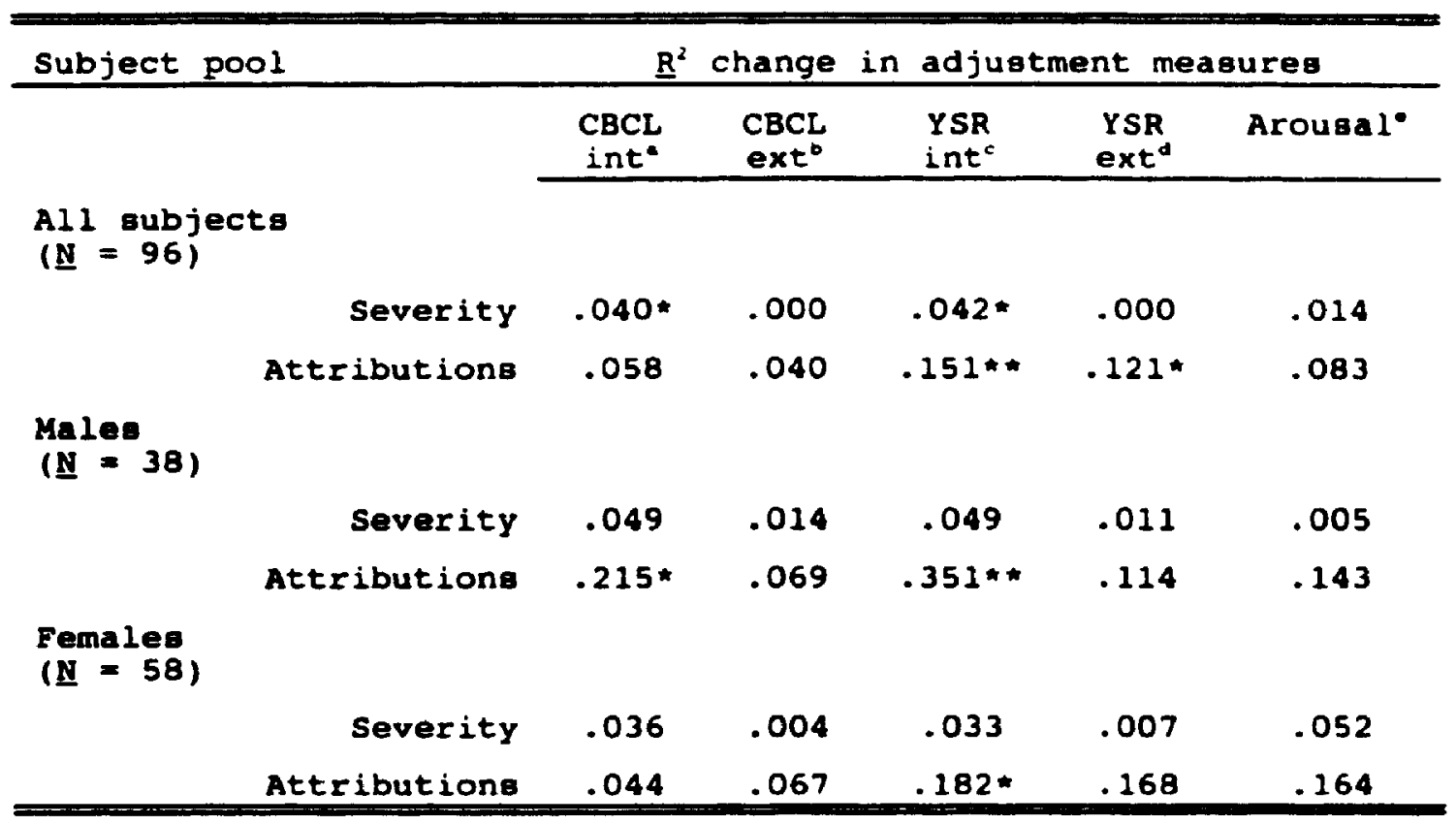

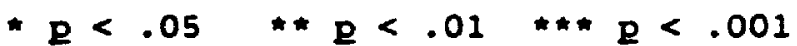

- Child Behavior Checklist Internalizing scale

- Child Behavior Checkligt Externalizing scale

- Youth Self Report Internalizing scale

- Youth Self Report Externalizing scale

- Anger Arousal Intensity subscale of the Anger Response Inventory 
Table 25 .

Hierarchical Rearegsions of Adjustment on sexual Abuge, controlling for severity

\begin{tabular}{|c|c|c|c|c|c|}
\hline Subject pool & & $\underline{\underline{R}}^{2} \mathbf{i}$ & Adjustment & Measures & \\
\hline & $\begin{array}{l}\text { CBCL } \\
\text { int }\end{array}$ & $\begin{array}{l}\text { CBCL } \\
\text { ext }\end{array}$ & $\begin{array}{l}\text { YSR } \\
\text { inte }\end{array}$ & $\begin{array}{l}\text { YSR } \\
\text { ext }\end{array}$ & Arougal* \\
\hline \multicolumn{6}{|l|}{$\begin{array}{l}\text { Al1 subjects } \\
(\underline{N}=53)\end{array}$} \\
\hline severity & .005 & .006 & .005 & .034 & .004 \\
\hline Attributions & .004 & .051 & $.334 * *$ & $.260 * *$ & $.324 * *$ \\
\hline severity & .016 & .092 & .001 & .035 & .008 \\
\hline Attributions & .111 & .106 & $.459 * * *$ & $.314 * *$ & $.373 * \star$ \\
\hline
\end{tabular}

$* \mathrm{~g}<.05 * \mathrm{E}<.01 * * t \mathrm{Q}<.001$

- Child Behavior Checkliat Internalizing ecale

- Child Behavior Checklist Externalizing scale

- Youth Self Report Internalizing scale

- Youth Self Report Externalizing acale

- Anger Arousal Intensity aubscale of the Anger Response Inventory 
When examining the separate equations for each sex, differences were apparent. Among males, neither severity nor attribution regarding hostile maltreatment accounted for significant variance in adjustment. The regults for females were more robugt. Severity of the physical or emotional abuse accounted for 15.38 of variance in self-reported (YSR) internalizing for temales, and an additional 188 was accounted for by attributions $(\underline{\mathrm{p}}<.001), \underline{\mathrm{R}}=.57, \mathrm{p}<.001$.

Family violence attributions. An interesting pattern of regults was obtained for family violence attributions (see Table 23). For the overall sample, the prediction of adjustment was significant at the .01 level for self-reported (YSR) internalizing (․ $=.46, \underline{Q}<.01$ ). Resulte for the combined sample suggested that the severity of family violence witnessed is very potent in predicting adjustment, but that attributione did not add significantly to prediction.

Examination of the equations for each Bex, however, revealed that the severity of family violence was predictive of behavior problems in boys, but predictive of anger arousal problems in girls. Among boys, their report of the severity of the violence they witnessed accounta for 14.58 and 19.38 of caretaker-reported (CBCL) internalizing and externalizing, respectively. (This is notable, because of the lack of method variance shared between self-and third-party-reporta.) For self-reported problems, severity accounted for 24.98 of self-reported (YSR) internalizing $(\underline{R}=.61, \underline{Q}<.05$ ) and 19.58 of self-reported (YSR) externalizing. For girlo, severity of famlly " olence did not dccount for any behavior problems, although it added 14.98 to their difflculties in managing physiologlcal anger arousal. With the power of analyses reduced by splitting the sample by sex, attributions did not often add significantly to prediction despite their absolute gize. However, 24.98 of variance in female's self-reported (YSR) internalizıng was accounted for by their attributions for the violence they had witnessed, $\underline{R}=.55$, $\underline{2<.05}$ 
Neqlect attr jutions. For the sample overall, multiple $\underline{R}$ between predictors and adjustment way significant for self-reported (YSR) internalizing $(\underline{R}=.44, \mathrm{Q}<.01)$, and nearly significant for selfreported (YSR) externalizing $(\underline{R}=.35, \underline{p}=.06)$. Over and above the contribution made by neglect severity, attributions for the neglect added 15.18 and 12.18 to prediction of self-report (YSR) internatizing and externalizing, respectively (see Table 24). Again, however, interpretation of the overall results must be qualified by understanding the different patterns within the sexes. For boys, attributions for neglect added 35.18 to self-reported (YSR) internalizing ( $\underline{R}=.63, \underline{D}<$ .01 ), and 21.58 to caretaker-reported (CBCL) internalizing. For girls, 18.2 ce gelf-reported (YSR) internalizing was accounted for when controlling for neglect severity, $\underline{P}=46, \mathrm{D}<.05$.

sexual abuse attributions. Finally, for sexual abuse, hierarchical regressions were conducted for the sample overall and females only (see Table 25). No equation was computed for the six males who made attributions about their sexual abuse (one sexualiy abused male refused to make attributions for this maltreatment type). Multiple $\underline{R}$ was aignificant beyond the .01 level for self-reported (YSR) internalizing $(\underline{R}=.58, \underline{P}<.01)$, self-reported $($ YSR) externalizing $(\underline{R}=$ $.54, \underline{D}<.01)$, and Anger Arousal Intensity $(\underline{R}=.57, \underline{Q}<.01)$. For all gexual abuse victims, severity added nothing to prediction. However, attribution for the abuse contributed substantially to all self-report measures: 33.48 for self-reported (YSR) internalizing, 268 to selfreported (YSR) externalizing, and 32.48 to Anger Arousal Intensity. When considering only females, the amount of variance accounted for was even larger: 45.98 for self-reported (YSR) internalizing ( $\underline{R}=.67, \mathrm{R}<$ $.001), 31.48$ for self-reported (YSR) externalizing ( $R=.59, E<.01$ ), and 37.38 for Anger Arousal Intensity $(\underline{R}=.61, \underline{D}<.01)$. That is, one third to one half of the variance in the behavior problems and 
subjective distress of female sexual abuse victims was due to their attributions regarding the experience.

The Unique Additivity of Specific Attributiong

Which of the attributions adds the most to the prediction of adjustment? Tables 26 through 29 present the univariate correlations of each attributional dimension (for each maltreatment) with each criterion variable. Controlling for Type I error by dividing a .05 alpha level by the 5 correlations associated with each adjustment measure yields an a)pha level of .01. Tables 30 through 33 present the squared semipartial correlations $\left(g \underline{g}^{2}\right)$ of all attribution variables and their associated tests of gignificance. These numbers represent the unique contribution of that predictor variable as a proportion of the total variance of the criterion variable. The test of $\mathbf{g r}^{2}$ is the test of the contribution of that variable to prediction of the criterion variable controlling for all other variables in the equation. Thus, the numbers represent the unique amount of variance accounted for by each attribution, above and beyond the variance accounted for by severity and all other attributions.

Both univariate and squared semipartial correlations indicated that self-blaming affect was strongly and cussistently associated with Belf-reported (YSR) internalizing across all forms of maltreatment. Self-blaming affect added unique variance to self-reported (YSR) internalizing for hostile maltreatment (118), family violence (48), neglect (58), and sexual abuse (198). It added to the prediction of Anger Arousal Intensity for hostile maltreatment (38), neglect (58), and sexual abuse (138). For sexual abuse and hostile maltreatment, selfblaming affect also added significantly to self-reported (YSR) externalizing (108).

Several attributions had significant univariate correlations with adjugtment measures. When controlling for all other severity and all 
Table 26.

Correlations between Adjugtment Measures and Attributions for Hostile Majtreatment

\begin{tabular}{|c|c|c|c|c|c|c|}
\hline \multirow[t]{2}{*}{ Subject Pool } & \multirow[t]{2}{*}{$\begin{array}{l}\text { Severity and } \\
\text { attributions } \\
\text { (Hostile) }\end{array}$} & \multicolumn{5}{|c|}{ Adjustment Measures } \\
\hline & & $\begin{array}{l}\text { CBCL } \\
\text { int } \\
\end{array}$ & $\begin{array}{l}\text { CBCL. } \\
\text { ext }\end{array}$ & $\begin{array}{l}\text { YSR } \\
\text { int } \\
\end{array}$ & $\begin{array}{l}\text { YSR } \\
\text { ext }^{d} \\
\end{array}$ & Aroubal• \\
\hline \multirow[t]{7}{*}{$\begin{array}{l}\text { A1l subjects } \\
(\underline{N}=130)\end{array}$} & & & & & & \\
\hline & Severity & .13 & -.06 & $.29 \star$ & .11 & .05 \\
\hline & self blame & .05 & .12 & .00 & .16 & .07 \\
\hline & Self excuse & .03 & .01 & .09 & .00 & .12 \\
\hline & $\begin{array}{l}\text { Self-blame } \\
\text { affect }\end{array}$ & .07 & -.04 & $.40 *$ & $.23 *$ & $.23 \star$ \\
\hline & $\begin{array}{l}\text { Perpetrator } \\
\text { blame }\end{array}$ & .08 & -.09 & .04 & -.09 & .01 \\
\hline & $\begin{array}{l}\text { Perpetrator } \\
\text { excuse }\end{array}$ & .00 & .01 & .15 & .00 & .14 \\
\hline \multirow[t]{6}{*}{$\begin{array}{l}\text { Male': } \\
(\underline{N}=54)\end{array}$} & Severity & .04 & .08 & .13 & -.01 & -.10 \\
\hline & seli blame & .00 & .10 & -.03 & .19 & .13 \\
\hline & Self excuse & .09 & .12 & -.04 & -.13 & -.07 \\
\hline & $\begin{array}{l}\text { Self-blame } \\
\text { affect }\end{array}$ & .07 & -.01 & .22 & .12 & .23 \\
\hline & $\begin{array}{l}\text { Perpetrator } \\
\text { blame }\end{array}$ & .01 & -.01 & -.13 & -.11 & -.01 \\
\hline & $\begin{array}{l}\text { Perpetrator } \\
\text { excuse }\end{array}$ & .00 & -.11 & .03 & -.18 & .00 \\
\hline \multirow[t]{6}{*}{$\begin{array}{l}\text { Females } \\
(\underline{N}=76)\end{array}$} & Severity & .20 & -.17 & $.39 \star$ & .18 & .17 \\
\hline & Self blame & .10 & .13 & .03 & .15 & .04 \\
\hline & Self excuse & .00 & -.03 & .17 & .05 & .23 \\
\hline & $\begin{array}{l}\text { Self-blame } \\
\text { affect }\end{array}$ & .07 & -.04 & $.52 *$ & $.28 *$ & .24 \\
\hline & $\begin{array}{l}\text { Perpetrator } \\
\text { blame }\end{array}$ & .12 & -.14 & .14 & -.10 & .05 \\
\hline & $\begin{array}{l}\text { Perpet.rator } \\
\text { excuse }\end{array}$ & .00 & .09 & .25 & .14 & .23 \\
\hline $\begin{array}{l}\text { - } \text { Child Bi } \\
\text { - Child Behav } \\
\text { c Youth Self } \\
\text { - Youth Self } \\
\text { - Anger Arous }\end{array}$ & $\begin{array}{l}\text { ior Checkligt } \\
\text { ior Checkligt } \\
\text { Report Interna } \\
\text { Report Externa } \\
\text { al Intenaity }\end{array}$ & $\begin{array}{l}\text { Interna: } \\
\text { Externa } \\
\text { lizing } \\
\text { lizing } \\
\text { ubscale }\end{array}$ & $\begin{array}{l}\text { izing } \\
\text { izing } \\
\text { cale } \\
\text { cale } \\
\text { of the }\end{array}$ & $\begin{array}{l}\text { le } \\
\text { le }\end{array}$ & le & \\
\hline
\end{tabular}


Table 27 .

Correlations between Adjustment Measures and Attributions for Family Violence

\begin{tabular}{|c|c|c|c|c|c|c|}
\hline \multirow[t]{2}{*}{$\begin{array}{l}\text { Subject } \\
\text { pool }\end{array}$} & \multirow[t]{2}{*}{$\begin{array}{l}\text { Severity and } \\
\text { attribution } \\
\text { (Family violence) }\end{array}$} & \multicolumn{5}{|c|}{ Adjustment Measures } \\
\hline & & $\begin{array}{l}\text { CBCL } \\
\text { int }\end{array}$ & $\begin{array}{l}\text { CBCL } \\
\text { ext }\end{array}$ & $\begin{array}{l}\text { YSR } \\
\text { int }^{c} \\
\end{array}$ & $\begin{array}{l}\text { YSR } \\
\text { ext }\end{array}$ & Arousa $1^{\bullet}$ \\
\hline \multirow[t]{6}{*}{$\begin{array}{l}\text { All } \\
\text { subjects } \\
(\underline{N}=72)\end{array}$} & Severity & .25 & .16 & $.39 *$ & $.30 *$ & $.35 *$ \\
\hline & Self blame & -.01 & .03 & .14 & .19 & .09 \\
\hline & self excuse & .03 & .00 & .00 & .08 & .07 \\
\hline & Self-blame affect & .03 & -.10 & $.32 \star$ & .16 & .12 \\
\hline & $\begin{array}{l}\text { Perpetrator } \\
\text { blame }\end{array}$ & .18 & .00 & .21 & .24 & .16 \\
\hline & $\begin{array}{l}\text { Perpetrator } \\
\text { excuse }\end{array}$ & .04 & -.09 & .09 & .03 & .12 \\
\hline \multirow[t]{6}{*}{$\begin{array}{l}\text { Males } \\
(\underline{N}=31)\end{array}$} & severity & .38 & $.43 \star$ & $.49 * *$ & $.44 \star$ & .31 \\
\hline & Self blame & .10 & -.01 & .10 & .14 & .11 \\
\hline & Self excuse & -.04 & .00 & -.13 & .06 & .04 \\
\hline & self-blame affect & -.12 & -.08 & .13 & .06 & .07 \\
\hline & $\begin{array}{l}\text { Perpetrator } \\
\text { blame }\end{array}$ & .24 & .17 & .08 & .35 & .12 \\
\hline & $\begin{array}{l}\text { Ferpetrator } \\
\text { excuse }\end{array}$ & -.23 & -.30 & -.13 & -.16 & .00 \\
\hline \multirow[t]{6}{*}{$\begin{array}{l}\text { Females } \\
(N=41)\end{array}$} & Severity & .10 & .00 & .24 & .18 & $.38 \star$ \\
\hline & Self blame & -.09 & .07 & .17 & .22 & .08 \\
\hline & self excuse & .15 & -.05 & .22 & .09 & .11 \\
\hline & Self-blame affect & .07 & -.05 & $.41 *$ & .25 & .14 \\
\hline & Perpetrator blame & .06 & -.03 & .24 & .17 & .17 \\
\hline & $\begin{array}{l}\text { Perpetrator } \\
\text { excuge }\end{array}$ & .27 & .09 & .28 & .20 & .21 \\
\hline $\begin{array}{l}\text { * } \text { Child } \\
\text { - Child } \\
\text { e Youth } \\
\text { \& Youth } \\
\text { - Anger }\end{array}$ & $\begin{array}{l}\text { Behavior Checklist In } \\
\text { Behavior Checklist Ex } \\
\text { Self Report Internali } \\
\text { Self Report Externali } \\
\text { Arousal Intengity gub }\end{array}$ & $\begin{array}{l}\text { ernaliz } \\
\text { zing sca } \\
\text { ing sca } \\
\text { acale of }\end{array}$ & $\begin{array}{l}\text { ing } \mathrm{sc} \\
\text { ing } \mathrm{sc} \\
\text { le } \\
\text { le } \\
\text { the } A\end{array}$ & ger Res & nse & ntory \\
\hline
\end{tabular}


Table 28.

Correlations between Adjustment Measures and Attributions for Neglect

\begin{tabular}{|c|c|c|c|c|c|c|}
\hline \multirow[t]{2}{*}{$\begin{array}{l}\text { Subject } \\
\text { pool }\end{array}$} & \multirow[t]{2}{*}{$\begin{array}{l}\text { Severity and } \\
\text { attribution } \\
\text { (Neglect) }\end{array}$} & \multicolumn{5}{|c|}{ Adjustment Measures } \\
\hline & & $\begin{array}{l}\text { CBCL } \\
\text { int: }\end{array}$ & $\begin{array}{l}\text { CBCL } \\
\text { ext }\end{array}$ & $\begin{array}{l}\text { YSR } \\
\text { int }\end{array}$ & $\begin{array}{l}\text { YSR } \\
\text { ext }^{\text {d }}\end{array}$ & Arousal' \\
\hline \multirow[t]{6}{*}{$\begin{array}{l}\text { All } \\
\text { subjects } \\
(\mathbb{N}=96)\end{array}$} & Severity & .19 & -.02 & .20 & .00 & .12 \\
\hline & Self blame & .05 & -.01 & .11 & $.22 \star$ & .02 \\
\hline & Self excuse & -.05 & .06 & -.01 & .06 & -.01 \\
\hline & $\begin{array}{l}\text { Self-blame } \\
\text { affect }\end{array}$ & .12 & -.06 & $.24 *$ & .10 & $.24 *$ \\
\hline & $\begin{array}{l}\text { Perpetrator } \\
\text { blame }\end{array}$ & -.09 & -.06 & -.16 & -.10 & .00 \\
\hline & $\begin{array}{l}\text { Perpetrator } \\
\text { excuse }\end{array}$ & .03 & -.18 & .16 & -.14 & .18 \\
\hline \multirow[t]{6}{*}{$\begin{array}{l}\text { Males } \\
(\mathbb{N}=54)\end{array}$} & Severity & .22 & .12 & .22 & .10 & -.02 \\
\hline & Self blame & -.05 & -.18 & -.11 & .00 & -.14 \\
\hline & Self excuse & -.19 & -.07 & -.12 & .06 & -.14 \\
\hline & $\begin{array}{l}\text { Self-blame } \\
\text { affect }\end{array}$ & .22 & -.11 & .03 & -.10 & -.05 \\
\hline & $\begin{array}{l}\text { Perpetrator } \\
\text { blame }\end{array}$ & -.18 & -.01 & $-.46 *$ & -.07 & -.28 \\
\hline & $\begin{array}{l}\text { Perpetrator } \\
\text { excuge }\end{array}$ & .02 & -.25 & -.09 & -.30 & .16 \\
\hline \multirow[t]{6}{*}{$\begin{array}{l}\text { Females } \\
(\underline{N}=58)\end{array}$} & Severity & .18 & -.06 & .18 & -.08 & .22 \\
\hline & Self blame & .12 & .10 & .26 & $.33 *$ & .13 \\
\hline & Self excuse & .01 & .15 & .04 & .06 & .05 \\
\hline & $\begin{array}{l}\text { Self-blame } \\
\text { affect }\end{array}$ & .06 & -.04 & $.39 \star$ & .22 & $.43 *$ \\
\hline & $\begin{array}{l}\text { Perpetrator } \\
\text { blame }\end{array}$ & -.04 & -.14 & .07 & -.09 & .16 \\
\hline & $\begin{array}{l}\text { Perpetrator } \\
\text { excuse }\end{array}$ & .07 & -.14 & $.33 *$ & -.06 & .20 \\
\hline
\end{tabular}


Table 29.

Correlationg between Adjugtment Measures and Attributions for Sexual Abuse

\begin{tabular}{|c|c|c|c|c|c|c|}
\hline \multirow[t]{2}{*}{$\begin{array}{l}\text { Subject } \\
\text { pool }\end{array}$} & \multirow[t]{2}{*}{$\begin{array}{l}\text { Severity and } \\
\text { attributions } \\
\text { (Sexual) }\end{array}$} & \multicolumn{5}{|c|}{ Adjustment Measures } \\
\hline & & $\begin{array}{l}\text { CBCL } \\
\text { int }\end{array}$ & $\begin{array}{l}\text { CBCL } \\
\text { ext } \\
\end{array}$ & $\begin{array}{l}\text { YSR } \\
\text { int } \\
\end{array}$ & $\begin{array}{l}\text { YSR } \\
\text { ext }^{d}\end{array}$ & Arousal' \\
\hline \multirow[t]{6}{*}{$\begin{array}{l}\text { All } \\
\text { subjects } \\
(\underline{N}=53)\end{array}$} & Severity & .07 & .07 & .07 & .18 & .06 \\
\hline & Self blame & .08 & .01 & .23 & .23 & $.35 *$ \\
\hline & Self excuse & .02 & .16 & $.33 *$ & $.39 *$ & $.38 *$ \\
\hline & $\begin{array}{l}\text { Self-blame } \\
\text { affect }\end{array}$ & .18 & .18 & $.52 *$ & $.44 *$ & $.49 *$ \\
\hline & $\begin{array}{l}\text { Perpetrator } \\
\text { blame }\end{array}$ & .14 & .06 & .23 & .28 & .19 \\
\hline & $\begin{array}{l}\text { Perpetrator } \\
\text { excuse }\end{array}$ & .01 & .07 & .00 & -.01 & .07 \\
\hline \multirow[t]{6}{*}{$\begin{array}{l}\text { Females } \\
(\underline{N}=47)\end{array}$} & Severity & .12 & .30 & .04 & .18 & .09 \\
\hline & self blame & .11 & .02 & .27 & .22 & $.34 *$ \\
\hline & self excuge & .09 & .26 & $.41 \star$ & $.45 *$ & $.43 *$ \\
\hline & $\begin{array}{l}\text { Self-blame } \\
\text { affect }\end{array}$ & .26 & .25 & $.60 *$ & $.43 *$ & $.52 *$ \\
\hline & $\begin{array}{l}\text { Perpetrator } \\
\text { blame }\end{array}$ & .29 & .23 & $.35 *$ & $.35 *$ & .26 \\
\hline & $\begin{array}{l}\text { Perpetrator } \\
\text { excuse }\end{array}$ & .01 & -.02 & .12 & .04 & .08 \\
\hline
\end{tabular}

$\star \mathrm{P}<.01$

- Child Behavior Checklist Internalizing ocale

- Child Behavior Checkligt Externalizing scale

c Youth Self Report Internalizing scale

- Youth Self Report Externalizing scale

- Anger Arousal Intensity subscale of the Anger Response Inventory 
Table 30.

The Unioue Addition of Each Attribution for Hostile Maltreatment (ar $\left.{ }^{2}\right)$ to Predicted Variance in Adjustment, Controliting for severity and All other Attributione.

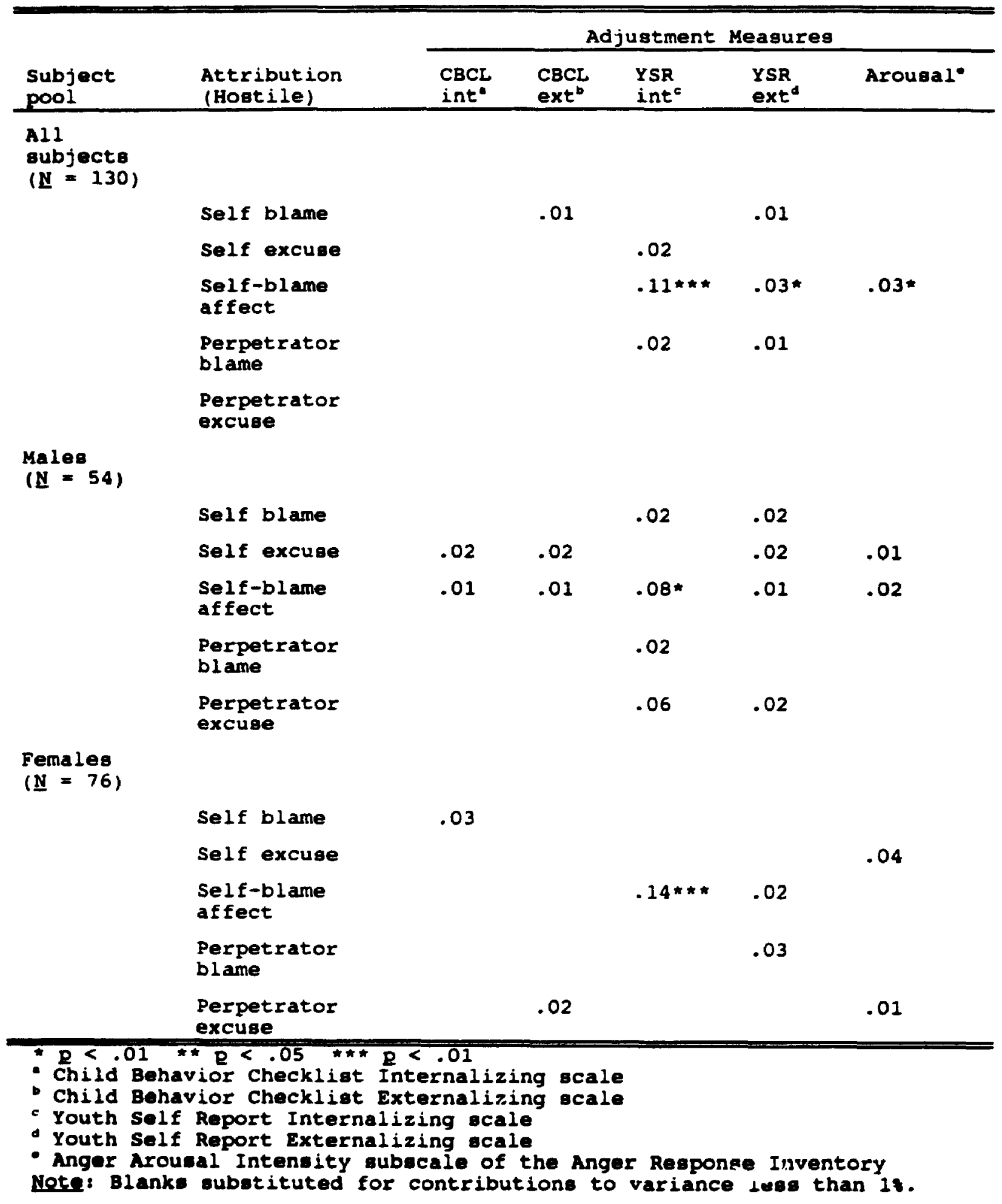


Table 31.

The Unique Addition of Each Attribution for Family Violence (8r ) to Predicted Variance in Adjustment, controlling for severity and All other Attributions.

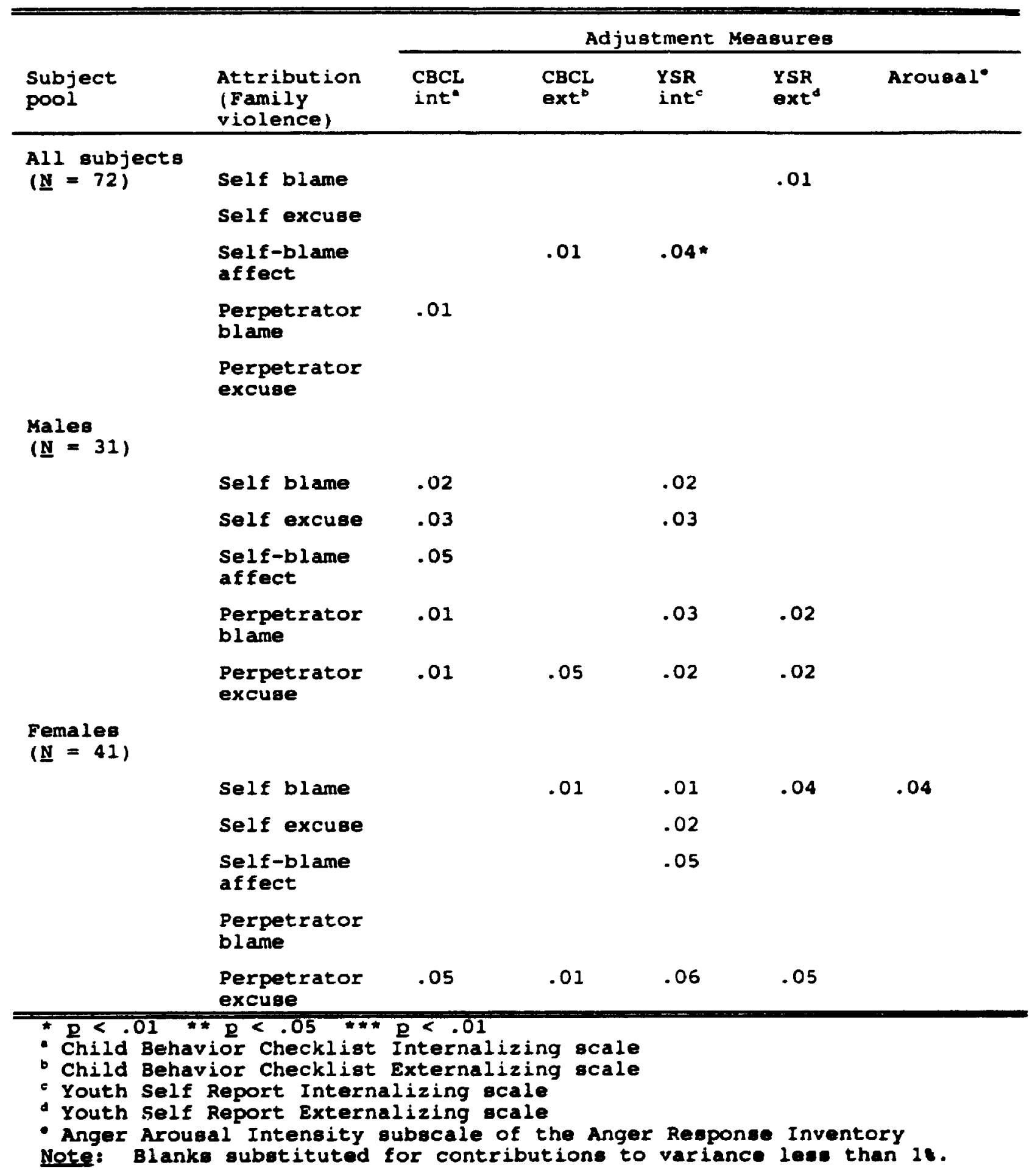


Table 32 .

The Unioue Contribution of Each Attribution for Neglect $\left(g r^{2}\right)$ to Predicted Variance in Adjustment, Controlling for severity and All other Attributione.

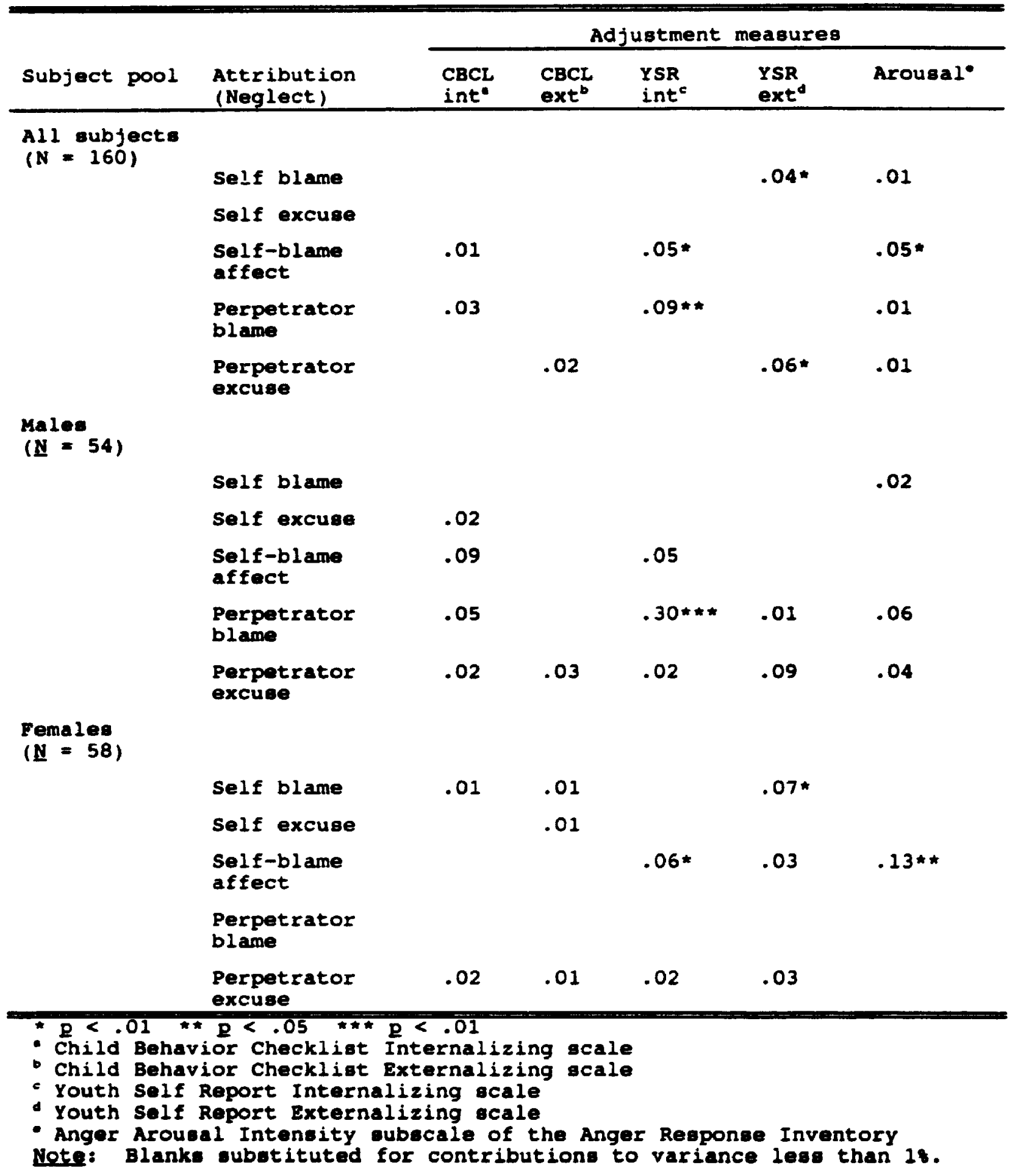


Table 33.

The Unique Contribution of Each Attribution for Sexual Abuge (gr') to Predicted Variance in Adjugtment, controliting for severity and All other Attributions.

\begin{tabular}{|c|c|c|c|c|c|c|}
\hline \multirow[b]{2}{*}{$\begin{array}{l}\text { Subject } \\
\text { pool }\end{array}$} & \multirow[b]{2}{*}{$\begin{array}{l}\text { Attribution } \\
\text { (Sexual } \\
\text { abuse) }\end{array}$} & \multicolumn{5}{|c|}{ Adjustment measures } \\
\hline & & $\begin{array}{l}\text { CBCL } \\
\text { int }\end{array}$ & $\begin{array}{l}\text { CBCL } \\
\text { ext }\end{array}$ & $\begin{array}{l}\text { YSR } \\
\text { int }\end{array}$ & $\begin{array}{l}\text { YSR } \\
\text { ext }\end{array}$ & Arouga ${ }^{\circ}$ \\
\hline \multicolumn{7}{|l|}{$\begin{array}{l}\text { Al1 } \\
\text { Bubjects } \\
(\mathbb{N}=53)\end{array}$} \\
\hline & Self blame & & & & & .01 \\
\hline & self excuse & & .01 & .02 & .04 & .03 \\
\hline & $\begin{array}{l}\text { Sel f-blame } \\
\text { affect }\end{array}$ & .01 & .02 & $.19 * *$ & $.10 * \star$ & $.13 * *$ \\
\hline & $\begin{array}{l}\text { Perpetrator } \\
\text { blame }\end{array}$ & .01 & & & & \\
\hline & $\begin{array}{l}\text { Perpetrator } \\
\text { excuse }\end{array}$ & & & .03 & .02 & .01 \\
\hline \multicolumn{7}{|l|}{$\begin{array}{l}\text { Eemales } \\
(N=47)\end{array}$} \\
\hline & self blame & & .01 & & & \\
\hline & self excuse & & .02 & .04 & .07 & .04 \\
\hline & $\begin{array}{l}\text { Self-blame } \\
\text { affect }\end{array}$ & .03 & .04 & $.19+*$ & $.07 *$ & $.13 * *$ \\
\hline & $\begin{array}{l}\text { Perpetrator } \\
\text { blame }\end{array}$ & .03 & & & .02 & \\
\hline & $\begin{array}{l}\text { Perpetrator } \\
\text { excuse }\end{array}$ & & .01 & .12 & & .01 \\
\hline
\end{tabular}

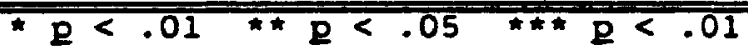

- Child Behavior Checklist Internalizing scale

- Child Eehavior Checklist Externalizing scale

c Youth Self Report Internalizing scale

d Youth Self Report Externalizing scale

- Anger Arousal Intensity subscale of the Anger Response Inventory

Note: Blanks substituted for contributions to variance less than 1 . 
other attributions, some variables retained this significant relationship. As perpetrator-blame increased among neglected boys, self-reported (YSR) internalizing problems decreased $(\underline{E}=-.46, \mathrm{P}<.01$ ) - this relationship remained significant when adding perpetrator-blame last into the equation $\left(\mathrm{BI}^{2}=.30, \mathrm{p}<.001\right)$. Among females, as Belfblame for neglect increased, self-reported (YSR) externalizing problems increased $(E=.33, P<.01)$, and the $\underline{B r}^{2}$ indicates that self-blame added unique variance to self-reported (YSR) externalizing for females (78). These results suggest that boys who blame the perpetrator for neglect fare well, but that girls who blame themselves fare poorly. In contrast, the association between self-excusing and all self-reported adjustment meseures found among sexual abuse victims was reduced to nonsignificance when controlling for other attributions. Likewise, the association between self-blaming cognition for sexual abuse and anger arousal did not remain significant when other attributions were controlled. Apart from the relationships mentioned, perpetrator-blame and self-blaming cognition were not significantly associated with any adjustment measure.

In oumary, the hypothesis that attributions for maltreatment accounted for significant variance in adjustment over and above the variance attributable to perceived maltreatment severity was supported. The strongest evidence was found for self-reported measures of adjustment, although caretaker-repo:ted behavior problems were predicted for boys. Attributions accounted for the largest proportion of variance in self-reported adjustment among sexual abuse victims. The value of adding attributions to severity to predict adjustment varied with the victim's gender. Across all maltreatment types, the attributions of females added significantly to explanation of self-reported (YSR) internalizing. The pattern for males was more complex. Males' attributions added to internalizing problems only for neglect; however, both self and other-reported behavior problems were predicted. For 
males, the severity of family violence was potent and robust across several multimethod measures of adjustment. Controlling for severity and all other attributions, self-blaming affect accounted for unique variance in the prediction of gelf-reported internalizing problems across all maltreatment types.

Hypothesis Five: Severity and Adjustment: Are Attributions Mediators or Moderators?

The fifth hypothesis concerned the nature of the relationship between maltreatment severity and adjustment, and the role of attributions between them.

Hypotheais Five: Self-blaming attributions will mediate or moderate the relationship between perceived maitreatment severity and internalizing behavior problems. Perpetratorblaming attributions will mediate or moderate the relationship between maltreatment severity and externalizing ذehavior problems.

\section{Tests of the Mediator Model}

According to Baron and Kenny (1986), three conditions must prevail for an appropriate test of a mediator. First, there must be a significant association between the predictor and the criterion. Second, there must be sign.ficant association between the predictor and the mediator. Third, when the influence of the predictor on the mediator and the influence of the mediator on the criterion are controlled, the association between the predictor and the criterion must be significantly reduced. In regression analysea with the present variables, the following conditions must hold: a) the regression coefficient for maltreatment severity and maladjugtment must be gignificant; b) the regression coefficient for maltreatment severity and a specific attribution must be significant; and $c$ ) in the regregsion equation in which both severity and the attribution are used to predict maladjustment, the coefficient for severity must be smaller than it was 
when tested alone (i.e., in the first equation). All three conditions muat be true for the attribution to be considered a mediator.

Examination of the univariate correlations between severity and adjustment (Tables 26 through 29) and between severity and other attributions (Tables 18 through 21 ) reveal that the first two conditions - that severity must be significantly associated with adjustment and with specific attributions - were rarely met. For neglect and sexual abues, for both sexes combined and separately, the primary condition that severity was significantly associated with adjustment was never met.

For hostile maltreatment, severity was aignificantly associated with self-reported (YSR) internalizing ( $\underline{x}=.29, \mathrm{p}<.001$ ). For the combined sample, there was no occasion in which adding an attribution to the prediction of eelf-reported (YSR) internalizing reduced tne size or agnificance of this coefficient. However, Table 26 indicates a greater association between severity and self-reported (YSR) internalizing anong females $(E=.39, g<.001)$. Among females, severity is also related to eelf-blaming affect $(I=.39, \mathrm{~g}<.001$; see Table 18). When Beverity and eelf-blaming affect are ueed concurrently to predict self-reported (YSR) internalizing scores among females, the size of the coefficient for severity is decreased from .39 to .21 , although it remained gignificant $(\mathrm{g}<.05)$ at the amaller gize. This pattern of results indicated that self-blaming affect may mediate $t^{*} e$ relationship between hootile maltreatment severity and self-repurted internalizing problems among females.

For family violence, severity was significantly associated with all self-reported adjustment measures for the combined sample (see Table 27). It was also associated with perpetrator-blame ( $\underline{\varepsilon}=.43, p<.002$, Table 19). In the combined sample, adding perpetrator-blame to the everity of family violence in the prediction of self-reported (YSR) externalizing reduced the coefficient for family violence severity from 
$.30(\mathrm{p}<.01)$ to .24 (n.s). Among boys, the coefficient went from .44 $(\mathrm{D}<.01)$ to $.35(\mathrm{n.s})$. The results suggested that perpetrator-blame may mediate gelf-reported externalizing problems, particularly among boys.

In summary, the prediction that self-blaming attributions for maltreatment would mediate internalizing problems recelved partial support. Self-blaming affect appeared to mediate the relationship between hostile maltreatment severity and self-reported internalizing among females. The hypothesis that perpetrator-directed attribution would mediate externalizing problems was also tentatively supported, in that perpetrator-blame appeared to mediate the impact of family violence on self-reported externalizing, particularly among boys".

Tests of the Modefator Model

As statisticians (Baron \& Kenny, 1986; Cohen \& Cohen, 1983) have described it, tests of the crossproduct between a moderator and a predictor variable convey whether these variables interact when predicting a criterion. Unlike the teat for mediatora, no preliminary assumptions must be met. To test moderator effects, maltreatment severity and the attribution were entered in the first atep in a hierarchical regression, and the crosspioduct of maltreatment severity and that attribution was eniered on the second step. Overall, 48 regresgions were computed (four types of maltreatment $x$ three blamerelated attributions $x$ four criterion measures). If both the multiple and the increment in variance due to the crosgproduct were oignificant, the interaction was plotted. The regression equation produced by a

\footnotetext{
"Tests of the mediation hypothesis can be accommodated to test attributions taken as a set. The results using a multivariate approach were the same as the univariate results. For hostile malt.reatment, for females, severity correlated with all attributions ( $R=.63, g<.001)$. The size of the coefficient linking geverity to YSR internalizing decreased from .39 ( $2<.001$ ) to .21 ( $<<.05$ ) in the presence of all attributions. For family violence, severity was associated with all attributions $(R=.44, g<.01)$. When controlling for all attributione, the influence of severity on YSR externalizing was reduced from .30 ( $R<$ .$(\mathrm{s})$ to .20 (n.8.). It reduced from .44 ( $<$ <.01) to.31 (n.s.) for boys.
} 
significant analysis was used to compute two separate regression lines predicting the criterion from maltreatment severity, one for subjects with low levels of the attribution lone SD below the mean of that attribution, and one for subjects with high levels of the attribution (one SD above the mean).

In accordance with the differential prediction hypothesis, the planned analyses focuseu on self-blaming cognition and self-blaming affect with internalizing problems. No significant interactions were detected. However, when extending the search to include adjustment problems generally, self-blaming affect for hostile maltreatment interacted with maltreatment severity to predict aretaker-reported (CBCL) externalizing problems $\left(\underline{R}=.30, \underline{D}<.05 ; \underline{R}^{2}\right.$ change $=.04, \underline{D}<$ .05). Figure 1 illustrates this relationship. Caretaker-reported (CBCL; externalizing behaviors were greatest for subjects with strong self-blaming feelings regarding their role in "mild" hostile maltreatment. The lowest scores were obtained by those whose emotional reaction was congruent with the severity of the abuse they experienced: those who had mild reactions to mild abuse scored equivalently to those with strong feelings about severe abuse. Those who claimed little emotional reaction to severe abuse scored intermediately.

In accordance with the differential prediction hypothesis, planned analyges focused on perpetrator-blame and externalizing symptomatoiogy. A significant amount of variance in caretaker-reported (CBCL) externalizing problems was predictes by the severity of family violence, blame towards the batterer, and their interaction $(\underline{k}=.42, \mathrm{p}=.01)$. controlling for main effects, the contribution of the interaction term was significant $\left(\underline{R}^{2}\right.$ change $\left.=.146, \mathrm{Q}<.001\right)$. However, when internalizing criteria were considered, a similar relationship was found for saretaker-reported (CBCL) internalizing problems $(\underline{R}=.34, p<.05)$, in which the crosgproduct term accounted for significant variance above 
Eigure 2. Self-blaming affect as a moderator of the relationship between severity of hostile maltreatment and adjustment.

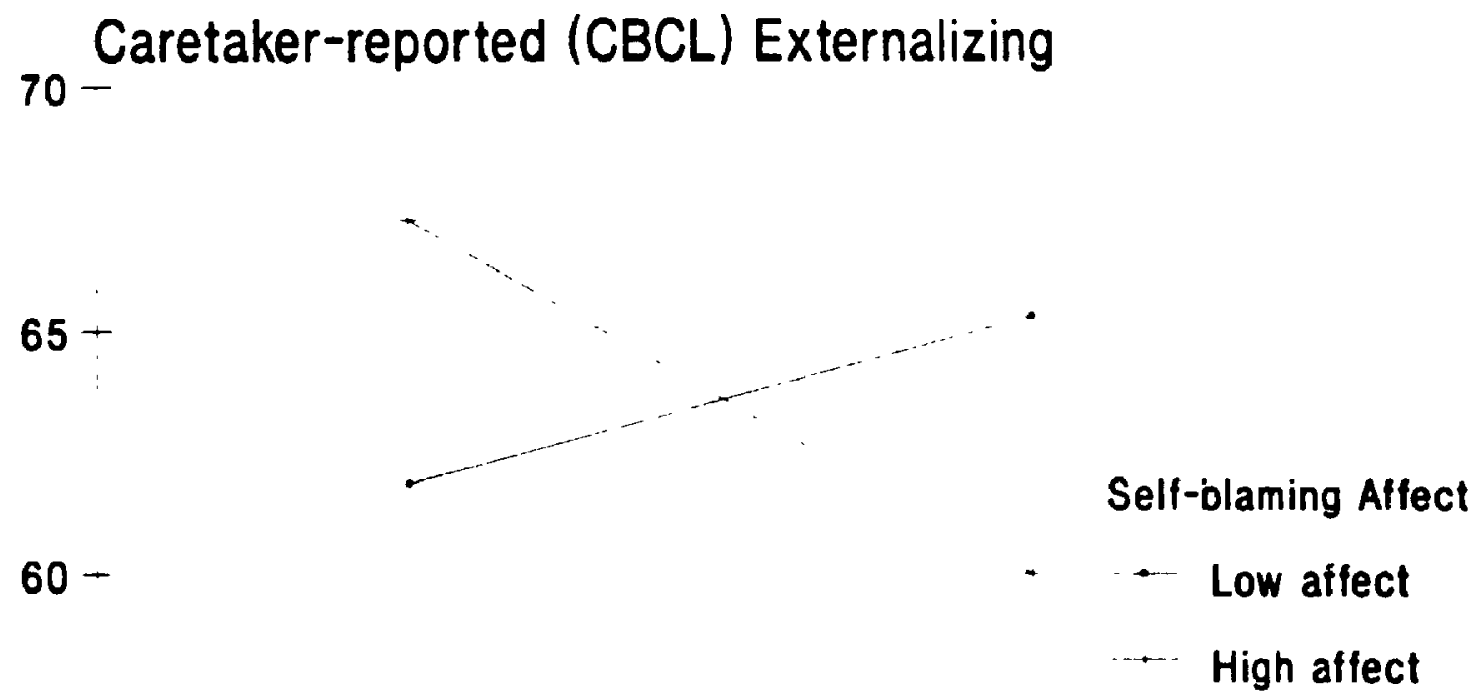

55

50

Mild Moderate Severe

Severity of Hostile Maltreatment

$N \cdot 130$ 
the main effects of severity or batterer-blame alone $\left(\underline{R}^{2}\right.$ change $=.05$, $Q$ <.05). Figure 2 illustrates these relationships. Those subjects whose level of blame towards the batterer was not congruent with the severity of the experience fared the worst. Subjects who attributed strong blame to the batterer for "mild" marital violence fared as badly as those who claimed little blame towards him for gevere violence. Those whose blame was congruent with the severity of the marital violence fared best: mild blame for mild violence, and strong blame for strong violence.

The general prediction that blame attribution would moderate the relationship between maltreatment severity and adjustment received some support. However, there was little evidence that self- and other-blame attributione differentially predicted internalizing and externalizing problems. Rather, the moderator relationship appeared to relate to ad: uetment generally. The importance of the moderator results is underscored by the fact that the maladjustment criteria referred to behavior problems observed by caretakers, thus sharing no method variance with self-reported severity or attribution. Moreover, the predicted scores were well into the clinical range. Also, the similarity of the patterns between moderator relationships suggested that incongruent thoughts or feelings regarding aggressive maltreatment can be associated with observable behavior problems in youth. Mediators or Moderatorg?

Are attributions mediators or moderators of maltreatment severity? The answer appears to be both, depending upon the reporting source for symptomatology. Perpetrator-blame for fanily violence was a mediator of self-reported externalizing behavior problems, but a moderator of caretaker-reported externalizing behavior problems. Using caretakerreport of behavior problems, greater difficulties were evident for those witnesses whose degree of batterer blame (or lack thereof) was not consistent with the severity of the violence they described. Uaing eelf-report of behavior problcms, batterer-blame appears to channel or 
Fiqure 2. Blaming the perpetrator of family violence as a moderator of the relationship between family violence severity and adjustment.

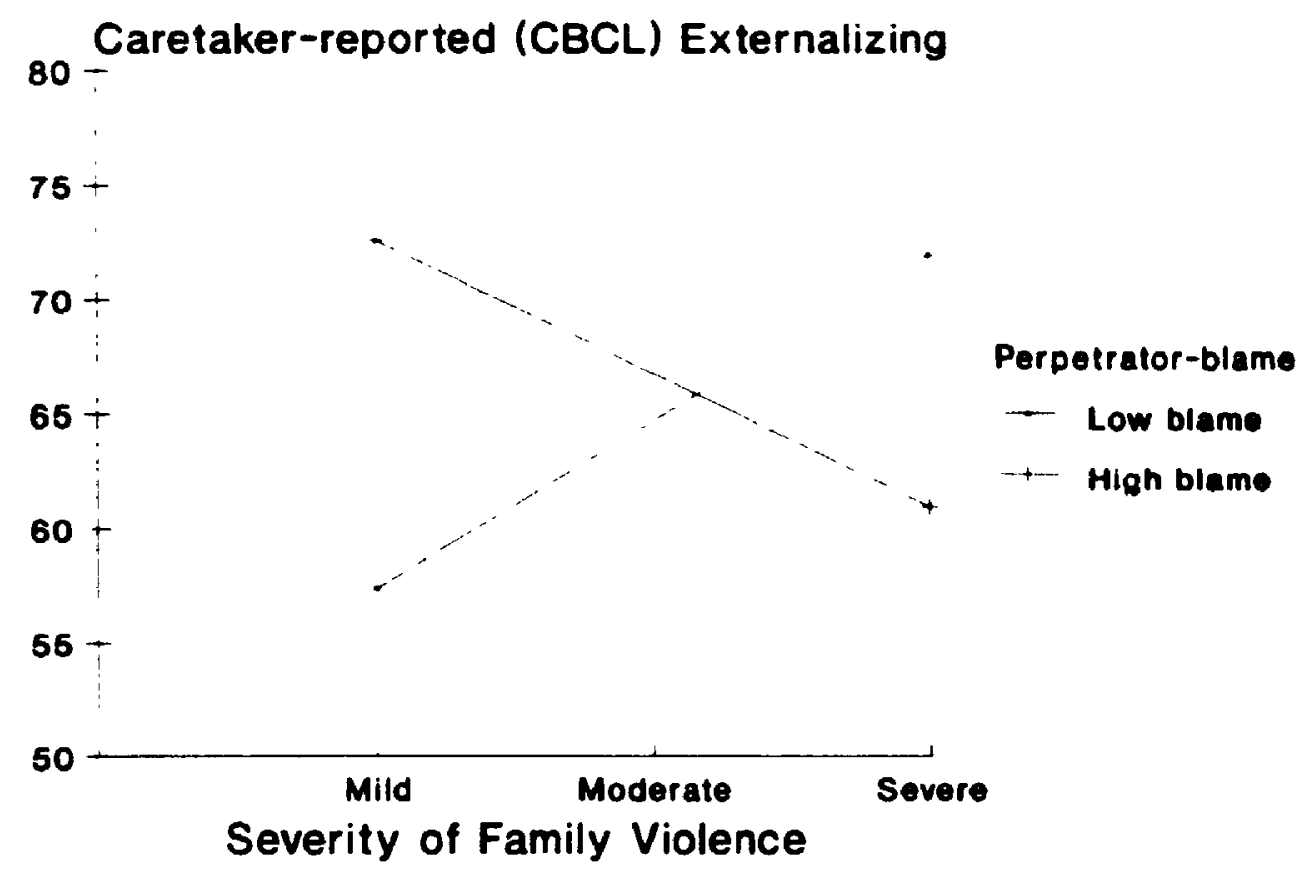

$\mathbf{N} \cdot 72$

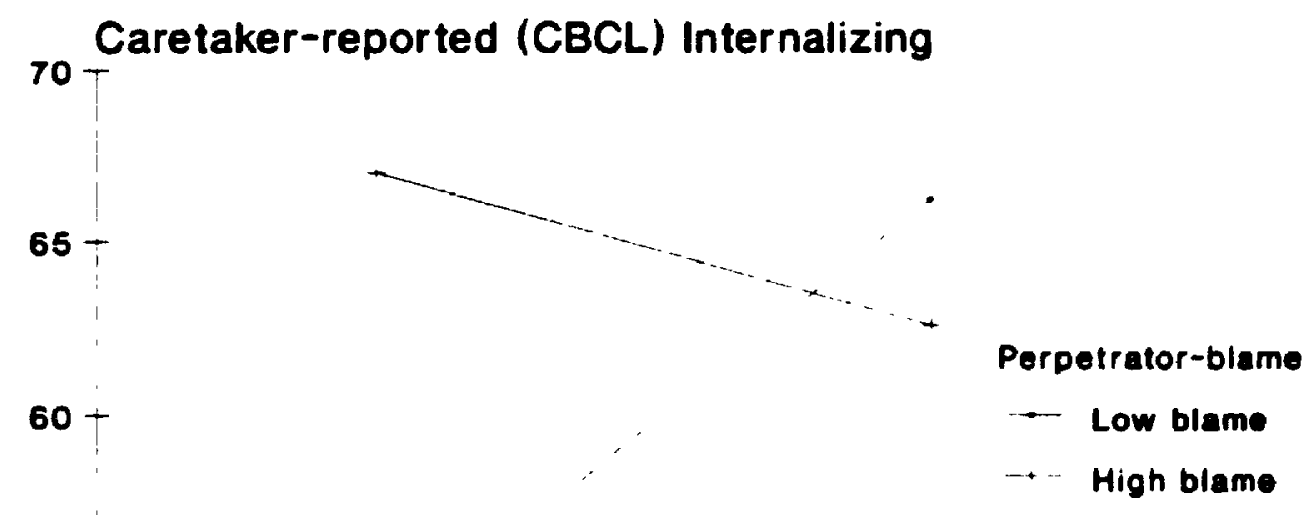

$55-$

Mild
Severity of Family Violence

N. 72 
transform the perceived severity of the wife assault into self-perceived probleme with aggression and delinquency. Similarly, self-blaming affect for hostile maltreatment mediated self-reported internalizing, but moderated caretaker-reported externalizing - again, with incongruent emotione relating to greater observed disturbance. In general, the results suggest that attributions act as mediators when predicting selfreport measures of adjustment, but moderators when predicting caretakerreport measures. 


\section{CEAPIER IV - DISCUSSION}

The results will be discussed in several major sections. First, the divergence between reporting sources will be examined. Second, the results relevant to social cognitive theory will be considered. Third, the results relevant to the role of attribution will be reviewed. Finally, the implications for research and clinical practice will be discusged.

Divergence of Reporting Sources: Comparing the Sociological and Subjective Approach to Defining Maltreatment

The present study conceptually defined maltreatment using the sociological and the subjective approaches. Maltreatment was operationally defined using three reporting sources: the social worker, the trained judge of case records, and the adolescent him or herself. The results sugge日t that there are important conceptual and methodological differences in the definitions employed by each reporting source and that these differences have important implications whon investigating the impact of maltreatment on adjustment.

Overall, there was more agreement than disagreement regarding tho presence of various types of maltreatment in the backgrounds of protection agency youth. Occurrence judgements made by social workera and file judges were often highly concordant. The extent of concurrence of official sources with adolescents varied with the type of abuse under examination. Official sources and adolescents concurred the most regarding the presence of sexual abuse, and the least regarding neglect.

There were also considerable discrepancies between reporting sources. Two kinds of discrepancy were examined: disagreement regarding maltreatment occurrence, and disagreement regarding maltreatment severity. With respect to occurrence, adolescents reported more physical abuse but less family violence, emotional maltreatment, and 
neglect relative to the official sources. Disagreement regarding severity was evident for all maltreatment types. When the sample was restricted to those individuals for whom all sources agreed the maltreatment occurred, the correlation among severity ratings was remarkably low.

There are geveral reasons why official and subjective estimates of maltreatment might disagree. Official sources often have access to information regarding experiences in the youth's infancy and toddlerhood that the adolescent may not remember. Primarily, each reporting source may employ overlapping conceptual definitions that nevertheless have unique elements. The different pattern of intercorrelations among maltreatment types found between official sources and adolescents suggests that adolescents construct or conceptualize their experience differently than professionals. Adolescents view maltreatment along the dimension of inadequate parenting: their ratings of physical

maltreatment covaried with neglect and emotional abuse. However, social workers and file judges appeared to view maltreatment along a dimension of aggression: their ratings of physical, verbal, and spousal aggression covaried. Both professionals and adolescents regarded sexual abuse as unlike other maltreatment types.

Reporting sources may also employ different heuristıcs, standards, or thresholds for evaluating what is considered maltreatment. Mandated by law to focus on child protection, agency personnel and their records will reflect statutory requirements when determining whether maltreatment occurred. Moreover, they will define severity in relative terms. That is, they will compare a given case to others they have seen. Lacking this basis for comparison, victims will evaluate whe'ser an event qualifies as maltreatment by the distinctiveness and painfulness of the experience. For example, adolescents concurred with profeseionale $\pi$ set often regarding the occurrence of sexual abuse, perhaps because all sources consider this maltreatment type distinctive. 
However, agreement regarding sexual abuse geverity was low. Examination of the distribution of self-reported sexual abuse shows that virtually all sexual abuse victims regarded their experience as severe. Thus, even when the criteria for judging occurrence ig gimilar between sources, the heuristic for judging severity may differ. Adolescents reported greater and more severe experiences with physical maltreatment than did agency sources. This finding may result from the more stringent standards for physical abuse employed by professionals. Some protecticn-related lawg emphasize physical maltreatment that leaves marks or injuries; lesser types of maltreatment may not be recorded by workers. Similarly, if a family is serviced for reasons other than physical abuse, this kind of information may be superseded in favour of more immediate casework concerns. The possibility that adolescents were exaggerating their maltreatment experiences was not supported by the relative minimization they exhibited with most other types of abuse. Moreover, previous research has found minimization of physical abuse to be common among self-report. of agency subjects (Femina, Yeagt., \& Lewis, 1990). Adolescents may include a broader range of parental behaviors (e.g., slapping, spanking; in their definition of phyoical maltreatment.

Relative to professionals, adolescents under-reported the occurrence of emotional maltreatment and neglect. Verbal hostility has been found to be chronic among troubled families (Burgess \& Conger, 1978; Patterson, 1982). Some protection agency youth may fail to 8ee such interaction as abusive or even distinctive. Similarly, conditions of neglect and deprivation may be so pervasive that some victims are unaware that better parenting exists. Agreement regarding emotional abuge severity may be low because of the relatively greater sophistication of professionals' concepts of emotional maltreatment. Professionals may include such subtle but damaging dynamicg as parentchild role reversal and exposure to criminal influences in their 
definition of emotional abuse - patterns that some victims may not recognize. That is, whereas adolescents may reflect on hostile verbal exchange, the social worker and file judges judge may concentrate on dysfunctional and chronic family patterns. Similarly, the lack of agreement regarding neglect severity may be due to differing breadth in definition. Professionals may use specific statutory definitions to rate neglect, whereas adolessents appeared to have included emotional neglect and rejection in their definition. The fact that file judges and social workers disagreed between themselves most often regarding the occurrence of neglect illustrates the nebulous nature of this maltreatment type.

Approximately 178 of this sample denied the presence of documented domestic violence in their backgrounds. Even when teens and professionals agree that family violence occurred, their concordance regarding severity was virtually non-existent. Some oubjects may have denied or minimized the family violence for fear that their parent would be criminally charged. Others may have regarded such marital behavior as normative. Professionals quantified family violence in terms of injury or severity of the violent act; adolescents may have quantified it in terms of chronicity. Further multimethod research on the perceptions of teens regarding family violence is warranted.

Divergence between the reporting sources may alsc be due to sources of error with each source. A variety of factors can influence the accuracy of each reporting source and hence the extent to which they will agree. Social worker ratings can be undermined by the rapid job turnover among caseworkers, such that current workers are not familiar with the early history of a case. Also, workers may be most concerned with service provision to families on their caseload and 1 ess preoccupied with previously documented abuse. As a worker's caseload increases, it becomes more difficult to know each case intimately. Also, ongoing involvement with families may also influence how "abusive" 
a family is regarded by the worker. That is, current receptivity or resistance of families to service may influence worker perception of a child's background. Ratinge by trained judges also have their pitfalla. Case files often do not contain detailed information on the nature or degree of certain abuse types. This is particularly true for more subtle kinds of maltreatment such as emotional maltreatment. Because exposure to wife assault is not itself legally actionable as a protection issue, case files often do not describe the specific acts of family violence. Global eeverity ratings can therefore become subjective and prone to error and halo effecta from other documented abuses. Often, files contain scant information on those familiee who are relatively new to the agency. Information on siblinge can be rare when the investigation and casework have focused on only one child in the family. Retrospective reports provided by adolescents are influenced by the limitations of memory, danial, and other biaser.

Taken together, the results euggest that the conclusions one drawe regarding maltreatment occurrence and severity depends upon whether one employs a sociological or oubjective approach to the measurement of maltreatment. Researchers should be aw:re of the limitations of the methods they use and recognize that the identification of abuse occurrence and severity will vary with the reporting source and the type of maltreatment under consideration.

Hypotheses Relevant to Social Cognitive Theory The Findings of the First Three Hypotheses Regarding Maltreatment and

\section{Adjustment}

The firgt three hypotheses concerned using maltreatment severity to predict maladjustment. Overall, the results affirm that maltreatment types are best considered in combination. Relatively weak associations are obtained when examining the univariate correlations of epecific maltreatment types and symptomatology. Prediction is lmproved, and the 
rolo of opecific maltreatment types is clarified, when maltreatment types are considered simultaneously (i.e., in regression analyses).

The first two hypotheses concerned differential prediction of the relationship between specific maltreatment experiences and -ymptomatology. Two approaches to evaluating the relationship between a specific maltreatment type and symptomatology are relevant to the discuseion of these hypotheses: the univariate correlation, and the squared semipartial correlation. The univariate correlation describes the association between a maltreatment type and behavior problem as it exists in nature, whereas the squart memipartial correlations describes it when the influence of the covariates (age, sex, SEs, receptive vocabulary, and stressful life events) and other maltreatment types is etatiotically controlled. Information from both approaches will be integrated in the discussion of the hypotheses. Hypothegis One: The Association Between Maltreatment Types and Externalizing and Internalizing Symptomatology

The first hypothesis predicted that aggressive maltreatment types (1.e., physical abuse, emotional abuse, exposure to family violence) would be associated with externalizing symptomatology, whereas nonaggressive maltreatment types (i.e., neglect, sexual abuse) would be associated with internalizing symptomatology. The present study found partial support for the hypothesis that the topography of adolescents. experiences will predict externalizing and internalizing disorders. Generally, maltreatment ratings made by adolescents were more strongly associated with adjustment than maltreatment ratings made by official sources.

The univariate correlations between each maltreatment type and symptomatology suggest that most maltreatment types were modestly but gignificantly associated with internalizing problems. However, the emipartial correlations indicated that differential prediction of externalizing symptomatology was evident when the co-occurrence of 
maltreatment types was taken into account. The univariate correlations of physical and emotional abuse with externabizing problems were relatively $\mathrm{kn}$, however, when these maltreatment types are considered in combination, their emipartial correlations were larger than their univariate correlations. This was particularly true for boys.

Physical abuee. For phyaical abuse, official ratings were not associated with any adjustment measure. When examining univariate correlations, adolescent ratings of physical abuse were most often associated with internalizing problems. Hoivever, when the influence of the covariates and other maltreatment types was taken into account, this relationship was no longer apparent. Rather, under those conditions, physical abuse accounted for significant variance in self-reported (YSR) externalizing problems. The results suggest that emotional abues acted as a suppressor variable: that is, when emotional abuse was considered simultaneously, the predictive potency of physical abuse was enhanced. The notion that emotional abuse and physical abuse act in tandem to contribute to externalizing problems has been demonstrated in other studies (e.g., Viseing et al., 1991).

Emotional abuse. Emotional abuse was the maltreatment type demonstrating the greatest association with adjustment. It had the strongest bivariate association with measures of adjusinent for both official and adolescent maltreatment ratings. Controlling for covariates and all other types of maltreatment, emotional abuse consistently accounted for the largest amount of unique variance in sejf-reported adjustment. Emotional abuse was particularly potent anong females.

Emotional abuse also appeared to influence the relationship between other maltreatment types and adjustment. When emotional abuse was controlled, "nonaggressive" maltreatment types no longer predicted internalizing problems. When controlled, it enhanced the predictive potency of physical abuse and, for boys, family violence. If omotional 
abuse was deleted from the equation, the other "aggressive" maltreatment types lost their predictive power. These findings underscore the importance of emotional maltreatment to adjustment and replicate the findings of other studieg that have controlled for physical abuse (Briere Runtz, 1988; Vissing et al.. 1991).

Family violence. When examining the results for males and females combined, ratings of exposure to family violence were not associated with any adjustment measure. Family violence did not add unique variance to the prediction of adjustment when considered in the context of the covariates and other maltreatment types for the overall aample, although it did for boys alone.

Neglect. Official ratinge of neglect did not covary with any adjuetment measure. Although neglect was associated with self-reported (YSR) internalizing at the bivariate level, it did not account for unique variance when controlling for the covariates and other maltreatment measures.

Sexual abues. As predicted, sexual abuse was most often associated with internalizing symptomatology. For both official and adolescent sources, sexual abuse was significantly correlated with caretaker-reported (CBCL) internalizing problems. When examined in the context of the covariates and other maltreatment types, sexual abuse accounted for unique variance in Anger Arousal Intensity problems. The association between sexual abuse and internalizing problems has been demonstrated in previous research (for reviews, see Beitchman et al., 1991; Browne Finkelhor, 1986; Friedrich et al., 1986).

Hypothesig Two: The Association between Agaressive Maltreatment Types and Externatizing Problems in Males

The hypothesis that aggressive types of maltreatment are more predictive of exterializing problems for males received some support. Uaing adolescent ratings of maltreatment, the asoociation between family violence and caretaker-reported externalizing was significantly greater 
among males than females. The suppressor variable relationships founc for the overall ample were even more apparent among males. For boys, none of the "aggressive" maltreatment types had a gignificant bivariate association with externalizing problems. However, when controlling for all other maltreatment types, physical abuse, Eamily violence, and emotional maltreatment each made unique contributiong to variance in self-reported (YSR) externalizing among boys. That is, relative to their univariate associations, the potency of the "aggressive" maltreatment types in the prediction of externalizing problems was increased. Moreover, physical abuse and family violence accounted for unique variance in YSR scores among males, but not among females.

Support for this hypothesis was also found in other analyees. When the sample was restricted to those boys who identified themselves as witnesses to family violence, perceived severity accounted for significant amounts of variance (approximately 15 to 258 ) in both selfreported and caretaker-reported behavior problems. These results suggest that family violence may have a greater impact on boya relative to girls. The : obust relationship between adjuatment and witnegsed wife assault in boys has been found in several previous atudies using different methods (for reviews, see Jaffe et al, 1990; Fantuzzo : Lindquist, 1989 ).

Hypothesis Three: The Increment in Prediction due to Maltreatment Iypes

It was predicted that the maltreatment ratings taken as a set would account for a significant amount of variance in eymptomatology, when controlling for the influence of sex, age, SES, receptive vocabulary, and stressful life events. This hypothesis received modest support when adolescent ratings were employed as predictors. When controlling for the influence of five covariates, and under stringent Type I error protection, adolescent maltrearment ratings accounted for approximately 108 to 208 of the variance in internalizing and externalizing symptomatology. The hypothesis was not supported when 
ratings from file judges's or social workers were uged. When the relatively small univariate correlations between gpecific maltreatment types and adjustment variables are considered, the strorger results obtained with a multivariate approach confirm the importance of regarding maltreatment types in combination. After all, maltreatment types occur in combination in uature.

Overail, bubjective estimates of victimization appear to be more predictive of behavior problems than objective estimates. Why were adolescents' perceptions of their maltreatment histories more predictive of adjustment than those of professionals? Some of the predictive potency of self-reported maltreatment may be due to shared method variance with self-reported adjustment measures. However, that is not the whole story: adolescents' reports of maltreatment were aleo associated with caretaker-reported behavior problems. Previous research has emphasized that subjective appraisals of life events are critical to adjustment generally (e.g., Lazarus \& Folkman, 1984). In the stress literature, it has been demonstrated that individuais' appraisals of streseor are more strongly associated with symptomatology than are estimates made by "expert" third parties (LazaruB, 1974; Affleck et al., 1985). Victims are in a better position to evaluate the impact of a stressful experience and may incorporate impact judgements into their definition of maltreatment. Indeed, the average correlation between severity ratings and the AFMI item "this rvent had a bad effect on my Iife" was . 46 .

\section{Implications for the Differential Preciiction of Externalizing Versus}

\section{Internalizing Behavior Problems}

could externalizing and internalizing problems be differentially predicted by "aggressive" and "nonaggressive" maltreatment types? The

\footnotetext{
"File judge ratings accounted for a significant increment in variance when predicting CBCL Total Behavior Problem scores (see Appendix J).
} 
answer depended upon whether maltreatment types were correlated to the adjustment measures singly, or whether they were taken in the context of the covariates and other maltreatment types. Emotional abuse was consistently and robustly associated with both types of symptomatology in both the univariate and multivariate context. Enotional abuse appeared to potentiate the reiationship between physical abuse and externalizing problems. Although physical abuse and, for boys, family violence were not associated with externalizing when regarded alone, they accounted for ignifican variance when emotional maltreatment was taken into account. The relationship between the "nonaggressive" maltreatment types and internalizing problems vanished when emotional maltreatment was controlled. These results suggest that differential prediction of externalizing problems from "aggressive" maltreatment types generally, and among boys in particular, is best obtained when the co-occurrence of maltreatment types is taken into account.

How can these results be understood? The problem may not lie in the data, but in the hypothesis itself. The distinction between "aggressive" and "nonaggressive" maltreatment types may represent misplaced emphasis. As the information from different reporting sources suggests, adolescents may not perceive maltreatment along the "aggressive-nonaggressive" continum perceived by officials (and by researchers!). For adolescents, reported ratings of physical abuse, emotional abuse, and neglect covaried. This pattern suggested that adolescents viewed these maltreatment types as overlapping a core construct of personal rejection by a caretaker. Emotional maltreatment is the type that may begt represent this construct. The univariate association of physical abuds and neglect. with internalizing problems may be duc to their shared variance with emotional maltreatment. When the veriance attributable to emotional maltreatment is taken into account, physical abuse and neglect no longer add to the prediction of 
internalizing problems. In the presence of emotional abuse, physical abuse predicts externalizing problems.

Another factor may have obscured the differential prediction of internalizing and externalizing symptomatology in some instances. Achenbach and Edelbrock (1983) emphasize that internalizing and externalizing problems covary significantly $(\underline{\underline{r}}=.70)$. That is, adolescents who are elevated on one scale are likely to be elevated on the other. In the present sample, the two scales were indeed correlated (.60 for the CBCL, .56 for the YSR). Because of this covariation, it may have been difficult to predict variance that was unique to internalizing and externalizing problems, as opposed to adjustment generally.

\section{Implications for Social Cognitive Theory}

The pattern of results, as well as the potency of emotional maltreatment, may be explicable in terms of Bandura's (1989) social cognitive theory. In accordance with this theory, there are two "internal" mechanisms by which maltreatment experiences could result in adjustment problems: disturbance in self-regulation through observational learning, and disturbance in affect regulation through vicarious emotional arousal.

According to social cognitive theory, modelling influences act primarily as instructors. The child develops his or her capacity for self-reinforcement through experiencing the rewards and punishments meted to them by caregivers. When these are harshly or arbitrarily administered, as they are in maltreatment situations, the child will learn to reinforce themselves in a similarly non-accepting mann $r$. The maltreating parent essentially teaches the child how to think about him or herself. Physical and emotional maltreatment would be most relevant to this process, as both maltreatment types have their origins in parenta! :riticism. Moreover, because similar models produce the most 
powerful observational learning effects, the critical behavior of the same-sex parent has the most impact on self-criticism. Previous research has demonstrated an association between self-criticism and retrospective reports of parental behavinr (McCranie 6 Bas8, 1984 ). Prospective longitudinal research (Koestner, Zuroff, \& Powers, 1991) has ouggested that parental rejection at age 5 is associated with selfcriticism at age 12. These results also showed that maternal rejection was predictive of later self-criticism in girls, whereas paternal rejection was predictive among boys. The socialization hypochesis might explain why emotional maltreatment had the greatest and most consistent contribution to internalizing problems. Relative to other maltreatment types, the denigration implicit in emotional maltreatment may represent a more direct and therefore more potent attack on the self.

social cognitive theory also emphasizes that observing aggressive behavior can result in the acquisiticn and expression of such behavior. When considered together, physical abuse, emotional maltreatuent, and, for boys, family violence were predictive of externalizing problems. This finding elupports the notion that males may be "primed" to learn aggressive behavior (Bussey \& Bandura, 1984). It also underscores the direct modelling tenets of social cognitive theory. One might also specslate that the direct modelling of aggressive parent behavior leads to aggressive behavior among children whose self-regulation has been undermined by concurrent emotional maltreatment.

Social cognitive theory also emphasizes the role of vicarious emotional experience in the socialization process. Parents' emotional reactions to cues in the environment tend to elicit emotional arousal in child observers. The child will "absorb" the model's reaction; when the child subsequently encounters the same or a similar environmental cue, he or she will reexperience this affect. Thus, affective reactions can be classically conditioned to environmental stimuli. As an extension of this reasoning, the child can vicariously acquire the caretaker 
affective reaction to his or her own self. The child victim may vicariously experience the negative affect the maltreating adult directs at him or her. He or ghe learns to feel negatively about him or herself. The affective hostility implied by emotional maltreatment may explain the greater potency of this maltreatment type. Thus, according to social cognitive theory, maltreated children will grow to internalize the critical voice of the maltreating parent. This will result in cognitively-based self-deprecation that subsequently influences eymptomatology. Vicarious absorption of and identification with the negative emotion communicated to the child by the maltreatment experience will result in a disturbance in the child's self-syetem, whereby the self becomes charged with negative affect. Exposure to and the inte-nalization of intense negative affect, particularly if it is self-directed, can overwhelm the child's capacity to regulate auch affect. Maltreated children are also exposed to models who themselves fail to appropriately regulate negative affect. These influences can result in a digturbance in the child's ongoing affect regulation. Taken together, all these socialization influences enter into a final common pathway by which maltreatment interferes with the victin's selfreinforcement and self-directed affect, and which can eventually lead to internalizing problems. If the child has also observed aggressive parent behavior, children with difficulty regulating negative affect may be more prone to display the externalizing behaviors they have witnessed. Poor affect regulation may potentiate aggressive acting out among children who have been exposed to or are recipients of violence. These social-cognitive principles may also explain the relatively greater impact on females of self-reported maltreatment in general, and emotional maltreatment in particular. Research indicates that females have a greater capacity for vicarious emotional arousal than males. Hoffman (1979; reviewed sex differences in empathy fo: 14 samples of children. He found that males and females were equally adept at 
perspective taking (i.e., assessing how someone else feels), but that "in girls, awareness of other's feelings is apt to be accompanied by vicarious affective response" (p. 716). Similarly, cohn (1991) also found a female advantage in emotional perspective taking in hig metaanalysis of personality development studies. If females are "primed" to absorb negative affect, they are more at rigk for developing internalizing problems when maltreated.

Like the original social learning theory, social cognitive theory emphasizes that children are more influenced by same-sex models. The majority of the sample was comprised of single-mother families; thus, females were most often maltreated by mothers. This may also explain the potency of family violence among those boys who identified themselves as witnesses. When exposed to wife assault, male witnesses are observers and absorbers of negative affect from a same-gex model.

In summary, the findings highlight the importance of the reporting source when measuring maltreatment. Subjective estimates of maltreatment were more potent than objective estimates provided by researchers or social workers. Maltreatment added significantly to the prediction of self-reported behavior problems, when controlling age, sex, SES, receptive vocabulary, and stressful life events. The prediction of adjustment depended upon whether maltreatment typer were regarded singly or conjointly. Considered singly, maltreatment predicted internalizing problems. Considered together (along with the covariates), "aggressive" maltreatment types predicted externalizing problems, particularly among boys. Emotional maltreatment was especially predictive of adjustment. The findings are consigtent with social cognitive theory. 
Maltreatment Severity, Attribution, and Adjustment The Nature of Blame in Maltreatment victims

The present investigation exanined several questions. It explored whether victims make behavioral or characterological self-blame attributions spontaneously. It examined how blame attributions could be quantified. It replicated previous studies by examining the relationship between self-blame, other-blame, and severity. The study probed whether information about blame-relevant attributions added to the prediction of symptomatology above the prediction afforded by information on maltreatment severity. It also examined whether blamerelevant attributions differentially predicted internalizing and externalizing behavior problems, and whether this was achieved using a mediator or moderator mechanism. The results underscored the sophistication of attributional processes and highlighted the need to integrate complex influences (e.g., maltreatment type, gender) into our understanding of the role of attribution of blame among victims. content of spcntaneous caugal Attribution

When asked to identify the major cause of the maltreatment, most victims identified aspects of the perpetrator. When probed regarding their personal contribution, the self-relevant causal explanation varied with the maltreatment type. For physical or emotional maltreatment, "misbehavior" or "defiance" were most often cited. For family violence and sexual abuse, personal failure to prevent the experience were most often described. Across maltreatment types, victims maintained that they could not have controlled the cause of the maltreatment (referring to the offender), but could have "controlled" the experience by avoiding it. Virtually no subject attributed the victimization to negative aspects of his or her character, spontaneously or otherwise. These results replicated previous studies in which victims distinguished between different kinds of responsibility, blame, and control. Abbey (1987) also found that rape victims attributed primary responsibility to 
the rapist, attributed "avoidability" responsibility to themselves, and did not express either characterological or behavioral blame.

These findings have implications for research on victim selfblame. Previous work has emphasized the distinction between behavioral and characterological blame, assuming that victims accept primary responsibility for their victimization. According to shaw and sulzer (1964), "foreseeability responsibility" is attributed when individuals are held responsible for aftereffects they should have foreseen oven if the outcomes were not intended. The content of victims' responses suggest that they did not accept primary responsibility for the maltieatment, but accepted "foreseeability" responsibility for it. This distinction has relevance for both clinical practice and research. It also ouggests that the current emphasis on the distinction between behavioral and characterological blame in victimization research may be misplaced.

\section{Attribution Subscales}

The present investigation demonstrated that blame attribution in victimization is complex and multifaceted. "Blame" is not a unitary construct: rather, it is comprised of several elements or dimensions. Evidence of the sophistication of the self- and other-blame process arises from the approach to quantification taken by the Attribution for Maltreatment Interview. Five factors emerged on the AFMI: self-blaming cognition, self-excusing, self-blaming affect, perpetrator-blame, and perpetrator-excusing. AFMI subscales were obtained using confirmatory factor analysis, using higher-order constructs to highlight response patterns (Bradbury \& Finchafu, 1991; see Appendix A for a description of the development of the AFMI). The obtained structure underscores the theoretical ontogeny of self- and other-blane and excuse constructs described in the theoretical literature. In support of the arguments of entailment theorists (Shaver, 1985; Finsham Bradbury, 1987), who argue that attributions of blame are contingent on a series of other 
judgments, the self-blaming cognition factor comprised items relevant to internality, control, and foreseeability as well as responsibility and blame. As predicted by Shaver (1985) and Excuse theorists (Snyder Higgins, 1988), who have emphasized the role of excuses in the blame process, self- and other-justification emerged as distinct factors. In accordance with theory and regearch suggesting that self-blaming affect is secondary to self-blaming cognition (Wollert \& Rowley, 1987), selfblaming affect emerged separately from cognitions about self-blame and/or self-excusing. The fact that there were three self-directed factors and two perpetrator-directed factors is consistent with the suggestion by some attribution theorists that self-directed attributions are more complex than other-directed ones (e.g., Heider, 1958, Jones \& Nigbett, 1974). In support of their validity, the factor structure underlying these attributional dimensions was robust across maltreatment types.

Severily, Self-blame, and Perpetrator-blame

Previous theory and research have suggested that as severity of maltreatment increases, perpetrator-blame will increase and self-blame will decrease (Herzberger et al., 1981; Holtzworth-Munroe, 1988; Tennen 4 Affleck, 1990; Ney et al., 1986). Several theorists have assumed that self-blame and perpetrator-blame are inversely related (e.g., Peterson \& Seligman, 1983). In the present study, maltreatment severity was strongly and consistently associated with perpetrator-blame across maltreatment types. However, an inverse reiationship between self-blame and severity, and between self-blame and perpetrator-blame, was evident only for hoatile maltreatment.

Unlike the other maltreatment types, hostile maltreatment (i.e., physical and emotional abuse) occlirs in the context of discipline (R. Herrenkohl et al., 1983). Children's tolerance for punishment is related to their perception of their own "deservingness" for misbehavior (Catron \& Masters, 1991; Rausch \& Kutson, 1991). As the severity of 
physical or emotional maltreatment increases, children may cease to see a correspondence between their behavior and the inflicted punishment. The child'a perception of the Beverity of parental treatment will increase to the extent that parental discipline exceeds the child"s perception of his or her "deservingness" for punishment. Similarly, the child's sense of the perpetrator's wrongdoing may increase as this threshold is exceeded.

For other maltrestment types, there was no association between self-blame and severity or perpetrator-blame. This may be due to the nature of the "gelf-blame" expreseed for these maltreatment typea. Ar the content analysis indicated, victims of family violence, sexual abuse, and neglect blamed themselves for their failure to avoid or prevent the events. Self-blame for an act of omiasion can exiet independently from perpetrator-blame and maltreatment severity. No matter how much the offender was at fault, and no matter how hurtful his or her behavior, one can continue to ruminate about how one might have avoided the experience. The finding that self-blame and perpetratorblame are uncorrelated auggeste that these constructe are not necessarily related in the "hydraulic" fashion indicated in previous social psychological theory. The findings underscore the importance of measuring self- and other-blame separately, and eschewing forced-choice or polarized formats to messure causal or responsibility judgements.

Self-blame and perpetrator-blame were either uncorrelated or positively related to self-excusing or perpetrator-excusing, respectively. They were not inversely related, as one might expect. There are several possible explanations for these findings. One might expect that as self-blame increases, the motivation to generate belfdirected excuses would also increase. Excuse theory (Snyder * Higgins, 1988) suggests that self-blaming thoughts will threaten self-esteom, and that this threat will stimulate the search for excuses. Because people are often motivated to avoid blaming aignificant othere (Heider, 1958; 
Jones \& Davis, 1965; Snyder Higgins, 1988; Tennen Affleck, 1990), the same process might govern children's excusing of parents. The positive associations between blaming and excusing may also be due to the nature of the items in the blame and excuse subscales. Items in both subscales emphasize the individual's behavior and his or her causal contribution to the event. For example, the blame composite items relevant to a behavior le.g.. I <or perpetrators should be blamed for my <or his/her> behavior") may share variance with excuse-relevant items addressing the same behavior (e.g.. "something made me <or perpetrators do it"). Again, the reaults highlight that blame and excusing may not relate to each other in a simple fashion, and emphasize the sophistication of blame processes.

Hroothesig Four: Additive value of Attribution to the Prediction of Adjustment

The hypothesis that attributions would account for a significant amount of variance in eymptomatology above and beyond that accounted for by maltreatment severity was supported. Attributions predicted selfreported but not caretaker-reported behavior problems. When controlling for the perceived severity of the maltreatment, and controlling for Type I exror, attributions explained approximately 98 to 318 of the variance in externalizing problems, and approximately 158 to 468 of the variance i1) interralizing problems. The Additive Value of Self-blaming Affect

Two items comprised the self-blaming affect composite ("When you think about your role in what happened, you feel angry" and "When...you feel sad"). As such, these items represent feelings about cognitions, and are conceptually and empirically distinct from purely cognitive attributions. The emergence of this construct from other factors on the AFMI is supported by research demonstrating that adolescents react to painful events with an "emotion blend" of sadness and anger (Harter \& 
Whitesel1, 1991; Renouf \& Harter, 1990; P. Shaver, Schwartz, Kirson, \& O. Conner, 1987 ).

Self-blaming affect had the greatest association with symptomatology. Relative to the other attribution composites, it yielded the strongest and most consigtent correlations with selfreported internalizing across all maltreatment types. Even when controlling for maltreatment severity and all other attributions, eslfblaming affect accounted for significant amounts of unique variance in self-reported (YSR) internalizing problems for all maltreatment typea, ranging from 48 (family violence) to 198 (aexual abuse). It was aleo associatad with self-reported (YSR) externalizing (108) and anger arousal problems (138) for sexual abuse. Thus, self-blaming affect had muze robust asenciations with internalizing problems.

Contrary to prediction, eelf-blaming cognition was not aesociated with any measure of internalizing problems. It remained significant in both the univariate and multivariate context only for the prediction of self-reported (YSR) externalizing among neglected females. Otherwise, significant univariate relationships between self-blaming cognition and adjustment vanished when the influence of severity and other attributions were controlled. Self-blaming cognition and belf-blaming affect were significantly correlated for all maltreatment types except hostile maltreatment.

The pattern of results obtained in the present atudy suggests that self-blaming affect was more important to adjustment than self-blaming cognition. Several authors have suggested that studies linking causal attribution to adjustment have actually been tapping into self-blaming affect (Mittelstaedt \& Wollert, 1991; Wollert et al., 1983; Wollert 4 Rowley, 1987). The equivocal results of previous studies in the victimization literature regarding self-blame (e.g., Gold, 1986; Meyer G Taylor, 1986) may have been due to this conceptual confusion. By measuring feelings that arise on the basis of cognition dietinctly from 
the cognitions themselves, the current study was able to examine the relative contribution of each. The results suggest that one's affective reaction to thinking about one's personal role in one's own maltreatment can contribute significantly to symptomatology - that is, feeling one is to blame can be relatively more important to adjustment than thinking one is to blame. The robust and consistent patterns obtained with the self-blaming affect composite indicate that it is a cognition/emotion blend worthy of fucure study in blame attribution research.

\section{Gender Differences in Prediction}

Generally, the adjustment of females was better predicted by the addition of attributions than was the adjustment of males. Attribution was important for all types of maltreatment for females. Moreover, the amount of variance accounted for by att: sutions was often relatively larger for females than males. When restricting the sample to semales, the amount of variancs in self-reported (YSR) internalizing accounted for by attributions was larger than for the overall sample: 18 for reglect and hostile maltreatment, 25 for family violence, and 46: for sexual abuge.

Females had higher levels of batterer-blane and self-blaming affect for family violence than males; otherwige, there were no differences in the level of attribution between the sexes. This general absence of main effects suggests that the attributions of females were not quantitatively different from those of males; rather, females' attributions were more predictive of adjustment. These results emphasizr; the importance of attributional processes in the relationship between victimization and symptomatology among females.

Why would attribution for victimization be more relevant for females? Examination of the univariate correlations and squared semipartial corzelations linking attribution to adjustment showe that self-blaming affect was more associated with adjustment in females than males. Because self-blaming affect captured the lion's share of 
variance in symptomatology, it is tre variable that contributed the most to the different results fo: males and femalea. Previous research has indicated that females are generally more ruminative than males in response to distressing emotion, and consequently are more prone to affective diaturbance (for a review, see Nolen-Hoeksema, 1987 ). Relative to males, females' self-blasing affect may be more likely to potentiate ruminative search and internaliz:ar problems.

Anong males, attributions for neglect accuunted for 35 of the variance in Belf-reported (YSR) internalizing problems. This relationship was due to the size and etrength of the inverge relationship between perpetrator-blame for neglect and self-reported (YSR) internalizing. Among males, blaming the neglector was associated with fewer irternalizing problems. Relative to females, males may bo sociaijzed to have a greater sense of entitlement, such that being ignored or not paid attention to merits more anger from them. Examination of the intercorrelations between attributions for neglect revealed that neglector-blame and self-excusing are correlated for malea but not females. These finding suggest that blaming the neglector may fortify gelf-justification and hence self-esteem in males.

Some gender differences in prediction may be also attributable to statiotical factors. Firgt, there were relatively fewer males in the study, regulting in less power in regression analyses involving males only. For example, for hostile maltreatment, the absolute amount of variance accounted for by attributions was virtually ldent 1 cal to that for females, but did not attain significance. Second, because the impact of family violence severity was so poteıt among males, the residual variance that could be explained was markedly reduced. 
Hypothesis Five: Differontial Prediction of Internalizing and Externalizing using the Mediator or Moderator Model

In accordance with previous literature, it was predicted chat self-blame attributions would mediate or moderate internalizing problems, whereas perpetrator-blame attributions would mediate or moderate externaizing problenis. The differential prediction of internalizing and externalizing problems was achieved when examining mediator relationships. Differential prediction was nic achieved when examining moderator relationships; rather, attributions moderated adjusinent generally. Whether attributions acted as mediators or moderaturg of maltreatment severity varied with the nature of the rriterion measure. Attributions mediated self-report adjusiment measures, but moderated caretaker-reported adjustment measures. Mediator Relationships

Self-blaming attribution. In accordance with prediction, one seif-blaming attriburion mediated between maitreatment and internalizing symptomatology. Self-blaming affect mediated the relationghip between the severity of hostile maltreatment and self-reported (YSR) internalizing among females. When the influence attributable to selfblaming affect was controlled, hostile maltreatment severity no longer had a aignificant relationship to internalizing problems among females. Perpetrator-blaming attribution. In accordance with prediction, one other-blame attribution mediated between maltreatment and externalizing symptomatology. Perpetrator-blame mediated the relationship between the severity of family violence and self-reported (YSR) exterzalizing. This relationship was particularly true among boys. When the influence attributable to batterer-blame was controlled, fanily violence severity no longer had a signif cant relationship to extel lizing problems.

The medidtor model. In the mediator model, all variables are "internal" to the individual. That is, attrabution acted as a mechanism 
or conduit through which the influence of maltreatment geverity was conveyed. The perceived severity of the individual's experience was altered by this internal appraisal, and this transformation contributed to the youth's report of his or her behavior problems. Because batterer-blame has an affective component, and because self-blaming affect is also affect-related, it is tempting to speculate that affect is the basis of the mediator relationship. The degree or extent of the affective arousal occasioned by the maltreatment may subserve the nature of the behavior problems the youth observes in him or herself.

\section{Moderator relationships}

It was predicted that self-blame attributions would moderate internalizing problems and that other-blame attributions would moderate externali. ing problems. Differential prediction was not evident. Selfblaming affect for hostile maltreatment moderated caretaker-reported (CBCL) externalizing problems. Batterer-blame moderated caretakerreported (CBCL) internalizing and externalizing behavior problems. Interegtingly, the attributions that acted as moderators were the same as the attributions acting as mediators. However, whereas the mediators predicted self-reported problems, the moderators predicted caretakerreported problems.

Self-blaming attribution. Self-blaming attributions did not moderate any internalızing problems. However, if externalizing problems were considered the criteria, self-blaming affect moderated the relationship between hostile maltreatment geverity and caretakerreported externalizing problems. Higher levels of observable externalizing behavior problems were evident among youth whose selfblaming affect was not congruent with the severity of the malt tment they described. As might be expected, for youth with low levela of self-blaming afiect, externalizing projlems increased as the severity of hostile maltreatment increased. Among those with high ievels of gelfblaming affect, externalizing problems decreased as perceived 
maltreatment severity increased. Those who claimed little self-blaming ftelings for severe maltreatment fared as poorly as those who had strong gelf-blaming feelings for mild maltreatment.

This pattern of results may be explained by the nature of hostile maltreatment. Physical and emotional abuse usually occur in the context of discipline. The content analysis revealed that most youth saw "misbehavior" to be their role in the maltreating events; hence, selfblaming affect for hostile maltreatment often referred to subjects' feelings of upset about that misbehavior. High leve $s$ of distress regarding a mila disciplinary interaction would be maladaptive. Similarly, feeling little guilt for a serious disciplinary interaction might signal a serious conduct disorder. Adolescents who claimed to have little emotional reaction to their involvement in severe maltreatment may also displaying the "tough" bravado common among externalizing youth. Youth whose affect was appropriately congruent with the maltreatment they experienced (i.e., those who had strong feelings about severe mistreatment or little reaction to mild mistreatment) displayed relatively better adjustment.

Perpetrator-blaming attributior. Perpetrator-blame was predicted to moderate maltreatment severity and externalizing problems. Battererblame was found to interact with maltreatment severity to predict both internalizing and externalizing problems observed by caretakers. The interaction pattern was similar for both types of behavior problems. Batterer-blame attributions that were not congruent with the severity of the family violence degcribed were associated with the greatest symptomatology. Among youth who attributed a low degree of blame to the batterer, behavior problems increased as the severity of witnessed violence increased. That is, youth who did not evaluate the battere:'s behavior as blameworthy were more vulnerable to the impact of witnessing violer.ce. Among those who attributed a high degree of blame to the batterer, behavior problems decreased as severity increased. This 
suggests that those youth who viewed the batterer's behavior as blameworthy thereby inoculated themselves against the impact of increasing severity of violence. This relationship was less marked in the prediction of caretaker-reported (CBCL) internalizing: at more severe levels of family violence, internalizing problems were less gensitive to differences in batterer-blame.

The moderator model. In the moderator model, moderating variables are not necessarily internal to the individual. Rather, they provide clarification regarding the conditions under which prediction between a predictor and a criterion will be achieved. The results indicated that self-blaming affect and batterer-blame that are not congruent with the putative severity of the experience are associated with greater Jevels of overt behavioral probiems. It is worth noting that the predicted CBCL $T$-scores were in the 60 - 70 range, indicating cilnical levels of disturbance. These results are additionally noteworthy in that no mood or method variance is shared between predictors and criter:a. Mediators or moderators?

The results indicated that attributions that mediate self-i aported behavior problems can also moderate caretaker-reported behavior problems. For the mediated relationships, the attributions acted as the conduit through which the severity of the maltreatment xperiences impacted upon subjective distress. For the moderator relationships, the attributiong predicted specific patterns of association between maltreatment severity and objective distress. Victims have access to their own feelings and internal processes, whereas caretakers do not. Perhaps the information provided by caretakern yielded grosser information about the relationship between maltreatment geve:ity and adjustment. Perhaps the caretakers are capturing, from their own perspective, the internal processes suggested by the mediator model. In any case, the results suggest that attributions can act as both 
mediators and moderators, and that the reporting source for Byn.ptomatology may influence which model best applies.

Implications for Clinical Practice and Future Research The results of the present atudy have several implications for clinical practice and future research with victimized children. As the incidence of maltreatment types in the sample indicated, adolescents from a protection agency population typically have experienced multiple maltreatment. In the present sample, over 908 experienced more than one type. "Pure" maltreatment types rarely exist in reality. Future research may need to eschew the "category" approach to maltreatment, in which protection agency youth are compared to nonabused controls. The "official" agency label for service, used so frequently in previous research, can often be an inaccurate and simplistic representation of the actual maltreatment status of many children and youth. It behooves researchers to document thoroughly the maitreatinent histories of potential subjects and to use statistical or design controls (i.e., protection agenry concrol groups) to assess the unique effects of any given maltreatment type. Different prediction patterns obtained when examining maltreatment types singly than jointly suggest that researchers and clinicians must respect the reality of multiple maltreatment. They must be aware that exposure to one tyfe of maltreatment may render the developing child more vulnerable to the effects of other types. Clinicians, therefore, should obtain a complete history of victimization for clients presenting with abuse-related isgues.

The resulta emphasise that the victims' subjective impression of victimization is most predictively important to adjustment. Previous research has generally emphasized objective labels based on officially documented information. The findings imply that relatively more research attention sinould be devoted to comprehending maltreatment from 
the victin's perspective. Studies of maltreated populations would benefit from incorporation of self-report measures regarding perceived maltreatment. This is particularly imperative because most clinicians rely upon the self-report of childhood experiences when dealing with adult clients. To be clinically relevant, issues relevant to the subjective appraisal of maltreatment experiences must be explored. For example, Future studies could address the heuristics victims employ when labelling an event "maltreatment". A host of research questions would surround such an enterprise: What processes govern whether maltreated youth come to view themselves that way (e.g., oocial comparison)? What is the relevance of the maltreatment-context factors (e.g., the identity of the perpetrator, the age of victimization)? What factors are associated with the perception of maltreatment severity (e.g., evaluation of impact)? At what stage of development are these considerations most influential?

Future research might also explore the implications of labeling oneself as "maltreated" for subsequent adjustment. In the present study, many youth denied experiencing neglect, emotional abuse, or family violence despite specific evidence to the contrary. Is this adaptive or maladaptive? Does this represent a genuine lack of awareness, selective memory, or a motivated repression of psychologically threatening information about a loved parent? Although the study indicated that maladjustment increased as perceived maltreatment increased, it did not contrast those who denied documented abuse to those that acknowledged it (sample size considerations forbade such comparisons). It would be interesting to determine both the short and long-range implications of the perception of porsonal maltreatment. Thus, for example, denying severe maternal neglect may serve to protect one from the immediate distress of this awareness; however, sucn dental could have serious imolications for one's own parenting otyle. Ideally, a prospective study could address whether denial or minimization of 
maltreatment in youth translates into poor parenting in the future. This kind of research could help guide cliniciang regarding whether to confront or ally with a client's perspective on inappropriate parental behavior.

The current study emphasized the importance of emotional maltreatment. Thig maltreatment type appeared to be the most predictively potent with respect to adjustment. It also appeared to potentiate the negative effects of physical abuse. In the present study, emotional maltreatment was measured very globally. Perhaps more information could be obtained by exploring victims' perceptions regarding the specific nature of the emotional maltreatment. What parent behaviors are regarded to be emotionally abusive? What behaviors were the most hurtful? Future research should also explore the pathways by which emotional maltreatment impacts upon subsequent adjustment. What are the unique and combined effects of specific emotional abuse experiencee (e.g., yelling, criticizing, unfair treatment)? which is most associated with externalizing or internalizing behaviors? what are the long-term consequences of each for develupment (e.g., for the selfschema in adulthood, for interaction in marriagej? cuinicians must be mindful of the potency of emotional maltreatment. Wich individual clients, they should explore the nature and meaning of the emotional abuse experienced by the client.

The results emphasize the importance of blame attributions, above and beyond the perceived severity of the maltreatment experience. This was particularly tzr for sexual abuse. Attributions accounted for approximately 508 of the variance in internalizing problems among sexually abuged girla. Univariate relationghips between the perceived severity of a maltreatment type and adjustment were often modest, with the kargest not exceeding .49 (258 of the variance). Thus, knowledge of perceived severity alone is often insufficient to understand the individual's experience of abuse. Although exam ning attributions is 
one atep toward this, future research must continue to explore the phenomenology of the abuse experience.

The fincings suggest that there is no single consistent attributional "gtyle" with respect to maltreatment. The low correlations of attribution subscales across maltreatment types, as well as the specificity of the adolescents' spontaneous causal attributions, suggest that attributions vary with the type and context of maltreatment. Research based on learned helplessness theory has umphasized the existence uf an attributional style with respect to victimization. The current findings suggest that researchers and prartitioners should be cognizant of the special asperta of ualtreatment types and not assume that all maltreatment yields a common attributional response. Indeed, the resuits suggest that an individual's understanding of the reasons for hostile maltreatment (physical and emotional maltreatment) are most likely to differ from those for other maltreatment types. Clinicians should be aware of the uniquenese of this maltreatment type when exploring the maltreated client's perceptions of self-blame.

The results also underscore the subtlety and complexity of blame processes in maltreatment. "Blame" can have a variety of connotations. The researcher or clinician ghould take cale to undergtand thoroughly whether victims, in "blaming" themselves, are referring to causal participation, foreseeability responsibility, or self-punitive affect. Characterological blame should not be assumed to be the only insidious blame process. To be maximally effectlve, therapeutic interventions aimed at the cognitive restructuring of self-blame should address the precise kind of "blame" the victim axperiences. Moreover, restructuring therapies that attumpt to alter self-blame by promoting pecpetratorblame (e.g., Hazzard, Celano, 6 Webb, 1993) may not be effective in view of the independence of these constructs for some maltreatment types. Thus, for example, in therapy with child witnesses of wife absault, it 
would be important to stress that they could not realistically have prevented the violence, in addition to stressing that their behavior did not cause it. The moderating relationships found in the present study suggest that emphasizing the wrongfulness and blameworthiness of bsttering may male youth less vulnerable to overt behavioral disturbance.

Previous research and some cognitive-behavioral therapies have focused on victims' blame-relevant cognitions. However, the results particularly emphazized the predictive potency of the affective component of aelf-blane. For research, this finding highlights the need for further exploration of the interface between emotion and cognition in the maltreatment context. Path analytic approaches may help establish the connections between thought and feelings of blame and their gequelae in terms of adjugtment. Clinically, recognition of the primacy of affective diffic lties may assist in eelection of therapeutic techniques aimed at modulation of affect (e.g., relaxation training, gestalt exercises). The finding that self-blaming affect and attribution generally are more predictive of adjustment in women suggests that clinicians should be particularly sensitive to the female client's explanation for maltreatment, and to the affect she displays. Future reeearch could examine additional cognitive and affective heuristics victims might employ when forming blame judgements. For example, how do victims employ covariation information in determining cause and blame (i.e., consensus, consistency, and distinctiveness)? Also, future studies could explore the influence of motivational biases on blame attribution. What does the victim perceive to be the personal or affective consequences of blaming or excusing? What affect or mood atates arise from blaming or excusing? clinically, attention to similar issues would translate into sensitivity regarding the feelings that arise for the client as he or she explores issues of blame in thexapy. 
The study also underscored the importance of language in describing subjective experiences. For example, when probed, several victims reported that they "did not do anything" in the face of the abuse. This reply had different meanings for differenc types of maltreatment. When used in the hostile maltreatment context, this was the victim's way oi his or her misbehavior did not merit the extent of maltreatment. For family violence or sexual abuse, it communicated a regretted failure to prevent the abusive events. For clin.cians, these findings imply that the overt verbal content of victims' statements may be identical, but the emotional connotation or communication may vary. Clinicians must thoroughly explore the victim's aubjective understanding, respecting that the same statement may be accorded different meanings even within the same individual.

Finally, the findings indicate that affect or attributiong that are incongruent with the perceived severity of the maltreatment experience may gignal overt behavioral problems. Victims who minimize the severity of their experiences and/or the strength of their reactions may be at risk for greater disturbance. Such contradictory messagea =or alert the therapist to ongoing inner conflict and are worthy of further exploration.

Subjective maltreatment severity estimates accounted for 10 to 258 of the variance in internalizing and externalizing problems. Knowledge of attribution improved prediction to as much as 50 . Nevertheless, at least 508 of the variance remained unexplained. Other theories and models of adjustment may account for this unexplained variance. Attachment theory (Bowlby, 1980) emphasizes that the quality of the mother-infant relationship influences adjustment by shaping an internal template (or "working model") on which children base future relationships. This study, which tocused on adolescents, assessed neither attachment quality nor internal working models. Also, a thorough treatment of social cognitive and developmental poycnopathology 
theories would irvolve specific measurement of affect regulation.

Future research would also benefit from examining resiliency and buffering models that emphasize the protective role of positive life experiences. For example, maltreated children who also have positive experiences with parents may fare better than those wro do not.

\section{Limitations of the Present Research}

The present research has several limitations. First and foremost, its correlational design does not allow for causal inference. Although maltreatment, attribution, and adjustment precede each other logically, reciprocal influence is also possible. For example, there is some evidence that conduct-disordered children are at greater risk for physical diacipline (Patterson, 1982; Wahier Dumas, 1986). However, some of the findings suggest caveats to the notion that maladjustment causes maltreatment. First, the findings also demonstrate an association between adjustment and maltreatment types that are not related to discipline (e.g., sexual abuse, exposure to family violence). Second, the greatest variance was shared between maltreatment and internalizing behaviors. Internalizing problems such as depression and withdrawal are not generally considered punishable.

A second possible critique concerning the attributiona: results is that youth with internalizing problems are suffering from depression and have the resultant depressive attributional biases. This association may indeed underlie the robust association between certain predictors and self-reported internalizing problems. However, it is worth noting that the criteria involved in the study are not primae facie descriptors of depressed affect. The Anger Intensity Scale is primarily a frequency rating of physiological symptoms, and the YSR is a checklist of behaviors. Although such measures share source variance with selfreported maltreatment and attributions, they are not based on items that describe depreseed feelings. Moreover, the criticism of tautology can 
be offeet, in part, by those results predicated on associations between measures that ghare no variance with the adolescent's mood or cognitivo processes (e.g., when incongruent batterer-blame and maltreatment Beverity predicted caretaker-reported internalizing problems).

In view of the significant differences between participating and non-participating families, the results cannot be generalized to higher functioning families. Because this sample was primarily white, external validity vis a vis other races and cultures is unestablished. The findinge aleo cannot be generalized to children younger than 11. Aleo, the findinge cannot be generalized to other measures of adjuetment or aymptomatology. Future research could focus on other outcoma measures (a.g.. future parenting competence).

Finally, several methodological procedures may have limited or obscured some potential findings. For ethical reasona, we could not explore the attributional processes of adolescente who denied experiencing certain types of maltreatment, even when their true background was known to us. In some cases, denial that the maltreatment occurred may represent the ultimate expression of distorted perception or pain. Physical and emotional abuge were combined to form the "hostile" attribution for maltreatment interview. Given the uniqueness of emotional maltreatment determined through the initial results, it may have been of value to keep these maltreatment types the subject of separate interviews.

The use of a four-point global rating scale for maltreatment may have resulted in restriction of range, thereby truncating the size of correlations. This may have been particularly likely for sexual abuse, which also had a small standard deviation and a s-gnificant gkew. The fact that gignificant relationships were obtained in this study, even with such regtricted variables, epeaks to the potency of child maltreatment. Future research may benefit from addresging these corserne. 
APPENDICES

APPENDIX A

The Development of the Attribution for Maltreatment Interview 


\section{The Attribution for Maltreatment Interview Introduction}

We are interested in how teens view events that may have happened to them We are interested in your opinion of what caused the events. whether the people involved were responsible for the outcome of those events. and whether those people are to blame for their behavior. Before we start. I would like to give you an example of what I mean by "cause". "responsibility", and "blame".

A cause refers to what or who made something happen. A cause could be something about a situation or it could be something about a person. For example, a car accident could have been caused by a slippery road. It could also be caused by a driver being careless. There could be many causes for an event. Can you think of other possible causes (e.g. fanled brakes, child walks out in front of car, drunk driver)? So if I asked you to tell me the causes for some event, you would tell me all the things that could have contributed to making that event happen.

If somebody is the cause of an everit, that person can sometimes be hela "responsible" for the outcome of the event. For example. if a person is a careless driver and hirts sumeone in an accident, that person could be considered responsible for the other person's injuries. When you are deciding how responsible someune is, you might think about differtu it things. You might consider whether the person could have foreseen a problem. whether he behaved that way on purpose. and whether he knew that what he did was wrong (e.g., in the casa or a drunk driver).

Blame is something you think about someone if you think that person's behavio was bad or wrong. If somebody dces something, and bad things happen because of that event. you might decide that the person should be blamed for whit he of she did.

Let's try an example. Let's say that when you were younger. you were faling asleep in class and getting in trouble at schoc!. At that time in your life, you had a babystter very often. Whenever she was over. you would ask her to stay up late. This babysitter rever seemed to pay much attention to you. She never made an eifort to get you to bed at a reasonable time On the mornings after she babysat, you were really tired.

What colld be the causes of why you did not get to bed on tıme? (Pause) (Prompt: Some possible causes might be a) the babysitter was careless, b) she was in a bad mood, c) the babysitter was not able to get you to go to bed).

Please rate on the scale provided how much you agree with the following statements

1) The babysitter was responsible for the problems that you had at schoo!

2) You were responsible for the problems you had at school.

(Proınpt: To answer these questions, you might want'; consıder what you and the babysitter were thınking on those occasions when you stayed up late).

3) The babysitter should be blamed for her behavior

4) You should be blamed ior your behavior. 
Now what we would like to do is ask ;nur opinion of the situations you made ratıngs about (refer to Ratings of Past Live Events) We will ask you what caused the events to occur Then I will read you some statements and you can tell me using this scale (reter to ayreement scale) how much you agree with the sia: mment.

Agan, these questions can be personal. Remember, you do not have to answer anything that makes you uncomfor:able. You are in control of this

Do you understand what I mean by cause, responsibility, and blame?

Interviewer global rating - to be completed after the interview.

of comprehension:

$$
\text { very poor }
$$

23

34

5

very high

of motivation:

1

2

3

4

5

very poor very high




\section{ATTRIBUTION FOR MALTREATMENT INTERVIEW (AFMI)}

\section{Hostile Maltreatment (Emotional and Physical Maltreatment)}

INSTRUCTIONS: Use both physical and emotional ratings in considering hostile mattreatment. If there are any equal ratings, ask child to identify the most upsetting. Otherwise, select the most severe rating from the Ratıngs of Past Life Events Scale).

We are interested in your thoughts about what caused (PERPETRATOR) to (REPORTED BEHAVIOR). What were some of the causes of what happened? What things contributed to (PERPETRATOR) (REPORTED BEHAVIOR)? Please give as many possible causes as you can.

If you had to pick the one maicr cause for what happened. what would it be?

I'm going to read you some statements. After each one, please tell me how much you agree with or believe that statement. You can use the agreement scale to help you.

$$
\begin{aligned}
& 1=\text { Do Not Agree } \\
& 2=\text { Agree a Little } \\
& 3=\text { Moderately Agree } \\
& 4=\text { Strongly Agree }
\end{aligned}
$$

1. These things had a bad effect on your life.

2. (THIS CAUSE) was due to something about you.
3. (THIS CAUSE) was due to something about your situation or circumstances.
4. (THIS CAUSE) was due to something about (PERPETRATOR).
5. (THIS CAUSE) was due to something about the situation or circumstances (PERPETRATOR) was in.
6. (THIS CAUSE) fluctuated or changed over time.
(Prompt: Something that came and went over time)
7. (THIS CAUSE) affected many areas of your life.
B. (THIS CAUSE) was something you could control or change. 
9. (THIS CAUSE) was something (PERPETRATOR) could control or change.

10. (PERPETRATOR) could have foreseen that what $s /$ he did or sard would have a bad effect on your life.

11. (PERPETRATOR) did and said the things $s /$ he did deliberately and on purpose.

12. By doing and saying those things, (PERPETRATOR) meant to make you into a better person.

13. (PERPETRATOR) couldn't help him/herself from doing and saying those things -- something made him/her do them.

14. At the time (PERPETRATOR) thought that she s/he did was okay.

15. (PERPETRATDR) was responsible for the effect this has had on your life.

16. (PERPETRATOR) should be blamed for his/her behavior.

17. When you think about (PERPETRATOR)'s role in what happened, you feel sad

18. When you think about (PERPETRATOR)'s role in what happened, you feel angry at him/her. 
At times, some kids feel that something they did, or something they did not do, contributed to what happened. You may or may not fee' that way at times. Is there anything that you did, or falled to do, that contributed to what happened? (Prompt: Refer to any self-directed cause listed on page 1)

(Prompt: Some kıds tell us they misbehaved sometimes, they accidentally provoked it.)

(Clinical prompt it participant appears troubled or confused: Even though they knew they did not cause what happened, or they could not have prevented it from happening, some kids say they still had those thoughts. Do you ever have such thoughts?)

1. You could have foreseen that what you did (or did not do) would have a bad effect on your life.

2. You did the things you did (or did not do) deliberately and on purpose.

3. You couldn't help yourself from doing those things - something made you do them (or something prevented you from doing them).

4. At the time, you thought that what you did (or did not do) was okay.

5. You were responsible for the effect this has had on your life.

6. You should be blamed for your behavior.

7. When you think about your role in what happened, you feel sad.

8. When you think about your role in what happened, you feel angry at yourself. 


\title{
ATTRIBUTION FOR MALTREATMENT INTERVIEW (AFMI)
}

\author{
Family Violence
}

INSTRUCTIONS: Interviewer selects the most severe ratıng from the Ratıngs of Past Life Events Scale.

We are interested in your thoughts about what caused (PERPETRATOR) to (REPORTED BEHAVIOR). What were some of the causes of what happened? What things contributed to (PERPETRATOR) (REPORTED BEHAVIOR)? Please give as many possible causes as you can.

If you had to pick the one major cause for what happened, what would it be?

I'm going to read you some statements. After each one. please tell me how much you agree with or believe that statement. You can use the agreement scale to help you.

$$
\begin{aligned}
& 1=\text { Do Not Agree } \\
& 2=\text { Agree a Little } \\
& 3=\text { Moderately Agree } \\
& 4=\text { Strongly Agree }
\end{aligned}
$$

1. These things had a bad effect on your life.

2. (THIS CAUSE) was due to something about you.

3. (THIS CAUSE) was due to something about your situation or circumstances.

4. (THIS CAUSE) was du. i sornething about (PERPETRATOR).

5. (THIS CAUSE) was due, , sc iething about the situation or circumstances (PERPETRATOR) was

6 (THIS CAUSE) fluctuated or changed over time.

(Prompt: Something that came and went over time)

7. (THIS CAUSE) affected many areas of your life.

8. (THIS CAUSE) was something you could control or change.

9. (THIS CAUSE) was something (PERPETRATOR) could control or change. 
10 (PERPETRATOR) could have foreseen that what $s /$ he did or said would have a bad effect on your life.

11 (PERPETRATOR) did and said the things s/he did deliberately and on purpose.

12. By doing and saying those thıngs, (PERPETRATOR) meant to make you into a better person.

13. (PERPETRATOR) couldn't help him/herseff from doing and saying those things -- something made $\mathrm{h} \mathrm{m} / \mathrm{her}$ do them.

14. At the time (PERPETRATOR) thought that she s/he did was okay.

15. (PERPETRATOR) was responsible for the effect this has had on your life.

16. (PERPETRATOR) should be blamed for his/her behavior.

17. When you think about (PERPETRATOR)'s role in what happened, you feel sad.

18. When you think about (PERPETRATOR)'s role in what happened, you feel angry at him/her. 
At times, some kıds feel that something they did. or something they did not do. contributed to what happened. You may or may not feel that way at times. Is there anything that you did. or failed to do, that contributed to what happened? (Prompt. Refer to any self-directed cause listed on page 1)

(Prompt: Some kids tell us tell us that they wished they could have stopped it or prevented it)

Clinical prompt if participant appears troubled or confused Even though they knew they did not cause what happeried or they could not have prevented it from happening. some kıds say they still had those thoughts. Do you ever have such thoughts?)

1. You could have foreseen that what you did (or did not do) would have a bad effect on your life.

2. You did the things you did (or did not do) deliberately and on purpose.

3. You couldn't help yourself from doing those things -- something made you do them (or something prevented you from doing them).

4. At the time, you thought that what you did (or did not do) was okay.

5. You were responsible for the effect this has had on your life.

6. You should be blamed for your behavior.

7. When you think about your role in what happened, you feel sad.

8. When you think about your role in what happened, you feel angry at yourself. 


\title{
ATTRIBUTION FOR MALTREATMENT INTERVIEW (AFMI)
}

\author{
Neglecting Maltreatment
}

INSTRUCTIONS: interviewer selects tie most severe rating from the Ratings of Past Lfe Events Scale.

We are interested in your thoughts about what caused (PERPETRATOR) to (REPORTED BEHAVIOR). What were some of the causes of what happened? What things contributed to (PERPETRATOR) (REPORTED BEHAVIOR)? Please give as many possible causes as you can.

If you had to pick the one major cause for what happened, what would it be?

I'm going to read you some statements. After each one. please tell me how much you agree with or believe that statement. You can use the agreement scale to help you.

$$
\begin{aligned}
& \dot{1}=\text { Do Not Agree } \\
& 2=\text { Agree a Little } \\
& 3=\text { Moderately Agree } \\
& 4=\text { Strongly Agree }
\end{aligned}
$$

1. These things had a bad effect on your life.

2. (THIS CAUSE) was due to something about you.

3 (THIS CAUSE) was due to something abcut your situation or circumstances.

4. (THIS CALSE) was due to something about (PERPETRATOR).

5. (THIS CAUSE) was due to something about the situation or circumstances (PERPETRATOR) was in.

6. (THIS CAUSE) fluctuated or changed over time.

(Prompt: Something that came and went over time)

7 (THIS CAUSE) affected many areas of your life.

8. (THIS CAUSE) was something you could control or inange.

9. (THIS CAUSE) was something (PERPETRATOR) could control or changt.

10. (PERPETRATOR) could have foreseen that what $s /$ he did or said would have a bad effect on your life. (Prompt: S/he failed to do.) 
11. (PERPETRATOR) did and sard the things s/he did deliberately and on purpose. (Prompt: S/he failed to do)

12. By doing and saying those things, (PERPETRATOR) meant to make you into a better person. (Prompt: By neglectıng you..)

13. (PERPETRATOR) couldn't [proper behavior .. e.g.. feed you. pay attention] -something prevented him/her from doing that.

14. At the time (PERPETRATOR) thought that she s/he did was okay.

15. (PERPETRATOR) was responsible for the effect this has had on your Iffe

16. (PERPETRATOR) should be blamed for his/her behavior

17. When you think about (PERPETRATOR)'s role in whet happened, you feel sad

18. When you think about (PERPETRATOR)'s role in what heppened, you feel angry at him/her. 
At tımes. some kids feel that something they did, or something they did not do. contributed to what happr ned. You may or may not feel that way at times. Is there anything that you did, or falled to do, that contributed to what happened? (Prompt. Refer to eny self-directed cause listed on page 1)

(Prompt. Some kids tell us tell us they wished they could have made (PERPETRATOR) pay attention, that they rejected (PERPETRATOR) themselves)

(Clinical prompt if participant appears troubled or confused: Even though they knew they did not cause the neglect or they could not have prevented it. some kids say they still had those thoughts Do you ever have such thoughts?)

1. You could have foreseen that what you did (or did not do) would have a bad effect on your life.

2. You did the things you did (or did not do) deliberately and on purpose.

3. You couldn't help yourself from doing those things - something made you do them (or something prevented you from doing them).

4. At the time, you thought that what you did (or did not do) was okay.

5. You were responsible for the effect this has had on your life.

6. You should be blamed for your behavior.

7 When you think about your role in what happened, you feel sad.

8. When you think about your role in what happened, you feel angry at yourself. 


\section{ATTRIBUTION FOR MALTREATMENT INTERVIEW (AFMI)}

\section{Sexual Abusd}

INSTRUCTIONS: Interviewer selects the most severe rating from the Ratings of Past Life Events Scale.

We are interested in your thoughts about what caused (PERPETRATOR) to (REPORTED BEHAVIOR). What were some of the causes of what happened? What things contributed to (PERPETRATOR) (REPORTED BEHAVIOR)? Please give as many possible causes as you can

If you had to pick the one major cause for what happened, what would it be?

I'm going to read you some statements After each one. please tell me how much you agree with or believe that statement. You can use the agreement scale to help you.

$$
\begin{aligned}
& 1=\text { Do Not Agree } \\
& 2=\text { Agree a Little } \\
& 3=\text { Moderately Agree } \\
& 4=\text { Strongly Agree }
\end{aligned}
$$

1. These things had a bad effect on you, life.

2. (THIS CAUSE) was due to something about you.

3. (THIS CAUSE) was due to something about your situation or circumstances.

4. (THIS CAUSE) was due to something about (PERPETRATOR).

5. (THIS CAUSE) was due to something about the situation or circumstances (PERPETRATOR) was in.

6. (THIS CAUSE) fluctuated or changed over time (Prompt: Something that came and went over time)

7. (THIS CAUSE) affected many areas of your life

8. (THIS CAUSE) was something you sould control or change.

9. (THIS CAUSE) was something (PERPETRATOR) could control or change.

10. (PERPETRATOR) could have foreseen that what $s /$ he did or sand would have a bad effect on your life. 
11. (PERPETRATOR) did and sard the things $s / h e$ did deliberately and on purpose.

12. By doing and saying those things. (PERPETRATOR) meant to make you into a better person.

13. (PERPETRATOR) couldn't help hım/herself from doing and saying those things -- something made him/her do them.

14. At the time (PERPETRATOR) thought that what s/he did was okay.

15. (PERPETRATOR) was responsible for the effect this has had on your life.

16 (PERPETRATOR) should be blamed for his/her behavior.

17. When you think about (PERPETRATOR)'s role in what happened, you feel sad.

18. When you think about (PERPETRATOR)'s role in what happened, you feel angry at him/her. 
At times. some kids feel that something they did. Or something they did not do. contributed to what happened. You may or may not feel that way at times. Is there anything that you did. or failed to do, that contributed to what happened?

(Prompt: Some kids tell us tell us that they wished they had told someone earlier or wished they could have stopped or prevented $i$ )

(Clinical prompt if participant appears troubled or confused. Even though they knew they did not cause what happened or they could not have prevented it from happening. some kids say they still had those thoughts. Do you ever have such thoughts?)

1. You could have foreseen that what you did (or did not do) would have a bad effect on your life.

2. You did the things you did (or did not do) deliberately and on purpose

3. You couldn't help yourself from doing those things -- something made you do them (or something prevented you from doing therri)

4. At the time, you thought that what you did (or did not do) was okay

5. You were respunsible for the effect this has had on your life.

6. You should be blamed for your behavior.

7 When you think about your role in what happened, you feel sad.

8. When you think about your role in what happened, you feel angry at yourself. 

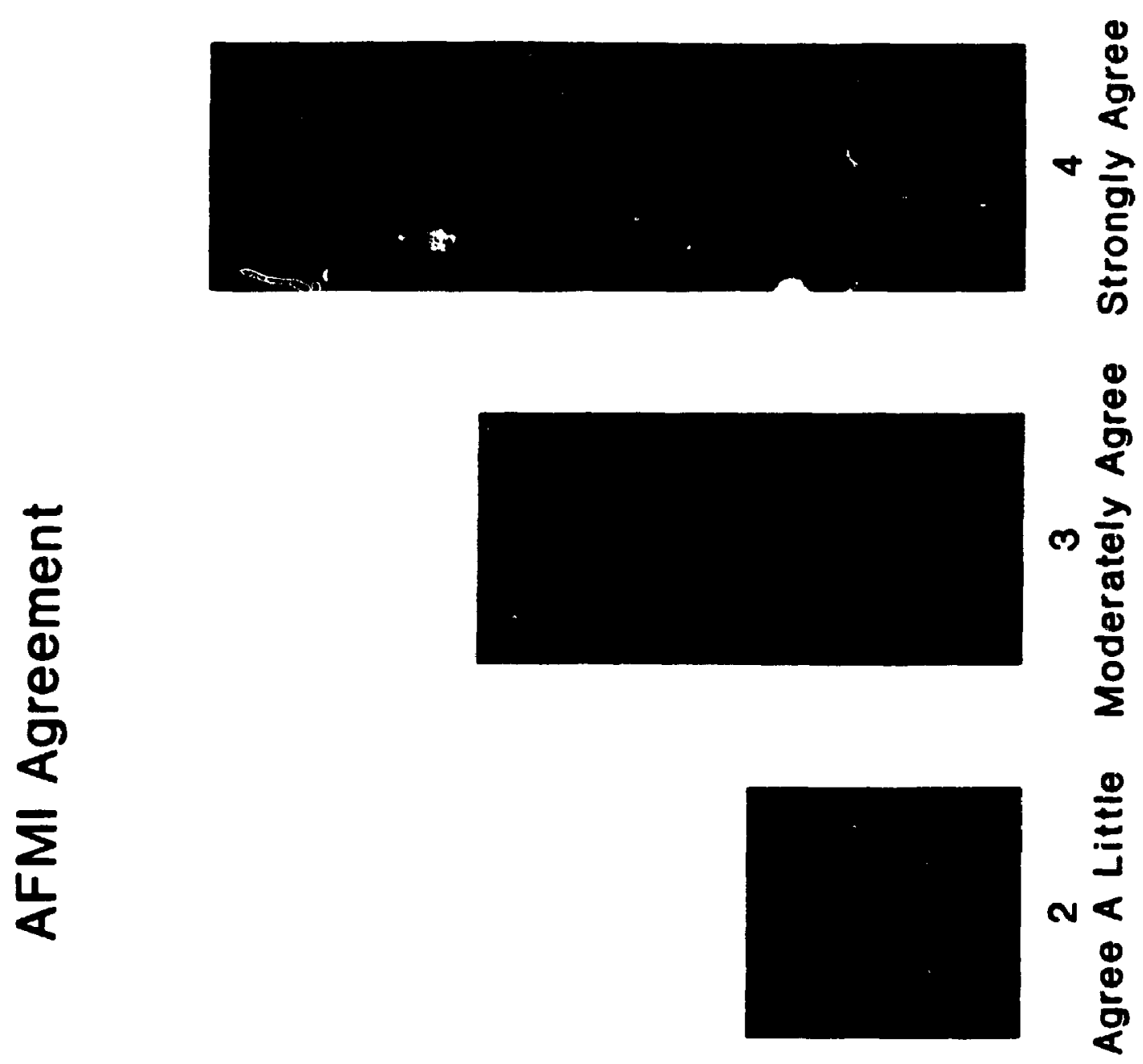

$$
\begin{array}{r}
\stackrel{8}{0} \\
\stackrel{0}{8} \\
-\frac{1}{0} \\
\hline 2 \\
0 \\
0
\end{array}
$$


The Development of the Attribution for Maltreatment Interviow

In the previous literature, there has been only one attempt to create a standardized measure of attribution among maltreated children. v. Wolfe, Wolfe, and Laroge (1986) composed the Children's Impact of Traumatic Events Scale (CITES) to assegs attributional style in responge to sexual abuse ( $V$. Wolfe Wolfe, 1988). The CITES is a 54-item semi-structured interview for sexual abuse victims. It was designed to assess the internal-stable-global dimensions of the learned helplessness model.

The crTes has several serious conceptual flaws. Firgt, the instrument does not appropriately represent the concepts it purports to measure. According to learned helplessness theory, the critical issue is the individual's attribution for the cause of a negative event. The CITES never examines this critical perception. As a result, few of the items comprising the internal, global, or stable subscales actually correspond to these attributional dimensions as they are understood in the social psychological Iiterature. For example, "people often take advantage of children" is considered an example of a global-specific attribution on the CITES. Appropriately viewed, a global attribution refers to the individual's perception that the cause of a negative event affects many areas of his or her life, as opposed to a single domain. A second but related criticism is that the attributional dimensions measured on the CITES are confounded with each other. For example, a stable attribution is traditionally understood as the individual's perception that the cause of the negative event is regarded as permanent or enduring across time (as opposed to temporary). The CITES, however, inappropriately labels perceptions of frequency (e.g.. "things like this will not happen again", as global attributions. Third, items reflective of an identical concept are often inappropriately loaded on different scales. For example "I was to blame for what happened" is loaded on the internal scale, whereas "I was not to blame for what happentd" is loaded 
on the guilt subscale. Fourth, even within a single attributional dimension, the items used to represent that dimension are used inconsistently. For example, "there are many people who do bad things to children" and "these things happen to a lot of children" are both considered glohal attributions. What is implied as "global" or pervasive varies between thcse statements. Perhaps as a consequence of its inadequate construction, the CITES has proven to be a poor predictor of adjustment (Gentile, 1988; Friedrich, personal communication). It was therefore necessary to develop a better attribution for maltreatment interview for the purpose of the present study. The Attribution for Maltreatment Interview (AFMI)

The Attribution for Maltreatment Interview was designed for the purposes of the study. The theoretical rationale and empirical development of the measure are outlined in the following section. In the previous literature, attributions generally have been measured using two approaches. The first is to ask questions about actual life events. This has been done in the depression literature (for reviews, see Brown \& Siegel, 1988; Norman Antaki, 1988) as well as the literature on victimization (e.g., Abbey, 1988; Bulman wortman, 1977; Miller \& Porter, 1983; Taylor et al., 1984; Tennen et al., 1986). The second approach is to provide respondents with hypothetical scenarios for which they must make attributions (Dodge, 1986; Fincham et al., 1987). This is a technique often used to ascertain attributional gtyle (e.g., The Attributional style Questionnaire (ASQ), Peterson, Semmel, von Baeyer, Abramson, Metalsky, \& Seligman, 1982; The Children's Attributional style Questionnaire (KASTAN), Kaslow, Rehm, \& Siegel, 1984).

The AFMI requires respondents to make attributions regarding their own maltreatment, as opposed to hypothetical scenarios. This decision was made for several reasons. First, masy authors (Cutrona, 1983; Cutrona, Russel1, \&ones, 1984; Norman Antaki, 1988) have criticized 
the hypothetical situation approach as conceptually and methodologically inadequate. Learned helplessness theory suggests that attributional style results as a generalization to other situations of attributions for a previously traumatic, uncontrollable event. A true test of this theory would inquire about attributions for those original events. Cutrona (1983) has argued that if there is a true relationship between hypothetical scenario attributions and depression, it is via attributions for real life events. Norman Antaki i1988) tested this hypothesis by asking respondents to complete the ASQ and a "Real Evento Attributional style Questionnaire". The latter used an identical metric to the ASQ, but asked for causal attributions for real positive and negative life events. Only real event attributions were significantly correlated with scores on a measure of depression; moreover, when attributions for real life events were statistically controlled, the small correlation between ASQ attributions and depression disappeared. Second, the ASQ and similar projectives have been found to have a weak relationship to depression in etudies designed to estimate the causal impact of attributional Btyle (for review, see Barnett Gotlib, 1988). Finally, the standard attributional style measures do not assess the reapondent's attributions about the responsibility or blame for the behavior of others. Taken together, these considerations suggest that "real life" attributions have more ecological and predictive validity than attributions for hypothetical events.

The AFMI elicits self- and other-directed attributions of causality, responsibility, blame, and affective reaction or each of four types of maltreatment: hostile maltreatment (physical abuse or psychological abuse), exposure to family violence, neglect, and sexual abuse. A standard set of questions is asked for each of the four types of maltreatment. Interviewees only respond with reopect to the forms of maltreatment they have experienced. Maltreatment types are grouped into four "types" for several reasons. First, there is considerable 
empirical $\in$ idence suggesting that physical and emotional maltreatment, as well as physical and psychological neglect, tend to co-occur (Egeland et al., 1983; R. Herrenkohl et al., 1983; Herzberger et al., 1981; Hinchey Gavelek, 1982; Snel1, 1988). Second, this approach expedites the interview process considerably and minimizes the fatigue or annoyance to the respondent while ensuring comprehensive data. Family violence merits a separate interview, given the attributional literature suggesting that attributions for events that occur to others differ from those in which one is personally involved (e.g., Jones Nisbett, 1972). Question method and metric. The AFMI employs statements and a five-point extent of agreement metric for each statement. In addition to being used as a measurement technique in much of the research or. self- and other-directed attributions in intimate relationships !e.g., Fincham \& Badbury, 1987), this style offers several advantages over other methods of attributiun meagurement.

In the previous literature, attributions have been assessed using a variety of techniques. The first technique requires the asaignment of blame to potentially causal or blameworthy factors. Typically, subjects are asked to divide 100 of the blame among these factors (e.g., Bulman \& Wortman, 1977). Anothe: technique forces the respondent to make an attribution either to the person or the situation (e.g., Taylor et al., 1984). The bipolar forced choice format can be considered a simplified vergion of the percentage format, in that the respondent must assign 1008 of the cause, responsibility, or blame to a single factor (Howard, 1987). When forced choice formats are expanded to bipolar multi-point response scales, the respondent is essentially allotting percentages to the two factors. All these types of measures have been criticized conceptually and methodologically because they impose interdependence and correlations between judgements (Elig Frieze, 1979; Howard, 1987). Thase measures assume a "hydraulic model" of attribution in which the total amount of attributional resources is finite. 
Bipolar ratings are common among measures of internal-external, stable-unstabie, and global-opecific dimensions of causality (e.g., the ASQ). This approach has several critics, particularly with respect to the "internal-external" dimension (Fincham et al., 1987; Miller, Smith, \& Uleman, 1981; Tennen \& Affleck, 1990; Shaver E Drown, 1986; Solomon, 1978). Typically, the locus dimension is phrased as "totally due to mo" versus "totally due to other people or circumstance". Shaver and Drown (1986) have stressed that circumstances are not capable of intentional action, and thus should be distinct from causal attributions to others. Also, Howard (1987) and Fincham (1985; Fincham et al., 1987) have poirited out that conceptual confusion can result when the locus judgement is made for interpersonal events. From the perspective of each actor, the other is part of the situation or circumstance. Simply removing "circumstances" from the external pole is not adequate, as previous research with partners in intimate relationships (Fincham et al., 1987) have indicated that individuals can attribute a high degree of caugality both themselves and to someone else simultaneously. Moreover, specificity is lost because global references to "persons" do not allow attributors to distinguish among personality characteristics, moods, abilities, and so forth. In view of all these issues, the AFMI employs a unipolar rating syotem.

Another technique used in attributional research is the "factor" approach in which respondents are asked the extent to which "each of the following factors" caused or was responsible for an event. kespondente are then presented with a list of very specific items which are rated along a unipolar metric. Although this approach has the advantage of greater reliability than global ratings (e.g., " how much do you believe you were to blame for the event?"), this approach has several limitations (Anderson \& Arnoult, 1985; Elig Erieze, 1979). Firet, subjects are restricted to factors that may not have been relevant in their situation. Second, it does not assegs the dimensionality of 
causal factors. Third, using this technique, a researcher may have maje galient causes the subject would not ordinarily consider. Fourth, Peterson et al. (1982) hav observed that the researcher may inaccurately label a specific cause as operationalizing a certain dimension, when in fact it is not viewed that way by the subject (e.g., "effort" can be regarded as both a stable and an unstable cause).

Another technique asks subjects to make ren-ended attributions for events, which are subsequently coded. Although this has advantages when a research domain is little understood (Anderson \& Arnoult, 1985; Howard, 1987), it is 1 ess reliable than fixed-format technigues (Elig Frieze, 1979). Ross (1977) has observed that the coding of open-ended causal attributions into abstract categories depends more on the grammatical form of the attribution than on its meaning. As a compromise, several researchers (e.g., Anderson Arnoult, 1985; Peterson et al., 1982) have recommended that subjects generate open-ended attributions which are then rated on the dimensions of interest. This is the strategy that has been employed on the AFMI. Interview structure and content. The standard question sets on the AFMI are structured into three broad sections: attributions regarding causality, attributions regarding the perpetrator, and attributions regarding the self. Affective reactions to thinking about the role of the perpetrator and of the self in the maltreatment are also assessed.

Interview data from the interview for each maltreatment type were submitted to analyses separately. This approach was adopted for several reasons. First, the maltreatment types differ in the circumstances ourrounding their occurrence: these factors may influence attribution. For example, unlike the other maltreatment types, perpetrators of sexual abuse are not always parent figures. Unlike all other maltreatment types, family violence involves a victim other than the witnessing child, thereby complicating the attributional stage. Phyoical and 
poychological ralcceatment often occur in the context of discipline, whereas the uther types do not, which can influence the "deservingness" attributions made by victims (Rausch Knutson, 1991).

The AFMI begins with a digcussion and example of what is meant by cause, rrfyonsibility, and blame. Previously, as part of the clinical intervi w, subjects were asked to rate the extent to which they had experienced any of the five forms of maltreatment lon a 4-point ocale ranging from "not at all" to "severely") for each of mother, father, or cther. The AFMI is aimed at the most serious or significant maltreating events. Thus, within a certain type of maltreatment (e.g., hostile abuse), the interviewer selects the event with the greatest severity rating to be discussed during the interview. In the event of a tie, the child is asked to identify the event they consider to be the most upsetting to them.

First, the subject is asked to list all the possible causes for the maltreating event. He or she is encouraged to ligt as many as they can. Then he or she is asked to select the one major cauge for the maltreatment. Then the interviewer reads the subject 26 gentences. The subject rates his or her agreement with the sentence on a 4 point metric ("do not agree at all" to "strongly agree"). The interviewer is free to vary the wording of certain statements to render them more understandable in context. For example, because neglecting maltreatment refers to acts of omission, items regarding the perpetrator's behavior can be changed accordingly (e.g., "he could not help himmelf from doing those things - something made him do it" could be altered to "he could not pay attention to you because something prevented him from doing it"). Similarly, interviewers can substitute the adolescent's language for the parental behavior in place of vague references to the maltreating event (e.g., "Your father hit you deliberately and on purpose" instead of "your father did what he did deliberately and on purposen ). 
Causality. The sentences in the causality cluster rate the cause along four dimensions: locus ("<this cause> was due to something about you"), stability ("<this cause> fluctuated or changed over time"), globa?lty ("<this calse> affected many areas of your life"), and controllability ("<this cause> was scnething you could have controlled or changed"). To adequately distinguish among causal attributions about thre self, the perpetrator, and the situation or circumstances, separate items are generated for each of these (Fincham, 1985). The conticollability dimension is added to those typically garnered in attribution research given recent research demonstrating its importance (e.g., Abramson et al., 1989; Anderson \& Arnoult, 1985; Brown \& Siegel, 1988;. Aiso, because it is suspected that controllability distinguishes "behavioral" from "characterological blame" (Brown \& siegel, 1988), specific items aimed at the latter two constructs were not added. Also, because perceptions of the perpotrator's ability to control or change his or her behavior is related to judgements of reeponsibility and blame in cases of repeated behaviors (Fincham et al.. in press; Fincham Bradbury, 1987; Shaver, 1985), an itam assessing this was also included. Also, the item "these things <the maltreating events> have had a bad effect on my life" is included at the beginning to evaluate the extent to which the subject views a life event as negative, an isgue considered critical to theories of depression (Abramson, Metalsky, A Alloy, 1989; Brown \& Siegel, 1988).

Regpongibility. In the reaporsibility cluster, items reflect Shaver's (1985) four criteria for responsibility judgements: awareness of future negative consequences or foreseeability ("he could have foreseen that what he did might have a bad effect on your 1 ife"); intent ("he did what he did deliberately and on purpose"); volition or absence of duress ("he couldn't help himself - something made him do it"); and regret or awareness of moral wrongfulness ("at the time, he thought that what he did was okay"). In keeping with the suggestion that role 
responsibility issues should be incorporated in research on attribution in hierarch,cal and parent-child relationships (Fincham et al., in press; Fincham \& Bradbury, 1987), a second item indicative of a socializing intent was included (i.e., "By doing and saying those things, <the perpetrator> was trying to make you into a better person"). Thus both immediate and long term intent are assessed. Global ratings of responsibility are also inciuded, one for the self and one for the perpetrator (e.g., "<Perpetrator> is responsible for the effect this has had on my life").

Blame and affect. Two global ratings of blame are also included. The blame attributiong are phrased in morally evaluative language ("<The perpetrators should be blamed for his/her behavior") to reflect the moral nature of these judgements. Anger and sadness are assessed separately for both the self and the offender (e.g.. "When you think about his/your role in what happened you feel angry at him/yourself "). Empirical Validation

The items on the AFMI were subjected to empirical analyses for several reasons. First, because each item was created to address a theoretically relevant attribution, it was necessary to see if items covaried in the direction predicted by responsibility attribution theory. Second, data reduction through aggregation of items into theoretically and empirically coherent subscales was required for subsequent regression analyses.

First, correlations between identical items were computed across maltreatment types. This procedure was conducted to confirm the decision to treat maltreatment types separately. If correlations of identical items across maltreatment types were high, it would suggest that victims adopt a consistent "attributional style" towards maltreatment experiences. If such correlations were low, it would suggest that the type of maltreatment experienced or the identity of the perpetrator involved represent important distinguishing influences on 
attribution items. The correlations between identical attributional iteme were in fact fairly low, ranging from .00 to.52, with an average correlation of .30. Moreover, relatively few subjects participated in all possible interviews, making an examination of cross-interview style difficult. Therefore, separate analyses were conducted for each maltreatment type.

Because of the importance of the self/other distinction in attributional literature (e.g., Jones \& Nibett, 1972; Tennen \& Affleck, 1990), items relevant to the perpetrator and thone relevant to the self were examined in separate factor analyses. The items relevant to impact, globality, and stability were not retained for the item pool, as theee items were not linked to either the self or the perpetrator. (They had been included in the AFMI to allow other teats of the learned helplessness model in a different study). Each item set was subjected to principal components analysis with varimax rotation.

Initial factor analytic results indicated that certain items loaded inconsiatently, or emerged as bingle item factors. Examination of the frequency distribution of these items indicated that several were very poorly distributed within the sample. The item "<This cause> was something you could have controlled or changed" was rarely agreed to by victims of family violence (98), sexual abuse (118), or neglect (288). Also, believing the perpetrator was "trying to make you a better person" by what $s$ /he did was very rarely endorsed by victims of family violence (48), sexual abuse (98) or neglect (208). The item 'At the time, <perpetrator> thought that what $s /$ he did was okay" loaded equally on both perpetrator blame and excuse factors. Respondents appeared to interpret this item inconsigtently during the interview. Some subjects used the item "the perpetrator thought the maltreatment was okay" in order to communicate the perpetrator's lack of conscience, while others endorsed it to communicate the perpetrator' a lack of knowledge. Finally, the item "<This cause> was due to something about your 
situation or circumstances" was also inconsigtently loaded. Subjects who identified the major cause as the perpetrator's personality had difficulty interpreting this item. Also, subjects who identifled the cause as external circumstances facing the entire family (e.g, lack of money) had difficulty distinguishing their parents' c1rcumstances from their own. These items were dropped and analyses recomputed. Final solution results are reported in Tables 34 to 41 .

Generally, a consistent factor structure was obtained for each item set across maltreatment types. A three factor solution and a two factor solution was obtained for self and perpetrator attributions, respectively. For the self-directed attributions, the three factors were tentatively labelled self-blaming cognition, excuse, and selfblaming affect. Items loading on the blame factor included the following items: you should be blamed for your behavior, you are responsible for the effect this has had on your life, the major cause was due to something about you, the major cause was something you could have controlled or changed, and you could have foreseen that what you did would have a bad effect on your life. Items on the excuse factor were you did what you did deliberately, at the time you thought what you did was okay, and you could sot help doing what you did. The selfblaming affect factor comprised the two affective responses: when you think about your role in what happened, you feel sad; and, when you think about your role in what happened, you feel angry at yourself. A similar factor structure was obtained for other-directed attributions. For perpetrators, a blame factor emerged that comprised the attributions related to blame, responsibility, anger, foreseeability, control, and deliberate intent, and a causal locug within the perpetrator. An excuse factor was also evident for perpetrators, compriged of attributing the causal locus to the perpetrator's situation or circumstances, feeling that the offender could not help how $s /$ he acted, and feeling sad about the offender's role in what happened. 
Table 34.

Final Pactor solution of the self-directed Items of the AFMI for Hostile Maltreatment.

\begin{tabular}{|c|c|c|c|}
\hline $\begin{array}{l}\text { Hostile Maltreatment } \\
\text { self-directed attribution }\end{array}$ & & Factor & \\
\hline & $\begin{array}{l}\text { Blame } \\
\text { Cognition }\end{array}$ & Excuse & $\begin{array}{l}\text { Blame } \\
\text { Affect }\end{array}$ \\
\hline $\begin{array}{l}\text { You should be blamed for your } \\
\text { behavior }\end{array}$ & .83 & & \\
\hline $\begin{array}{l}\text { (Cause) wag something you could } \\
\text { have controlled or changed }\end{array}$ & .75 & & \\
\hline $\begin{array}{l}\text { You are responsible for what } \\
\text { happened }\end{array}$ & .74 & & \\
\hline $\begin{array}{l}\text { (Cause) was due to something about } \\
\text { you }\end{array}$ & .61 & & \\
\hline $\begin{array}{l}\text { You did what you did deliberately } \\
\text { and on purpose }\end{array}$ & & .74 & \\
\hline $\begin{array}{l}\text { You couldn't help it... Bomething } \\
\text { made you }\end{array}$ & & .70 & \\
\hline $\begin{array}{l}\text { At the time, you thought what you } \\
\text { did was okay }\end{array}$ & & .57 & \\
\hline $\begin{array}{l}\text { You could have foreseen that what } \\
\text { you did... }\end{array}$ & & .56 & \\
\hline $\begin{array}{l}\text { When you think of your role in what } \\
\text { happened you feel bad }\end{array}$ & & & .84 \\
\hline $\begin{array}{l}\text { When you think of your role in what } \\
\text { happened, you feel angry at } \\
\text { yourself }\end{array}$ & & & .78 \\
\hline
\end{tabular}


Table 35 .

Final Factor solution of the Self-directed Items of the AFMI for Famzly Viotence.

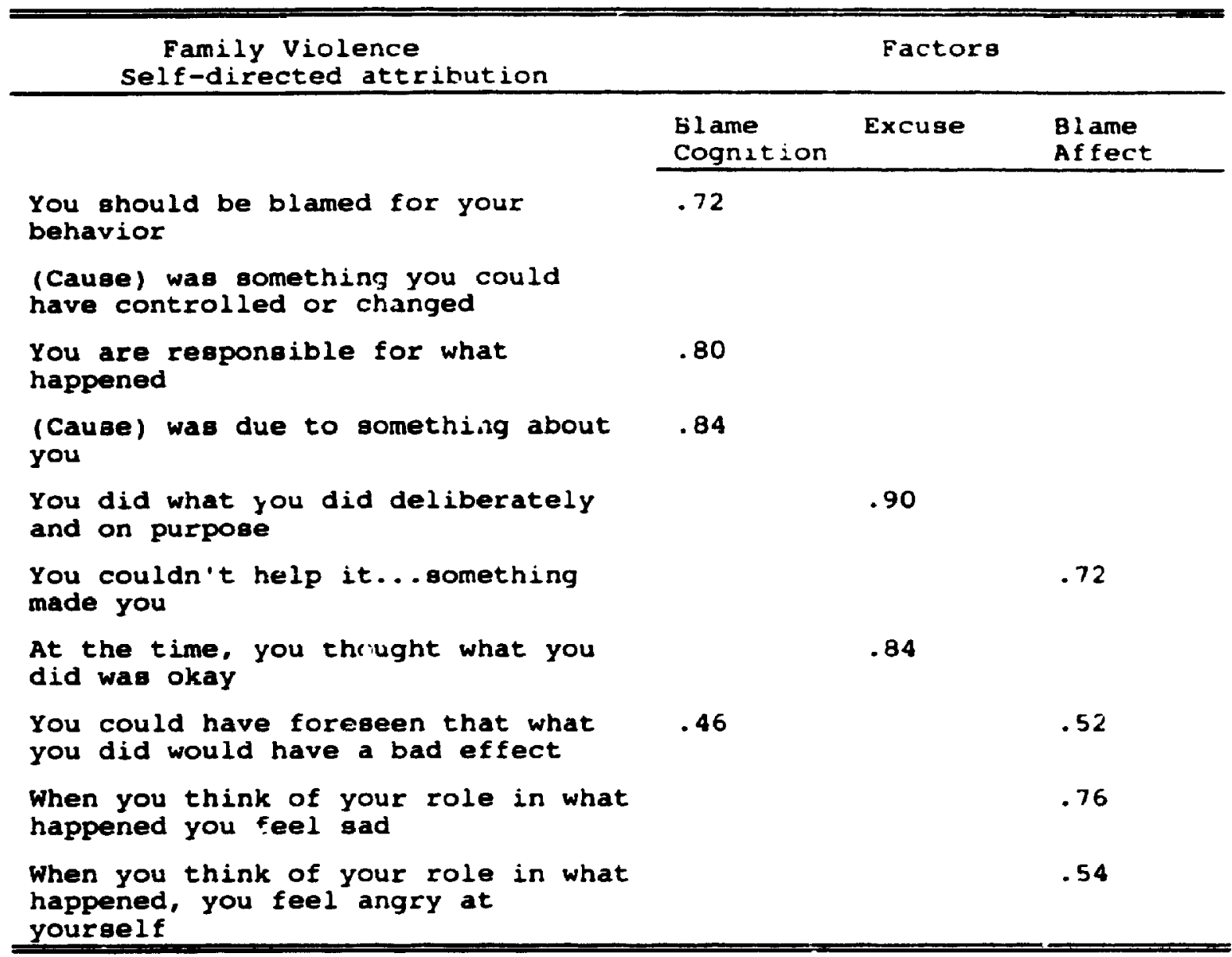


Table 36 .

Pinal Factor solution of the self-directed items of the AFMI for Neqlect.

\begin{tabular}{|c|c|c|c|}
\hline \multirow{2}{*}{$\begin{array}{l}\text { Neglecting Maltreatment } \\
\text { Self-directed attribution }\end{array}$} & \multicolumn{3}{|c|}{ Factors } \\
\hline & $\begin{array}{l}\text { Blame } \\
\text { Cognition }\end{array}$ & Excuse & $\begin{array}{l}\text { Blame } \\
\text { Affect }\end{array}$ \\
\hline $\begin{array}{l}\text { You should be blamed for your } \\
\text { behavior }\end{array}$ & .87 & & \\
\hline $\begin{array}{l}\text { (Cause) was something you could } \\
\text { have contrclled or changed }\end{array}$ & & & \\
\hline $\begin{array}{l}\text { You are responsible for what } \\
\text { happened }\end{array}$ & .76 & & \\
\hline $\begin{array}{l}\text { (Cause) was due to something about } \\
\text { you }\end{array}$ & & & \\
\hline $\begin{array}{l}\text { You did what you did deliberately } \\
\text { and on purpose }\end{array}$ & .55 & .59 & \\
\hline $\begin{array}{l}\text { You couldn't help it... something } \\
\text { made you }\end{array}$ & & .82 & \\
\hline $\begin{array}{l}\text { At the time, you thought what you } \\
\text { did was okay }\end{array}$ & & .60 & \\
\hline $\begin{array}{l}\text { You could have foreseen that what } \\
\text { you did... }\end{array}$ & .45 & & .64 \\
\hline $\begin{array}{l}\text { When you think of your role in what } \\
\text { happened you feel sad }\end{array}$ & & & .78 \\
\hline $\begin{array}{l}\text { When you think of your role in what } \\
\text { happened, you feel angry at } \\
\text { yourself }\end{array}$ & & & .75 \\
\hline
\end{tabular}


Table 37.

Final Factor solution of the Self-directed items of the AFMI for sexual Abuse.

\begin{tabular}{|c|c|c|c|}
\hline \multirow{2}{*}{$\begin{array}{l}\text { Sexual maltreatment } \\
\text { self-directed attribution }\end{array}$} & \multicolumn{3}{|c|}{ Faccors } \\
\hline & $\begin{array}{l}\text { Blame } \\
\text { Cognition }\end{array}$ & Excuse & $\begin{array}{l}\text { Blame } \\
\text { Affect }\end{array}$ \\
\hline $\begin{array}{l}\text { You should be blamed for your } \\
\text { behavior }\end{array}$ & .42 & & \\
\hline $\begin{array}{l}\text { (Cause) was something you could } \\
\text { have controlled or changed }\end{array}$ & & & \\
\hline $\begin{array}{l}\text { You are responsible fcx the effect } \\
\text { this had on your life }\end{array}$ & .75 & & \\
\hline $\begin{array}{l}\text { (Cause) was due to something about } \\
\text { you }\end{array}$ & .70 & & \\
\hline $\begin{array}{l}\text { You did what you did deliberately } \\
\text { and on purpose }\end{array}$ & & .77 & \\
\hline $\begin{array}{l}\text { You couldn't help it... something } \\
\text { made you }\end{array}$ & & .55 & .58 \\
\hline $\begin{array}{l}\text { At the time, you thoughe what you } \\
\text { did was okay }\end{array}$ & & .86 & \\
\hline $\begin{array}{l}\text { You could have foreseen that what } \\
\text { you did... }\end{array}$ & .70 & & \\
\hline $\begin{array}{l}\text { When you think of your role in what } \\
\text { happened you feel bad }\end{array}$ & & & .83 \\
\hline $\begin{array}{l}\text { When you think of your role in what } \\
\text { happened, you feel angry at } \\
\text { yourself }\end{array}$ & & & .65 \\
\hline
\end{tabular}


Table 38 .

Final Factor solution of the perpetrator-directed Items of AFMI for Hoatide Maltreatment.

\begin{tabular}{|c|c|c|}
\hline Hostile maltreatment & $\mathbf{F a}$ & ings \\
\hline & Blame & Excuse \\
\hline $\begin{array}{l}\text { <Perpetrators should be blamed for } \\
\text { his/her behavior. }\end{array}$ & .78 & \\
\hline $\begin{array}{l}\text { (Caube) was due to something about } \\
\text { <Perpetrators }\end{array}$ & .76 & \\
\hline $\begin{array}{l}\text { <Perpetrators is respongible for the } \\
\text { effect this has had on your life }\end{array}$ & .74 & \\
\hline $\begin{array}{l}\text { When you think about <Perpetrators> } \\
\text { role in what happened, you feel angry } \\
\text { at <him/her> }\end{array}$ & .74 & \\
\hline $\begin{array}{l}\text { <Perpetrator> (behavior) deliberately } \\
\text { and on purpose }\end{array}$ & .69 & \\
\hline $\begin{array}{l}\text { (Cause) was something <perpetrators } \\
\text { could have controlled or changed }\end{array}$ & .62 & \\
\hline $\begin{array}{l}\text { <Perpetrators could have foreseen } \\
\text { that (behavior) would have a bad } \\
\text { effect on my life }\end{array}$ & .52 & \\
\hline $\begin{array}{l}\text { <Perpetrator> could not help } \\
\text { (behavior), eomething made } \mathrm{him} / \mathrm{her} \text { do } \\
\text { it }\end{array}$ & & .76 \\
\hline $\begin{array}{l}\text { (Cause) was due to <perpetrators> } \\
\text { eituation or circumstances }\end{array}$ & & .66 \\
\hline $\begin{array}{l}\text { When you think about <perpetrator's> } \\
\text { role in what happened, you feel sad }\end{array}$ & & .66 \\
\hline
\end{tabular}


Table 39.

Final Factor Solution of the Perpetrator-directed Items of the AFMI for Family violence.

\begin{tabular}{|c|c|c|}
\hline \multirow{2}{*}{$\begin{array}{l}\text { Family violence } \\
\text { Perpetrator-directed attribution }\end{array}$} & \multicolumn{2}{|c|}{ Factor Loadinga } \\
\hline & Blame & Excuse \\
\hline $\begin{array}{l}\text { <Perpetrator> should be blamed for } \\
\text { his/her behavior. }\end{array}$ & .69 & \\
\hline $\begin{array}{l}\text { (Cause) was due to something about } \\
\text { <Perpetrator> }\end{array}$ & .42 & \\
\hline $\begin{array}{l}\text { <Perpetrator> is responsible for the } \\
\text { effect this has had on your life }\end{array}$ & .72 & \\
\hline $\begin{array}{l}\text { When you think about <Perpetrators> } \\
\text { role in what happened, you feel angry } \\
\text { at <him/her> }\end{array}$ & .69 & \\
\hline $\begin{array}{l}\text { <Perpetrator> (behavior) deliberately } \\
\text { and on purpose }\end{array}$ & .56 & \\
\hline $\begin{array}{l}\text { (Cause) was something <perpetrator> } \\
\text { could have controlled or changed }\end{array}$ & .44 & \\
\hline $\begin{array}{l}\text { <Perpetrators could have foreseen } \\
\text { that (behavior) would have a bad } \\
\text { effect on my life }\end{array}$ & .67 & \\
\hline $\begin{array}{l}\text { <Perpetrator> could not help } \\
\text { (behavior), something made him/her do } \\
\text { it }\end{array}$ & & .74 \\
\hline $\begin{array}{l}\text { (Cause) was due to <perpetrators> } \\
\text { situation or circumstances }\end{array}$ & & .55 \\
\hline $\begin{array}{l}\text { When you think about <perpetrator's> } \\
\text { role in what happened, you feel gad }\end{array}$ & & .63 \\
\hline
\end{tabular}


Table 40.

Final Factor solution of the Perpetrator-directed Items of the AFMI for Neqlect.

\begin{tabular}{|c|c|c|}
\hline \multirow{2}{*}{$\begin{array}{l}\text { Neglect } \\
\text { Perpetrator-directed attribution }\end{array}$} & \multicolumn{2}{|c|}{ Factor Loadings } \\
\hline & Blame & Excuse \\
\hline $\begin{array}{l}\text { <Perpetrator> ahould be blamed for } \\
\text { hie/her behavior. }\end{array}$ & .80 & \\
\hline $\begin{array}{l}\text { (Cause) was due to something about } \\
\text { <Perpetrator> }\end{array}$ & .53 & \\
\hline $\begin{array}{l}\text { <Perpetrator> is responsible for the } \\
\text { effect this has had on your life }\end{array}$ & .78 & \\
\hline $\begin{array}{l}\text { When you think about <Perpetratora> } \\
\text { role in what happened, you feel angry } \\
\text { at <him/hers }\end{array}$ & .69 & \\
\hline $\begin{array}{l}\text { <Perpetrator> (behavior) s'eliberately } \\
\text { and on purpose }\end{array}$ & .58 & \\
\hline $\begin{array}{l}\text { (Caues) was something <perpetrators } \\
\text { could have controlled or changed }\end{array}$ & .45 & \\
\hline $\begin{array}{l}\text { <Perpetrators could have foreseen } \\
\text { that (behavior) would have a bad } \\
\text { effect on my life }\end{array}$ & .53 & .45 \\
\hline $\begin{array}{l}\text { <Perpetrators could not help } \\
\text { (behavior), something made } \mathrm{him} / \mathrm{her} \text { do } \\
\text { it }\end{array}$ & & .68 \\
\hline $\begin{array}{l}\text { (Cause) was due to <perpetratore> } \\
\text { situation or circumstances }\end{array}$ & & .50 \\
\hline $\begin{array}{l}\text { When you think about <perpetrator's> } \\
\text { role in what happened, you feel sad }\end{array}$ & & .62 \\
\hline
\end{tabular}


Table 41.

Final Factor Solution of the Perpetrator-directed Iteins on the AFMI for Sexual Abuge.

\begin{tabular}{|c|c|c|}
\hline \multirow{2}{*}{$\begin{array}{l}\text { Sexual maltreatment } \\
\text { Perpetrator-directed attribution }\end{array}$} & \multicolumn{2}{|c|}{ Factor Loadings } \\
\hline & Blame & Excuge \\
\hline $\begin{array}{l}\text { <Perpetrator> ghould be blamed for } \\
\text { hig/her behavior. }\end{array}$ & .67 & \\
\hline $\begin{array}{l}\text { (Cause) was due to something about } \\
\text { <Perpetrator> }\end{array}$ & .54 & .40 \\
\hline $\begin{array}{l}\text { <Perpetrator> is responsible for the } \\
\text { effect this has had on your life }\end{array}$ & .56 & \\
\hline $\begin{array}{l}\text { When you think about <Perpetrators> } \\
\text { role in what happened, you feel angry } \\
\text { at <him/her> }\end{array}$ & .44 & \\
\hline $\begin{array}{l}\text { <Perpetrators (behavior) deliberately } \\
\text { and on purpose }\end{array}$ & .61 & \\
\hline $\begin{array}{l}\text { (Cause) was something <perpetrator> } \\
\text { could have controlled or changed }\end{array}$ & .52 & \\
\hline $\begin{array}{l}\text { <Perpetrator> could have foreseen } \\
\text { that (behavior) would have a bad } \\
\text { effect on my } 1 \text { ife }\end{array}$ & .61 & \\
\hline $\begin{array}{l}\text { <Perpetrators could not help } \\
\text { (behavior), Bomething made him/her do } \\
\text { it }\end{array}$ & & .66 \\
\hline $\begin{array}{l}\text { (Cause) was due to <perpetrators> } \\
\text { situation or circumstances }\end{array}$ & & .71 \\
\hline $\begin{array}{l}\text { When you think about <perpetrator's> } \\
\text { role in what happened, you feel gad }\end{array}$ & & .40 \\
\hline
\end{tabular}


Uaing a combination of the factor analytic reaults and theoretical considerations, the items were aggregated into subscales sorresponding to the blame cognition, excuse, and blame affect dimensions. For several reagons, scales were constructed using the same items regardless of maltreatment type, despite ambiguities in factor structure among types. First, attributional theory supports the notion that interpersonal attributions separate into blame and excuse constructs (e.g., Tennen \& Affleck, 1990; Snyder Higging, 1988; Shaver \& Drown, 1986). The self-blaming affect factor within the self-directed attribution set also makes theoretical sense. These items ("When you think about your role in what happened, you feel...") are not true attributions in the cognitive sense. Rather, they represent the amotional valence associated with thinking about one's role in the maltreatment. In essence, they are emotions about cognitions, and thus should be conceptually and operationally distinguighed from the pure cognitions described by the other items. Because attributional theory (e.g., Heider, 1958; Jones Nisbett, 1972) suggests that attributions about oneself are often more complex than attributions about others, the fact that a third factor should emerge for the self is understandable. To maintain the theoretical integrity of the blame cognition, excuse, and blame affect constructs, and to facilitate interpretation and comparison of the subscales across maltreatment types, items were aggregated consistently across interviews.

Because of excellent simple structure obtained on perpetratorrelevant attributions, no adjugtments were made to the scales suggested by these factor analyses. However, on the self-directed items, when there was any ambiguity regarding an item because of inconsistent factor location, a decision was reached on the basis of theoretical and empirical considerations. For example, the item "You could have foreseen that what you did would have a bad effect on your life" loaded on the excuse factor for hostile maltreatment, the self-blaming affuct 
factor for neglect and family violence, and the blame factor for sexual abuse. (This different structure is likely attributable to the fact that a substantial number of physical/emotional maltreatment victima identified their "misbehavior" as a major cause of the maltreatment. Failure to foresee punishment for an action could be considered an excuse. However, for family violence, neglect and sexual abuse, many victims identified their personal role in the maltreatment as their failure to prevent the maltreating act. These victims may regard a failure to foresee as associated with a blameworthy or distreseing failure to prevent). In such complicated instances, the item's factor loading on other factors was examined to assiat in decision-making. "Foreseeability" also loaded highly $(>.40)$ on the blame factore of family violence and neglect, suggeating it reflects the blame conatruct in three of the four maltreatment types. To ensure the conceptual purity of the self-blaming affect scale (that is, to keep it unadulterated with cognitions), foreseeability could not te retained on the blame affect factor. Taken together, theoretical, empirical, and consistency considerations suggested that the foreseeability item was best included in the composition of the self blame cognition factor for all maltreatment types.

Rather than use item factor loadings, items were given unit weightings and summed to form a subscale. This approach was adcpted for several reasons. First, statistical literature suggrsts that unit weightings replicate better than factor loadings (Kim \& Meueller, 1978). Also, Macintyre (1990) suggests that use of unit weightings avoids indeterminacy problems in factor analytic solutions. Second, suming agreement ratings over attributional items is an approach used extensively in other attributional regearch (e.g., Bradbury Flncham, 1990; Peterson et al., 1982). Simple addition of item scores is readily understandable and interpretable. Also, this approach renders the 
AFMI' subscale etructure more accessible and replicatable for future research.

Internal reliabilities (Cronbach's alpha) were computed on each derived subscale (Table 42). Reliabilitieg were lowest for the scale reflecting perpetrator excusing (ranging from .40 to .53), and highest for those reflecting perpetrator blame $(.65$ to .84$)$. The mean internal reliability coeffisient was .61 , and the median was .63 . Because the internal consistency of a scale increases as the number of items increase (Dick Hagerty, 1971), Cronbach's alpha may be an underestimate of the 3-item perpetrator-excuse factor. The spearman Brown step-up formula, which allows one to compute the reliability a scale would have with more items, estimates reliability of the perpetrator-excuse factors at .69 (hostile), .61 (family violence), .57 (neglect) and .64 (sexual abuse) with 6-item scales.

The test-retest reliability of the AFMI subscales was also determined with 33 subjects (268 of the original sample) at a mean interval of one month. The subscales had good to excellent test-retest reliability. Table 43 illustrates that retest reliability ranges from .68 (family violence perpetrator blame) to .98 (sexual abuse perpetrator blame $)(\underline{M}=.83$, median $=.85)$. In summary, therefore, the AFMI provides a theoretically and empirically sound approach to the measurement of attributions of several types of maltreatment. 
Table 42.

Internat Reliability Coefficients for the AFMI Subgcaleg.

\begin{tabular}{|c|c|c|c|c|c|}
\hline \multirow{3}{*}{$\begin{array}{l}\text { Maltreatment } \\
\text { Interview }\end{array}$} & \multicolumn{5}{|c|}{ Cronbach's alpha' } \\
\hline & \multicolumn{2}{|c|}{ Perpetrator scales } & \multicolumn{3}{|c|}{ Self scaleg } \\
\hline & Blame & Excuse & $\begin{array}{c}\text { Blame } \\
\text { Cognition }\end{array}$ & Excuse & $\begin{array}{l}\text { Blame } \\
\text { Af fect }\end{array}$ \\
\hline $\begin{array}{l}\text { Hostile } \\
\text { (physical \& } \\
\text { emotional) }\end{array}$ & .84 & .53 & .72 & .53 & .61 \\
\hline $\begin{array}{l}\text { Family } \\
\text { violence }\end{array}$ & .72 & .44 & .70 & .61 & .51 \\
\hline Neglect & .76 & .40 & .71 & .56 & .58 \\
\hline sexual & .65 & .48 & .76 & .69 & .59 \\
\hline
\end{tabular}

- Standardized Item alpha 
Table 43.

Test-Retegt Reliability Coefficients for the AFMI Subscales.

\begin{tabular}{|c|c|c|c|c|c|}
\hline \multirow{3}{*}{$\begin{array}{l}\text { Maltreatment } \\
\text { Interview }\end{array}$} & \multicolumn{5}{|c|}{ Retest Reliability Coefficients" } \\
\hline & \multicolumn{2}{|c|}{ Perpetrator Scalea } & \multicolumn{3}{|c|}{ Self scaleg } \\
\hline & Blame & Excuse & $\begin{array}{c}\text { Blame } \\
\text { Cognition }\end{array}$ & Excuse & $\begin{array}{l}\text { Blame } \\
\text { Affect }\end{array}$ \\
\hline $\begin{array}{l}\text { Hostile } \\
\text { (phyeical } \\
\text { emotional) }\end{array}$ & .78 & .73 & .85 & .86 & .88 \\
\hline $\begin{array}{l}\text { Family } \\
\text { violence }\end{array}$ & .68 & .74 & .83 & .87 & .94 \\
\hline Neglect & .73 & .71 & .88 & .87 & .91 \\
\hline Sexual & .98 & .69 & .98 & .98 & .83 \\
\hline
\end{tabular}

- Mean retegt interval of 31 days 
APPETDIX $B$

Rationale for the selection of Criterion Measures 
Rationale for the Selection of Criterion Measures

The study originally included the Children's Depression Inventory (CDI; Kovacs, 1981), and all the Maladaptive Behavior and Maladaptive Cognition subscales of the Anger Response Inventory. The Skill Deficit and Cognitive Deficit subscales of the ARI were not included in the present study for two reasons. First, skill deficits did not correspond to the specific construct of interest (i.e., self-report of externalizing temper control difficulties). Second, these dimensions proved to be those most influenced by social desirability in the normal population (Horner, 1991). The means and gtandard deviations of all adjugtment measures are reported in Table 44.

The CDI is a self-report measure of depressive symptomatology in children. The CDI has become the most widely used measure of affective disorders in children (Kazdin, 1987; Kerr, hoier, Versi, 1987). The CDI consist of 27 items designed to assess a variety of sympt-ns, such as vegetative disturbance (e.g., appetite 108s, insomia), dysp.sria, and euicidal ideation. For each item, the respondent is requested to endorse one of three sentences describing his or her functioning in the past two weeks. The sentences range from normal or mild states ("I am sad once $\vdots$ a while") to clinically significant symptoms ("I am sad all the time"). The least severe self-description is given a rating of 0 , whereas the most severe is given a 2. A summary score is obtained to a maximum total of 54. The CDI has high internal consistency (Cronbach's alpha of .78 with a nonclinical population). Test-retest reliability ranges from .38 to .87 , depending on interval length and population (Saylor, Finch, Spirito, Bennett, 1984). Finch, Saylor, Edwards (1985) report means and standard deviations for a normative sample for the CDI. These norms were used to generate $T$-scores in the present etudy. 
Table 44.

Meange Standard Deviationg and Skewness of Covariate and Adjugtment Measure日

\begin{tabular}{|c|c|c|c|c|}
\hline Measure & Mean & S.D. & Median & Skewness \\
\hline \multicolumn{5}{|l|}{ Covariates } \\
\hline Age & 13.8 & 1.7 & 14.0 & -.164 \\
\hline Stressful life events" & 5.8 & 3.2 & 6.0 & .544 \\
\hline Receptive vocabulary" & 89.9 & 12.3 & 89.0 & $.871 *$ \\
\hline \multicolumn{5}{|l|}{ Adjustment moasures } \\
\hline $\begin{array}{l}\text { CBCLc Behavior Problem } \\
\text { Total }\end{array}$ & 63.0 & 11.41 & 65.0 & $-.605 *$ \\
\hline CBCL Internalizing & 61.2 & 12.4 & 61.5 & -.346 \\
\hline CBCL Externalizing & 63.1 & 10.7 & 64.0 & -.250 \\
\hline $\begin{array}{l}\text { YSR Behavior Problam } \\
\text { Total }\end{array}$ & 57.6 & 10.1 & 58.0 & .258 \\
\hline YSR Internalizing & 56.5 & 10.0 & 56.0 & -.200 \\
\hline YSR Externalizing & 58.2 & 9.7 & 58.5 & .147 \\
\hline $\begin{array}{l}\text { Child Depression } \\
\text { Inventory }\end{array}$ & 49.8 & 9.7 & 47.7 & 1.07. \\
\hline Maladaptive behavior & 49.1 & 9.9 & 46.0 & $.799 *$ \\
\hline Maladaptive cognition" & 47.8 & 10.2 & 46.4 & $.595 *$ \\
\hline Arousal intensity* & 47.5 & 9.4 & 46.2 & $.876 *$ \\
\hline Arousal duration ${ }^{*}$ & 47.7 & 8.8 & 46.7 & $.967 *$ \\
\hline
\end{tabular}

* indicates significant departure from normality, $e<.01$

- Life Events Checklist - number of bad life events in past year

- Peabody Picture Vocabulary Test - Revised, staridard score

child Behavior Checkligt

d Youth Self Report

- subscales on the Anger Response Inventory 
Research with the CDI has demonstrated that it shares considerable variance with other measures of negative affect (e.g., anxiety) in children ( $V$. Wolfe, Finch, Saylor, Blount, Pallmeyer, \& Careck, 1987). This finding suggests that the CDI is best considered as an indicant of "broad band" negative affect characteristic of internalizing disorders. Thus, the CDI can be regarded as a self-report measure of internalizing symptoms, and can be used to corroborate third-party ratings obtalned on the internalizing dimension of the CBCL.

Table 45 shows the intercorrelations of all the criterion measurea. Because the ultimate plan for the criterion variables was to use them as criteria in several subsequent analyses, it was necessary to select the few most important ones. This strategy was essential to optimize conceptual clarity and minimize tedium for the reader. In view of their conceptual importance, the distinction between reporting sources (self vergus caretaker) was retained. Moreover, factor analyses of the criteria revealed that they dimensionalzzed by reporting source. Therefore, gingle criterion variables representing internalizing and externalizing problems using self and caretaker-report, respectively, were selected. High correlations between criterion variables, signalling potential redundancy, were used as a selection guideline (Tabachnick \& Fidell, 1989). Self-reported depression as measured by the Child Depression Inventory correlated highly wi.th the same construct measured through the Youth Self Report $(\underline{I}=.67)$, and therefore was dropped. Similarly, self-reported aggression based on the Maladaptive Behavior subscale of the Anger Response Inventory was redundant with the Youth Self Report of externalizing problems $(\underline{\underline{x}}=.70), \cdots$ it was also dropped. The self-report of duration of anger arcusal on the Anger Regponse Inventory was redundant with Anger Intensity scores from the same instrument $(E=.84)$. Because the latter (e.g., "I get choked up") logically precedes the former (e.g., "I get choked up for hourg"), 
Table 45.

Intercorrelations of Adjustment Measures

\begin{tabular}{|c|c|c|c|c|c|c|c|c|c|c|}
\hline $\begin{array}{l}\text { Adjustment } \\
\text { measure }\end{array}$ & 2 & 3 & 4 & 5 & 6 & 7 & 8 & 9 & 10 & 11 \\
\hline $\begin{array}{l}\text { 1. CBCL" } \\
\text { Behavior } \\
\text { Problem Total }\end{array}$ & .89 & .87 & .39 & .29 & .37 & .24 & .26 & .20 & .20 & .15 \\
\hline $\begin{array}{l}\text { 2. } \mathrm{BCL} \\
\text { Internalizing }\end{array}$ & & .60 & .38 & .36 & .29 & .28 & .23 & .21 & .21 & .17 \\
\hline $\begin{array}{l}\text { 3. CBCL } \\
\text { Externalizing }\end{array}$ & & & .30 & .14 & .41 & .15 & .24 & .17 & .17 & .11 \\
\hline $\begin{array}{l}\text { 4. YSR } \\
\text { Behavior } \\
\text { Problem Total }\end{array}$ & & & & .89 & .80 & .67 & .62 & .57 & .59 & .55 \\
\hline $\begin{array}{l}\text { 5. YSR } \\
\text { Internalizing }\end{array}$ & & & & & .56 & .67 & .43 & .52 & .54 & .54 \\
\hline $\begin{array}{l}\text { 6. :SR } \\
\text { Externalizing }\end{array}$ & & & & & & .55 & .70 & .49 & .49 & .40 \\
\hline $\begin{array}{l}7 . \text { Child } \\
\text { Depregsion } \\
\text { Inventory }\end{array}$ & & & & & & & .57 & .40 & .36 & .33 \\
\hline $\begin{array}{l}\text { 8. Maladaptive } \\
\text { behaviore }\end{array}$ & & & & & & & & .58 & .46 & .40 \\
\hline $\begin{array}{l}\text { 9. Maladaptive } \\
\text { cognitione }\end{array}$ & & & & & & & & & .68 & .65 \\
\hline $\begin{array}{l}\text { 10. Arougal } \\
\text { intensity }\end{array}$ & & & & & & & & & & .84 \\
\hline $\begin{array}{l}\text { 11. Arougal } \\
\text { duration }\end{array}$ & & & & & & & & & & \\
\hline
\end{tabular}

$\underline{N}=160$

- Child Behavior Checklist

- Youth Self Repcrt

c subscales on the Anger Response Inventory 
Arousal Duration was dropped. Finally, Maladaptive Cognition was highly correlated with anger intensity $(\underline{\underline{c}}=.68)$, and therefore was dropped.

The decision was made to retain Arousal Intensity of all the subscales of the Anger Response Inventory (as opposed to maladaptive cognition, or some aggregation of anger subscales). This decision was made for several reasons. First, the conceptual purity of the subscale - measurement of physiological distress when angry - is maintained. It is unalloyed with other indices of poor temper control. Second, Table 45 indicatep that anger arousal intensity is clearly neither an externalizing nor an internalizing cnnstruct - it sorrelates similariy with both $(\varepsilon=.49$ and .54 , respectively). Ostengibly, poor management of anger arousal could lead to either behavioral outcome. Retaining arousal intensity allowe one to explore this variable as a theoretical precursor of internalizing or externalizing behavior. Fourth, peychometric information obtained from the normative sample of 230 adolescents that compared the arousal intensity subscale to the other ARI subscales indicated that arousal intensity had no relationship with social desirability $(\underline{E}=.03)$, and had excellent internal reliability (Cronbach's alpha $=.86$ ). Fifth, because some research suggests that arousal is managed differently in males and females (Harris siebel, 1976), this subscale may also act in a differential fashion. Finally, because the subscale is based on self-report of physiological symptoms, it is lese prone to the critique of tautology when used as a criterion for cognitive predictors. It could be argued that maladaptive angry cognitions cause negative attributions, rather than the reverse. The causal direction of the association between arousal intensity and negative attributions is less suspect. Thus, the intensity of anger arousal was retained as a criterion variable for all subsequent analyees.

The internalizing and externalizing subscales of the Child Bahavior Checkliet and the Youth Self Report were also retained. The 
CBCL and the YSR have been employed extensively in the previous literature. Also, the internalizing and externalizing scales represent multi-source measurement of the constructs of theoretical interest to this research. To ensure replicability and clarity, they were not amalgamated into aggregate variables. The behavior problem totals were not retained, given their high correlations ( $\underline{x}=.89$ ) with their corresponding internalizing and externalizing scales. 
APPEIDIX C

The Anger Response Inventory 


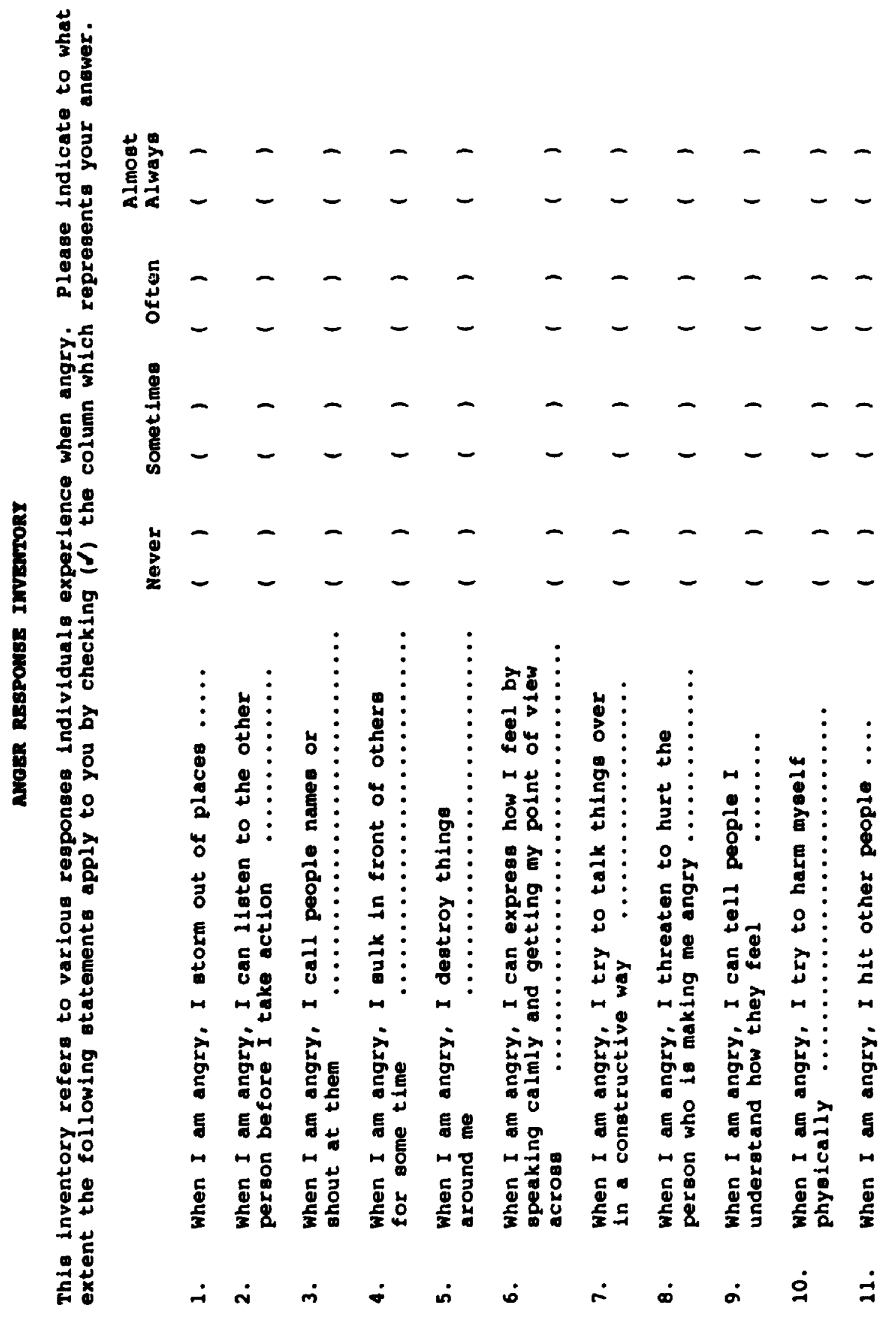




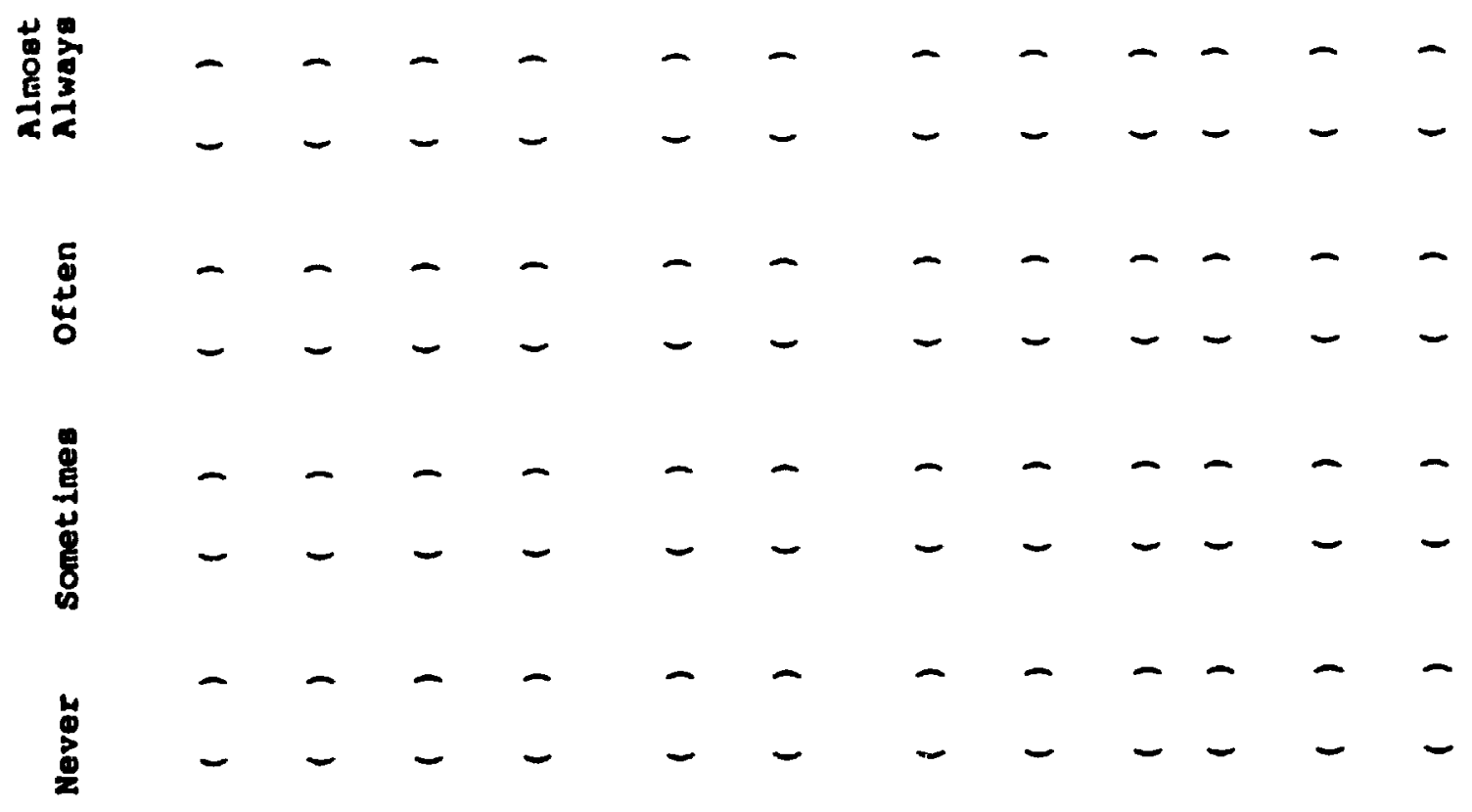

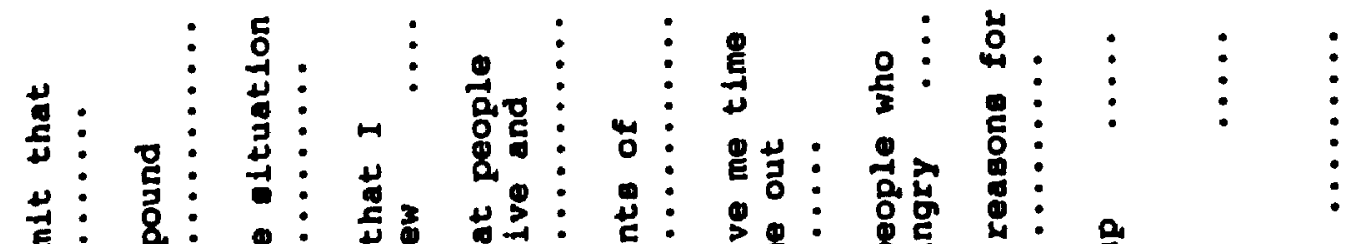

声：

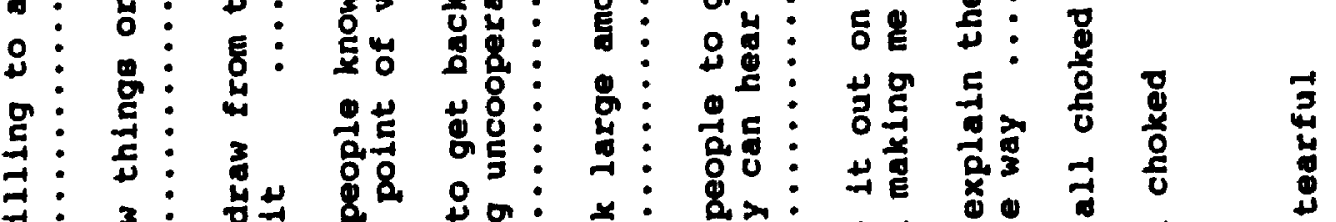

声:

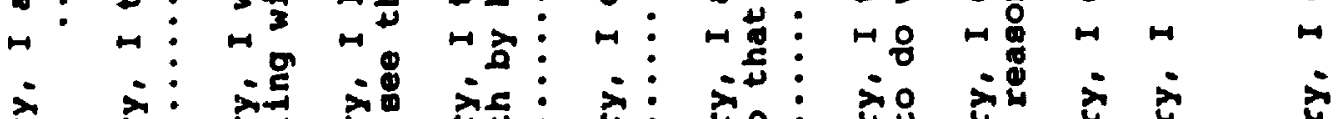

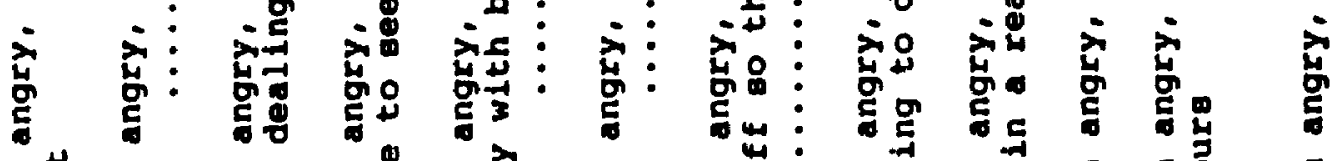

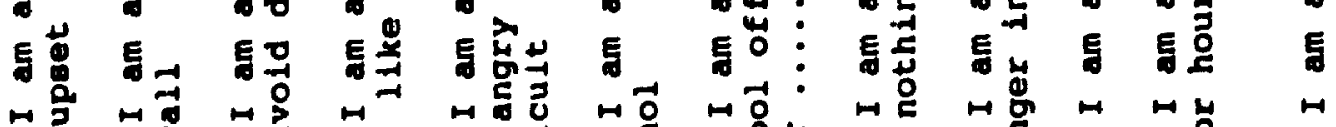
它志

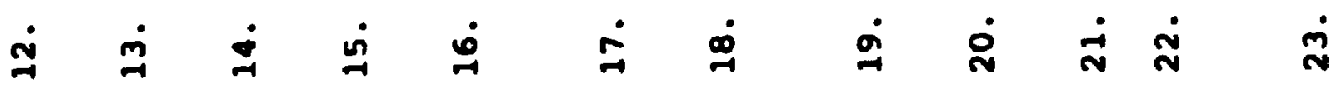


蕞尌

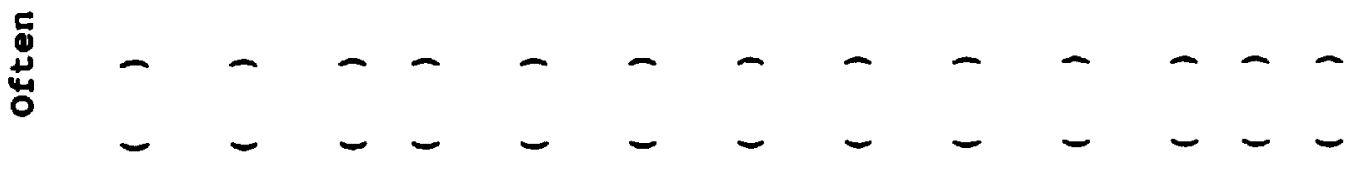

b-

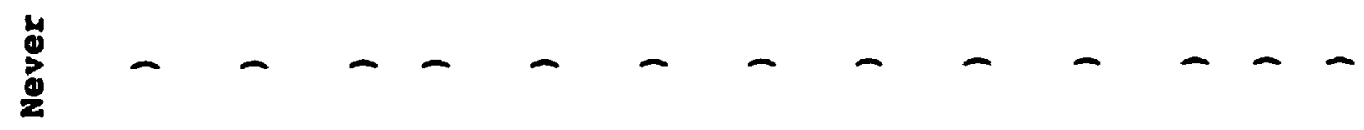

-

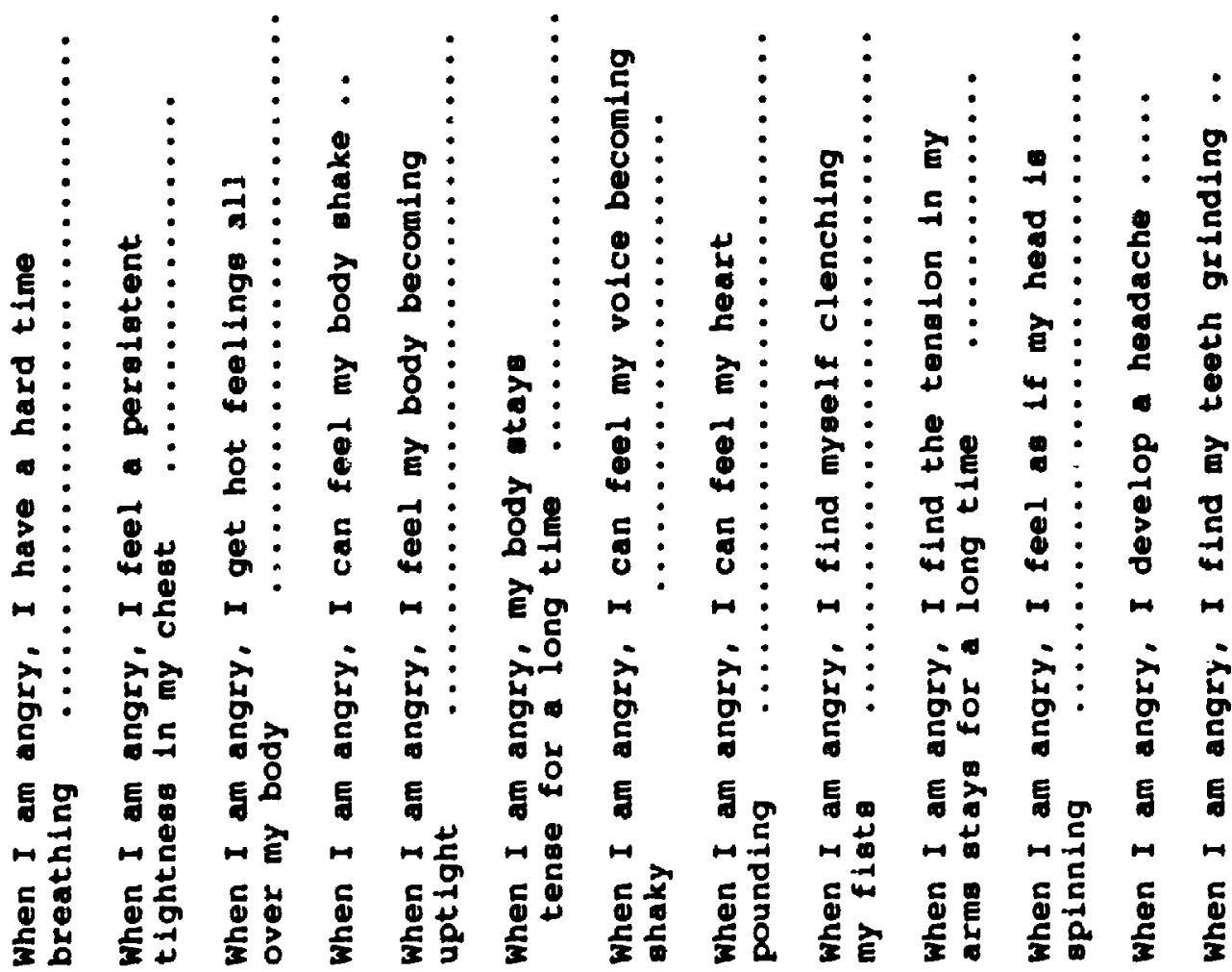

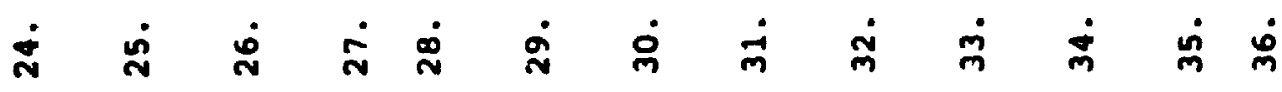



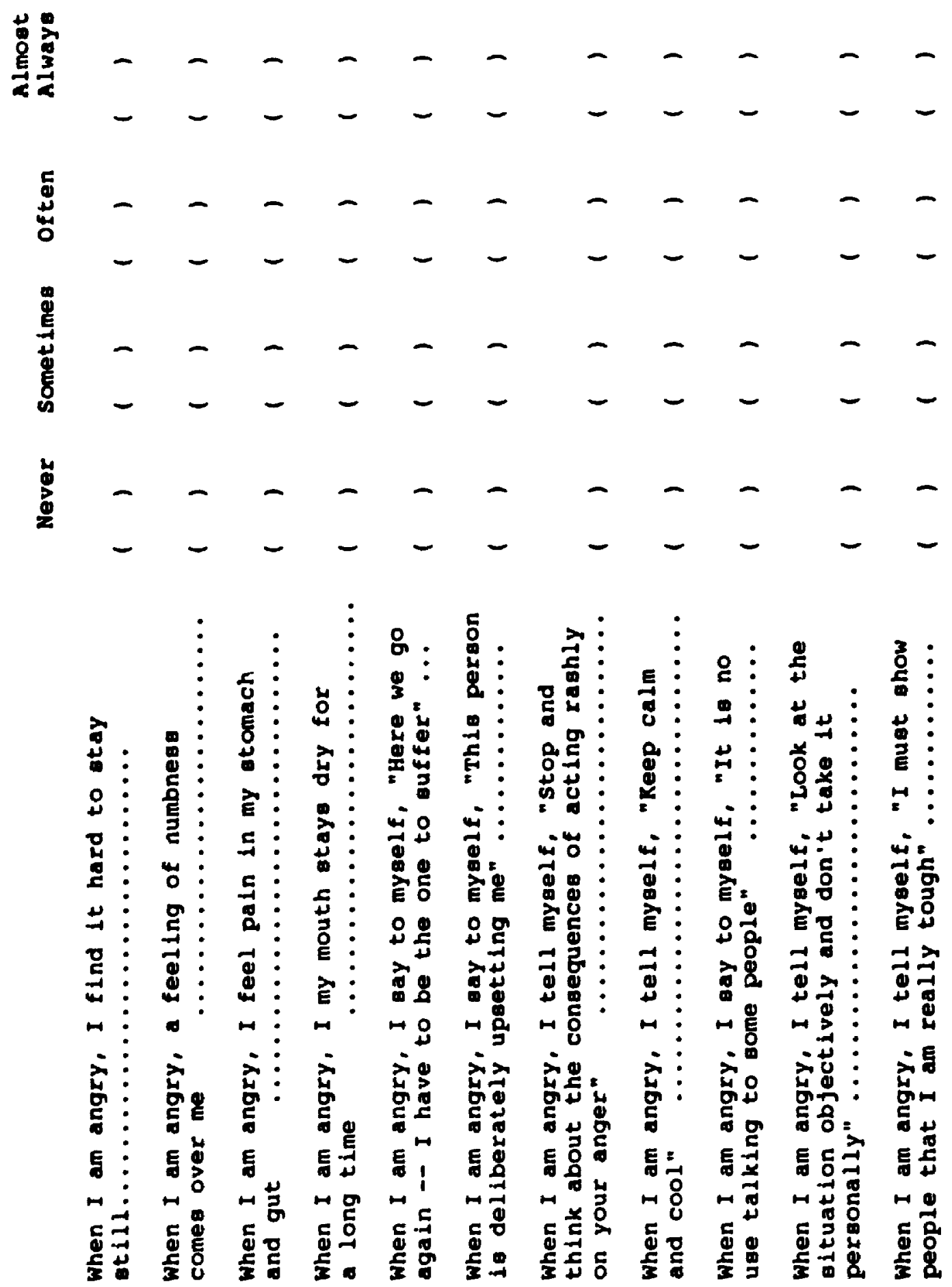

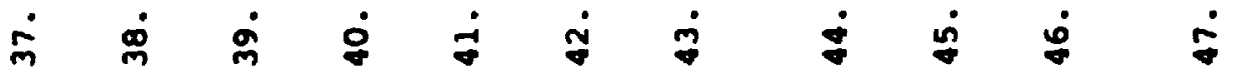




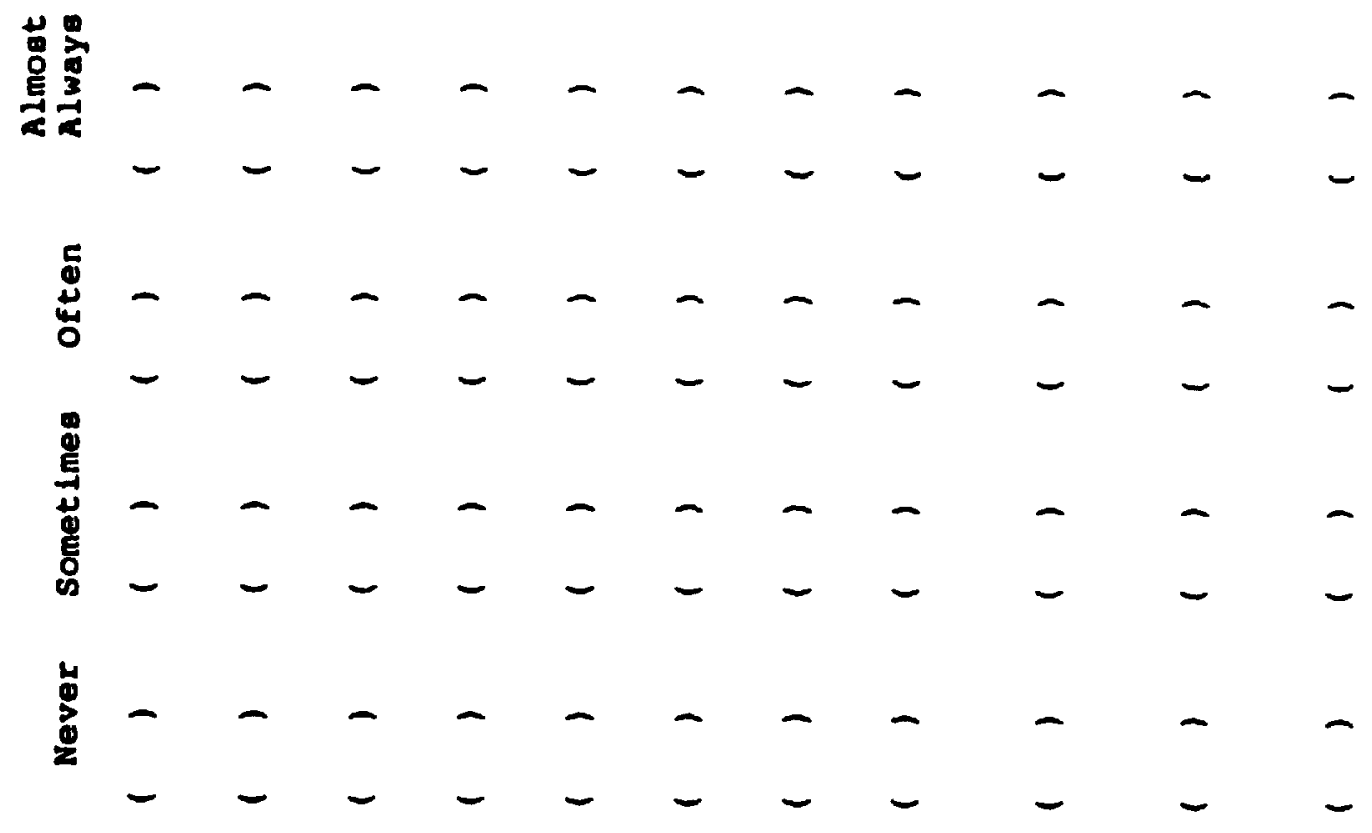

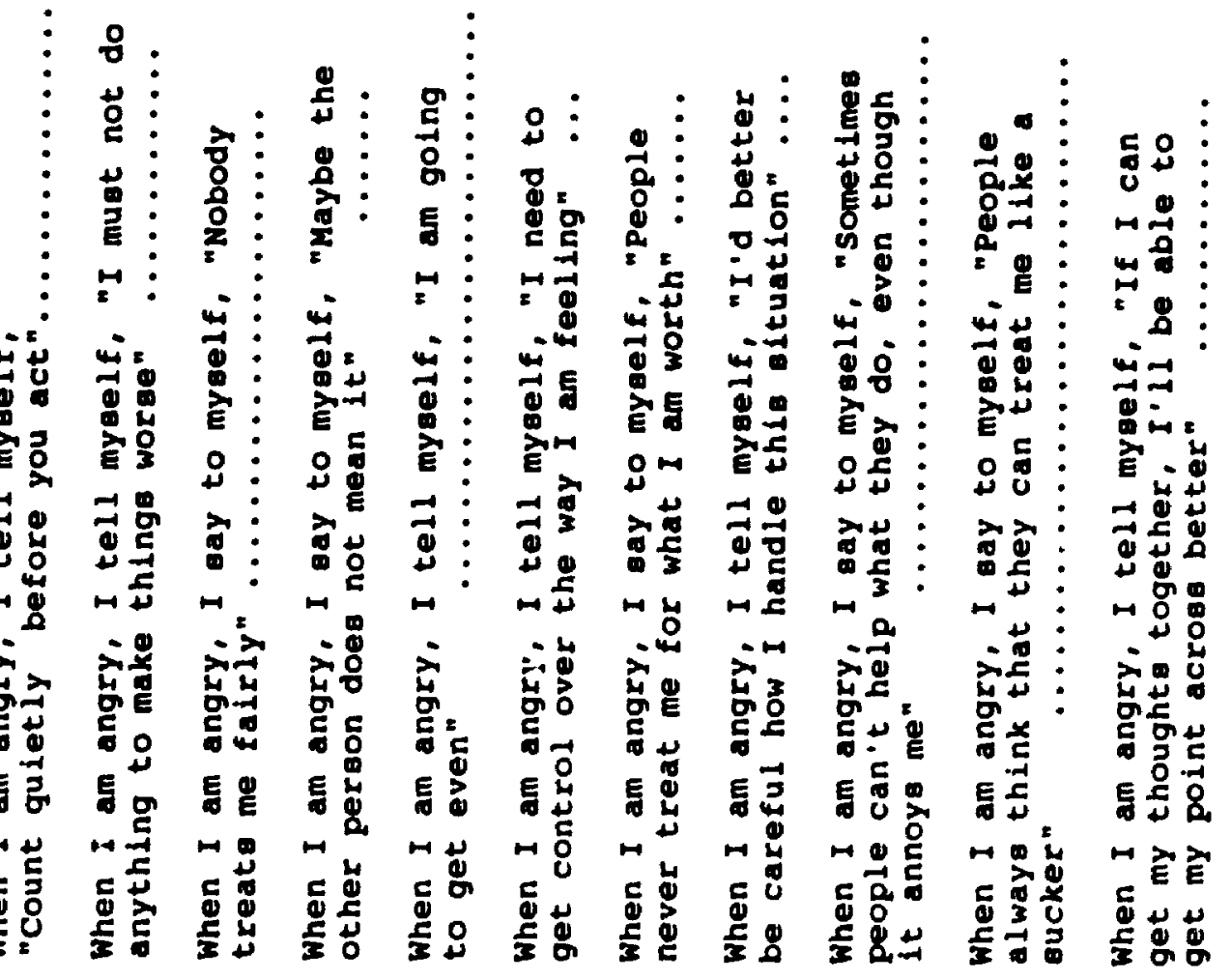

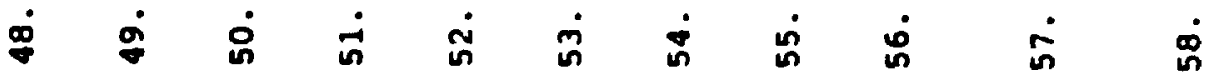



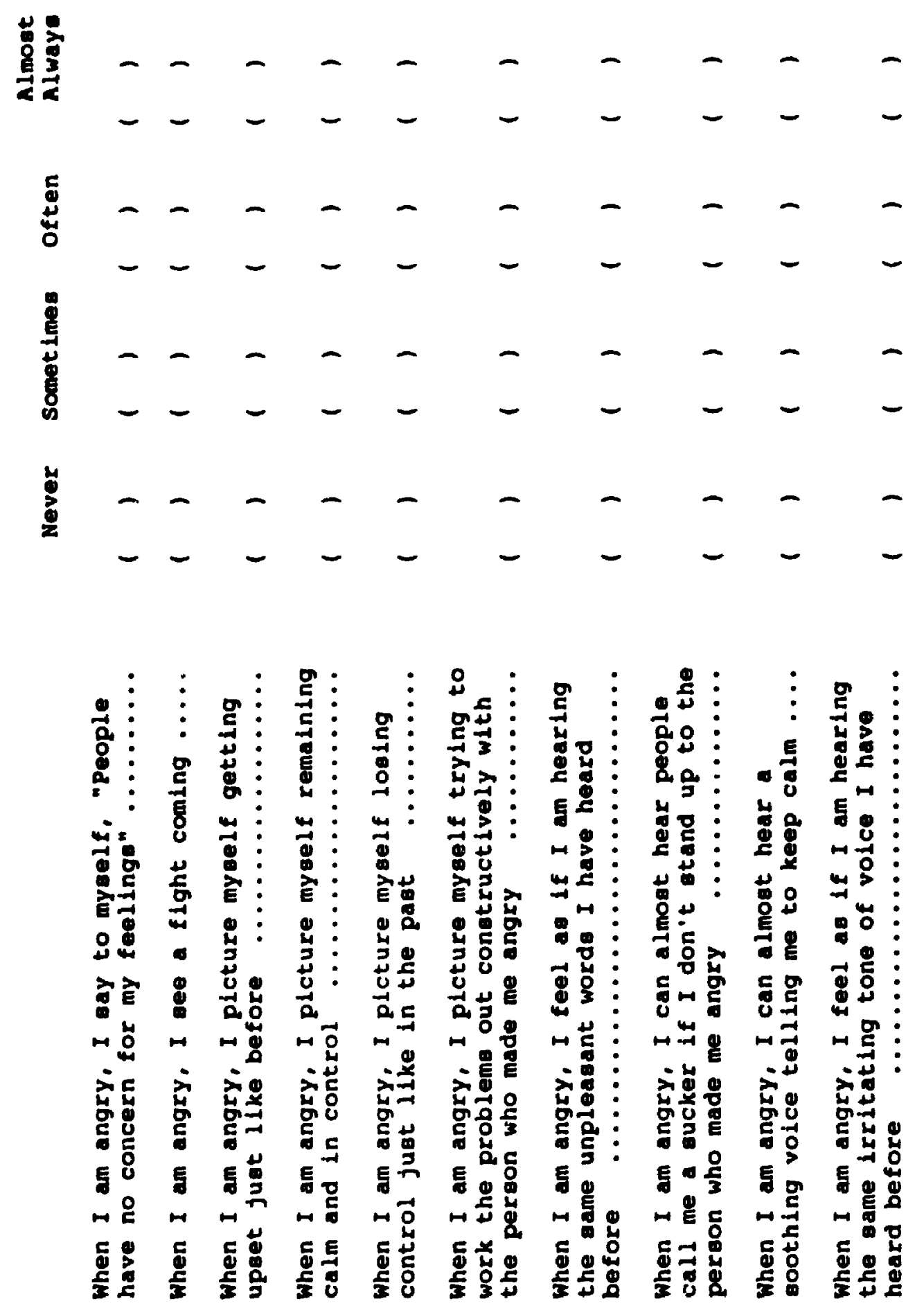

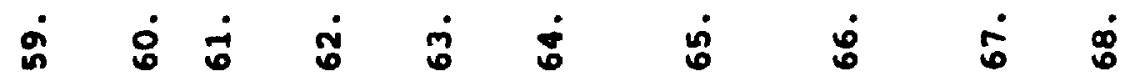




\section{APPENDIZ D}

A Record of Maltreatment Experiences (pages 1 to 3)

Interrater Reliability Coefficients for File Judges 
Name of child

Agency file

Todaye date

Child's date of birth

1

Child's current address

Name of mother

Name of father

Mother's higheat level of education

Mother's current occupation

Otficial agency clasuification/reason for service

1) At intake (abel/code)

2) Currently (Inbel/code)

$(d / m / y)$ $(d / m / y)$
Caseworker

Sex of child: D M F

Current school grade

Over the child's life, to what extent ha he/ahe experiestced the following? Plenee indicate the perpetratorts).

\begin{tabular}{|c|c|c|c|c|}
\hline & Not at all & Mildiy & Moderately & Severely \\
\hline Physical abuse & $\begin{array}{l}\text { Q Mocher } \\
\text { Q Futher } \\
\text { Q Ober (identify) }\end{array}$ & $\begin{array}{l}\text { Q Mocher } \\
\text { Q Futher } \\
\text { Q Oher (identify) }\end{array}$ & $\begin{array}{l}\text { D Mocher } \\
\text { Q Father } \\
\text { Q Other (identify) }\end{array}$ & $\begin{array}{l}\text { O Mother } \\
\text { Q Futher } \\
\text { O Oher (identify) }\end{array}$ \\
\hline Sermal abure & $\begin{array}{l}\text { Q Molner } \\
\text { Q Fother } \\
\text { Q Ober (identify) }\end{array}$ & $\begin{array}{l}\text { Q Mocher } \\
\text { Q Fuber } \\
\text { Q Other (identify) }\end{array}$ & $\begin{array}{l}\text { Q Moiner } \\
\text { Q Facher } \\
\text { D Odher (ideatify) }\end{array}$ & $\begin{array}{l}\text { Q Mocher } \\
\text { Q Father } \\
\text { Q Oher (idencify) }\end{array}$ \\
\hline Exposare to wife assanls & $\begin{array}{l}\text { Q Mother } \\
\text { a Fuher } \\
\text { Q Ober (identify) }\end{array}$ & $\begin{array}{l}\text { Q Mother } \\
\text { Q Fuher } \\
\text { D Obher (identify) }\end{array}$ & $\begin{array}{l}\text { O Mother } \\
\text { O Father } \\
\text { O Odher (identify) }\end{array}$ & $\begin{array}{l}\text { Q Mother } \\
\text { D Father } \\
\text { D Ober (idenify) }\end{array}$ \\
\hline Pisychological maloreament & $\begin{array}{l}\text { Q Mother } \\
\text { Q Futher } \\
\text { D Other (ideatify) }\end{array}$ & $\begin{array}{l}\text { D Mother } \\
\text { D Father } \\
\text { D Other (ideatify) }\end{array}$ & $\begin{array}{l}\text { D Mother } \\
\text { Facher } \\
\text { D Ocher (identify) }\end{array}$ & $\begin{array}{l}\text { D Mother } \\
\text { D Facher } \\
\text { D Oher (idencify) }\end{array}$ \\
\hline Neglect & $\begin{array}{l}\text { Q Mother } \\
\text { Q Father } \\
\text { Q Other (identify) }\end{array}$ & $\begin{array}{l}\text { Q Mother } \\
\text { O Father } \\
\text { O Other (idenufy) }\end{array}$ & $\begin{array}{l}\text { Q Mocher } \\
\text { Dather } \\
\text { Q Oher (identify) }\end{array}$ & $\begin{array}{l}\text { I Mothe } \\
\text { D Falher } \\
\text { O Other (identify) }\end{array}$ \\
\hline
\end{tabular}

MoCer, RA. Wolle, DA \& Wileon S.K (1990).

(Ooer)

Dept of Paycholory. Unuverniry of Wexern Onerto

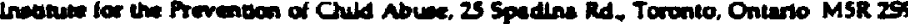


Family Information

1. Indicate how often this child has contact with the parents.

$\begin{array}{lcccccc} & \text { No contect } & \text { Daily } & \text { Weekly } & \text { Monthly } & 34 \text { trmesiyear } & \text { Yearly } \\ \text { Natural Mother } & 0 & 0 & 0 & 0 & 0 & 0 \\ \text { Natural Father } & 0 & 0 & 0 & 0 & 0 & 0\end{array}$

2. Using the chart below, please provide background information on the followng individuals:

\begin{tabular}{|c|c|c|c|c|}
\hline & $\begin{array}{c}\text { Neohol } \\
\text { abuse }\end{array}$ & Drug abuse & Psychintric prob!eme & Crimunal behenour \\
\hline $\begin{array}{l}\text { Natural } \\
\text { Mother }\end{array}$ & $\begin{array}{l}\text { No a } \\
\text { Yes } 0\end{array}$ & No a Yes O Substance: & No a $Y e$ O Diagnosis: & No a tes O Convicuon \\
\hline $\begin{array}{l}\text { Natural } \\
\text { Father }\end{array}$ & $\begin{array}{l}\text { No } 0 \\
\text { Yes } D\end{array}$ & No O Ye Q Substance: & No J Yes Q Dugnouss. & No C Yes O Connction \\
\hline $\begin{array}{l}\text { Step/ } \\
\text { Cornmon-law } \\
\text { Mother }\end{array}$ & $\begin{array}{l}\text { No } 0 \\
\text { Yes } 0\end{array}$ & No 0 Yes D Subutance: & No O Yes O Diagnous: & No a Ye O Convicton: \\
\hline $\begin{array}{l}\text { Stepl } \\
\text { Conmon-law } \\
\text { Father }\end{array}$ & $\begin{array}{l}\text { No D } \\
\text { Yes }\end{array}$ & No O Yes D Substance & No O Yes O Diagrosis: & No o Ye D Connction: \\
\hline
\end{tabular}


rable 51.

The "Mator Cauge" for Neglect and the Adolescent's Perceived Role in it

\begin{tabular}{|c|c|}
\hline Major cause & Percentage \\
\hline Perpetrator cared more for someone eloe & 22.7 \\
\hline Perpetrator did not love me & $12 \cdot 4$ \\
\hline $\begin{array}{l}\text { Perpetrator bugy with } \\
\text { otier problems }\end{array}$ & 11.3 \\
\hline My migbohavior & 8.2 \\
\hline Perpetrator forced to by someone else & 8.2 \\
\hline Perpetrator'a bad temper & 6.1 \\
\hline I was st imporrant & 5.2 \\
\hline PeIp rator's personaitiy, cruelty & 5.2 \\
\hline Perpetrator's drinking & 5.2 \\
\hline Perpetraior's fear/ignorance of parenting & 5.1 \\
\hline No money & 4.2 \\
\hline Perpeis 3 :or is mentally ill & 4.1 \\
\hline \multirow[t]{2}{*}{ Perpetrator abused as a child } & 2.1 \\
\hline & 1008 \\
\hline \multicolumn{2}{|l|}{ Adolescent 's role in maltreatment } \\
\hline Did not do anything & 32.3 \\
\hline Did not prevent it & 19.8 \\
\hline Miebehavior & 19.8 \\
\hline Defied or rejected perpetrator & $12 \cdot 5$ \\
\hline $\begin{array}{l}\text { Was unacceptable to ferpetrator (e.g., not their } \\
\text { natural child) }\end{array}$ & 8.3 \\
\hline Uninientionally provoked & $5 \cdot 2$ \\
\hline Tried to escape, withdraw & 2.1 \\
\hline & 1008 \\
\hline
\end{tabular}

$\underline{N}=96$ 
Table 46.

Interrater Reliability Coefficients for File Judges Maltreatment Ratings.

\begin{tabular}{|c|c|c|c|}
\hline \multirow{2}{*}{\multicolumn{2}{|c|}{ Maltreatment Type }} & \multicolumn{2}{|c|}{$\begin{array}{c}\text { Reliability Coefficient } \\
\text { File Raterg } \\
\end{array}$} \\
\hline & & Maximum score & Perpetrator score \\
\hline \multicolumn{4}{|l|}{ Physical } \\
\hline & Mother & .89 & .75 \\
\hline & Father & & .94 \\
\hline & other & & .93 \\
\hline Sexual & & .96 & \\
\hline & Mother & & - \\
\hline & Father & & - \\
\hline & other & & .96 \\
\hline Family Violence & & .87 & \\
\hline & Mother & & .87 \\
\hline & Father & & .93 \\
\hline & Other & & .84 \\
\hline Emotional & & .79 & \\
\hline & Mother & & .81 \\
\hline & Father & & .90 \\
\hline & Other & & .84 \\
\hline Neglect & & .79 & \\
\hline & Mother & & .86 \\
\hline & Father & & .77 \\
\hline & Other & & .95 \\
\hline
\end{tabular}


APPENDIX $\mathbf{E}$

\author{
Ratings of Past Life Events Scale \\ Test-retest Reliability Coefficients
}




\section{RATINGS OF PAST LUFE EVENTS}

As an important part of what we are doing, we want to hear your thoughts and feelings about things you have experienced in your past. Particularly, we are interested in your perceptions of how you have been treated by adults during your life.

Some people find these questions to be personal. If they make you uncomfortable, just let us know. You do not have to answer if you do not want to.

Score

Physically maltreated (hit, slapped): Mother

Father

Other

Sexually maltreated (touched in a

Mother

sexual way that made you feel

uncomfortable)

Father

Other

Exposed to violence between adults (physical fighting between your parents, parent/partner)

Mother

Father

Other

Negiected (e.g., not looked after

Mother

properly, ignored, not paid attention)

Father

Other

Emotional (e.g., criticized, yelled at,

Mother

or treated in a way that was

unfair to you)

Father

Other 


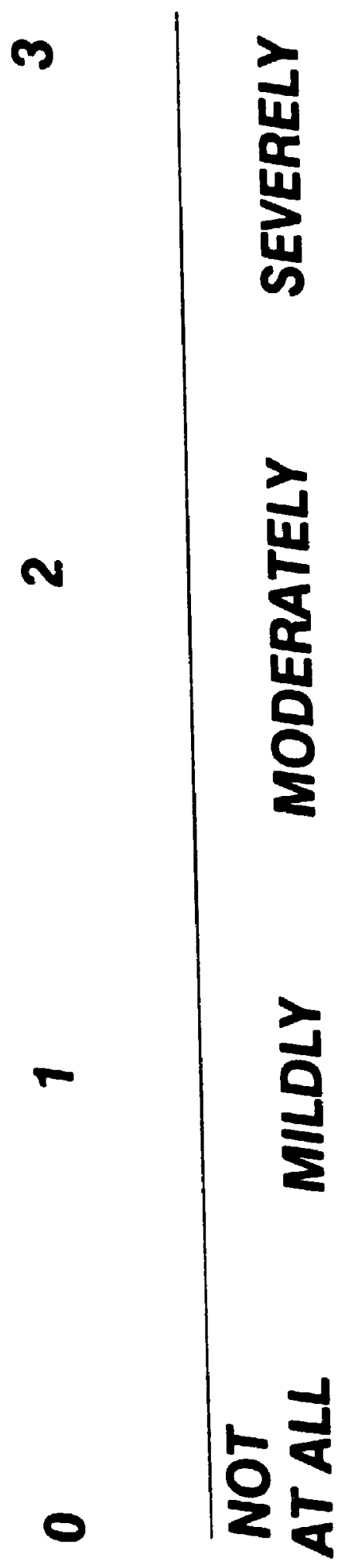


Table 47.

Test-retest Reliability Coefficients for Adolescent Maltreatment Ratings.

\begin{tabular}{|c|c|c|c|c|}
\hline \multirow{2}{*}{\multicolumn{2}{|c|}{ Maltreatment Type }} & \multicolumn{3}{|c|}{$\begin{array}{c}\text { Reliobility coefficient } \\
\text { Adolescent Retest: }\end{array}$} \\
\hline & & Maximum score & Perpetrator & score \\
\hline \multicolumn{5}{|l|}{ Physical } \\
\hline & Mother & .90 & .96 & \\
\hline & Father & & .94 & \\
\hline & Other & & .93 & \\
\hline Sexual & & .93 & & \\
\hline & Mother & & - & \\
\hline & Father & & - & \\
\hline & other & & .93 & \\
\hline Family Violence & & .92 & & \\
\hline & Mother & & .81 & \\
\hline & Father & & .93 & \\
\hline & other & & .94 & \\
\hline Emotional & & .70 & & \\
\hline & Mother & & .83 & \\
\hline & Father & & .84 & \\
\hline & other & & .68 & \\
\hline Neglect & & .89 & & \\
\hline & Mother & & .73 & \\
\hline & Father & & .93 & \\
\hline & Other & & .85 & \\
\hline
\end{tabular}

- Mean retest interval 31 days $\mathrm{N}=33$ 
APEANDIX F

The Life Events Checklist 


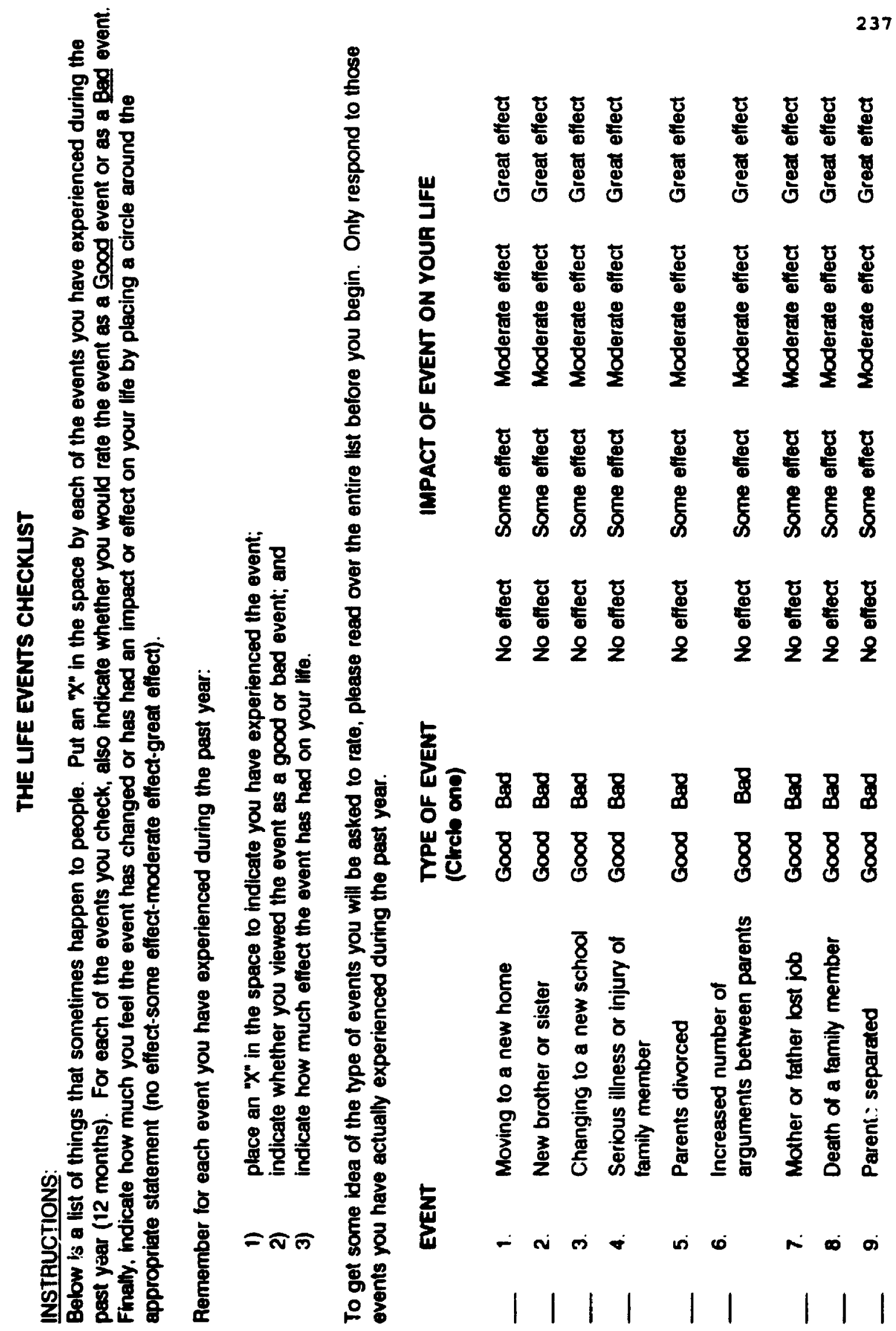




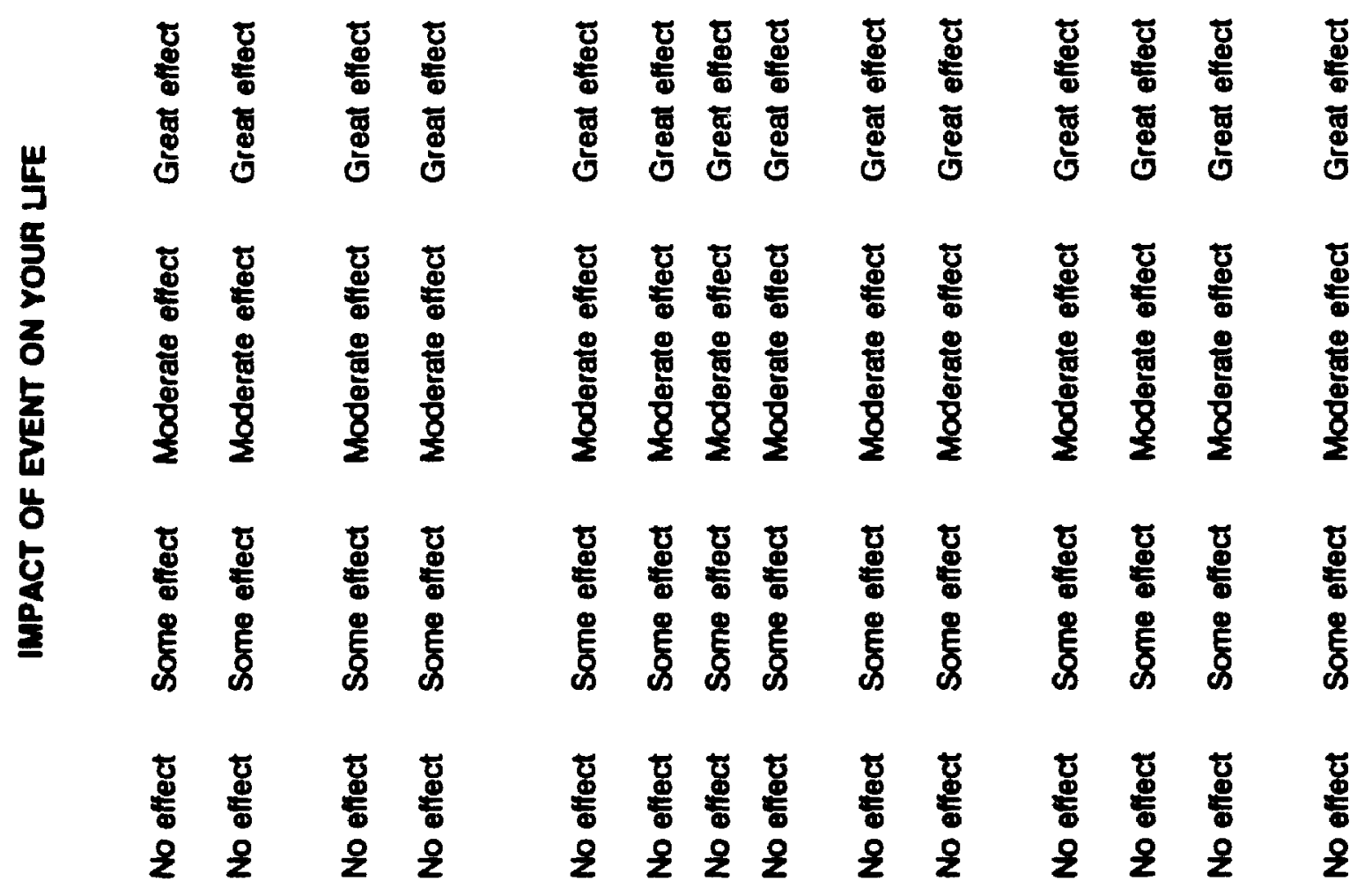

5

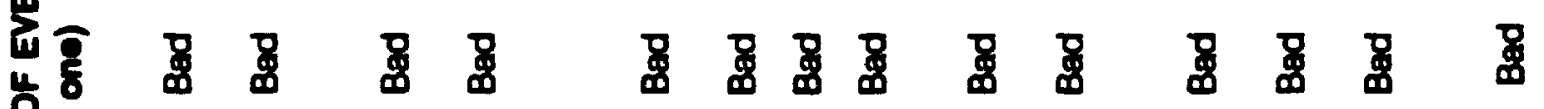

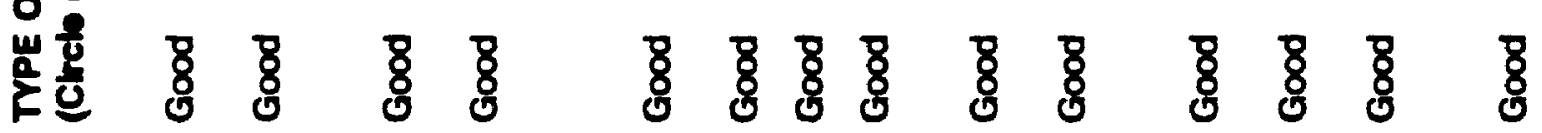

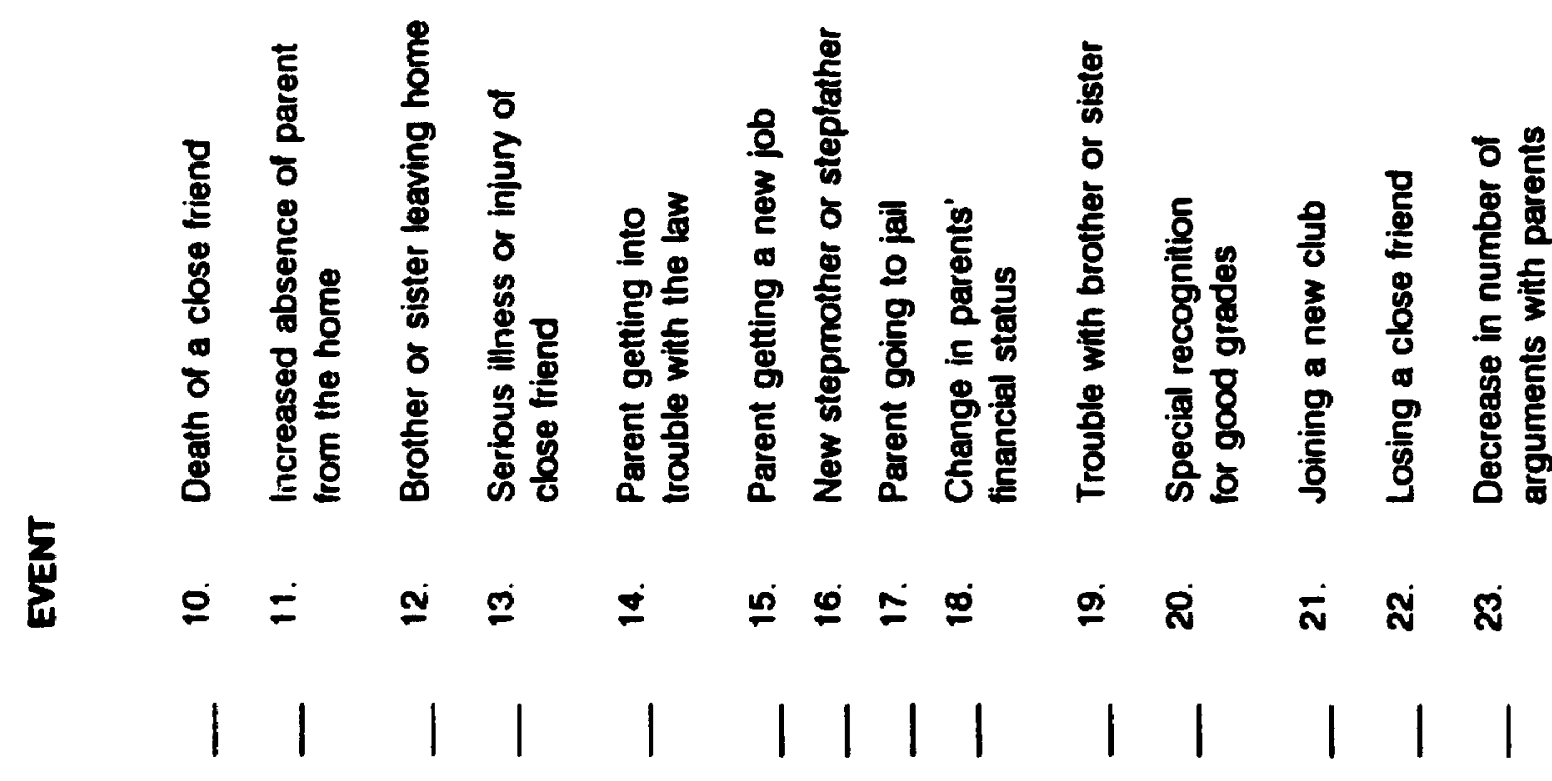




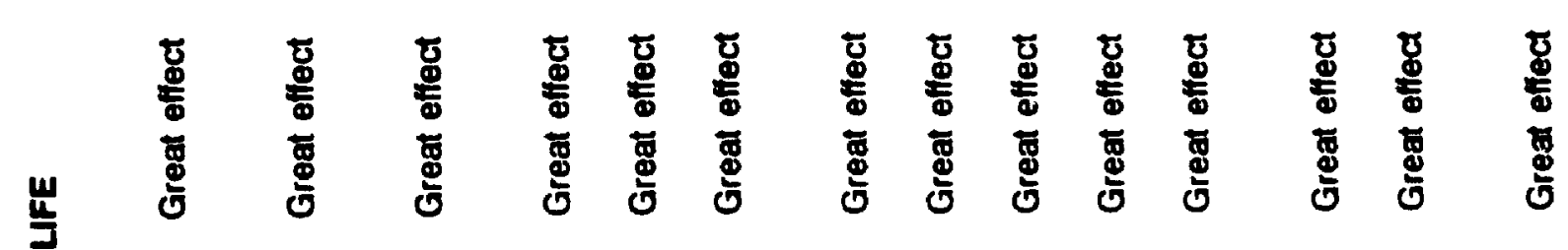

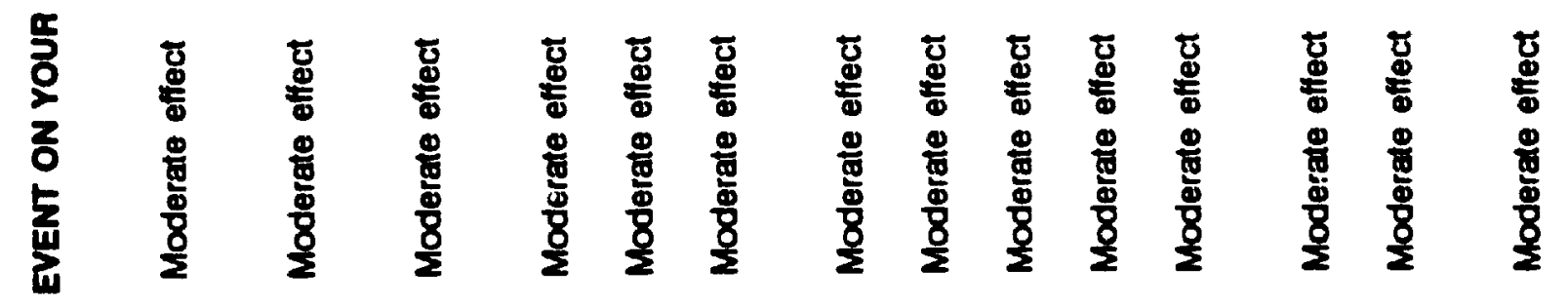

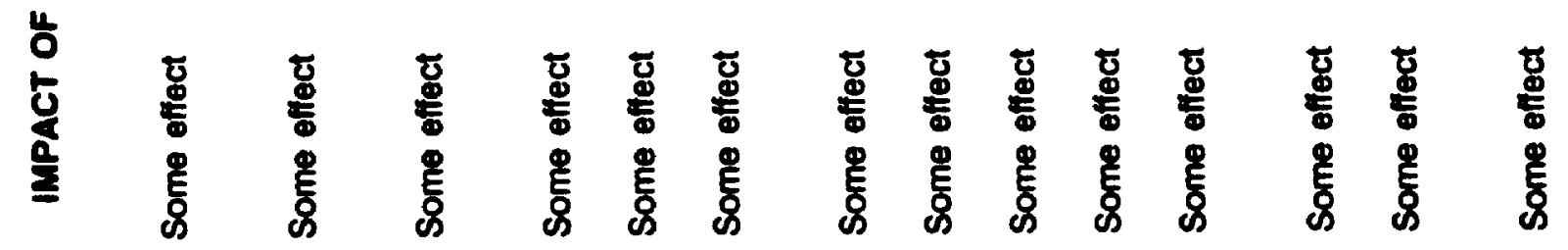

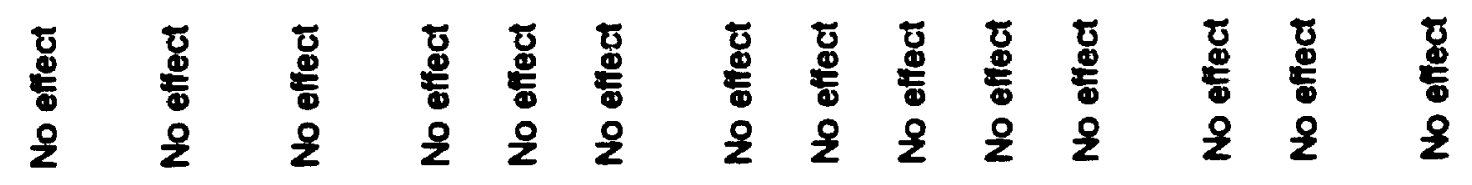

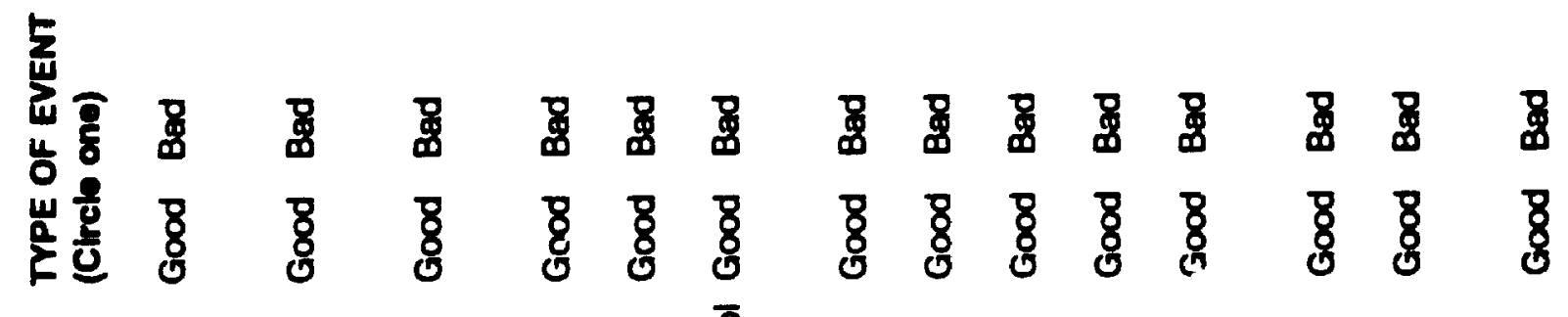

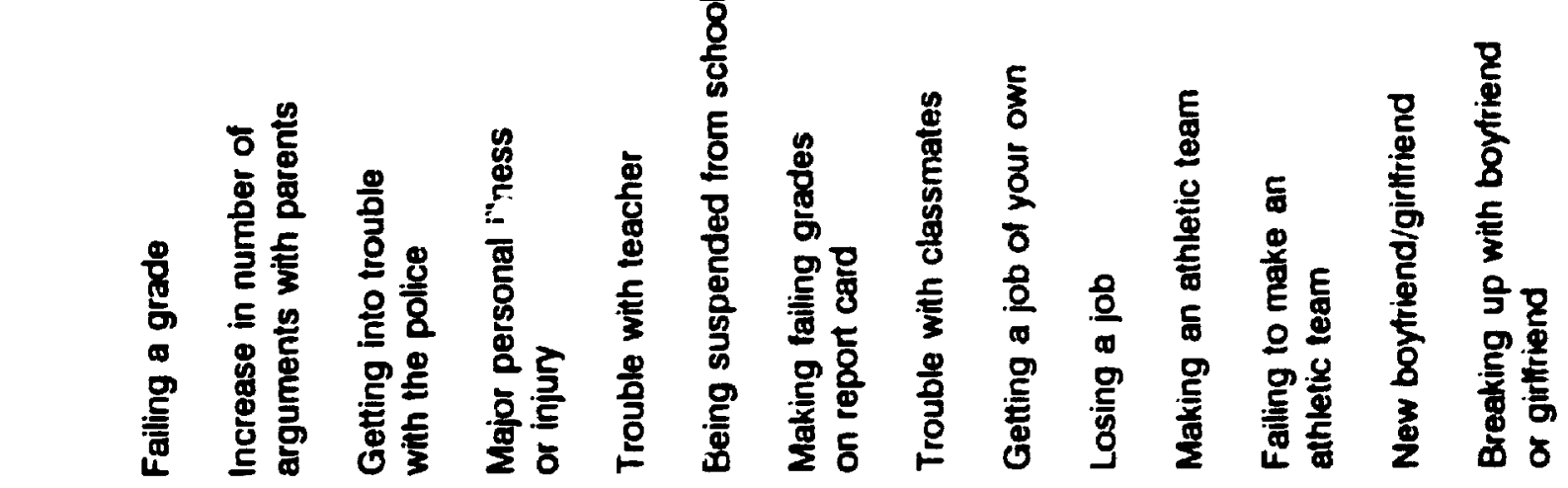
意

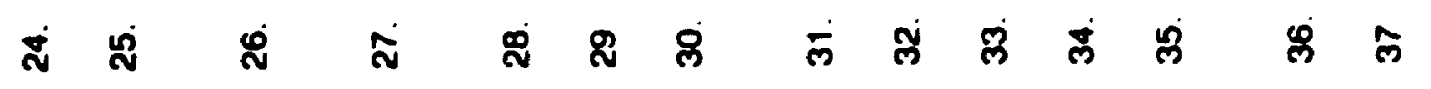

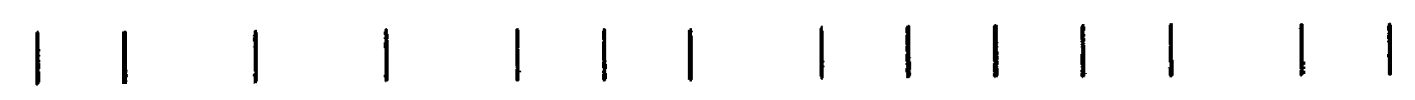




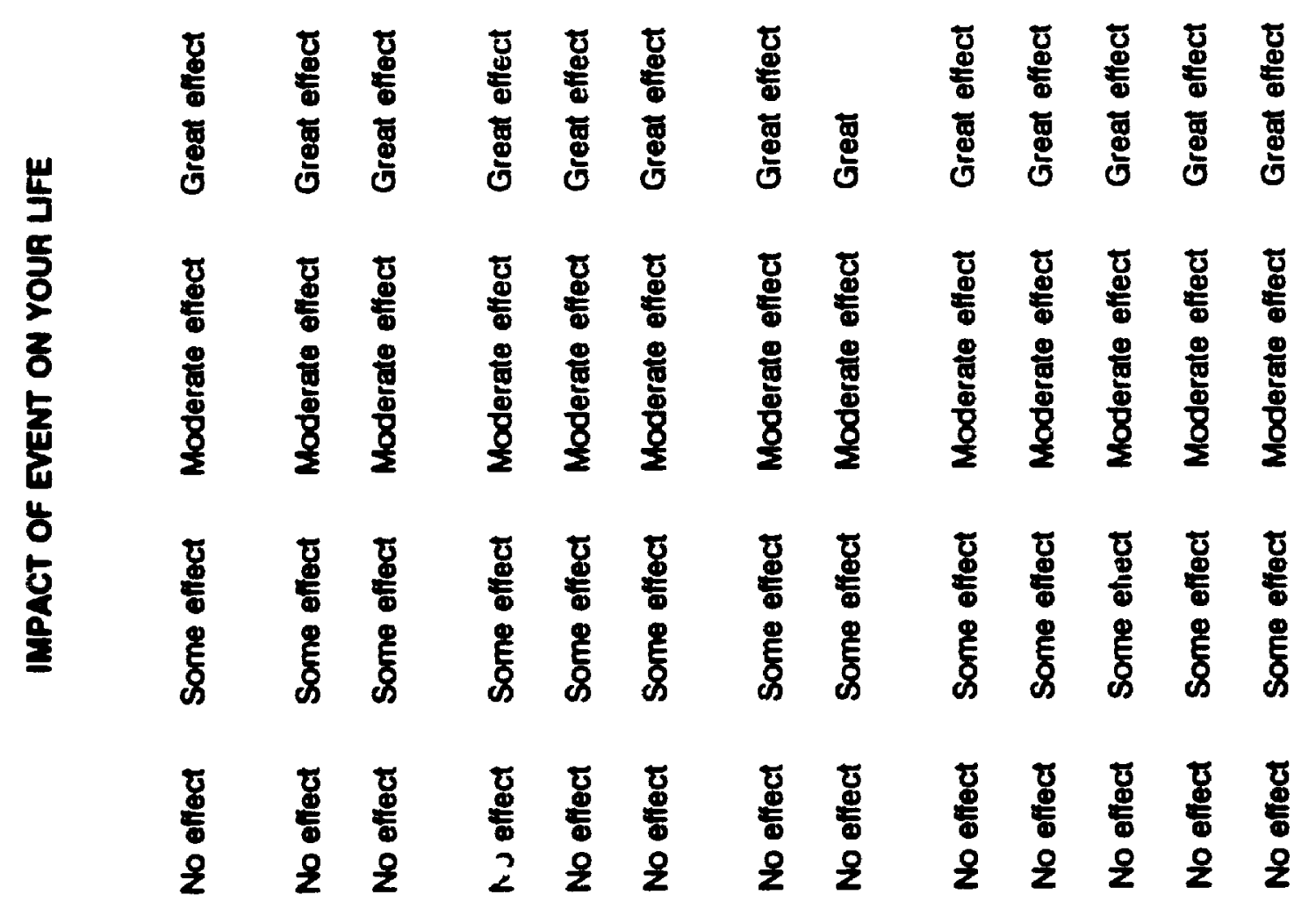

5

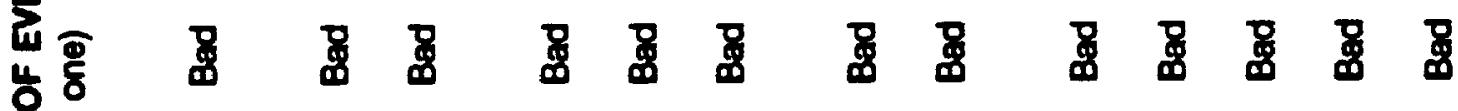

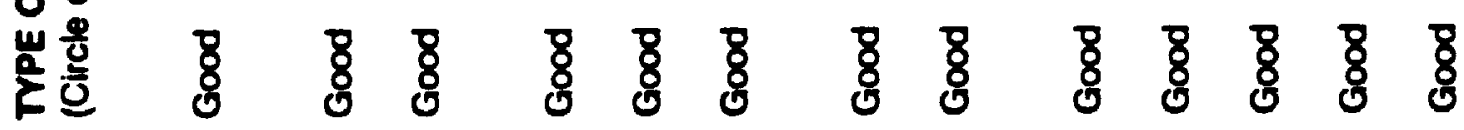

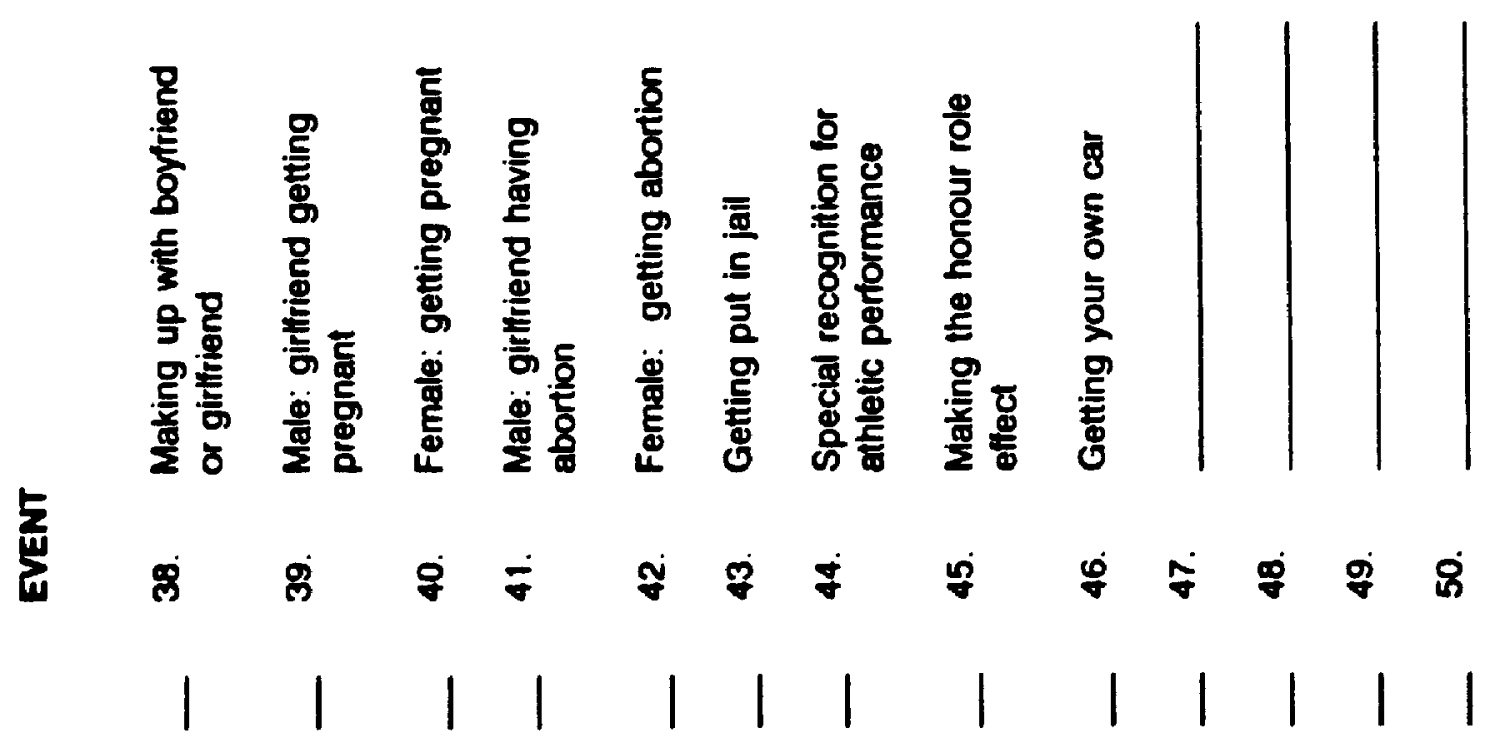


APPATDIX 0

Letter of Permision to Contact 
Letter of Permission to contact

Dear Parant:

Our agency is involved in a research project in association with researchers from the University of western Ontario. The purpose of the study is to examine the relationship between life experiences and adolescent development. Your family name has been picked at random from all the families served by Family and Children's Services, giving your child/ren an opportunity to participate. Your child would be paid $\$ 15.00$ for completing questionnaires and attending an interview.

In the next week, research gtaff member Jean Carnochan will be contacting you by telephone to ask if you would consent to your child's participation in the study. If you do not want to be telephoned, please tell me or leave a meseage for Jean Carnochan. Participation is completely voluntary - refusal to participate in no way harmo your statue with the agency or affects the eervice you will receive.

Jean Carnochan will explain the research in greater detail when she contacte you. If you have any questions in the meantime, please call her at 434-8461 ext 311, or leave a meseage. Thank you for your coneideration.

Youre aincerely. 
APPWDII $\mathbf{B}$

Letter of Research Explanation anc Informed Consent (Parents and Adolescents) 


\title{
RESEARCE INFORUATION FOR PARENTS
}

\begin{abstract}
My students and $I$ are interested in learning how childhood experiences with family members affect a child's behavior and adjustment later on during adolescence. As you know, parents have a major influence on how the child comes to view him or her gelf and others. For this reason, we hope to identify the manner in which a child's upbringing and family life can affect his or her later sense of wel1being. To accomplish this task, we are requesting your permission and that of your son or daughter to participate in a study of adolescents' adjustment and family background. He or she will be paid $\$ 15$ for his or her participation, even if you or your child decide to discontinue being a part of the otudy.
\end{abstract}

Firet, a member of our research team will come to your home. She will give several questionnaires to your adolescent and one to you. Your questionnaire will ask about your son's or daughter's behavior at l.ome, at school, and with friends. It will take about 20 minutes to complete. Your adolescent ' g questionnaires wili ask about his or her recent behavior, thoughts, and feelings. They will take about an hour to complete.

Next, we will interview your son or daughter privately at the Children's Aid Society. During the interview, he or she will be asked to discuen his or her thoughts and feelings about positive and negative experiences with family members in the past. Altogether, the interview will take one hour to complete. Finally, your caseworker will be asked to provide information on your child's amily background and experiences prior to involvement with the agency.

No family member will be identified in any manner as being a part of this study, and all of the interview and questionnaire materials will be restricted to our research group and destroyed within five years of the completion of the study. Therefore, your answers are kept confidential (subject to the Child and Family services Act, which requires reporting to the Children's Aid society if a child is believed to be in danger). Neither you nor your child is obliged to answer any questions you find objectionable or that make you feel uncomfortable. If at any time your child indicates that he or she does not wish to participate, he or she will be excused with no penalty. You may also withdraw your consent at any time. If you do not wish your child to participate in this study, this decision will in no way affect his or her status with Children's Aid.

There are no costs, special fees, or known risks associated with your involvement in this study. To assist in planning for your family, we are prepared to send a summary of the findings to your social worker at the agency with your written permission, and we will discuss the results with you in person should you so desire.

Thank you very much for your consideratior. Please complete the attached form if you decide to participate in this study. If you have any questions or comments please feel free to contact:

Dr. David A. Wolfe

Professor, The University of Western Ontario Psychologist, Children'a Aid Society of London/Middlezex Phone: 661-3683 


\section{PARENT'S CONSENT TO RESEARCH PARTICIPATION}

I understand what is involved in Dr. Wolfe's study on family background and adolescent adjustment, and I voluntarily consent to having my child, - and myself participate in the study. (Child's name)

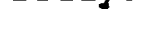

We also would like your permiseion to contact you again in the future if we do further research on this topic. If agreeable, please initial:

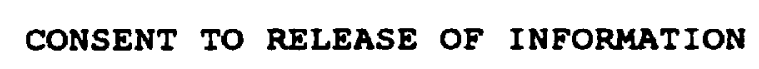

I agree to have information about my child and family obtained from this assessment to be prepared as a written report and sent to my social worker at the Children's Aid Society:

(Name of Social Worker) 


\section{RESEARCH INFORMATION FOR ADOLESCENTS}

We are intsrested in learning more about how teens and their family members got along in the past may affect the teen'e behavior and adjustment later on. As you know, your parents play a major role in how you come to view yourself and others. For this reason, we hope to identify the manner in which a child's upbringing and family life can affect his or her later sense of well-being. To accomplish this task, we are requesting your permibsion and that of you parent or guardian to participate in a study of teenagers' adjustment and family background. You will be paid $\$ 15.00$ for your time and effort, even if you or your parent decide to discontinue being a part of the atudy.

Firgt, a member of our research team will cone to your home. She will give several questionnaires to you and one to your parent/guardian. Your questionnaires will ask ahout your recent behavior, thoughts, and feelinge. Your questionnaires will take about an hour to complete. Your parent/guardian's questionnaires will ask about your behavior at home, at school, and with friends. It will take about 20 minutes to complete.

Next, we will interview you privately at the Children's Aid Society. During the interview, you will be asked to discuss your thoughts and feelings about positive and negative experiences with family members in the past. Altogether, the interview wi] take one hour to complete. Finally, your caseworker will be asked .o provide information on your family background prior to involvement with the agency.

You will not be identified in any manner as being a part of this study, and all of the inter: $w$ and questionnaire materials will be restricted to our research group and destroyed within fi-s years of the completion of the otudy. Therefore, your answers are kept confidential (subject to the Child and Family Services Act, which requires reporting to the Children's Aid society if a child is believed to be in danger). You are not obliged to anewer any questions you may find objectionable or that make you feel uncomfortable. If at any time you indicate thict you do not wish to participate, you will be excused with no penalty. If you do not wish to participate in this study, this decision will in no way affect your status with the Children's Aid Society.

There are no costs, special fees, or known risks associated with your involvement in this study. To assist in planning for your family, we will send a summary report of the "indings to your social worker at the agency with your written permission, and we will discuss the results with you in person should you so desire.

Thank you very much for your consideration. Please complete the attached form if you decide to participate in this study. If you have any questions or comments please feel free to contact:

Dr. David A. Wolfe

Professor, The University of Western Ontario

Psychologist, Children's Rid society of London/Middlesex Phone: 661-3683 


\section{ADOLESCENT'S CONSENT TO RESEARCH PARTICIPATION}

I understand what is involved in Dr. Wolfe's study on family background and teenagers' adjustment, and I voluntarily consent to participate. 
APPENDIX I

Comparison of Participants to Nonparticipants 
Comparison of Participants to Nonparticipants

One hundred and sixty-two families agreed to allow their teen to participate in the study, and 97 refused. The primary reason for refusal was recorded among agency families who did not participate in the study. One third of the refusals (36.18) said they had no interest in the research, and 78 added that they were too busy. Twenty-nine percent were unwilling to cooperate with a project sponsored by the CAS, due to hostility between the family and the agency. In 218 of the refusals, other family crises (e.g., adolescent had run away, emotional difficulties with mother) prevented participation. Finally, in 68 of the cases, the target child had been moved outside the jurisdiction boundaries of the child protection agency.

To assegs the limits of generalizability, comparisons were made between participating and non-participating families. No differences were found between groups on adolescents' age, sex, or frequency of contact with natural parents. However, several other regults indicated that families who refused to participate were actually highor functioning than those who did participate. Compared to participants (368), nonparticipants were more likely to come from working (518) than welfare families, $x^{2}(1, \underline{N}=257)=5.7, \underline{P}<.01$. Although they did not differ on parent's history of alcohol, drug abuse, or criminal activity, differences were found regarding parental psychiatric problems. Mothers in the non-participant group were less likely to have a psychiatric history (348) than participant mothers $(52 z), x^{2}(1, \underline{N}=247)=7.2, \mathrm{R}<$ .01. Similarly, the incidence of psychiatric problems among fathers was les3 among nonparticipants (13.88) than participants $(348), \chi^{2}(1, \underline{N}$ * 170), $\mathrm{p}<.01$. Participants and non-participant families also differed on the official reason for agency service. Nonparticipants were les. likely to receive service for parental inadequacy or neglect-related reasons $(17.58)$ compared to participants $(29.48), x^{2}(3, \underline{N}=257)=9.2$, 
p $<.05$. The level of maltreatment experienced by the target child also differed between participating and nonparticipating familieg. Following a significant MANOVA using social worker maltreatment ratings as criterion variaties $(\underline{E}(5,251)=3.86, \underline{Q}<.01)$, differences were found among individual ratings. Although the mean differences approached aignificance, ratings of physical maltreatment $(p=.06)$ and family violence did not differ between the groups $(2=.07)$. However, nonparticipants had lower mean scores on sexual abuse $(\underline{M}=.35)$, emotional abuse $(\underline{M}=1.5)$, and neglect $(\underline{M}=1.1)$ compared to participants $(\underline{M}=$ 81, 1.9, and 1.4, respectively), (all t. $\mathrm{g}(255)>7.0, \mathrm{p}<.01)$. Taken together, these results suggest that the participating sample represents the more disadvantaged and dyefunctional clients from the population of those serviced by the child protection agency. Therefore, results may not generalize to higher-functioning clients serviced by child welfare agencies. 


\section{APPENDIZ J \\ The Prediction of caretaker-reported (CBCL) and self-repozted (YSR) Behavior Prublem Total Scores}


The Prediction of Caretaker-reported (CBCL) and Self-reported (YSR) Behavior Problem Total Scores

To determine the contribution of predictors to overall maladjustment, the analyses used to predict internalizing and externalizing oymptomatology were also used to predict the Behavior Problem Total scores on the CBCL and the YSR. These total problem scores are comprised of internalizing, externalizing, and four subscales relevant to the sex, social, attention, and thought problem domains. In each instance in which gignificant variance was added, multiple $\mathrm{R}$ was significant at the .01 level.

Above and beyond the covariates, social worker ratings of maltreatment did not add significantly to general maladjustment. File judge ratings accounted for 9.88 of the CBCL Behavior Problem Total scores ( $P<.01$ ), but added nothing in the prediction of YSR Behavior Problem Total scores. Adolescent ratings did not predict CBCL total problems. However, they accounted for 9.1t of YSR total problems ( $2<$ $.01)$. The results were greater for females (14.98, $\mathrm{p}<.01$ ).

Above and beyond their respective perceived maltreatment severity levels, attributions for maltreatment types added significantly to YSR total problems. Uniformly, the ancrement was greater for females. Beyond hostile maltreatment severity, 178 was added (218 for females), both po <.001. Beyond neglect severity, 188 was added $(278$ for females), both ps <.01. Beyond sexual abuse severity, 348 was added (42) for females), both ps <.001. No significant increment was obtalned for family violence. No significant increment was obtained in analyses with males only. Controlling for severity, attributions did not significantly predict CBCL total problem scores. These increments are similar to those deacribed in the text. 
APPENDIX $\mathbf{K}$

Content Analyses of Subjects' Responges to the Attribution For Maltreatment Interview 


\section{Content Analyses of Subjects' Responses to the Attribution For Maltreatment Interview.}

In order to thoroughly understand the attribution ratings made by adolescent victims, it is helpful to know the substance of their thoughts on maltreatment. Table 48 identifies the breakdown of interviews by perpetrator discussed. For hostile maltreatment, natural mother (37.88), natural father (27.38) and "other" (358) were approximately equally represented; also, the interviews were evenly distributed among physical (46.98) and emotional abuse (53.18). Family violence was approximately equally split between natural parenta (46.38) and parent-atepparent pairs (53.78). Neglect interviews focused primarily on natural parents, almost evenly split between fathers (41.48) and mothers (38.48). In contrast, three-quarters (768) of sexual ajuse interviews were mostly directed at "others". Of these $\mathbb{N}=$ 40) 21.78 were stepfathers, 23.98 acquaintances, and 37 other relatives. Sexual abuse by natural father accounted for 21.8 of the interviews. Only one sexually abusive mother was discussed. Thus, with the natural exception of sexual abuse, no one type of perpetrator was overrepresented in the interviews. Such an even distribution among perpetrators may help to minimize syatematic perpetrator-related bias in attribution scores. Chi-square analyses revealed no gender differences in the perpetrator selectiun: males and females were equally likely to select "mother", "father", and/or "other."

What did adolescents perceive to be the major cause of the maltreatment? Tables 49 through 52 present the major causes cited by adolescents for each of hostile maltreatment, family violence, neglect, and sexual abuse, respectively. Each table also presents the breakdown of adolescent's responses to the probe regarding their own role in the maltreatment. Causes are listed in descending order. It is worth noting that adolescents did not always identify their own role among the 
Table 48.

Breakdown of Attribution for Maltreatment Interviews by Perpetrator and Maltreatment subtype

\begin{tabular}{lll}
\hline Interview & $\begin{array}{l}\text { Maltreatment } \\
\text { subtype }\end{array}$ & $\begin{array}{l}\text { Percentage of } \\
\text { interviewg }\end{array}$ \\
\hline Hostile $(\underline{N}=130)$ & Physical mother & 15.4 \\
& Physical father & 15.4 \\
& Physical other & 16.1 \\
& Emotional mother & 22.4 \\
& Emotional father & 11.9 \\
& Emotional other & 18.9 \\
Family violence $(\underline{N}=72)$ & Natural parents & 46.3 \\
& Parent/partner & 53.7 \\
Neglect $(\underline{N}=96)$ & Mother & 38.4 \\
& Father & 41.4 \\
& Other & 20.2 \\
Sexual $(\underline{N}=53)$ & Nother & 1.8 \\
& Father & 21.8 \\
& Other & 76.4 \\
\hline
\end{tabular}

Note: $N$ 's for each type represent the number of respondents who identified themselves as victims and completed relevant AFMI interview. 
Table 49.

The "Maior Cauge" for Hostile Maltreatment and the Adolescent's Perceived Role in it

\begin{tabular}{|c|c|}
\hline Major cause & Percentage \\
\hline My misbehavior & 33.0 \\
\hline Perpetrator's bad temper & 24.0 \\
\hline Perpetrator's drinking & 12.1 \\
\hline Perpetrator hates me, rejects me & 6.4 \\
\hline Perpetrator's personality, crue'ty & 6.1 \\
\hline Perpetrator abused as a child & $5 \cdot 4$ \\
\hline I defied/rejected perpetrator & 3.8 \\
\hline Perpetrator favoured another child & 3.1 \\
\hline Perpetrator'b fear/ignorance of parenting & 2.3 \\
\hline Perpetrator is mentally ill & 2.3 \\
\hline \multirow{2}{*}{ Perpetrator forced to by eomeone else } & 1.5 \\
\hline & 1008 \\
\hline \multicolumn{2}{|l|}{ Adolescent's role in maltreatment } \\
\hline My misbehavior & $5 \dot{7} .3$ \\
\hline Unintentionally provoked & 16.0 \\
\hline Did not do anytning & 12.2 \\
\hline Defied or rejected perpetrator & 6.9 \\
\hline Did not prevent it & 3.8 \\
\hline $\begin{array}{l}\text { Was unacceptable to perpetrator } \\
\text { (e.g., not their naturaj child) }\end{array}$ & $2 \cdot 3$ \\
\hline Did not disclose & .8 \\
\hline Tried to escape, withdraw & .8 \\
\hline & 1008 \\
\hline
\end{tabular}


Table 50.

The "Major Cauge" for Family Violence and the Adolescent's Perceived Role in it

\begin{tabular}{ll}
\hline Major cause & Percentage \\
\hline Perpetrator's drinking & 33.3 \\
Perpetrator's bad temper & 30.5 \\
Marital Problems & 23.6 \\
Perpetrator's persondlity, cruelty & 11.2 \\
Perpetrator is mentally ill & 1.4 \\
\hline Adolegcent's role in maltreatment & 1008 \\
\hline Did not do anything & 33.3 \\
Did not prevent it & 27.8 \\
My misbenavior & 12.5 \\
Tried to escape, witidraw & 8.3 \\
Intervened in family violence & 8.3 \\
Unintentionally provoked & 5.6 \\
Defied or rejected perpetrator & 4.2 \\
\hline \hline
\end{tabular}


rable 51.

The "majer Cause" for Neglect and the Adolescent's Perceived Role in it

\begin{tabular}{|c|c|}
\hline Major cause & Percentage \\
\hline Perpetrator cared more for someone else & 22.7 \\
\hline Perpetrator did not love me & 12.4 \\
\hline $\begin{array}{l}\text { Perpetrator busy with } \\
\text { otwer problems }\end{array}$ & 11.3 \\
\hline My misbehavior & 8.2 \\
\hline Perpetrator forced to by someone else & 8.2 \\
\hline Perpetrator's bad temper & 6.1 \\
\hline I was st Important & 5.2 \\
\hline Perpe rator's personaitity, cruelty & 5.2 \\
\hline Perpetrator'日 drinking & 5.2 \\
\hline Perpetracor's fear/ignorance of parenting & 5.1 \\
\hline No money & 4.2 \\
\hline Perpeis $\approx$ or is mentally ill & 4.1 \\
\hline \multirow[t]{2}{*}{ Perpetrator abused as a child } & 2.1 \\
\hline & 1008 \\
\hline \multicolumn{2}{|l|}{ Adolescent's role in maltreatment } \\
\hline Did not do anything & 32.3 \\
\hline Did not prevent it & 19.8 \\
\hline Migbehavior & 19.8 \\
\hline Dafied or rejected perpetrator & 12.5 \\
\hline $\begin{array}{l}\text { Was unacceptable to ferpetrator (e.g., not their } \\
\text { ratural child) }\end{array}$ & 8.3 \\
\hline Unintentionally provoked & 5.2 \\
\hline \multirow[t]{2}{*}{ Tried to escape, withdraw } & 2.1 \\
\hline & 1008 \\
\hline
\end{tabular}

$\underline{N}=96$ 
Table 52 .

The "Major Cause" for Sexual Abuse and the Adolescent's Perceived Role in it

\begin{tabular}{|c|c|}
\hline Major cause & Percentage \\
\hline Perpetrator is a pervert & 37.1 \\
\hline $\begin{array}{l}\text { Perpetrator thought he could } \\
\text { get away with it }\end{array}$ & 16.7 \\
\hline Perpetrator's personality, cruelty & 13.1 \\
\hline Perpetrator's drinking & 11.1 \\
\hline I was unprotected, vulnerable & 7.4 \\
\hline Perpetrator abused as a child & 7.4 \\
\hline Perpetrato: was lonely & 3.7 \\
\hline Perpetrator's fear/ignorance re parenting & 1.9 \\
\hline \multirow[t]{2}{*}{ Perpetzator is mentally ill } & 1.9 \\
\hline & 1008 \\
\hline \multicolumn{2}{|l|}{ Adolescent's role in maitreatment } \\
\hline Did not do anything & 50.9 \\
\hline Did not disclose & 18.9 \\
\hline Did not prevent it & 17.0 \\
\hline Misbehavior & 3.8 \\
\hline Trusted perpetrator & 3.8 \\
\hline I was attractive & 3.8 \\
\hline \multirow[t]{2}{*}{ Tried to escape, withdraw } & $1 . \bar{y}$ \\
\hline & 1008 \\
\hline
\end{tabular}


initial list of major causes. The specific probe was often needed to identify their perceived contribution to the maltreating events. For subjects identifying themselves as victims of physical or emotional abuse $(I I=130)$, the most common major cause was their own misbehavior (33t). Nevertheless, a substantially larger number felt that something about the pexpetrator caused the abuse (638). Principally, subjects identified the perpetrator' bad temper (248), drinking (12.18), personality (6.18) or rejection of them (6.48) as the major cause of phyeical or emotional abuse. When probed on their own role, an adcitional 24t felt their misbehavior contributed to what happened, making a total of 57 of this opinion. Others (16.38) felt they had provoked the attacks through inadvertent behavior (e.g., accidentally breaking a household object). Some (12.28) said they "did not do anything" to rause the maltreatment, or to escape it. Some subjects (6.98) spoke proudly of the defiance or "talking back" they did to the perpetrator, clarifying that they did not consider this to be misbehavior.

of the self-identified witnesses to family violence $(\underline{\underline{N}}=72)$, none identified their misbehavior as the major cause of the marital violence. Rather, they attributed the violence to the batterer's temper (30.58), drinking (338), and marital problems (23.68). When asked about their perceived role, a third of the respondents (33.38) said they "didn't do anything" in the face of the violence. Another third (27.88) were more explicit in saying that they failed to do anything to prevent the violence. Interestingly, although no witnegs gaw $h_{i}$ or her migbehavior as the rajor cause for the wife assault, when probed 12.52 identified their misbehavior as the subject over which the marital violence otarted.

Of the subjects who considered themselves victims of neglect $(\underline{N}=$ 96), most (22.78) believed that this resulted from the perpetrator caring more for someone else, typically another child. The second most- 
cited reason was that the perpetrator did not love them (12.48). Although 8.28 felt that their misbehavior was the major cause of the neglect, more (19.88) identified this as an issue when probed for their contribution. A third of the reglected subjects could not identify any contributing or responsive role in the neglect - they baid they "didn't do anything" in the bituation (32.38).

of sexually abused subjects $(\underline{N}=53)$, virtually all (92.68) identified aspects of the perpetrator as the major cause of what happened. Most responded that the offender "was a pervert" (37.18), while others emphesised his serse of legal impunity (16.78), personality (13.18) or drinking (11.18) as the primary causal agent. When probed, half of the sexual abuse victims said they "did nothing" to cause or confront the abuse. Othere were more epecific, outlining acte of omiseion such as failure to fight off the perpetrator (17.18! or failuro to disclose the abuse (18.98). Very few victims felt $t$.ie abuse occurred as punishment for their misbehavior $(3.8 z)$, or felt that aspocts of themselves (e.g., attractiveness, naive trust) contributed to the eventa.

In summary, the majority of adolescents viewed the major cause for all types of maltreatment as being due to aspects of the offender. With the notable exception of hostile maltreatment (i.e., physical and emotional abuse), few subjects identified their misbehavior as the majo. cause for what happened. Nevertheless, when probed more pointedly, adolescents do perceive themselves to have had a role in their victimization. When discussing family violence and sexual abuse, for example, acts of omission (e.g., failure to prevent or "do anything" about the abuse) appear to dominate their thought. 


\section{RBEREACES}

Abbey, A. (1987). Perceptions of personal avoidability versus responsibility: How do they differ? Basic and Applied social Reychology, B. 3-19.

Aber, J. L., \& Allen, J. P. (1987). The effects of maltreatment on young children's socioemotional developinent: An attachment theory perefective. Developmental Psychopathology, 23, 406414.

Aber, J. L., \& Zigler, E. (1981). Developmental considerations in the definition of child maltreatment. In R. Rizley $\& D$. Cicchetti (Edo.), Developmental pergpectives in child maltreatment (pp. 1-29). San Francisco: Jossey-Bas8.

Abramson, L. Y., Metalsky, G. I., Alloy, L. B. (1989). Hopelesenese depression: A theory-based subtype of depression. paycholoqical Review, 96, 358-372.

Abramson, L. Y., Seligman, H. E., \& Teasdale, J. D. (1978). Learned helplesenese in humane: Critique and reformulation. Journal of Abnormal Peychology, 87, 49-74.

Achenbach, T. M. (1991a). Manual for the Child Behavior Checklist/ $4-18$ and 1991 Profile. Burlington, VT: University of vermont.

Achenbach, T. M. (1991b). Manual for the Youth Self Report and 1991 profile. Burlington, VT: University of Vermont. Achenbach, T. (1991)

Achenbach, T. M. E Edelbrock, C. S. (1987). Manual for the Youth Self-report and Profile. Burlington, VT: University of Vermont, Department of Psychiatry.

Achenbach, T. M., Edelbrock, C. S. (1983). Manual for the Child Behavior Checklist and Child Behavior Profile. Burlington: University of Vermont.

Achenbach, T. M., Mcconaughy, S. H., Howell, C. T. (1987). Child/ Adolescent behavioral and emotional problems: Implications of cross-informant correlations for situational specificity. Psychological Bulletin, 101, 213-232.

Affleck, G., Allen, D. A., Tennen, H., McGrade, B. J., G Ratzan, S. (1985). Causal and control cognitions in parent coping with a chronically ill child. Journal of Social and clinical Pgychology, $3,369-379$.

Alloy, L. B., Ahrens, A. (1987). Depression and pessimism for the future: Biased use of statistically relevant insormation in predictions for self versus others. Journal of personality and Social Psychology, 52, 366-378.

Alter, C. F. (1985). Decision-making factors in cases of child neglect. Child Welfare, 64, 99-111. 
Alter-Reid, K., Gibbs, M. S., Lachenmeyer, J. R., Sigal, J., G Maseoth, N. A. (1986). Sexual abuee of children: A review of the empirical findinge. Clinical Paychology Review, 6, 249266.

Ammerman, R. T., Cassisi, J. E., Hersen, M., G Van Hasselt, V. B. (1986) Consequences of physical abuse and negiect in children. Clinical Paychology Review, 6, 291-310.

Imsterdam, B., Brill, M., Bell, N. W., E Edwards, D. (1979). Coping with abuse: Adclescents' views. Victimology: An Internationel Journal. 4. 278-283.

Anderson, C. A., \& Arnoult, L. H. (1985). Attributional modela of depreseion, loneliness, and shyness. In J. H. Harvey $G$. Weary (Eds.), Attribution: Basic isgueg and applications (pp. 235-279). New York: Academic Prese.

Anderson, C. A., f Jenninge, D. I. (1980). When experiences of failure promote expectations of euccess: The impact of attributing failure to ineffective atrategies. Journal of Personality, 48, 393-407.

Andrews, B., \& Brewin, C. R. (1990). Attributions of blame for marital violence: $A$ study of antecedents and consequences. Journal of Marriage and the Family, 52, 757-767.

Aragora, J. A., Eyberg, S. M. (1981). Neglected children: Mother' report of child behavior probleme and observed verbal behavior. Child Development, 52, 417-423.

Bach-y-Rita, G. Eeno, A. (1974). Habitual violence: A profile of 62 men. American Journal of Peychiatyy, 131, 1015-1017.

Badgley, R. F. (1984). Sexual offenses against children: Repurt of the committee on sexual offenses against children and youth (Vol 1). Ottawa: Canadian Government Publishing Centre.

Banuura, A. (1989). Social cognitive theory. In R. Vasta (Ed.) Annals of child development, volume gix six theorieg of child development, revised formulations and current isgueg (pp. 1-60). Greenwich, CT: JAI Presg.

Bandura, A. (1977). Social learning theory. Englewood Cliffo, NJ: Prentice Hall.

Barahal, R. M., Waterman, J., G Martin, H. P. (1981). The social-cognitive development of abused children. Journal of Conoulting and Clinical Pgychology, 49, 508-516.

Barun, R. M., Kenny, D. A. (1986). The moderator-mediator variable distinction in social psychological research: Conceptual, strategic, and statistical ionsiderations. Journal of Personality and Social Psychology, 51, 1173-1162.

Barnett, D.. Manly, J. T., \& Cicchetti, D. (1991). Continuing toward an operational definition of psychological maltreatment: A commentary. Development and Prychogathology. 3, $19-29$ 
Barnett, P. A., Gotlib, I. H. (1988). Psychosocial functioning and depression: Distinguiahing between antecedents, concomitants, and consequences. Psycholoqical Bulletin, 104, 97-126.

Bar-Tal, D. (1978). Attributional analysis of achievement-related behavior. Review of Educational Research, 48, 259-271.

Baum, A., Flemming, R., \& Singer, J. E. (1983). Coping with victimization by technological disaster. Journal of Social Issueg, 39, 119-140.

Baumrind, D., Black, A. E. (1967). Sorialization practices asscciated with dimensions of competenze in preschool boys and girls. Child Development, 38, 291-327.

Beck, A. T. (1976). Cognitive therapy and the emotional disorderg. New York: Hoeber.

Beitchman, J. H., Zucker, K., J., Hood, J. E., Dacosta, G. A., \& Akman, D. (1991). A review of the short-term effects of child sexual abuse. Child Abuse and Neglect, 15, 537-556.

Berger, A. M., Knutson, J. F., Mehm, J. G., \& Perkins, K. A. (1988). The self-report of punitive childhood experiences of young adults and adolescents. Child Abuse and Neglect, 12, 251-262.

Besharov, ", J. (1981). Toward better research on child abuse and neg: $t$ : Making definitional issues an explicit methodological conc. in. Child Abuse and Neqlect, 5, 383-390.

Bousha, D. M., \& Twentyman, C. T. (1984). Mother-child interactional style in the abuse, neglect and control groups: Naturalistic observations in the home. Journa: of Abnormal Psychology, 93, 106-114.

Bowlby, J. (1980). Attachment and 108s: Losg, sadness, and depression. New York: Basic Books.

Bradbury, T. N., Fincham, F. D. (1990). Attributions in Marriage: Review and Critique. Psychological Bulletin, 107, 3-33.

Brassard, M, R., Germain, R., \& Hart, S. N. (1987). Pgychological maltreatment of children and youth. New York: Pergamon.

Briere, J., Runtz, M. (1990). Differential adult symptomatology associated with three types of $\mathrm{h}$ hild abuse histories. Child Abuse and Neglect, 14, 357-364.

Briere, J. \& Runtz, M. (1988). Multivariate correlateg of childhood psychological and physical maltreatment among university women. Chifd Abuge and Neqlect, 12, 331-341.

Brown, S. (1984). Social cliss, child maltreatment, and delinguent behavior. Criminology, 22, 259-278.

Brown, J. D., siegel, J. M. (1988). Attributiong for negative ife events and depression: The role of perceived control. Journal of Pergonality and Social Paychology, 54, 316-322. 
Browne, A., \& Finkelhor, D. (1986). Impact of child sexual abuse: A review of the literature. Poychological Buldetin, 99, 6677.

Bulman, R., \& Wortman, C. (1977). Attrihutions of blame and coping in the "real world": Severe ac:ide.ut victims react to their lot. Journal of Pergonality and social Pgychology, 35, 351-363.

Burger, J. 1. (1981). Motivational biages in the attrit.ticn of responsibility for an accident: A meta-analysis of the defensive attribution hypotheria. Pgychological Bulfetin. 90. 495-512.

Burgese, A. W., Hartman, C. R., McCausland, M. P., E Powers, P. (1984). Response patterns in children and adolescents exploi:ed through sex ringe and pornography. American Journal of Pgychiatry. 141. 656-662.

Burjess, R., C Conger, R. (1978). Family interacticn in abusive, neylectful, and normal families. Child Developme.7t, 19, 1163-1173.

Bussey, K., \& Bandura, A. (1984). Influence of gender constancy and social power on sex-linked modelling. Journal of Personality and Social Psychology, 47, 1292-1302.

Carmen, E. H., Russo, N. F., Miller, J. B. (1981). Inequality and women'g mental health: An overview. American Journal of Psychiatry, 138, 1319-1330.

Catron, T. F., \& Masterg, J. C. (1991, April). Chitdren'g and mother's judgments about the acceptable use of corporal punishment. Paper presented at the Piennial Mseting of the Society for Research in Child Development, Seattle.

Cicchetti, D. (1990). The organization and coherence of socioemotional, cognitive, and representational development: Illustrations through a developmental paychopathology perapeztive on Down Syndrome and child maltreatment. In $R$. Thompson (Ed.), Nebraska symposily on motivation (Vol 36 , pp. 259-366). Lincoln, Nebraska: University of Nebraska Pre日8.

Cicchetti, D., \& Barnett, D. (1991). Toward the development of a scientifi.c nosology of child maltreatment. In D. Cicchetti and $w$. Grove (Eds.), Thinking clearly about psychology: Essays in honour of Paul E. Meehl (Pp. 346-377). Minneapolis: University of Minnesota Press.

Claussen, A. H., Arittenden, P. M. (1991). Physical and psychological maltreatment: Relations among types of maltreatment. Child Abire and Neglect, 15, 5-18.

Conte, J.R., \& Schuerman, J. R. (1987). Factors associated with an increased impact of child sexual abuse. Child Abuse and Neqlect, 11, 201-211.

Cohen, J., \& Cohen, P. (1983). Applied multiple reacesoion correlation analyeig for the behavioral scienceg (2nd Rd.). Hillsdale, NJ: Lawrence Erlbaum. 
Cohn, L. (1991). Sex differences in the course of personality development: A meta-analyois. Psychological Bulletin, 109, 252-266.

Connell, J. P. (1985). A new multidimensional measure of children's perceptions of control. Child Development, 56, 1018-1041.

Cook, T. D., \& Campbel1, D. T. (1979) . Quasi-experimentation: Desion and analysis issues for field settings. New York: Rand-McNally.

Crittenden, P. M., Ainsworth, M. (1989). Child maltreatment and attachment theory In D. Cicchetti V. Carlaon (Eds.), Child meltreatment: Theory and research on the rauses and consecuences of child abuse and neglect (pp. 432-463). New York: Cambridge University Prese.

Crittenden, P. M., Bonvillian, J. D. (1984). The relationghip between maternal risk status and maternai sensitivity. Anerican Journal of Orthopsychiatiry, 54, 250-262.

Crocker, J., Alloy, L. B., Kayne, N. T. (1988). Attributional etyle, depreseion, and perceptions of consensus for events. Journal of Personality and social Paychology, 54, 840-846.

Cummings, E. H. (1987). Coping with background anger in early childhood. Child pevelopment, 58, 976-984.

Cummings, E. M., Iannotti, R. J., G Zahn-Waxlex, C. (1985). Influence of conflict between adults on the emotions and aggression of young children. Developmental Paychelogy, 21, 495-507.

Cummings, E. H., Zahn-Waxler, C., \& Radke-Yarrow, H. (1984). Developmental changes in children's reactions to anger in the home. Journal of Child Pgychology and Peychiatry, 25, 63-74.

Cutler, S. E., Nolen-Hoeksema, S. (1991). Accounting for sex cifferences in depression through female victimization: Childhood sexual abuse. Sex Roles, 24, 425-438.

Cutrona, C. E. (1983). Causal attributicns and perinatal deoression. Journal of Abnormal Pgychology, 92, 161-172.

Cutrona, C. E., Russell, D., \& Jones., R. V. (1984). Cross-situational consistency in causal attributions: Does attributional style exigt? Journal of Pergonality and Social Pgychology, 47, 10431058.

Darley, J. M., Klosson, E. C., E Zanna, M. P. (1978). Intentions and their contexts in the moral judgements of children and adults. Child Development, 49, 66-74.

Davison, G. E Neale, J. (1982). Abnormal Paychology. Wiley: New York.

Dehorn, A. Klinge, V. (1978). Correlations and factor analysis of the WISC-R and the Peabody Plcture Vocabulary Test for an adolescent peychiatric sample. Journal of Consuling and clinical peychology, 46, 1260-1161. 
DiLalla, L. F., \& Gottegman, I. I. (1991). Biological and genetic contributore to violence - widom's untold tale. Paychological Bulletin, 109, 125-129.

Didgon, N., G Gotlib, I. H. (1985). Developmental considerations in the study of childhood depression. Developmental Review, 15, 162-199.

Dodge, K. A. (1986). A social information precessing model of social competence in children. In M. Perlmutter (Ed.), Minnesota eymposium on child psychology (Vol. 18) (pp. 77-125). Hillsdale, NJ: Erlbaum.

Dodge, K. A. (1980). Social cognition and children's aggreseive behavior. Child Development, 51, 162-170.

Dodge, K. A., Bates, J. E., \& Pettit, G. S. (1990). Mechanisms in the cycle of violence. Science, 250, 1678-1683.

Dodge, K. A., \& Frame, C. I. (1982). Social cognitive biases and deficits in aggressive boys. Child pevelopment, 53, 620-635.

Dodge, K. A., Murphy, R. R., \& Buchsbaum, K. (1984). The assessment of intention-cue detection skills in children: Implications for developmental poychopathology. Child pevelopment, 55, 163-173.

Dodge, K. A., \& Richard, B. A. (1985). Peer perceptions, aggreesion, and the development of peer relations. In J. B. Pryor G J. D. Day (Eds.) The development of social cognition (Pp. 35-58). New York, Springer-Verlag.

Dohrenwend, B. P., Shrout, P. E. (1985). "Hassles" in the conceptualization and measurement of life stress vaciables. imerican Psychologist. 40, 780-785.

Doherty, W. J. (1982). Attributional style and negative problem-solving in marriage. Family Relations, 31, 23-27.

Dohrenwend, B., \& Dohrenwend, B. (1975). Sex differences and psychiatric disorders. American Journal of Sociology, 80 , 1447-1454.

Downey, G., Walker, E. (1989). Social cognition and adjugtment in children at risk for psychopathology. Developmental pgychology, $25,835-845$.

Duncan, D. F. (1978). Measuring the generation gap. Attitudes towards parents and other adults. Adolescence, $13,77-81$.

Dunr, I. M., Dunn, L. M. (1981). Manual for the PPVT-R. Circle Pines, MN : American Guidance Service.

Egeland, B., sroufe, A. (1981a). Attachment and early maltreatment. Child Development, 52, 44-52.

Egeland, B., \& Sroufe, A. (1981b). Developmental sequelae of maltreatment in infancy. In R. Rizley and D. Cicchetti (Eds.) New Directions for Child Development, 11, 77-92.

Egeland, B., Sroufe, A., Erickson, M. (1983). The developmental consequence of different patterns of maitreatment. Chidd Abune and Neglect, $7,459-469$. 
Elig, T. W., Frieze, I. H. (1979). Measuring causal attributions for success and failure. Journal of Personality and Social Psychology. 37, 621-634.

Eme, R. F. (1979). Sex differences in childhood poychopathology: A review. Psychological Bulletin, 86, 574-595.

Erickson, E. H. (1968). Identity: Youth in crisig. New York: W. W. Norton.

Erickson, M. F., Egeland, B. (1987). A developmental view of the paychological consequences of maltreatment. School Paychology Review, 16, 155 168 .

Eron, L. D., Huesman, L. R., Lefkowitz, M. M., \& Walder, L. 0. (1972). Does television violence cause aggression? American Paychologist, 27, 253-263.

Fantuzzo, J. W., Lindquist, C. U. (1989). The effects of observing conjugal violence on children: $A$ review and analyeis of research methodology. Journal of Family violence, 4, 77-94.

Femina, D. D., Yeager, C. A., LewiB, D. O. (1990). Child Abuse: Adolescent records versus adult recall. Child Abuge and Neglect, 14, 227-231.

Feshbach, S. (1980). Child abuse and the dynamics of human aggression and violence. In J. Gerbner, C. J. Ross, \& E. Zigler (Eds.), Child abuse: An aganda for action. New York: oxford University Press.

Fincham, F. D. (1985). Attribution in close relationships. In J. H. Harvey and G. Weary (Eds.), Attribution: Basic issues and applicationg (Pp. 203-234). New York: Academic Press.

Fincham, F. D., Beach, S., Nelson, G. (1987). Attribution processes in distressed and nondistressed couples: 3 . Causal responsibility attributions for spouse behavior. Coanitive Therapy and Regearch, i2, 71-86.

Fincham, F. D., Bradbury, T. N. (1987). Cognitive processes and conflict in close relationshifs: An attıibution-efficacy model. Journal of Personality and Social Psycholog, 53, 1106-1119.

Fincham, F. D., Bradbury, T. N., E Grych, J. H. (1990). Conflict in close relationghipg: The role of intrapersonal phenomena. In $S$. Graham \& V.S. Folkes (Eds.), Attribution theory: Applications to achievement, mental health, and interpersonal conflict. Hillsdale, NJ : Lawrence-Erlbaum.

Fincham, F. D., \& Jaspers, J. M. F. (1980). From man the scientist to man as lawyer. In L. Berkowitz (Ed.), Advances in experimental social psychology (Vol 13, pp. 81-138). New York: Academic Press.

Finctam, F. D., \& O'Leary, K. D. (1983). Causal inferences for spouse behavior in maritally distressed and nondistressed couples. Journal of Social and Clinical Paychology, 1, 42-57.

Finkelhor, D. (1984). Child yexual abuse: New theory and research. New York: The Free Press. 
Follingstad, D. R., Neckerman, A. P., G Vormbrock, J. (1988). Reactions to victimization and coping atrategies of battered women: The tieB that bind. Clinical Paychology Review, $\underline{8}, 373-390$.

Fontana, V. J. (1984). The maltreatment syndrome of children. Pediatric Annalg, 13, 736-744.

Frankl, V. (1963). Man's search for meaning. New York: Washington Square Presa.

Friedrich, W. N., Urquiza, A. J., Beilke, R. L. (1986). Behavior problems in sexually abused young children. Journal of Pediatric Psychology, 11, 47-57.

Frieze, I. H. (1979). Perception of battered wives. In I. H. Frieze, D. Bar-Tal, \& J. S. Carroll (Eds.), New approaches to social probleme: Applicationg of attribution theory (pp. 79-108). San Francisco, CA: Josegy-Base.

Frodi, A., smetana, J. (1984). Abused, neglected, and nonmaltreated preschoolers' ability to discriminate emotione in others: The effects of IQ. Child Abuse and Neglect, $\underline{B}$, 459-465.

Gad, H. T.. \& Johnson, J. H. (1980). Correlates of adolescent life atrese a related to race, SES, and levele of perceived aocial support. Journal of clinical child Psycholoox, 2, 13-16.

Garbarino, J., Guttman, E., seeley, J., (1986). The pgychologically battered child. San Francisco: Jossey-Base.

George, C. Main, M. (1979). Social interactions of young abused children: Approach, avoidance, and aggression. Child Development, 50. 306-318.

Gentile, c. (1988). Factors mediating the impact of child gexual abuge: Severity of abuse, attributional otyle, and learned helplesanere. Unpublished master's thesig, The University of Weatern Ontario, London, Ontario, Canada.

Gold, E. R. (1986). Long-term effects of sexual victimization in childhood: An attributional approach. Journal of Consulting and Clinical Psychology, 54, 471-475.

Gomes-Schwartz, B., Horowitz, J. M., \& Cardarelli, A. P. (1990). Child sexual abues: The initial effects. Newbury Park, CA.: Sage.

Green, A. H. (1978). Psychopathology of abused children. American Journal of Psychiatey, 135, 579-582.

Green, A. H., Voeller, K., Gaines, R., \& Kubie, J. (1981). Neurologlcal impairment in maltreated children. Child Abuge and Neqlect, $\geq$. $129-134$.

Green, S. J. C Cicchetti, D. (1991, Apri1). Depregsion in maltreated children: An application of the learned helplessness model? Paper presented at the Biennial Meeting of the society for Regearch in Child Development, Seattle.

Gregg, C. S., Elmer, E. (1969). Infant injuries: Accident or abuse. Pediatrice, 44, 434-439. 
Gulley, K. J., Pepping, M., Dengerink, H. A. (1982). Gender C'fferences in third-party reports of violence. Journal of Marriage and the Family, 44, 497-498.

Hanson, R. K. (1990). The peychological impact of Bexual assault on women and children: A review. Annals of Sex Regearch, 3, $187-232$.

Harris, M. B., Siebel, C. E. (1976). Affect, aggression, and altruism. Developmental Poycholoay, 11, 623-627.

Harter, 5. (1988). Manual for the self Perception Profize for Adolegcente. Denver, Co: The Unlversity of Denver.

Harter, S., Whitesell, N. R. (April, 1991). Depregsion as a combination of emotions amona young adolescents: Application of emotion prototype theory. Paper presented at the Biennial Meeting of the Society for Research in Child Development

Hazzard, A., Celano, M., Webb, C. (March, 1993). Treatmert of traumagenic beliefe in Bexually abuged girlog. Paper presented at the biennial meeting of the society for Research in Child Development, New Orleans, LA.

Hazzard, A., Christensen, A., Margolin, G. (1983). Children B perceptione of parental behaviors. Journat of Abnormal Child Peychology, 11, 49-60.

Heider, F. (1958). The peychology of interpersonat felations. New York: Wiley.

Herrenkohl, R., Herrenkohl, E. C. E Egolf, B. (1983). Circumstances gurrounding the occurrence of child maltreatment. Journal of coneulting and Clinical Peychology, 51, 424-431.

Herrenkohl, E. C., Herrenkohl, R. C., Toedter, L., \& Yanushefski, A. M. (1984). Parent-child interactions in abusive and nonabusive families. Journal of the American Academy of Child Pgychiatry, 23, 641-648.

Herzberger, S., Potts, D., Dillon, M. (1981). Abusive and nonabusive parental treatment from the child's perspective. Journal of Consulting and Clinical Psychology, 49, 81-90.

Hinchey, F.S., \&avelek, J.R. (1982). Empathic responding in children of battered mothers. Child Abuse and Neqlect, $6,395-401$.

Hoffman, M. L. (1977). Sex differences in empathy and related beheviors. Psychological Bulletin, 84, 712-722.

Hof fman, M. L. (1970). Moral development. In P. H. Mussen (Ed.), Carmichael's manual of child peycholoay (Vol. 2, f?. 261-359). New York: John wiley.

Hof fman-Plotkin, D., \& Twentyman, C. T. (1984). A multimodal assessment of behavioral and cognitive deficits in abused and neglected preschoolers. Child Development, 55, 794-802.

Hollingshead, A. B. (1975). Four-factor index of gocial status. Unpublished manuscript. New Haven: Yale University. 
Holtzworth-Munroe, A. (1988). Causal attributions in marital violence: Theoretifal and methodological issues. Clinical Pgychology Review, g. $331-344$.

Hook, J. G. (1989). Heider's foreseeability level of responsibility attribution: Does it come after intentionality? Child Development, 60, 1212-1217.

Hoshmind, L. T., Austin, G. W. (1987). Validation Btudies of a multifactor cognitive-behavioral anger control inventory. Journal of Pergonality Asgugsment, 51, 417-432.

Howard, J. A. (1987). The conceptualization and measurement of attributions. Jodrnal of Expeririental Social Pgychology, 23, 3258.

Howard, J. A. (1984). Societal influences on attribution: Blaming some victims more than others. Journat $b_{i}$ Pergonality dnd social Paychology, 47, 494-505.

Hughes, H. M. (1988). Psychological and behavioral correlates of farily violence in child witnesses and victims. American Journal of Orthopsychiatry, 18, 77-90.

Hughes, H. M., E Bacad, S. J. (1983). Paychological functioning of children in a battered women'B shelter: A preliminary inveatigation. American Journal of Orthopgychiatry, 53, 525-531.

Hyde, J. S. (1986). Gender differences in aggregeion. In J. S. Hyde E M. C. Linn (Eds.) The psychology of gender: Advances through meta-analysis (pp. 51-66). Baltimore: John Hopkins University Prese.

Hyde, J. S., Linn, M. C. (1988). Gender differences in verbal ability: A meta-analysis. Psychologlcal Bulletin, 104, 5y69.

Jacobson, N. S., McDonald, D. W., Follette. W. C., B Berley, R. A. (1985). Attribution processes in distressed and nondistressed couples. Cognitive Therapy and Research, 9, 35-50.

Jaffe, P., Wolfe, D. A., wilson, S. (1990). Chlldren of battered women. Newbury Park: Sage.

Jaffe. P., Wolfe, D. A., Wilson, S., \& Zak, L. (1986a). Similaritiea $2 n$ behavioral and social maladjustment among chlld victims and witnesses to family violence. American Journal of Orthopoychtatry, 56, 142-146.

Jasfe, P., Wolfe, D. A., Wilson, S., \& Zak, L. (1986b). Family violence and child adjustment: A comparative analysis of girla" ar. I boys behavioral gymptoms. American Journal of Psychiatry. $143,74-77$.

Janoff-Bulman, R. (1979). Characterological versus behavioral gelfblame: Inquiries into depression and rape. Journal of Pprgozolity and Sceial Psychology, 37, 1753-1809.

Janoff-Bulman, R. (1982). Feteem and control baseg of blame: "Adaptivo" strategies for victims versus obaervers. journal of Pergorality. 50, $180-191$. 
Kazdin, A. E., Moser, J., Colbug, D., \& Bel1, R. (1985). Depressive eymptoms among physically abused and psychiatricaliy disturbed children. Journal of Conulting and Clinical psychology, 94, 298-307.

Kelley, H. H. (1971). Attribution in social interaction. Morristown, N. J.: General Learnine Press.

Kelley, H. H. (1972). Causal schemata and the attribution process. In E. E. Jones, D. Kanouse, H. H. Kelley, R. E. Nisbett, S. Valins, B. Weiner (Eds.), Attribution: Percejving the causes of behavior (nf151-174). Morristown, N.J. General Learning Press.

Kempe, C. H., Silverman, F. N., Steele, B. F., Droegemueller, $W . \&$ Silver, H. K. (1962). The battered child syndrome. Journal of the American Medical Association, 181, 17-24.

Kerr, M. M., Hoier, T. S., Versi, M. (1987). Methoúlogical isguea in childhood depression: A review of the literature. American Journal of Orthopsychiatry, 57, 193-198.

Koestner, R., zuroff, D. C., \& Powerz. T. A. (1991) . Family origins of adolescent self-cri:icism and its continuity into adulthosd. Journal of Abnozinal Psychology, 100, 191-197.

Koski, P. R., Mangold, W. D. (1988). Gender effects in attitudes about family violence. Journal of Family Violence, 3, 225237.

Kovacs, M. (1981). Rating scales to assess depression in schoolaged children. Acta Paedopsychiatry, 46, 305-315.

Kovacs, M. B Beck, A. T. (1975). An empirical-clinical approach toward a definition of childhood depression. In J. G. Schulterbrandt $\&$. Raskin (Eds.), Depression in childhood: Diagnosis, treatment, and conceptual models (Pp. 1-26). New York: Raven Press.

Kratocoski, P. C. (1985,. Youth violence directed toward significant others. Journal of Adolescence, $\underline{8}, 145-157$.

Krulewitz, J. E. (1982). Reactions to rape victims: Effects of rape circumstances, victim's emotional response, and sex of helper. Journal of Coungeling Psychology, 29, 645-654.

Krulewitz, J.E., \& Nash, J.E. (1979). Effects of rape victim resistance, assault outcome, and sex of observer on attributions of rape. Journal of Personality, 47, 557-574.

Lamb, M., Gaensbauer, T. J., Nalkin, C.M., \& Schultz, L. A. (1985). The effects of child maltreatment on security of infant-adult attachment. Infant Behavior and Development, 8 , $35-45$.

Lamphear, V. S. (1985). The impact of maltreatment on children's psychosocial adjustment: A review of the research. Child Abuge and Neqlect, $9,251-263$.

Larzelere, R. E. \& Mulaik, S. A. (1977). Single-sample tests for many correlations. Psychological Bulletin, 84, 557-569. 
Kazdin, A. E., Moser, J., Colbug, D., Bell, R. (1985). Depressive symptoms among physically abused and psychiatricaliy disturbed children. Journal of Conulting and clinical Psychology, 94, 298-307.

Kelley, H. H. (1971). Attribution in sooifl interaction. Morristown, N. J.: General Learnins Press.

Kelley, H. H. (1972). Causal schemata and the attribution process. In E. E. Jones, D. Kanouge, H. H. Kelley, R. E. Nisbett, S. Valins, E B. Weiner (Eds.), Attribution: Percejving the causes of behavior (me. 151-174). Morrigtown, N.J. General Learning Press.

Kempe, C. H., Silverman, F. N., Steele, B. F., Droegemueller, W. \& Silver, H. K. (1962). The battered child Byndrome. Journal of the American Medical Association, 181, 17-24.

Kerr, M. M., Hoier, T. S., G Versi, M. (1987). Methoúsiogical iseues in childhood depression: A review of the literature. American Journal of Orthopgychiatry, 57, 193-198.

Koestner, R., zuroff, D. C., \& Powerz, T. A. (1991). Family origins of adolescent self-criticism and its continuity into adulthesd. Journal of Abnutinal Psychology, 100, 191-197.

Koski, P. R. \& Mangold, W. D. (198A). Gender effects in attitudes about family violence. Journal of Family Violence, 3 , 225237.

Kovacs, M. (1981). Rating scales to assess depression in schoolaged children. Acta Paedopsychiatry, 46, 305-315.

Kovacs, M. \& Beck, A. T. (1975). An empirical-clinical approach toward a definition of childhood depression. In J. G. Schulterbrandt $A$. Raskin (Eds.), Depression in childhood: Diagnosis, treatment, and conceptual models (PP. 1-26). New York: Raven Press.

Kratocoski, P. C. (1985, . Youth violence directed toward ignificant others. Journal of Adolescence, 8 , 145-157.

Krulewitz, J.E. (1982). Reactions to rape victims: Effects of rape circumstances, victim's emotional response, and sex of helper. Journal of Counseling Psychology, 29, 645-654.

Krulewitz, J. E., \& Nash, J.E. (1979). Effects of rape victim resistance, assault outcome, and sex of observer on attributions of rape. Journal of Personality, 47, 557-574.

Lamb, M., Gaensbauer, T. J., Nalkin, C.M., \& Schultz, L. A. (1985). The effects of child maltreatment on security of infant-adult attachment. Infant Behavior and Development, $a$, $35-45$.

Lamphear, V. S. (1985). The impact of maltreatment on children's poychosocial adjustment: A review of the research. Child Abuse and Neglect, $9,251-263$.

Larzelere, R. E. G Mulaik, S. A. (1977). Single-sample testa for many correlations. Psychological Bulletin, B4, 557-569. 
La-arus, R. S. (1974). Prychological strese and coping in adaptation and illness. Internationai Journal of Pgychiatry in Medicine, $5,321-333$.

Lazarus, R. S., \& Folkman, S. (1984). Stress, appraisal, and coping. New York: Springer.

Lees, M. C., \& Neufeld, W. J. (in press). Matching the limits of clinical inference to the limits of quantitative methods: $A$ formal appeal to practice what we congistently preach. Unpublished manusiript, University of Western Ontario.

Lerner, M. J., \& Miller, D. T. (1978). Just world research and the attribution proress: Looking back and ahead. Paychological Bulletin, 85, 2030-1051.

Lewis, D. O., E Shanok, S. S. (1977). Medical histories of delinquent and nondelincuent children: An upidemiological study. American Journal of PEychiatry, 134, 1020-1025.

Lewis, D. O., Shanok, S. S., Pincus, J. H., \& Glazer, G. H. (1979). Violent juvonile delinquents: Psychiatric, neurological and ablse factors. Journal of the American Academy of child Poychiatry, 18, 307-319.

Iindenberg, F. H., \& Distad, L. J. (1985). Survival regponeen to incest: Adolescents in criels. Child Abuse and Neglect, $\underline{9}$, 521-526.

Lusk, R. Waterman, J. (1986). Effects of sexual abude on children. In K. MacFarlane \& J. Waterman (Eds.), Sexual abuse of young children: Evaluation and treatment (pp. 101118). New York: Guilford Pregs.

Iytton, H., \& Romney, D. (1991). Parents' differential socialization of boys and girls: A meta-analysis. Psychological Bulletin, 109, 267-296.

Maccoby, E. \& Jacklin, C. (1974). The pgychology of sex differences. Stanford, CA.: Starford University Presi.

Macintyre, P. (1990). Issues and recommendation in the use of factor analysis. The Western Journal of Graduate Research, 2. 59-72.

Mackinnon, C. E. (April, 1989). The relation between mother/son attributions and the coerciveness of their interactions. Paper pregented at the biennial Meeting of the Society for Regearch ir Child Development, Kangas City.

Malamuth, N. M., Sockloskie, R. J., Koss, M. P., \& Tanaka, J. S. (1991). Characteristicg of aggressors against women: Testing a model using a national sample of college students. Journal of congulting and Clinical Pgychology, 59, 670-681.

Martin, H. P., Beezley, P. (1977). Behavioral observations of abused children. Developmental Medicine and Child Neurology, $19,373-387$.

Martin, M. J., G Walters, J. (1982). Familial correlates of selected types of child abuse and neglect. Journal of Mafriage and the Eamity, 44, 267-276. 
Mash, E. J., Wolfe, D. A. (1991). Methodological issues in research on physical child abuse. Criminal Justice and Behavior, 18, 8-29.

McArthur, L. A. (1972). The how and what of why: Some determinants and consequences of causal attributions. Journal of Personality and Social Psychology, 22, 171-193.

McCord, J. (1983). A 40-year perspective on effects of child abuse and neglect. Child Abuse and Neglect, $7,265-270$.

McCranie, E. W., \& Bass, J. D. (1984). Childhood family antecedents of dependency and self-criticism: Implications for depresiion. Journal of Abnormal Psychology, 93, 3-8.

McGee, R. A. (1989). Burnout and professional decision-making: An analouge study. Journat of Coungeling Psychology, 36, 345-351.

McGee, R. A. (1990) The Ratings of Past Life Events Scale. Unpublished manuscript, The University of Western Ontario.

MCGee, R. A. (1990). The Attribution for Maltreatment Interview. Unpublished manuscript. The University of Western Ontario.

MCGee, R. A., Wolfe, D. A. (1991a). Psychological maltreatment: Towards an operational definition. Development and Psychopathology, 3, 3-18.

McGee, R. A.. Wolfe, D.A. (1991b). Between a rock and a hard place: Where do we go from here in defining paychological maltreatment? Development and Psychopathology, 3, 119-124.

McGee, R. A., Wolfe, D. A. (1990). Development of a record of maltreatment experiences. Toronto: The Institute for the Prevention of Child Abuse.

McGee, R. A., \& Wolfe, D. A., \& Wilson, S. K. (1990). A Record of Maltreatment Experiences. Unpublished mar.uscript, The University of Western Ontario.

Meyer, B., Taylor, S. E. (1986). Adjustment to rape. Journal of Personality and social Pgychology, 50, 1226-1234.

Miller, D. T., \& Porter, C. A. (1983). Self-blame in victims of violence. Journal of Social Issues, 39, 139-152.

Miller, F. D., Smith, E. R., \& Uleman, J. (1981). Measurement and interpretation of situational and dispositional attributions. Journal of Experimental Social Pgychology, 17, 80-95.

Mittelstaedt, W. H., Wollert, R. (1991). Blame and the devel spment of depressed mood. Canadian Journal of Behavioral science, 23, 1-11

Nasby, W., Hayden, B., de Paulo, B. M. (1980). Attributional bias among aggressive boys to interpret unambiguous social stimuli as dieplays of hostility. Journal of Abnormal Pgycholooy, 89, $459 \cdots 458$.

Ney, P.G. (1987). Does verbal abuse leave deeper scars: A study of children and parents. Canadian Journal of Pgychiat.ry, 32, 371-378. 
Ney, P. G., Moore, C. MaPhee, J., \& Trought, P. (1986). Child abuse: A study of the child's perspective. Child Abuse and Neglect, 10, 511-518.

Nolen-Hoeksema, $\mathrm{S}$. (1987). Sex differences in unipolar depression: Evidence and theory. Esychological Bulletin, 101, 259-282.

Norman, P. D., \& Antaki, C. (1988). Real events attributional style questionnaire. Journal of Social and Clinical Pgychology, $7,97-$ 100 .

Owens, D. J., \& Straus, M. A. (1975). The social structure of violence in childhood and approval of violence as an adult. Agqressive Behavior, 1, 193-211.

Pagel. M. D., Becker, J., \& Coppel, D. D. (1985). Loss of control, Belfblame, and depression: An investigation of opouse caregivers of Alzheiner's disease patients. Journal of Abnormal Psychology, 94, 169-182.

Parke, R. D., slaby, R. G. (1983). The development of aggression. In E. M. Heatherington (Ed.), Handbook of child peychologr (Vol 4 , pp. 547-641).

Patterson, G. R. (1982). Coercive family procesg. Eugene, OR: Castalia.

Pedhazur, E.J. (1982). Multiple regression in behavioral research: Explanation and prediction. New York: Holt, Rinehart and Winston.

Peters, S. D. (1988). Child sexual abuse and later psychological problems. In G. E. Wyatt \& G. J. Powell (Eds.), Lasting effects of child sexual abuse (pp. 101-117). Newbury Park, CA.: Sage.

Peterson, C., S Seligman, M.E. (1983). Learned helplessness and victimization. Journal of Social Issue日, 2, 103-116.

Peterson, C., Semmel, A., Von Baeyer, C., Abramson, L. J., Metaloky, G. I. Seligman, M. E. P. (1982). The attributional style questionnaire. Cognitive Therapy and Research, 6, 287-300.

Piaget, J. (1965). The moral judgement of the child. New York: Free Press.

Plotkin, R. C., Azar, S., Twentyman, C. T., E P critical evaluation of the regearch mer.", yy mployed in the investigation of causative factors of $c^{h_{1}} \cdot$, bu $\mathrm{t}$ and neglect. Child Abuse and Neqlect, $5,449-455$.

Porter, B., \& O'Leary, K. (1980). Marital discord and child behavior problems. Journal of Abnormal Child Psychology, 80, 287-295.

Powers, J. L., Eckenrode, J., \& Jaklitach, B. (1990). Maltreatment among runaway and homeless youth. Child Abuse and Neglect. 14. $87-98$.

Proulx, J., Dyck, K., Quinonez, R., Chohan, M., G Koverola, C. (June, 1992). Attributional dimensions and clinical symptomatology in sexual abuse survivors. Paper presented at them 53rd annual meeting of the Canadian prychological Association. Quebec City. 
Rausch, R., \& Knutson, J. F. (1991). The self-report of personal punitive childhood experiences and those of siblings. Child Abuse and Neqlect, 15, 29-36.

Reidy, T J. (1977). The aggressive characteristics of abused and neglected children. Journal of Clinical Psychology, 33, 1140-1145.

Renouf, A. G., \& Harter, S. (1990). Low self-worth and anger as components of depressive experience in young adolescents. Development and Psychopathology, 2, 293-310.

Rholes, W. S., Blackwe: J., Jordan, C., \& Wallers, C. (1980). A developmental study of learned helplessness. Developmental Psychology, 16, 616-624.

Rholes, W. S., \& Ruble, D. N. (1984). Children's understanding of dispositional characteristics of others. Child Development, 55, 550-560.

Richard, B. A., \& Dodge, K. A. (1982). Social maladjustment and problem-solving in school-ageó chiidren. Journal of Consulting and clinicat Paychology, 50, 226-233.

Ringwalt, C., \& Caye, J. (1989). The effect of demographic factors on perceptions of child neglect. Children and Youth Servicea Review, 11, 133-144.

Roherbeck, C. A., \& Twentyman, C. T. (1986). Multimodal assessment of impulsiveness in abusing, neglecting, and nonmaltreating mothers and their preschool children. Journal of consu?ting and Clinical Paychology, 54, 231-236.

Rosenbaum, A., O'Leary, K. D. (1981). Children: The unintended victims of marital violence. American Journal of Orthopgychiatry, 51 , 692-699.

Ross, L. D. (1977). The intuitive psychologist and his shortcomings. In L. Berkowitz (Ed.), Advances in experimental gocial poycholouy (Vol 10, pp. 173-220). New York: Academic Press,

Rowlison, R. T., \& Felner, R. D. (1988). Major life events, hassles, and adaptation in adolescence: Confounding in the conceptualization and measurement of 1 ife stress and adjustment revisited. Journal of Personality and Socia) Psychology, 55, 432-444.

Rubin, K. H., \& Krasnor, L. R. (1986). Social-cognitive and social behavioral perspectives on problem solving. In M. Perlmutter (Ed.), The Minnesota symposia on child psychology (Vol 18) (Pp. 1-68). Hillsdale, NJ: Erlbaum.

Ruble, D. M., Feldman, N. S., \& Higgins, E. T. \& Karlovac, M. (1979). Locus of causality anc the use of information in the development of causal attributions. Journal of Personality, 47, 595-614.

Runtz, M., Briere, J. (1986). Adolescent "acting-out" and childhood history of sexual abuse. Journal of Interpersonal violence, $1,326-334$.

Russell, D. (1982). The causal dimension scale: A measure of how individual's perseive causes. Journal of Personality and social Parcholouy, 42, 1137-1145. 
Rutter, M. (1983). Stress, coping, and development: some isoues and questions. In N. Garmezy \& M. Rutter (Eds.), Stress, coping, and development in chiliren (Pp. 1-41, . New York: McGraw-Hill.

Salzinger, S., Feldman, R. S., Hammer, M., \& Rooario, M. (1991). Constellations of family violence and their differential effects on children's behavioral disturbance. Victimology, 11, 65-79.

Salzinger, S., Kaplan, S., Pelcov1tz, D., Samit, C., Krieger, R. (1984). Parent and teacher assesement of children's behavior in child maltreating families. Journal of the American Academy of Child Paychiatry, 23, 458-464.

Salzinger, S., Rosario, M., Feldman, R. S., Hammer, M., Alvarado, L., Carabalio, L., \& Ortega, A. (1989, April). Social relationshipe of physically abused preadolescent urban school children. Paper presented at the Biennial Meeting of the Society for Research in Child Development, Kansas City, Mo.

Sansonnet-Hayden, H., Haley, G., Marriage, K., Eine, S. (1987). Sexual abuse and psychopathology in hospitalized adolescents. Journal of the American Academy of Child and Adolescent Pgychiatry, 26, 753-757.

Sanvitale, D., Saltstein, H. D., \& Blank, R. (1987). Foreseeability and self-interest as moral judgement factors with normal and acting-out adolescent boys. Journal of Applied Developmental Psychology, B, 377-390.

Sattler, J. (1988). The assessment of children (3rd ed.). San Diego, CA: Jerome Sattler.

Saylor, C. F., Spirito, A., E Finch, A. J. (1984). The Children's Depression Inventory: A systematic evaluation of poychometric properties. Journal of Consulting and Clinical Psychology, 52, 955-967.

Scheppele, K. L., Bart, P. B. (1983). Through women's eyes: Defining danger in the wake of sexual assault. Journal of social Isdueg, 39, $63-81$.

Schleifer, M, Shultz, T. R., \& Lefebvre-Pinard, M. (1983). Children's judgements of causality, responsibility, and punishment in cases of harm due to omission. British Journal of Developmental Psychology, $\therefore$, 87-87.

Schuiz, R., \& Decker, S. (1985). Long-term adjustment to physical disability: The role of social support, perceived control, and self-blame. Journal of Personality and Soclal Pgychology, 48, 1162-1172.

Shaver, K. G. (1970). Defensive attribution: Effects of severity and releyance on the responsibility assigned to an accident. Journal of Personality and Social Psychology, 14, 101-113.

Shaver, K. G. (1985). The attribution of blame: Caugality, responsibility, and blameworthinesg. New York: Springer-Verlag. 
Shaver, K. G., \& Drown, D. (1986). On causality, responsibility, and self-blame: A theoretical note. Journal of Personality and Social Peychology, 50, 697-702.

Shaver, Y., Schwartz, J., Kirson, D., O O'Conner, C. (1987). Emotion knowledge: Further exploration of a prototype approach. Journat of Pergonality and Social Pgychology, 52, 1061-1086.

Shaw, M. E., Sulzer, J. L. (1964). An empirical test of Heider's lavels in attribution of responsibility. Jcurnal of Abnormal al. 2 Social Paychology, 69, 39-46.

Shirk, S. R. (1988). The interpersonal legacy of physical abuse of children. In M. B Straus (Ed.), Abuse and Victimization across the life span. Baltimore, MD: John Hopkins Press.

Silver, R. L., Boon, C., \& Stones, M. L. (1983). Searching for meaning in misfortune: Making sense of incest. Journal of Social Issues, 39, 83-103.

Silver, R. L., Wortman, C. B. (1980). Coping with undesirable life events. In J. Garber and M. E. P. Seligman (Eds.), Human helplessnegs. New York: Academic Press.

Skiffington, S. T. (1983). Empathy effects on perception of persons involved in domestic violence. Family Therapy, 10, 253-264.

Smetana, J. G., Kelly, M. E Twentyman, C. T. (1984). Abused, n'ylected, and nonmaltreated children's concepts of moral and social-conventional tranggressions. Child Development, 55 , 277-287.

Snell, K. A. (1989). Pgychological maltreatment, dysfunctional attitudes and maladaptive behavior, is there a relationship? Unpublished honour's thesis, The University of Western Ontario, London, ontario, Canada.

Snyder, C. R., Higging, R. L. (1988). Excuses: Their effective role in the negotiation of reality. Psychological Bulletin, $104,23-35$.

Snyder, C. R., Higging, R. L., \& Stucky, R. J. (1983). Excuses: Masquerades in search of grace. New York: John Wiley sons.

Solomon, S. (1978). Measuring dispositional and situational attributions. Personality and Social Psychology Bulletin, 4, 589594.

Spielberger, C. D., Jacobs, G., Russe11, S., \& Crane, R. S. (1983). Assessment of anger: The State-Trait anger Scale. In J. N. Butcher \& c. Spielberger (Eds.), Advances in personality assegsment (Vol 2). Hillodale, NJ: Lawrence Erlbaum Associates, Inc.

Steinberg, M., \& Dodge, K. A. (1983). Attributional bias in aggressive adolescent boys and girls. Journal of Social and Clinical Psychology, $1,312-321$.

Stiffman, A. R. (1989). Physical and sexual abuse in runaway youths. Child Abuge and Neglect, 13, 417-426. 
Strainer, K. E., \& Thieman, A. (April, 1991). The relation of child, parent, and family characterlstics to the geverity of child maltreatment. Poster pregented at the biennial meeting of the Society for Research in Child Development. Seattle, WA.

Straus, M. A. (1979). Measuring intrafamily conflict or violence: The Conflict Tactics (CT) Scales. Journal of Marriage and the Family, 41, 75-88.

Straus, M., Gelles, R., \& steinmetz, S. K. (1980). Behind closed doors: Violence in the American family. Garden City, NY: Anchor Pregs.

Taylor, S. E., i Brown, J. D. (1988). Illusion and well-being: A social psychological perspective on mental health. Psychological Bulletin, 103, 193-210.

Taylor, S. E., Lichtman, R. R., \& Wood, J. V. (1984). Attributions, beliefs about control, and adjustment to breast cancer. Journat of Fersonality and social Psychology, 46, 489-502.

Tennen, H. Affleck, G. (1990). Blaming others for threatening life events. Pgychological Bulletin, 108, 209-232.

Tennen, H., Affleck, G., Gershman, K. (1986). Self-blame among parents of infants with perinatal complications: The role of oelfprotective motives. Journal of Personality and Social Psychology. 50, 690-696.

Thornton, B., Ryckman, R. M. . Robbins, M. A. (1982). The relationships of observer characteristics to beliefs in the causal responsibility of victims of sexual assault. Human Relations, 35, 321-330.

Titchener, J. L., Kapp, F. T., \& Winget, C. (1976). The Buffalo Creek gyndrome: Symptoms and character change after a major jisaster. In H. J. Parad, H. L. P. Resnik, and L. G. Parad (Eds.), Emerqency and disaster management. Bowie, MD: Charles Press.

Trickett, P. K., Aber, J.L., Carlson, V., \& Cicchetti, D. (1991). Relationship of socioeconomic status to the etiology and developmental sequelae of physical child abuse. Developmental Psychology, 27, 148-158.

Vissing, Y. M., Straus, M. A., Gelles, R. J., \& Harrop, J. W. (1991). Verbal aggression by parents and psychosocial problems of children. Child Abuse and Neglect, 15, 223-238.

Wahler, R., Dumas, J. (1986). Family factors in childnood prychopathology: Toward a coercion-neglect model. In $\mathrm{T}$. Jacob (Ed.), Family interaction and psychopathology: Theories, methods and findings. (PP. 581-627). New York: Plenum Press.

Walker, L. E., Browne, A. (1985). Gender and victimization by intimates. Journal of Personality, 53, 179-195.

Weiner, B. (1985). "Spontaneous" causal thinking. Paychological Bulletin, 97, 74-84.

Weiner, B. (1985). An attributional theory of achievement motivation and emotion. Paychological Review, 95, 548-573. 
Wicks-Nelson, R., \& Israel, A. C. (1991). Behavior disorders of childhood. New Jergey: Prentice-Hall.

Widom, C. S. (1989). Does violence beget violence?: A critical examination of the literature. Pgychological Bulletin, 106. 3-28.

Winne, P. H. (1983). Digtortions of congtruct validity in multiple regression analysis. Canadian Journal of behavioral Science, 15. 187-202.

Wolfe, D. A. (1987). Child abuse: Implications for child development and peychopathology. Newbury Park, CA: Sage.

Wolfe, D. A., Bourdeau, P. A. (1987). Current issues in the assessment of abusive and neglectful parent-child relationships. Behavioral Assessment, 9 , 271-290.

Wolfe, D.A., Jaffe, P.J., Wilson, S.R., \& Zak, L. (1985). Children of battered women: The relation of child behavior to family violence and maternal stress. Journal of Congulting and Clinical Psychology, 53, 657-665.

Wolfe, D. A.. Mosk, M. D. (1983). Behavioral comparisons of children from abusive and distressed families. Journal of Consulting and Clinical Paychology, 51, 702-708.

Wolfe, V. V., Finch, A. J., Saylor, C. F., Blount, R. L., Pallmeyer, T. P., Carek, D. J. (1987). Negative affectivity in children: A multitrait-multimethod investigation. Journal of Consulting and Clinical Paychology, 55, 245-250.

Wolfe, V. V., Gentile, C., Bourdeau, P. (1986). The Higtory of Victimization Form. Unpublished manuscript, Children's Hospital of Western Ontario. London, Ontario.

Wolfe, V. V., Gentile, C., \& Wolfe, D. A. (1989). The impact of sexual abuse on children: A PTSD formulation. Behavior Therapy, 20, 215228 .

Wolfe, V. V., \& Wolfe, D. A. (1988). The sexually abused child. In E. J. Mash and I. G. Terdal (Eds.), Behavioral asgessment of childhood disorders (Pp. 670-714). New York: Guilford Press.

Wolfe, V. V., \& Wolfe, D. A. Gentile, C., \& Laroge, L. (1987). Children's Impact of Traumatic Events Scale - Revised. Unpublished manuscript. London, Ontario: University of Western Ontario.

Wollert, R., Heinrich, L., Wood, D., \& Werner, w. (1983). Causal attributions, sanctions, and normal mood variatione. Journal of Pergonality and Social Pgychology, 45, 10?9-1044.

Wollert, R., \& Rowley, J. (1987). Concurient and longitudinal patterng among sanctions, mood, and attributions. Journal of Personality and Social Pgychology, 53, 608-613.

Wortman, C. B. (1976). Causal attributions and personal control. In J. H. Harvey, W. J. Ickes, E R. G. Kidd (Eds.), New directions in attribution cesearch (Vol 1, pp. 23-54). Hillsdale, NJ: Lawrence Erlbaum. 
Zurvain, S. J. (1991). Research definitions of child physical abuse and neglect: Current problems. In R. Starr \& D. Wolfe (Eds.), The effects of child abuse and neglect: Issuer and research (PP. 100-128). New York: Guilford. 